\title{
Análise Comparativa das Interfaces de Implantes de Conexão Externa e Interna em Restaurações Unitárias Cimentadas e Parafusadas, Antes e Após Ensaios de Fadiga
}

Rudys Rodolfo De Jesus Tavarez

Tese apresentada à Faculdade de Odontologia de Bauru da Universidade de São Paulo, como parte dos requisitos para obtenção do título de Doutor em Odontologia, área de Reabilitação Oral.

(Edição Revisada) 


\section{Análise Comparativa das Interfaces de Implantes de Conexão Externa e Interna em Restaurações Unitárias Cimentadas e Parafusadas, Antes e Após Ensaios de Fadiga}

Rudys Rodolfo De Jesus Tavarez

Tese apresentada à Faculdade de Odontologia de Bauru da Universidade de São Paulo, como parte dos requisitos para obtenção do título de Doutor em Odontologia, área de Reabilitação Oral.

(Edição Revisada)

Orientador: Prof. Dr Wellington Cardoso Bonachela 
De Jesus Tavarez, Rudys Rodolfo

D34a Analise comparativa das interfaces de implantes de conexão externa e interna em restaurações unitárias cimentadas e parafusadas, antes e após ensaios de fadiga / Rudys Rodolfo De Jesus Tavarez. 2011 p. : il. ; $29,5 \mathrm{~cm}$.

Tese. (Doutorado) -- Faculdade de Odontologia de Bauru. Universidade de São Paulo.

Orientador: Prof. Dr. Wellington Cardoso Bonachela

Autorizo, exclusivamente para fins acadêmicos e científicos, a reprodução total ou parcial desta dissertação/tese, por processos fotocopiadores e outros meios eletrônicos.

Assinatura: Ridys Rodorto be lesos Thirez Data: $12 / 05 / 03$ 
Nascimento

Filiação

$1985-1990$

$1991-1995$

$1995-1997$

$1997-2000$

$2000-2003$
11 de setembro de 1966

Santiago - República Dominicana

Luz Ondina Tavarez de Jesus

Plínio De Jesus Garcia

Curso de Graduação em Odontologia, pelo Departamento de Odontologia,

Universidade Autônoma de Santo

Domingo.

Professor Assistente do Departamento de Odontologia, Universidade Autônoma de Santo Domingo - UASD.

Curso de Pós-graduação em Reabilitação

Oral, em nível de Mestrado Departamento de Prótese da Faculdade de Odontologia de Bauru, Universidade de São Paulo - FOB / USP.

Professor Adjunto do Departamento de Odontologia, Universidade Autônoma de Santo Domingo - UASD.

Curso de Pós-graduação em Reabilitação Oral, em nível de Doutorado Departamento de Prótese, da Faculdade 
de Odontologia de Bauru, Universidade de São Paulo- FOB / USP.

Associações

Associação Odontológica Dominicana

Sociedade Brasileira de Pesquisas

Odontológicas - SBPqO. 


\title{
DEDICATÓRIA
}

\begin{abstract}
A Deus,
Por ser criador de todos, por dar-me luz e força para a realização do curso e a culminação deste trabalho.
\end{abstract}

A meus pais Plínio e Luz Ondina,

Exemplos de dedicação e amor familiar. Por sua força e ajuda, que apesar da distância estiveram presentes em cada momento de minha vida. Pelo seu interesse e apoio na minha profissão.

À minha esposa Adriana,

Por toda sua dedicação e interesse na minha realização e futuro profissional, pelo seu carinho e amor brindado em todo momento; que apesar da distância sempre manteve fé e confiança em mim e em nossa relação. Por todo o que estamos vivendo e todo o que viveremos juntos no resto de nossas vidas.

A meus irmãos: José Luis, Yudelka, Daisy e Edgar: e minha tia Cucha, Por seu amor familiar, incentivo e seu interesse na minha profissão.

Dedico este trabalho 
Ao meu orientador Professor Doutor Wellington Cardoso Bonachela, por dar-me todo o apoio e orientação na realização deste e demais trabalhos desenvolvidos durante o curso. Pelo seu tempo, empenho e esforço dedicado neste trabalho. Por sua ajuda desinteressada em todo momento e a confiança em mim depositada, pela oportunidade e os conhecimentos transmitidos no transcorrer do curso. 


\section{AGRADECIMENTO ESPECIAL,}

Ao Professor Doutor Luiz Fernando Pegoraro,

Pela confiança em mim depositada para a realização do curso. Por ser uma pessoa modelo de conhecimentos e dedicação ao ensino. 


\section{AGRADECIMENTOS,}

À Faculdade de Odontologia de Bauru - Universidade de São Paulo, representada por sua diretora Prof. Dra. Maria Fidela de Lima Navarro.

A comissão de Pós Graduação representado pelo seu presidente Prof. Dr. José Carlos Pereira

Aos Professores do Departamento Accácio Lins do Valle, Carlos dos Reis Pereira de Araujo, Gerson Bonfante, Jose Henríquez Rubo, Lucimar Falavinha Vieira, Luiz Fernando Pegoraro, Milton Carlos Gonçalves Salvador, Wellington Cardoso Bonachela, Paulo César Rodrigues Conti, Paulo Martins Ferreira, Renato de Freitas e Vinicius Porto.

Ao Prof. Dr. Accácio Lins do Valle, pelo carinho, amizade, e sua confiança depositada no meu trabalho.

Ao Prof. Dr. Milton Carlos Gonçalves Salvador e a Prof. Dra. Lucimar Falavinha Vieira, pelas suas orientações e ensino na área de prótese total.

Ao Prof. Dr. Gerson Bonfante, pelo seu apoio e amizade.

Ao Prof. Dr. Jose Roberto Pereira Lauris, pelas orientações e realização estatística deste trabalho. 
Ao Prof. Dr. Luiz Geraldo, do departamento de materiais dentários da Faculdade de Odontologia da UNESP - Araraquara, pela sua orientação e ajuda na parte experimental deste trabalho.

Aos meus colegas Stefania e Anuar, Pelos conhecimentos compartilhados, pela sua amizade desinteressada e ajuda durante todo o curso.

Aos meus colegas do curso de doutorado: Anuar, Carlinhos, Gildo, Juliano Nelsinho, Stefania, Vinicius e William.

Aos meus colegas do curso de mestrado: Jeffersson, Rafael, Estela, Paulo, Leyla, Luciana, Mauro, Luis, Renato, Mariana, Osvaldo, e Tatiana.

Aos funcionários do Departamento de Prótese, Edna, Débora, Reivanildo, Sr. Geraldo, Claudia, Walkiria, Marcelo e Didi por sua disposição e ajuda.

Aos funcionários da Pós-Graduação, Dona Ana, Cleusa, Aurélio, Giane por todos os serviços prestados.

A toda minha familia que sempre me dispensou um grande carinho e respeito.

Ao Dr. Victor Castellanos e sua família: Mônica, Esther, Victor, Jayme, Don Carlos e Dona Marina, pela sua força e interesse no meu futuro, e por sempre me receber e tratar com muito carinho e afeto familiar. 
À família Santos Malheiros, em nome de Sr Luis, Dona Leia, Tatiana, Adriana, e Luciana, que me receberam como parte de sua família; meu muito obrigado estarei eternamente agradecido.

Ao amigo e colega Materson e sua esposa Paula, e toda sua família, pela grande amizade que mantemos desde o curso de mestrado, e pela ajuda prestada em todo momento.

À empresa Conexão sistemas de prótese, em nome do Dr. Rodolfo Candia Alba Jr. pela cessão de uma parte do material utilizado neste trabalho.

À empresa Emfils, em nome do Dr. Adolfo Embrar Filho, pela cessão de uma parte do material utilizado neste trabalho.

À empresa Pressing Dental, em nome do Dr. Massimo Corigliano e o Sr Giorgio Monticelli, pela cessão de uma parte do material utilizado neste trabalho.

À CAPES pela concessão da bolsa de estudo para a realização deste curso.

Ao Brasil e todo o povo brasileiro que me recebeu e acolheu.

A Todos os amigos e conhecidos que de alguma forma, contribuíram para a realização deste curso. 
LISTA DE FIGURAS

$x$

LISTA DE TABELAS

xiv

LISTA DE GRÁFICOS

xviii

LISTA DE ABREVIATURAS E SÍMBOLOS

xix

RESUMO

$\mathrm{XX}$

1- INTRODUÇÃO

1

2- REVISÃO DA LITERATURA

7

3- PROPOSIÇÃO

93

4- MATERIAL E MÉTODOS

95

5- RESULTADOS

123

6- DISCUSSÃO

151

7- CONCLUSÕES 177

8- ANEXOS 181

9- REFERÊNCIAS BIBLIOGRÁFICAS 193

10-ABSTRACT

210 
FIGURA 4.3.1: Implantes TMI (T), master screw (MS), colosso (C).

Figura 4.3.2: Pilares UCLA (U), pré-fabricado de titanio colosso (PTC), préfabricado de titânio TMI (PTT), ceraone (C).

FIGURA 4.3.3: Paquímetro digital (Mitutoyo / Japan código 500-171, modelo CD6C, serie 0112103).

FIGURA 4.3.4: Desenho esquemático de implante de hexágono externo e suas medidas obtidas.

FIGURA 4.3.5: Desenho esquemático de implante de hexágono interno e suas medidas obtidas.

FIGURA 4.3.6: Esquema de um dos parafusos de fixação determinando suas áreas de medidas.

FIGURAS 4.4.1 A e B: Dispositivo metálico para fixação dos implantes em posição vertical e inclusão em blocos de resina acrílica autopolimerizável, partes 1, 2, e 3 .

FIGURAS 4.4.2 A e B: Implante de hexágono externo fixado no dispositivo metálico; e as partes do dispositivo unidas e o espaço preenchido com resina acrílica autopolimerizável.

FIGURA 4.4.3: Implante de hexágono externo fixado em bloco de resina acrílica com forma hexagonal e com exposição de $2 \mathrm{~mm}$ da base de assentamento do implante. 
FIGURAS 4.4.4 A e B: Implante com pilar UCLA torneado e enceramento realizado.

FIGURA 4.4.5: Corpos de provas fundidos e fixados sobre os implantes. Um corpo de prova de cada um dos cinco grupos testados.

FIGURA 4.5.1: Corpo de prova na prensa estática durante o processo de cimentação.

FIGURAS 4.6.1 A e B: Torquímetro analógico Tohnichi BTG60CN / JAPAN.

FIGURA 4.6.2: Corpo de prova fixado em dispositivo metálico no momento da aplicação do torque.

FIGURA 4.7.1 : Microscópio óptico Mitutoyo TM- modelo 5050 / Japan.

FIGURA 4.7.2: Detalhe do cabeçote micrométrico do microscópio óptico Mitutoyo TM.

FIGURA 4.7.3: Corpo de prova em posição no microscópio no momento de avaliação da interface implante / pilar.

FIGURA 4.7.4: Desajuste vertical da interface implante / pilar, em um corpo de prova.

FIGURA 4.8.1: Máquina de ensaios MTS 810, (Material Testing System / MTS Systems Corporation / USA), utilizada ensaio de fadiga.

FIGURA 4.8.2: Parte superior e inferior da máquina de ensaios com dispositivo de teste fixado. 
FIGURA 4.8.3: Parte superior do dispositivo para realização do ensaio de fadiga.

FIGURA 4.8.4: Parte inferior do dispositivo para realização do ensaio de fadiga.

FIGURA 4.8.5: Multímetro analógico FTG modelo FT-1000A, determinando a relação de contato entre o dispositivo e o corpo de prova.

FIGURA 4.8.6: Aplicação da carga no corpo de prova a $3 \mathrm{~mm}$ fora do centro do implante.

FIGURA 4.8.7: Tela do computador com programação do ensaio através do programa Test Works.

FIGURAS 6.1, e 6.2: Fotomicrografias da interface Implante / Pilar dos grupos I e II, mostrando alterações em sentido horizontal.

FIGURAS 6.3, e 6.4: Fotomicrografias da interface Implante / Pilar dos grupos III e IV.

FIGURAS 6.5: Fotomicrografia da interface Implante / Pilar do grupo V.

FIGURAS 6.6, 6.7: Fotomicrografias de implante e pilar de conexão externa (sistema Conexão).

FIGURAS 6.8, 6.9: Fotomicrografias de implante e pilar de conexão interna (sistema Emfils).

FIGURAS 6.10, 6.11: Fotomicrografias de implante e pilar de octágono interno (sistema TMI). 
FIGURAS 6.13, e 614: Fotomicrografias da interface implante / pilar dos grupos I e II respectivamente, mostrando bordas arredondadas (A) e / ou biseladas (B).

FIGURAS 6.15, e 616: Fotomicrografias da interface implante / pilar dos grupos III e IV, mostrando bordas arredondadas (A) e / ou biseladas (B).

FIGURAS 6.17: Fotomicrografia da interface implante / pilar do grupo $V$, mostrando bordas arredondadas (A) e / ou biseladas (B). 


\section{LISTA DAS TABELAS}

TABELA 4.2.1: Material utilizado:

TABELA 4.3.1: Composição dos grupos de corpos de provas testados.

TABELA 5.1.1: Médias e desvio padrão em $\mathrm{mm}$, do diâmetro da base de assentamento, altura do hexágono / octágono e diâmetro do sextavado / octágono dos implantes dos sistemas avaliados.

TABELA 5.1.2: Médias e desvio padrão em $\mathrm{mm}$ do diâmetro do hexágono / octágono e do diâmetro da base de assentamento dos pilares nos sistemas avaliados.

TABELA 5.1.3: Médias e desvio padrão em $\mathrm{mm}$, do diâmetro da base de assentamento dos implantes e o diâmetro da base de assentamento dos pilares e as diferenças entre as médias, nos sistemas de implantes avaliados.

TABELA 5.1.4: Médias e desvio padrão em $\mathrm{mm}$, do diâmetro do hexágono / octágono dos pilares e o diâmetro do hexágono / octágon dos implantes e as diferenças entre os valores médios, nos sistemas avaliados.

TABELA 5.1.5: Médias e desvio padrão em $\mathrm{mm}$, dos comprimentos dos parafusos, das roscas dos parafusos e dos diâmetros das roscas dos parafusos, nos sistemas de implantes avaliados.

TABELA 5.2.1: Médias e desvio padrão em $\mu \mathrm{m}$ da desadaptação vertical na interface implante / pilar antes do ensaio de fadiga. 
TABELA 5.2.2: Médias e desvio padrão em $\mu \mathrm{m}$ da desadaptação vertical na interface implante / pilar após o ensaio de fadiga.

TABELA 5.2.3: Análise de variância (ANOVA) a dois critérios (Grupo, Desadaptação) para comparação das diferenças entre as médias das medidas de desadaptação vertical na interface implante / pilar, dos grupos avaliados.

TABELA 5.2.4: Teste Tukey para comparações de grupos homogêneos, da desadaptação da interface implante / pilar antes do ensaio de fadiga.

TABELA 5.2.5: Teste Tukey para comparações de grupos homogêneos, da desadaptação da interface implante / pilar depois do ensaio de fadiga.

TABELA 5.2.6: Teste Tukey para comparação de cada grupo examinado, na desadaptação da interface implante / pilar, antes e depois da do ensaio de fadiga.

TABELA 5.3.1: Médias e desvio padrão em N.cm do torque e do destorque inicial realizado nos parafusos de fixação, antes do ensaio de fadiga.

TABELA 5.3.2: Médias e desvio padrão em N.cm do torque, do destorque final e suas diferenças, realizados nos parafusos de fixação, após 0 ensaio de fadiga.

TABELA 5.3.3: Médias e desvio padrão em N.cm do destorque inicial, e do destorque final realizado nos parafusos de fixação, após o ensaio de fadiga. 
TABELA 5.3.4: Análise de variância (ANOVA) a dois critérios (Grupo, Destorque) para comparação das diferenças entre as médias do destorque dos parafusos de fixação do pilar, dos grupos avaliados.

TABELA 5.3.5: Teste Tukey para comparações de grupos homogêneos, das médias destorque em N.cm do parafuso de fixação do pilar, antes do ensaio de fadiga.

TABELA 5.3.6: Teste Tukey para comparações de grupos homogêneos, das médias destorque em N.cm do parafuso de fixação do pilar, após o ensaio de fadiga.

TABELA 5.3.7: Teste Tukey para comparação das médias em N.cm de cada um dos grupos avaliados, antes e após o ensaio de fadiga.

TABELA 5.3.8: Médias e desvio padrão expressos em percentagens da redução de torque antes do ensaio de fadiga. Diferença obtida entre o torque inicial de $30 \mathrm{~N} . \mathrm{cm}$ e o destorque inicial antes do ensaio de fadiga.

TABELA 5.3.9: Análise de variância (ANOVA) a um critério (Grupo) para comparação da redução de torque dos grupos avaliados, antes do ensaio de fadiga.

TABELA 5.3.10: Teste Tukey para comparação dos grupos examinados em relação à redução de torque, antes do ensaio de fadiga.

TABELA 5.3.11: Médias e desvio padrão expressas em percentagens da redução de torque após a aplicação da carga. Diferença do torque inicial de 30 N.cm e o destorque final após o ensaio de fadiga. 
TABELA 5.3.12: Análise de variância (ANOVA) a um critério (Grupo) para comparação da redução de torque dos grupos avaliados, depois do ensaio de fadiga.

TABELA 5.3.13: Teste Tukey para comparação dos grupos avaliados em relação à redução de torque, após o ensaio de fadiga.

TABELA 5.3.14: Médias e desvio padrão expressas em percentagens da redução real do torque. Diferença do destorque inicial e o destorque final depois do ensaio de fadiga.

TABELA 5.3.15: Análise de variância (ANOVA) a um critério (Grupo) para comparação da redução real do torque dos grupos avaliados.

TABELA 5.3.16: Teste Tukey para comparação dos grupos avaliados em relação à redução real do torque. 
GRÁFICO 5.1.1: Representação gráfica das medidas em $\mathrm{mm}$ do diâmetro dos implantes, altura e diâmetro do hexágono / octágono dos implantes nos sistemas avaliados.

GRÁFICO 5.1.2: Representação gráfica das médias em $\mathrm{mm}$ do diâmetro do hexágono / octágono, e do diâmetro da base de assentamento dos pilares, nos sistemas avaliados.

GRÁFICO 5.1.3: Representação gráfica das médias em mm do comprimento dos parafusos, comprimento e diâmetro das roscas, nos sistemas avaliados.

GRÁFICO 5.2.1: Representação gráfica das médias em $\mu \mathrm{m}$ da desadaptação vertical na interface implante / pilar dos grupos avaliados, antes e após o ensaio de fadiga.

GRÁFICO 5.3.1: Representação gráfica das médias em N.cm do destorque inicial e final dos parafusos de fixação dos grupos avaliados.

GRÁFICO 5.3.2: Representação gráfica das médias em percentagens da redução inicial, final, e real de torque dos parafusos de fixação dos grupos avaliados.

GRÁFICO 6.12: Representação gráfica das médias expressas em ìm da desadaptação dos sistemas estudados antes da aplicação do ensaio de fadiga. 
GRÁFICO 6.13: Representação gráfica das médias expressas em ìm da desadaptação dos sistemas estudados antes e depois ensaio de fadiga.

GRÁFICO 6.14: Representação gráfica das médias expressas em percentagens de redução de torque dos sistemas estudados antes e depois 0 ensaio de fadiga. 


\begin{tabular}{|c|c|}
\hline $\mathbf{N}$ & Newton \\
\hline kgf & quilogramas \\
\hline $\mathrm{mm}$ & Milímetro \\
\hline $\mathrm{mm}^{2}$ & Milímetros quadrados \\
\hline $\mathrm{Hz}$ & Herz \\
\hline kN & Kilo newton \\
\hline N.cm & Newton por centímetros \\
\hline$d p$ & Desvio padrão \\
\hline ìm & Micrometro \\
\hline $\mathrm{MPa}$ & Mega Pascal \\
\hline$\%$ & Percentagem \\
\hline g & Gramas \\
\hline Min & Minuto \\
\hline $\mathrm{ml}$ & mililitro \\
\hline NE & Não eugenol \\
\hline${ }^{\circ} \mathrm{C}$ & Graus Celcius \\
\hline HE & Hexágono externo \\
\hline $\mathrm{HI}$ & Hexágono interno \\
\hline Ol & Octágono interno \\
\hline OE & Octágono externo \\
\hline MEV & Microscopia eletrônica de varredura \\
\hline USA & United States of America \\
\hline UCLA & University California Los Angeles \\
\hline CAD / CAM & $\begin{array}{l}\text { (Computer Assisted Designed/Computer } \\
\text { Assisted Machined) }\end{array}$ \\
\hline MTS & Material Testing System \\
\hline
\end{tabular}


RESUMO 


\section{RESUMO}

O sucesso da restauração protética suportada por implantes osseointegrados e a saúde dos tecidos circundantes estão intimamente relacionadas à precisão e adaptação dos componentes, a estabilidade da interface implante / pilar, assim como à resistência desta interface quando é submetida a cargas durante a função mastigatória. A restauração unitária é biomecanicamente mais complicada quando se trata da substituição de elementos dentários nas áreas de pré-molares e molares, devido às forças oclusais serem maiores nestas áreas, podendo levar a elevados níveis de tensão. Dessa forma, o objetivo deste trabalho foi o de estudar as alterações na interface implante / pilar em sistemas de conexão externa e interna através das medidas da desadaptação, e a condição de torque e destorque dos parafusos de fixação quando submetidos a ensaios de fadiga.

Cinqüenta corpos de provas divididos em cinco grupos foram estudados: Grupo / implante HE e pilar UCLA, com restauração cimentada; Grupo // implante de HI e pilar pré-fabricado, com restauração cimentada; Grupo III implante OI e pilar pré-fabricado, com restauração cimentada; Grupo IV implante de HE e pilar UCLA, com restauração parafusada; e Grupo $V$ implante HE e pilar ceraone, com restauração cimentada. As dimensões das bases de assentamento dos implantes e pilares, e dos parafusos dos cinco grupos foram medidas. Os corpos de prova foram submetidos a ensaios de fadiga até 500.000 ciclos utilizando-se uma máquina de ensaio MTS 810. Testes de torque e destorque nos parafusos de fixação, e análise da desadaptação da interface implante / pilar antes e depois da aplicação das cargas foram realizados.

Através da análise variância com nível de significância de $5 \%$ e do teste Tukey para comparações múltiplas, foi possível observar que: (1) houve diferenças no diâmetro da base de assentamento dos implantes e pilares entre 0,03mm a 0,75mm; e no diâmetro do hexágono / octágono entre implantes e pilares entre 0,01 e $0,05 \mathrm{~mm}$, sendo que no grupo que utilizou hexágono interno não foram encontradas diferenças; (2) o comprimento dos parafusos variou entre 
$5,95 \mathrm{~mm}$ e $8,83 \mathrm{~mm}$, o comprimento das roscas variou entre 4,52 e $5,72 \mathrm{~mm}$, enquanto que o diâmetro entre 1,79 e 1,97mm; (3) após o ensaio de fadiga, houve um aumento hexágono externo que utilizaram pilares UCLA e no grupo de octágono interno; sendo a menor desadaptação observada no grupo de hexágono externo que utilizou pilares Ceraone (3,81 ìm); (4) houve redução estatisticamente significante da condição de torque dos grupos estudados após o ensaio de fadiga. A menor redução foi encontrada no grupo de hexágono interno com 5,3 N.cm (17,67\%); e a maior redução no grupo de hexágono externo que utilizou pilares UCLA parafusados com 20,5 N.cm (68,33\%); (5) houve uma forte correlação entre a aplicação das cargas cíclicas e a diminuição da condição de torque; enquanto que nas demais variáveis não existiu esse tipo de correlação. 


\section{1- INTRODUÇÃO}




\section{INTRODUÇÃO}

A perda de estruturas dentárias continua sendo um problema que afeta a saúde de todo o sistema estomatognático em uma grande parte da população, onde causas de origem multi fatoriais podem levar à ocorrência deste problema. Historicamente, a substituição destas estruturas perdidas tem sido um grande desafio para os profissionais da área odontológica. É por isso que a cada dia o desenvolvimento de novo material e novas técnicas vêm-se acentuando dentro do universo odontológico.

A consolidação da osseointegração como modalidade de tratamento, observada a partir das pesquisas realizadas por BRANEMARK, ZARB e ALBREKTSSON ${ }^{25}$, gerou a possibilidade de substituir as estruturas dentárias nos pacientes totalmente edêntulos, melhorando as funções do sistema estomatognático e conseqüentemente a qualidade de vida; mas possibilitou também que desdentados parciais fossem reabilitados com a utilização de implantes osseointegrados. A osseointegração foi definida como uma conexão direta, estrutural e funcional entre o osso vital organizado e a superfície de um implante de titânio capaz de receber carga funcional, 25 .

Os altos índices de sucesso clínico com implantes osseointegrados em pacientes total e parcialmente edêntulos ${ }^{2}$; levaram ao desenvolvimento e introdução de novas técnicas e componentes protéticos para sua utilização em restaurações unitárias; sendo este tipo de restauração considerada uns dos maiores desafios da odontologia reabilitadora, já que além dos requisitos técnicos e biomecânicos, é necessária uma localização ideal do implante para que a restauração acompanhe o contorno dentário e gengival dos dentes vizinhos e se obtenha uma estética adequada ${ }^{43}$.

Dentre as principais vantagens do uso dos implantes unitários em relação às próteses fixas convencionais estão: a de evitar preparo de tecidos dentários sadios dos dentes adjacentes ao espaço protético; também a obtenção de dentes individualizados sem necessidade de união de três elementos; perfil de emergência saindo de dentro do sulco periimplantar, em substituição ao pôntico em sobreposição à gengiva; preservação da integridade e estética dos tecidos 
gengivais marginais e dos dentes vizinhos ao espaço protético; além de que quando existe necessidade de reparos ou substituições nestas restaurações, estas são mais simples que as próteses parciais fixas convencionais ${ }^{43}$.

O sucesso no uso dos implantes osseointegrados como modalidade de tratamento nas restaurações unitárias, foi e é demonstrado por resultados de estudos longitudinais de avaliações clinicas existentes na literatura; onde estudos com intervalos de tempo de seis meses a dez anos, mostram entre $91 \%$ e $100 \%$ de sucesso da osseointegração, em implantes colocados na região anterior e posterior da boca ${ }^{3}, 4,6,7,9,10,13,41,44,51,57,58,64,65,70,71,72,88,93,97$, 99; porém complicações protéticas são comumente encontradas nestes tipos de restaurações.

Mobilidade da prótese relacionada ao afrouxamento ou fratura dos parafusos, fratura da cerâmica ou material de cobertura, dissolução do cimento em próteses cimentadas, exposição da margem das restaurações e fístulas associadas ao afrouxamento dos parafusos são reportadas nas avaliações clínicas

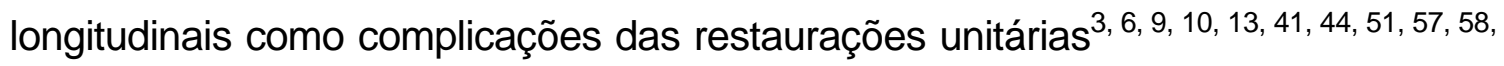
$65,70,71,73,93,97,99$.

A complicação protética mais freqüente neste tipo de restaurações é o afrouxamento do parafuso que retém a prótese ao implante $6,9,13,41,51,57,58,65,70,72$, 93, 97; entre $1 \%{ }^{4}$ e $57 \% 58$ das avaliações clinicas de dois e três anos, porém o estudo de dez anos de PRIEST ${ }^{93}$ relatou uma incidência de $7,1 \%$ de afrouxamento em um estudo de acompanhamento clinico longitudinal. Problemas os quais estão relacionados a este tipo de complicação, traduzem-se como sobrecarga e danos aos implantes e tecidos de suporte, além de maior tempo clínico consumido e altos custos. A freqüente visualização destas complicações tem levado a procurar mecanismos que visem minimizar estes problemas.

Uma interação de fatores dínicos são relatados como possíveis causas do afrouxamento dos parafusos e decorrente disto há a perda da condição de précarga, a qual se traduz como a tensão gerada no parafuso quando é aplicado o torque durante o aperto ${ }^{50,77}$. A pré-carga mantém as partes do pilar e implante conectados pela produção de uma força de aperto que deve ser suficiente para 
prevenir o afrouxamento, quando as próteses estão em função. Durante a précarga o parafuso é alongado e os filetes das roscas são mantidas sob tensão; assim a força de atrito gerada entre as roscas do parafuso e do implante mantémse em equilíbrio, determinando na prótese uma ausência de movimento, propiciando um contato entre o pilar e implante ${ }^{91}$.

A condição de pré-carga pode ser perdida devido às cargas funcionais axiais ou não, que provocam redução da friç̧ão entre as roscas do parafuso de fixação e implante. Vários mecanismos podem causar o afrouxamento dos parafusos e conseqüentemente a perda da pré-carga ${ }^{16,28,50,96}$. Embora uma força de atrito grande entre a união das roscas do parafuso evite seu afrouxamento, cargas aplicadas externamente reduzem essa fricção por compressão da cabeça do parafuso contra a base do pilar, assim sendo a união das roscas perde a tensão e o parafuso se afrouxa. Também cargas funcionais oclusais axiais e não axiais advindas da mastigação atuam sobre as restaurações podendo provocar micromovimentos dos pilares, e induzindo a perda da pré-carga. Uma outra causa pode estar associada ao desenho geométrico e precisão da adaptação na união dos componentes. Também a estabilidade do parafuso esta relacionada à qualidade óssea da área receptora do implante, assim diferenças significantes existentes entre maxila e mandíbula, determinam uma maior deformação do osso maxilar devido a sua arquitetura medular, o que se traduz em uma maior tensão na união osso / implante e conseqüentemente uma maior instabilidade do parafuso ${ }^{16}$.

As forças friccionais geradas no parafuso durante a aplicação da pré-carga dependem também da geometria e as propriedades do material dos componentes na interface implante parafuso ${ }^{28}$; dessa forma o tamanho da área de superfície de contato das roscas, a distância entre as roscas, o raio do parafuso, e o diâmetro da cabeça do parafuso são de fundamental importância na relação do torque aplicado e a pré-carga produzida ${ }^{54}$. O comprimento do parafuso também influencia na área de contato das roscas, já que um parafuso comprido tem uma maior área da superfície de contacto nas roscas. 
Outro aspecto importante a ser analisado é o tipo de liga do parafuso de fixação. Uma maior produção de pré-carga foi encontrada por MCGLUMPHY; KERBY; ELFERS ${ }^{76}$, MARTIN et $\mathrm{al}^{74}$, nos parafusos de ouro quando comparada com a mesma condição produzida nos parafusos de titânio, aplicando-se forças de torque similares; isto é creditado como conseqüência de um maior coeficiente de atrito entre a união das roscas do parafuso e implante, o que provoca um aumento nas forças de aperto; da mesma forma HAACK et $\mathrm{al}^{50}$ encontraram diferenças nas forças de pré-carga produzida em parafusos de ouro e de titânio quando submetidos às forças de torque recomendadas de 32 e $20 \mathrm{~N} . \mathrm{cm}$ respectivamente, assim mesmo JAARDA, RAZOOG e GRATTON ${ }^{55}$, encontraram diferenças na máxima resistência a tração quando compararam parafusos de retenção de ouro Nobelpharma a parafusos de retenção de ouro e de titânio de outros fabricantes.

A configuração geométrica estrutural da conexão dos implantes também tem sido mencionada como uma condição diferencial na manutenção da estabilidade da interface implante / prótese ${ }^{1,8,15,23,40,79, ~ 84, ~ 86, ~ 87, ~ 100, ~ 103, ~} 113$. Assim, os dois grandes grupos de conexão mais conhecidos são: externa e interna; sendo subdividas em: hexagonal, octagonal, cone parafuso, cone hexagonal, cilíndrica hexagonal, entre outras ${ }^{19}$. Uma maior estabilidade da interface implante / pilar esta relacionada a conexões internas onde as paredes do pilar estão em contato com a superfície interna do implante, diminuindo a possibilidade de micromovimentos durante as cargas $^{19}$; nesse sentido, estudos experimentais de cargas estática e dinâmica utilizando diferentes tipos de conexão externa e interna têm mostrado

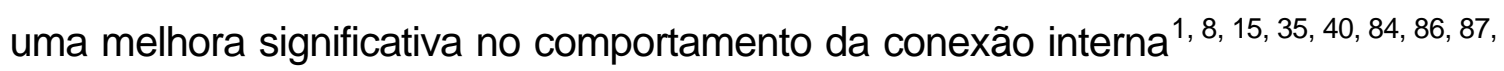
100 .

Outro aspecto relatado como importante na estabilidade da interface implante / pilar, é o grau de liberdade rotacional entre os componentes ${ }^{15,18,20,22,67 .}$ Uma correlação direta foi encontrada por BINON; $M C H U G H^{22}$ entre a desadaptação rotacional dos hexágonos do implante e pilar, e o afrouxamento do parafuso, de forma que quanto menor é a liberdade rotacional, maior será a estabilidade do parafuso; uma adaptação rotacional com até $5^{\circ}$ de liberdade foi considerada adequada para promover uma união estável. 
A adaptação passiva do pilar ao implante ou do cilindro protético ao pilar, pode influenciar também a estabilidade do parafuso. Quando superfícies usinadas não se adaptam passivamente e o parafuso é apertado na tentativa de aumento do assentamento, isto provoca danos nas roscas internas, afrouxamento do parafuso, possível fratura e potencial perda do implante ${ }^{16}$. Da mesma forma, os procedimentos de fundição acabamento e polimento de pilares ou cilindros calcináveis têm um efeito deletério na produção da pré-carga no parafuso de fixação; pelo que o uso de componentes pré-fabricados torna-se recomendável para obter-se uma máxima précarga ${ }^{31}$.

A seleção de um sistema de prótese cimentada ou parafusada é outro aspecto bastante discutido, onde a seleção do sistema baseia-se muitas vezes, em preferências pessoais, porém vantagens são mencionadas em cada um dos sistemas; assim a principal vantagem das próteses parafusadas está relacionada à reutilização da prótese, enquanto que na prótese cimentada a estética e a oclusão são mencionadas com as principais vantagens, além de uma menor geração de tensão ${ }^{49,52}$.

Assim, testes de cargas cíclicas são utilizados com para determinar em condições experimentais a estabilidade de uniões parafusadas; com o objetivo dos resultados obtidos serem de interesse clinico. $\mathrm{Na}$ busca destas informações e respostas propusemo-nos a estudar as interfaces implante / pilar de conexões externa e interna, quando submetidas a ensaios de fadiga, comparando-os sistemas em condições de parafusamento e cimentação. 


\section{2- REVISÃO DA LITERATURA}

ASPECTOS BIOMECÂNICOS DAS PRÓTESES UNITÁRIAS SUPORTADAS POR IMPLANTES 


\section{REVISÃO DA LITERATURA}

No ano de 1991, LAZZARA $^{68}$ publicou um trabalho enumerando as vantagens dos implantes com hexágono externo, que segundo ele, inicialmente este hexágono, foi desenhado para levar o implante ao leito cirúrgico. As principais vantagens deste tipo de conexão são obtidas na fase protética, onde uma conexão mais estável entre o implante e a restauração é necessária. O mecanismo antirotacional desta conexão é importante para estabilizar a correta angulação dos pilares, isto é fundamental em restaurações unitárias. Uma das vantagens do hexágono coronal é que sua posição pode ser transferida para o modelo de trabalho através de componentes de moldagens, que transferem a localização do implante; permitindo ao técnico reproduzir a correta posição deste; isto permite selecionar componentes para próteses unitárias, idealizando a angulação do implante e dos componentes, assim como o perfil de emergência, o que permite a construção de uma restauração estética e funcional. O pilar tipo UCLA também comentado pelo autor neste trabalho, adapta-se à conexão hexagonal do implante, permitindo a construção de restaurações unitárias onde existam $4 \mathrm{~mm}$ ou menos de altura do dente antagonista à parte superior do implante; podendo ser encontrado em plástico ou pré-fabricado em ouro, este último é recomendado por ser mais exato e preciso, diminuindo os erros laboratoriais no encaixe ao implante. Este tipo de pilar também permite a construção de restaurações onde é eliminada a possibilidade de emergência do parafuso de retenção através da face vestibular. Segundo o autor, assentamento positivo do parafuso de retenção e um encaixe preciso dos hexágonos são críticos para a estabilidade ao longo do tempo da restauração, já que a restauração unitária é estabilizada através do hexágono coronal do implante.

NIZNICK ${ }^{85}$ no mesmo ano denominou a conexão implante / pilar como a chave do sucesso protético. Segundo o autor, o sistema Screw Vent introduzido desde 1986 com um desenho de hexágono interno combina um bisel interno de $1,7 \mathrm{~mm}$ de profundidade com roscas internas abaixo deste bisel, que aceita pilares 
do tipo cimentados e rosqueados. Em sistemas com este tipo de conexão a interdigitação dos hexágonos são um fator para obter uma conexão estável e precisão na transferência, porém variações na fabricação podem resultar em $0,1 \mathrm{~mm}$ de espaço entre as partes. Este problema foi resolvido nos sistemas Spectra e o Swede-Vent pela conformação de uma conexão cônica dos hexágonos, o que permite uma interdigitação com rotação zero e uma adaptação friccional que aumenta a estabilidade durante a função. Para o autor a vantagem de utilizar uma conexão de hexágono interno é o aumento da resistência, a qual reduz a possibilidade de complicações como afrouxamento ou fraturas dos parafusos. Neste desenho o centro de fixação do parafuso que é unido as paredes do implante é protegido pelo $1,7 \mathrm{~mm}$ de hexágono do pilar, dessa forma, forças laterais são transmitidas diretamente às paredes do implante devido ao comprimento e o íntimo contato dos hexágonos; a diferença dos pilares segmentados unidos à conexão de hexágono externo, onde as forças laterais são transmitidas ao parafuso de retenção, no ponto onde este entra no implante, assim como no ombro do implante, o que pode provocar afrouxamento ou fratura deste parafuso.

McGLUMPHY; ROBINSON; MENDEL ${ }^{78}$, em 1992, quantificaram e compararam a força necessária para causar falhas em vários sistemas de implantes sob uma carga em "Cantilever". As amostras consistiram de diferentes combinações implante / pilares de diferentes fabricantes. As combinações testadas foram: (1) Implante Branemark / pilar convencional Branemark; (2) Implante Branemark / pilar cônico 3i; (3) Implante Swede-Vent / pilar Swede-Vent; (4) Implante integral Calcitek / pilar; (5) Implante Screw-Vent / pilar Screw-Vent; (6) Implante IMZ / pilar titânio; (7) Implante IMZ / pilar 4,0mm Polyoxymethylene; (8) Implante Steri-Oss / pilar; e (9) Implante IMZ / pilar 3,3mm Polyoxymethylene. Cada implante foi unido a um anel de alumínio, e o pilar apertado em posição; sobre este, uma prótese teste com um "Cantilever" de $18 \mathrm{~mm}$ fundido em ouro foi fixado por meio do parafuso coronal cedido pelo fabricante. Uma carga foi aplicada na extremidade do "Cantilever" até causar falha de um dos componentes, 
sendo registrado o tipo e a máxima força para que a falha ocorresse em cada combinação. Os resultados mostraram médias de força máxima para causar falha entre 1,22 a 17,23kg. Não foram encontradas diferenças estatisticamente significantes entre os grupos 3, 4 e 5; e entre os grupos 1 e 7; porém diferenças estatisticamente significante foram encontradas nos demais grupos. Todas as cinco amostras de cada grupo fraturaram no mesmo lugar durante cada ensaio, na área do parafuso do pilar e no pilar. Os resultados deste estudo sugerem que são necessárias maiores forças para causar falhas em sistemas e componentes de implantes de maiores diâmetros.

PATTERSON; MECH; JOHNS ${ }^{91}$ (1992), desenvolveram um método para calcular a resistência a fadiga dos componentes parafusados em sistemas de próteses fixas sobre implantes. Relataram que a ausência de adaptação passiva faz com que as superfícies dos componentes não entrem em contato quando a pré-carga é aplicada, dessa forma o parafuso passa a receber toda a carga, tendo seu tempo de fadiga reduzido. Para predizer a sobrevida de um componente à fadiga, a distribuição de tensão naquele componente deve ser determinada, e este depende das cargas que estão sendo aplicadas ao componente. Segundo os autores quando o parafuso é apertado, uma pré-carga é produzida no parafuso e isto induz a uma tensão compressiva nos componentes e quando cargas externas são aplicadas aos componentes unidos, produzem um relaxamento da tensão compressiva e parte desta aumenta a tensão no parafuso. Observaram que existem duas áreas principais de concentração de tensão nos parafusos, nas quais provavelmente se inicia a fadiga e conseqüentemente a falha; a primeira está entre a haste e a cabeça do parafuso; esta concentração é uma conseqüência do raio e o diâmetro da curvatura. A segunda área onde existe alta concentração de tensão é na primeira rosca do parafuso; está é conseqüência da geometria da rosca que produz uma concentração neste ponto em todas as roscas e é particularmente um resultado da concentração da carga na primeira rosca. Em seu estudo, utilizando os princípios de engenharia mecânica sobre um modelo, afirmaram que quando uma prótese total fixa é construída de forma precisa sobre 
suficientes implantes eqüidistantes, a resistência à fadiga do parafuso do pilar pode chegar até 20 anos, porém esta pode ser reduzida drasticamente quando as condições de tensão e carga não são satisfeitas. Concluíram que, devido à possibilidade de incorporar pequenos erros nos diferentes procedimentos, é necessário que os parafusos estejam apertados ao máximo, aumentado dessa forma o tempo de vida útil dos mesmos e para que isso ocorra, recomendam a aplicação de torque apropriado.

Procurando determinar o torque necessário para afrouxamento do parafuso do pilar em restaurações sobre implantes unitários após função simulada, BREEDING et $\mathbf{a l}^{26}$, em 1993, compararam três diferentes combinações pilar / implante em dois diferentes períodos de tempo. Um selante adesivo também foi testado para determinar seu efeito no torque necessário para afrouxar os parafusos sob as mesmas condições experimentais. As combinações testadas foram: (1) Implante Calciteck integral Omnilock com desenho de octágono interno e um pilar antirotacional Integral Omnilock (Calcitek); (2) Implante Bio-Vent com hexágono interno e pilar antirotacional Hex-lock (Dentsply / Core-Vent); e (3) Implante Minimatic com hexágono externo e pilares anti-rotacionais unitarios do mesmo sistema. Sobre cada pilar foi encerado um dente com forma de pré-molar, reproduzindo-se dez réplicas para cada sistema; as quais foram fundidas em liga metálica. Os implantes foram fixados em blocos de resina acrílica autopolimerizável com o auxilio de um delineador e com um mínimo de 24 horas os parafusos dos pilares de um grupo pré-teste, constituídos de quatro combinações pilar / implante, de cada sistema foram apertados com um torque de $22,6 \mathrm{~N} . \mathrm{cm}$ utilizando um torquímetro (Tohnichi); esta medida foi realizada novamente após dez minutos, e o torque necessário para afrouxar os parafusos foi registrado dois minutos após o aperto, sendo que esta medida foi utilizada como grupo controle. Três grupos testes foram analisados, observando-se a diferença entre os valores de torque de afrouxamento do grupo pré-teste e os valores de torque de afrouxamento de cada grupo. (1) O grupo 1 foi constituído de cinco combinações de cada sistema, os parafusos foram apertados como no grupo pré 
teste, e em cada pilar uma coroa foi cimentada com um cimento resinoso; uma hora após a cimentação, uma força de $6 \mathrm{~kg}$ foi aplicada para cada coroa e foram geradas forças laterais e verticais simulando às forças intraorais; cada amostra recebeu 16.667 ciclos em 3,25 horas; após a aplicação destas forças foi registrado o torque necessário para afrouxar o parafuso, sendo as medidas comparadas com as do grupo pré teste. (2) O grupo 2 também foi constituído de cinco amostras de cada sistema, a diferença com o grupo anterior foi que um selante adesivo (Ceka Bond) foi aplicado antes do aperto do parafuso do pilar, após isto os mesmos procedimentos do grupo anterior foram realizados. (3) O grupo 3, constituído de cinco amostras de cada sistema, nas quais o adesivo tinha sido aplicado. Neste grupo, as amostras foram submetidas a 100.002 ciclos ou 19,5 horas e como nos grupos anteriores, registrado o torque necessário para afrouxamento dos parafusos. Os resultados encontrados mostraram que:

- O sistema Calcitek Omnilock com octágono interno e o sistema Minimac com hexágono externo, não exibiram diminuição significativa, no torque necessário para afrouxar os parafusos após os testes de carga cíclica de 16.667 ciclos e 100.002 ciclos.

- O sistema Core-Vent com hexágono interno exibiu uma diminuição significativa no torque necessário para o afrouxamento dos parafusos após os testes de carga cíclica.

- O adesivo não aumentou significativamente o torque necessário para o afrouxamento dos parafusos nos sistemas Calcitek e Minimac.

- Quando o adesivo foi utilizado no sistema Core-Vent foi requerido um torque significativamente maior para afrouxar os parafusos.

SUTTER; WEBER; SORENSEN ${ }^{104}$ (1993) apresentaram o desenho e engenharia do "Octa-abutment" o qual é um pilar restaurativo do sistema ITI (Bonefit). Relataram também os resultados de testes de vários parâmetros críticos para a estabilidade longitudinal do complexo implante / supraestrutura com este pilar. O desenho do mesmo se acopla na porção coronária do implante e é composto de um cone de $8^{\circ} \mathrm{com}$ um parafuso de $2 \mathrm{~mm}$ de diâmetro. A porção 
coronal do pilar consiste de uma cabeça octagonal com uma altura total de $1,5 \mathrm{~mm}$ acima do ombro do implante, sobre o qual é acoplado um cilindro de ouro que tem um encaixe preciso até o ombro do implante. Utiliza um parafuso de retenção de titânio oclusal de $2 \mathrm{~mm}$ de diâmetro, com cabeça de 2,5mm. Dois desenhos diferentes são disponíveis para os cilindro de ouro; um para restaurações unitárias com desenho anti-rotacional e outro para múltiplas restaurações. Resultados dos testes mecânicos com os pilares relatados pelos autores garantem que o desenho cônico interno proporciona adaptação friccional, o que elimina o risco de rotação ou afrouxamento das partes. Os resultados dos testes da aplicação de força de rotação até a falha proporcionaram forças maiores de $400 \mathrm{~N} . \mathrm{cm}$. Quando foram comparados testes de torque de aperto contra torque de afrouxamento os resultados revelaram que o torque de afrouxamento foi entre 10 e $15 \%$ superior ao torque de aperto, o que segundo os autores resulta em um aumento de $20 \%$ na resistência ao afrouxamento para um nível de torque determinado. Em testes de carga dinâmica, foi relatado que após dois milhões de ciclos, o torque de afrouxamento não diminuiu quando comparado com o torque de aperto antes da carga; por estes resultados, os autores acreditam que a estabilidade mecânica deste sistema favorece biologicamente, sendo obtidas restaurações estéticas com procedimentos técnicos simples, o que fornece garantia de sucesso à restauração.

ANDERSON et $\mathbf{a P}^{5}$, em 1994, avaliaram a resistência mecânica de estruturas em pilares ceraone na área de incisivo superior. No estudo testaram os seguintes grupos: (1) coroas metal cerâmica com infra-estrutura em ouro, com cerâmica aplicada; (2) coroas de cerâmicas com infra-estrutura pré-fabricada de alumina densamente sinterizada cerâmica aplicada; (3) coroas cerâmicas preparadas com a mesma cerâmica que a utilizada para as coroas metal cerâmicas; (4) infra-estrutura de alumina sinterizada; e (5) um sistema completo com um implante de $15 \mathrm{~mm}$ com um pilar de $5 \mathrm{~mm}$, parafuso de ouro e coroa metal cerâmica, iguais às utilizadas no grupo 1. Em todas as amostras foram aplicadas cargas na bordas incisais utilizando-se uma máquina de ensaio universal, até a falha do sistema. A carga e a deformação foram registradas. Três diferentes 
situações clínicas foram selecionadas para cálculos teóricos levando em conta a possibilidade das coroas unitárias resistir às cargas. Os resultados mostraram que, no grupo 1 onde foram testadas coroas metalocerâmicas, não foram observadas fraturas ou deformações, mas os pilares foram flexionados. Fraturas foram encontradas nas coroas cerâmicas e nas infra-estruturas cerâmicas (grupos 2 a 4) sendo que nenhuma deformação foi encontrada para os pilares. No grupo 5 , onde foi testado o sistema completo, deformação plástica do parafuso de ouro foi encontrado. Os autores concluíram que o parafuso de ouro do pilar é o elo fraco do sistema, já que as cargas para falhas foram menores que as cargas para as falhas das coroas; concluíram também que existe uma margem de segurança contra as fraturas em coroas metalocerâmicas e total cerâmica.

Em um estudo sobre os aspectos biomecânicos dos parafusos, BINON ${ }^{16}$ em 1994, afirmou que deficiente aperto dos parafusos, próteses inadequadas, pouca adaptação dos componentes, carga excessiva, falta de assentamento dos parafusos, desenho inadequado do parafuso e a elasticidade do osso contribuem para a instabilidade dos parafusos. Segundo o autor, para se obter uma união estável, valores de torque recomendados nos vários tipos de componentes devem ser seguidos, sendo que para os mesmos devem ser utilizados dispositivos mecânicos de torque que ofereçam maior consistência nas diferentes áreas da cavidade oral. Assim mesmo, afirmou que, a adaptação passiva dos componentes se torna essencial para evitar micromovimentos e instabilidade do parafuso. Um outro fator comentado por ele é a condição de carga excessiva, devido ao número e localização dos implantes, assim como o desenho de um esquema oclusal deva ser adequadamente observado para evitar sobrecargas que levem à instabilidade dos parafusos. Da mesma forma, afirmou que características como diâmetro, comprimento, tipo de roscas, e conexidades dos parafusos nos diferentes sistemas podem predispor fraturas; sendo que a rugosidade excessiva, usinagem ruim, liga com resistência insuficiente e elongação afetam as características desses parafusos. Assim como a qualidade óssea da área receptora do implante tem importância na estabilidade do parafuso, sendo que na maxila, devido a maior 
quantidade de osso esponjoso, existe uma maior deformação quando forças compressivas são aplicadas. Cargas oclusais na maxila resultam em maior tensão na união osso implante e na união do implante com a prótese, tendo-se como resultado uma maior instabilidade do parafuso. Da mesma forma, afirmou que falhas dos parafusos são mecanismos de proteção dos implantes; sendo que na configuração padrão do sistema Branemark, a fratura plástica dos parafusos de ouro ocorrem em $16,5 \mathrm{~N} . \mathrm{cm}$ e no caso dos parafusos do pilar tipo UCLA em elementos isolados, ocorre em $40 \mathrm{~N} . \mathrm{cm}$; o que permite que o torque seja aumentado em aproximadamente $80 \%$.

No mesmo estudo SHUTTER ${ }^{103}$ afirmou que o parafuso deve ser considerado como uma parte importante do desenho da supra - estrutura dos implantes e não como um elemento isolado, acreditando que os problemas relacionados a este envolvem a qualidade e desenho da conexão entre o implante e o pilar. Segundo ele a utilização de um parafuso cônico de oito graus em conjunção com $2 \mathrm{~mm}$ de roscas elimina a rotação do pilar através de uma adaptação da fricção mecânica; nesta conexão cônica micromovimentos nas roscas são eliminados não existindo a transmissão de uma carga funcional nas roscas, já que a precisão da cone xão cônica absorve as vibrações. Afirma que entre o torque de aperto e o torque de afrouxamento está a diferença principal. Segundo ele no desenho do parafuso tradicional o torque de afrouxamento é $10 \%$ menor que o torque de aperto enquanto que no parafuso cônico o torque de afrouxamento é 10 a $20 \%$ maior que o torque de aperto. Segundo ele quando estes parafusos foram testados em uma situação de carga dinâmica, onde foram apertados com $50 \mathrm{~N} . \mathrm{cm}$ e com uma carga de $200 \mathrm{~N}$, o torque de afrouxamento depois de 500.000 ciclos foi de 51 N.cm e depois de 2.000 .000 de ciclos foi de 56 N.cm, o que significa a inexistência de afrouxamento. No caso de parafusos com desenhos convencionais o torque de afrouxamento foi para $36 \mathrm{~N} . \mathrm{cm}$ depois de 500.000 ciclos e $27 \mathrm{~N} . \mathrm{cm}$ depois de 2.000 .000 ciclos, sendo estes apertados a 50 N.cm, o que sugere micromovimentos e tendência para afrouxamento do parafuso. Um outro aspecto discutido por SHUTTER é sobre o parafuso oclusal; 
quando este é de titânio de $2 \mathrm{~mm}$ de diâmetro pode ser conseguido um maior momento de afrouxamento que com o parafuso de ouro de diâmetro menor, sendo que o mesmo princípio da conexão cônica aplicada no parafuso do pilar.

Explicando as características de aperto dos parafusos em implantes, BURGUETE et al $^{28}$ (1994), afirmaram que a importância no aperto é a aplicação de uma ótima pré-carga, sendo que o mecanismo envolve a aplicação do torque. Acima do limite de deformação elástica e inicio de deformação plástica o torque aplicado e a pré-carga são inversamente proporcionais um ao outro, isto devido à influência das forças de fricção sobre a cabeça do parafuso; dessa forma, com o torque, se produz estiramento das roscas, ocorrendo a união do implante / pilar ou do pilar / prótese. Quando as forças da mastigação causam algum deslizamento entre as roscas, a força de alongamento do parafuso (pré-carga) é perdida, assim como a pré-carga abaixo do nível crítico, qualquer vibração faz com que as interfaces se separem. Segundo os autores a pré-carga depende do coeficiente de fricção, da geometria das roscas e das propriedades do material; mais o primeiro fator é de uma relevância maior. Dessa forma, o coeficiente de fricção depende da dureza do material, do polimento da superfície, da quantidade e propriedade do lubrificante e da velocidade do aperto. O coeficiente de fricção aumenta com a dureza do material e a rugosidade de superfície. Da mesma forma quando diminui a quantidade de lubrificante aumenta o coeficiente de fricção.

GOHEEN et af $^{45}$ (1994), avaliaram a quantidade de torque manual gerada por diferentes profissionais utilizando parafusos Branemark de ouro (fenda e hexagonal) e parafusos para fixação de pilares. Avaliaram também, diferentes dispositivos de torque, determinando a magnitude e variabilidade do torque gerado por cada dispositivo. Na sua metodologia cinco clínicos gerais e 11 especialistas em próteses foram orientados a aplicar 10, 20, e 32N.cm de torque em um componente de implante apropriado utilizando chaves manuais Branemark. Uma situação clínica foi simulada sobre um manequim sendo que os participantes utilizaram luvas seguindo a mesma técnica, as quais eles realizam normalmente 
intraoral. Seis repetições foram realizadas para cada torque em diferentes intervalos de tempo, no período da manha, e no período da tarde simulando ambos cenários clínicos e a fadiga do operador. Na outra parte do estudo três dispositivos eletrônicos de torque Branemark foram testados em 10, 20, 32N.cm; e dois dispositivos de torque manual um "Accu-torque wrench", e um "3i Torque Driver" em 10, e $20 \mathrm{~N} . \mathrm{cm}$. Seus resultados mostraram que os clínicos gerais e os especialistas, produziram médias de torque manual de 0,7 a $18,1 \mathrm{~N} . \mathrm{cm}, 1,4$ a 33,7 N.cm; de 8,2 a 36,2N.cm, para 10, 20, e 32N.cm respectivamente. Sendo que no primeiro grupo o torque gerado foi significativamente menor que o requerido. Dessa forma, os valores experimentais, excluindo o torque de $32 \mathrm{~N} . \mathrm{cm}$, tiveram uma variação de $23 \%$ a $48 \%$ abaixo dos valores de torque de referência, encontrando-se uma variação dentro dos grupos de $21 \%$ a $56 \%$ para clínicos gerais e de $22 \%$ a $48 \%$ para os especialistas. Na segunda parte da pesquisa, os dispositivos de torque mecânicos produziram valores de torque dentro da tolerância especificada por seus fabricantes, observando-se uma significante variação dos valores de torque em função da velocidade de aperto com os dispositivos de torque eletrônico, porém uma calibração dos dispositivos deva ser realizada quando um adequado procedimento de torque vai ser realizado.

MCGLUMPHY; KERBY; ELFERS ${ }^{76}$, em 1994, compararam os valores de pré-carga gerados em cinco combinações implante / pilar, desenhadas para restaurações unitárias. Um implante Branemark foi montado em um dispositivo teste para cada uma das quatro amostras de cada grupo testado. Em cada amostra, tanto o parafuso como a superfície de união com o pilar, foram avaliados como são utilizados clinicamente incluindo o processo de fundição. O parafuso foi apertado com um torque de $32 \mathrm{~N} . \mathrm{cm}$ no seu respectivo pilar, sendo que o torque foi aplicado cinco vezes e a pré-carga gerada por cada aperto foi medida por uma célula de carga (MTS). Os valores da pré-carga foram calculados e comparados entre os diferentes sistemas testados. Um teste de regressão linear foi utilizado para analisar o efeito de repetidos apertos no parafuso. Os resultados encontrados foram os seguintes: 


\begin{tabular}{cccc}
\hline Parafuso & Pilar & $\begin{array}{c}\text { Diferença } \\
\text { significante }\end{array}$ & $\begin{array}{c}\text { Pré-carga } \\
\text { N }\end{array}$ \\
\hline Branemark ouro & Ceraone titânio & A & 539,6 \\
Branemark ouro & UCLA usinado & B & 431,6 \\
UCLA titânio & UCLA calcinável & C & 365,4 \\
UCLA titânio & UCLA calcinável & C & 343,4 \\
UCLA titânio & escareado & & 331,1 \\
\hline Com os resultados deste estudo os autores sugerem que a liga, desenho e
\end{tabular}

a superfície de união têm efeito no desenvolvimento da pré-carga no sistema. Contrário aos pilares comparados, os parafusos de ouro geraram uma pré-carga significativamente maior que os parafusos de titânio, para o nível de torque selecionado. Os resultados mostraram também que repetidos apertos de um parafuso individual diminuem a pré-carga que o parafuso pode desenvolver.

MILLER; MCGLUMPHY; KERBY ${ }^{82}$, (1994) compararam os valores de précarga gerados em diferentes tipos de parafusos, quando foram aplicados valores de torques diferentes, e avaliaram a relação entre desenho do pilar e a força de pré-carga. Seis diferentes pilares foram avaliados com seus respectivos implantes. As amostras foram fixadas a uma célula de carga (em uma máquina de ensaios MTS), a qual registrou a pré-carga gerada pelo torque. 20 e $32 \mathrm{~N} . \mathrm{cm}$ de torque foram aplicados para cada combinação implante / pilar, o torque foi aplicado três vezes utilizando um dispositivo eletrônico de torque. Os resultados mostraram os seguintes valores de pré-carga em cada torque aplicado: 


\begin{tabular}{lcccc}
\hline \multicolumn{1}{c}{ Pilar } & $\begin{array}{c}\text { Torque } \\
\text { N.cm }\end{array}$ & $\begin{array}{c}\text { Pré-carga } \\
\text { N }\end{array}$ & $\begin{array}{c}\text { Torque } \\
\text { N.cm }\end{array}$ & $\begin{array}{c}\text { Pré-carga } \\
\text { N }\end{array}$ \\
\hline Omniloc Shouldered & 32 & 356,2 & 20 & 214,0 \\
IMZ UCLA & 32 & 337,6 & 20 & 250,8 \\
Stryker Flat Top & 32 & 288,3 & 20 & 188,0 \\
Esteticone & 32 & 229,5 & 20 & 145,4 \\
3i convencional "standard" & 32 & 215,8 & 20 & 142,9 \\
Branemark convencional & 32 & 194,4 & 20 & 124,8 \\
"standard" & & & & \\
\hline
\end{tabular}

Com os resultados deste estudo os autores sugerem que valores de torques altos levam a maiores valores de pré-carga, e que o pilar e o desenho do parafuso influenciam na geração da pré-carga.

Avaliando diferentes conexões protéticas BALFOR; O'BRIEN ${ }^{8}$ em 1995, compararam três sistemas de implantes com desenhos diferentes para restaurações de elementos isolados. Conexões de hexágonos externos, octágonos internos e hexágonos internos, com seus respectivos pilares protéticos, foram submetidos a testes de torque, cargas compressivas e testes de fadiga através de cargas cíclicas. Para os testes de torque amostras de cada grupo foram fixadas rigidamente, e com um dispositivo de aplicação de torque unido ao pilar, foi aplicada uma força lateral de torque até que houvesse a falha de um dos componentes, registrando-se o máximo de torque e o modo de falha. Para os testes de cargas compressivas as amostras foram fixadas a uma máquina de ensaios com uma angulação de $30^{\circ}$ para reproduzir uma força sobre uma condição clínica de um elemento isolado ou uma carga sobre um cantilever, aplicando-se uma carga até a falha de um dos componentes, sendo registrado o máximo de carga e o modo da falha destes. Nos ensaios de fadiga, as amostras foram submetidas a cargas cíclicas a 14 hertz, sendo registrado os números de ciclos e quando a falha foi evidente. 
Os resultados do estudo mostraram que nos testes de resistência a torque, os implantes com desenho de octágono interno tiveram um comportamento inferior aos outros desenhos, encontrando valores médios de 98,3N.cm para o hexágono externo, 37,3N.cm para o octágono interno e 192,1 N.cm para o hexágono interno. O modo de falha para os implantes com hexágono interno foi limitado a conexão do pilar, enquanto que nos implantes de hexágono externo e octágono interno o modo de falha danificou tanto os pilares quanto à conexão do implante, dando como resultado uma maior estabilidade para os implantes de hexágono interno. Nos testes de cargas compressivas, os resultados mostraram uma maior resistência no desenho de hexágono interno, sendo necessário uma força de $814 \mathrm{~N}$ para provocar a falha; os desenhos de hexágono externo e octágono interno forças de $756 \mathrm{~N}$ e $587 \mathrm{~N}$, respectivamente, foram necessárias para provocar falhas nos componentes. Nos testes de fadiga, limites de resistência para os desenhos de hexágono e octágono interno de $367 \mathrm{~N}$ e $400 \mathrm{~N}$ respectivamente foram encontrados, enquanto que no desenho de hexágono externo foi de $242 \mathrm{~N}$; porém três amostras de hexágono externo se mantiveram estáveis após cinco milhões de ciclos, enquanto que dos desenhos de octágono e hexágono interno 1 e 2 amostras respectivamente foram estáveis.

Com o objetivo de avaliar a precisão e a consistência da usinagem, BINON $^{14}$, (1995) avaliou 13 implantes de diferentes marcas comerciais com extensão hexagonal externa e determinou a liberdade rotacional entre o hexágono externo do implante e o hexágono interno do pilar. As medidas foram realizadas no diâmetro da base do implante, roscas, altura e largura da extensão hexagonal, com a utilização de um micrometro digital e um micrometro microscópico. A liberdade rotacional foi medida em graus utilizando um dispositivo desenvolvido com esse objetivo. Implantes Nobelpharma, Stryker, Steri-Oss, 3i, Osseodent, Implant Support Systems, IMTEC, Denstply-Core-Vent, Impla-Med, Bud Ind. Crossmark, Interpore Int, foram utilizados. 
Concluiu que especificações da usinagem podem variar significativamente entre os diferentes fabricantes, entretanto sistemas disponíveis exibem uma tolerância pequena e excelente precisão e consistência; sendo que:

-Baseado no índice de composição a menor tolerância foi observada para os

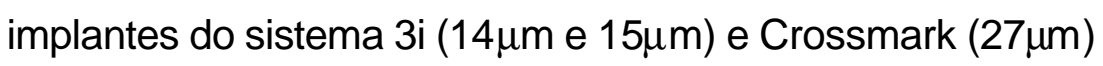

- A menor variação na largura hexagonal foi observada nos implantes $3 \mathrm{i}$ $(1 \mu \mathrm{m})$, Nobelpharma $(4 \mu \mathrm{m})$, e Impla-med $(5 \mu \mathrm{m})$; e a maior variação no sistema Swede Vent $(27 \mu \mathrm{m})$.

- A menor variação na altura do hexágono foi observada no sistema IMTEC $(18 \mu \mathrm{m})$ e Stryker $(28 \mu \mathrm{m})$ e a maior no sistema Steri-Oss $(147 \mu \mathrm{m})$

- A menor liberdade rotacional entre o implante e o pilar foi observado no sistema Crossmark $\left(4,0^{\circ}\right), 3 i\left(4,6^{\circ}\right)$, e Impla-med $\left(5,0^{\circ}\right)$.

- A menor liberdade rotacional entre componentes de diferentes sistemas foi observa para Nobelpharma / Impla-Med (3,5), Implant Support Systems / Impla-Med $\left(4,2^{\circ}\right)$, 3i / Impla-Med $\left(4,3^{\circ}\right)$, e Nobelpharma / $3 \mathrm{i}$ $\left(4,9^{\circ}\right)$.

Com o objetivo de criar dados base "Baseline" para aplicação do torque nos parafusos do pilar sem afetar a osseointegração dos implantes CARR et $\mathbf{a l}^{30}$ realizaram um estudo onde determinaram a resistência ao torque da interface tecido / implante de implantes osseointegrados colocados em mandíbulas e maxilas de animais adultos do tipo "baboon". Os implantes colocados foram de $3,8 \times 10 \mathrm{~mm}$ Steri-Oss com três tipos de biomateriais. (1) Titânio comercialmente puro; (2) Ti-6Al-4V; e (3) Ti-6Al-4V com camada de hidroxiapatita. Estes foram colocados e esperado o tempo de cicatrização de 3 a 4 meses; após este período os animais foram sacrificados e as mandíbulas dissecadas e incluídas em blocos de gesso. Os dados de torque foram obtidos com um dispositivo de torque computadorizado, sendo que os mesmos representaram o pico de torque ocorrido dentro de uma rotação de 20 a $30^{\circ}$. Todos os dados foram obtidos pelo mesmo operador com intervalos de tempo de 12, 13, 14, 15, e 16 semanas. Com relação aos valores obtidos na mandíbula e a maxila os resultados mostraram maiores 
valores médios na resistência ao torque dos implantes colocados na mandíbula que os colocados na maxila, porém sem diferença estatisticamente significante. Em relação ao biomaterial na superfície dos implantes valores diferentes foram encontrados nos três tipos testados sendo de: $189,29 \mathrm{~N}$.cm nos implantes com camada de hidroxiapatita; de 79,03N.cm no Ti-6Al-4V; e de 74,51N.cm nos implantes de titânio comercialmente puro. Os autores afirmam que a implicação clínica dos dados sugerem que o torque recomendado de $35 \mathrm{~N} . \mathrm{cm}$ para a fixação do parafuso do pilar pode dar uma margem de segurança para os desenhos e materiais dos implantes utilizados neste estudo.

DIXON et $\mathbf{a l}^{40}$, (1995) compararam três sistemas de implantes de diferentes fabricantes, determinando a flexão do complexo pilar / implante durante a aplicação de forças e a quantidade de torque necessária para afrouxar o parafuso do pilar. Neste estudo, utilizaram implantes de hexágono externo, hexágono interno e octágono interno, nos quais foram fixados pilares retos e angulados, sobre os quais coroas de $10 \mathrm{~mm}$ de altura foram confeccionadas e cimentadas. Cargas cíclicas foram aplicadas por 4.63 horas (16,667 ciclos) a $4 \mathrm{~mm}$ do centro do implante utilizando-se uma máquina de ensaio de fadiga desenvolvida para o experimento. Os parafusos foram apertados com um de dois dispositivos de torque disponíveis, Tohnichi 6BTG-A e Torque dyne, com um torque de $29 \mathrm{~N} . \mathrm{cm}$. Os resultados não mostraram diferenças estatisticamente significantes entre pilares retos e angulados nos testes realizados para os diferentes sistemas. $\mathrm{Na}$ quantidade de torque necessária para afrouxar os parafusos depois da carga, obteve-se uma perda média de $2.97 \mathrm{~N} . \mathrm{cm}$ no sistema de hexágono externo, de $1.62 \mathrm{~N} . \mathrm{cm}$ no sistema de octágono interno e $5.58 \mathrm{~N} . \mathrm{cm}$ no sistema de hexágono interno.

HAACK et $\mathbf{a l}^{50}$, (1995) desenvolveram um método para determinar a précarga inicial de parafusos tipo UCLA, utilizando a medida da elongação destes, depois de aplicar forças de torque conhecidas; no mesmo estudo, determinaram 0 torque de afrouxamento quando é aplicado um torque de $32 \mathrm{~N} . \mathrm{cm}$ em parafusos 
UCLA de ouro e de 20N.cm em parafusos UCLA de titânio, determinando também o máximo de torque de aperto sem deformação plástica de cada parafuso. Para obter a medida da elongação, pilares UCLA foram fixados a implantes de titânio por meio de parafusos de ouro e de titânio, com um torque de 32 e $20 \mathrm{~N} . \mathrm{cm}$ respectivamente, o comprimento de cada parafuso foi obtido removendo-se a porção coronal do pilar e apical do implante de forma a expor a cabeça e as ultimas três roscas do parafuso, dessa forma, depois de aplicado o torque, foi medida a elongação antes e depois de aplicado o torque utilizando-se um micrometro digital; com esta medida e através de uma fórmula, foi calculada a tensão das roscas em cada parafuso. O torque de afrouxamento foi registrado depois do aperto máximo, sendo este processo repetido dez vezes em cada parafuso no mesmo implante. Seus resultados mostraram que a elongação dos parafusos depois de aplicar as forças de torque recomendadas pelos fabricantes permaneceu dentro dos limites de elasticidade, sendo esta de 57,5\% e 56\%, nos parafusos de ouro e titânio, respectivamente. Seguindo os torques recomendados pelos fabricantes, a pré-carga média foi de $468,2 \mathrm{~N}$ utilizando os parafuso de ouro e de $381,5 \mathrm{~N}$ com os parafusos de titânio. Com base na análise estatística destes resultados os autores acreditam que pode ser possível apertar os parafusos além dos níveis de torques recomendados para minimizar os problemas de afrouxamento, porém as forças mastigatórias provavelmente atuam para elevar a tensão de estresse nos parafusos. Quando foi avaliado o torque de afrouxamento, foi observado que este foi entre um 20 e $30 \%$ menor que o torque de aperto em ambos tipos de parafusos.

JAARDA, RAZZOOG, GRATTON ${ }^{55}$, (1995) examinaram os parâmetros geométricos de maior impacto na relação torque / pré-carga, de cinco parafusos de retenção protéticos intercambiáveis. Através de microscopia eletrônica de varredura (MEV), parafusos testes de fenda de dois tipos de ligas foram selecionados de três fabricantes sobre o fato de estes serem intercambiáveis com o parafuso de retenção de ouro Nobelpharma; sendo que estes foram utilizados como grupo controle com o qual os parafusos testes foram comparados. Os 
parafusos de ouro 3i, Impla-Med, e Nobelpharma; e os parafusos de titânio 3i, e Implant Support Systems foram testados. Cinco parafusos de cada tipo e oito parâmetros foram medidos: $(A)$ diâmetro da cabeça do parafuso; (B) comprimento do parafuso; (C) distância entre o pico das roscas; (D) diâmetro principal; (E) diâmetro do pescoço do parafuso; (F) comprimento do pescoço; (G) largura da crista. Os resultados mostraram diferenças estatisticamente significantes em cinco parâmetros, sendo que somente nos parâmetros C e G não apareceram diferenças. Para o parâmetro A o diâmetro da cabeça do parafuso de ouro 3i, e do parafuso de titânio Implant Support Systems, foram maiores que os parafusos de ouro Nobelpharma. Para o parâmetro $B$, os comprimentos dos parafusos de ouro e de titânio 3i foram menores do que os parafusos do grupo controle; entretanto os parafusos de ouro da Impla-Med e de titânio da Implant Suport System foram maiores. No parâmetro D os parafusos de ouro da Impla-Med tiveram um diâmetro significativamente menor que os parafusos controles. No parâmetro $E$, os parafusos de ouro Impla-Med e de titânio 3i foram significativamente menores. No parâmetro $\mathrm{F}$, os parafusos de ouro e de titânio 3i tiveram pescoços maiores, enquanto que os parafusos de ouro Implat Support System foram menores. Dessa forma, os autores concluíram que as diferenças encontradas entre os parafusos podem introduzir variáveis desconhecidas no tratamento dos pacientes, e que na base dos princípios de engenharia em relação a desenho dos parafusos, e a relação torque pré-carga, pode ser que as recomendações de torque de aperto para os parafusos Nobelpharma não sejam aceitas como certas para todos os desenhos de parafusos.

SAKAGUCHI; BORGERSEN ${ }^{96}$, em 1995, utilizaram um método de elementos finitos para avaliar o mecanismo de transferência de carga entre os componentes protéticos. Criaram modelos baseados na marca 3i representando um pilar reto com seu parafuso, um cilindro de ouro de $3,0 \mathrm{~mm}$, e um parafuso de fixação de ouro de $3,0 \mathrm{~mm}$, fixados a um implante $3,75 \mathrm{~mm}$ de diâmetro. Nestes componentes foi avaliada a distribuição da tensão nos parafusos depois da aplicação de um torque de $10 \mathrm{~N} . \mathrm{cm}$ ao parafuso de fixação de ouro e de $20 \mathrm{~N} . \mathrm{cm}$ 
ao parafuso de titânio do pilar e sua possível predisposição a falha. Seus resultados mostraram que a elongação do parafuso é obtida enquanto se permite a recuperação elástica do parafuso para produzir uma força de ajuste nos elementos de fixação. A pré-carga no parafuso do pilar resultou em contato na interface implante / pilar; nas primeiras quatro roscas de parafusos do pilar e na interface parafuso de pilar / pilar. As forças mais altas foram geradas na interface implante / pilar $(120,6 \mathrm{~N})$. As forças no pilar na interface parafuso / pilar foram similares em magnitude aquelas roscas dos parafusos $(75 \mathrm{~N})$. As forças totais de contato na interface pilar / implante foram de $188,3 \mathrm{~N}$ e $187,2 \mathrm{~N}$ no pilar na interface pilar / parafuso em direção axial. As maiores tensões foram verificadas em direção da segunda e terceira roscas do parafuso do pilar (10,9Mpa) com a tensão mais alta em direção axial ocorrendo no ângulo formado entre a haste do parafuso do pilar e sua cabeça (240,7Mpa). Para o torque de $20 \mathrm{~N} . \mathrm{cm}$ simulado no parafuso de titânio do pilar o limite máximo de elasticidade foi de $52 \%$ da resistência ao escoamento. Depois do carregamento do parafuso de retenção de ouro a força total de contato na interface do parafuso foi de $131,5 \mathrm{~N}$, assim como a força de contato na interface cilindro de ouro / pilar. A força de contato na interface implante / pilar aumentou 20,2\% para 226,4N em direção axial. Existiu uma diminuição de $49,8 \%$ na força total de contato, no pilar, na interface pilar / parafuso para $94,0 \mathrm{~N}$ da força de contato inicial de 187,2N. As maiores tensões foram observadas na união entre a haste do parafuso e sua cabeça. A máxima tensão foi 222,2Mpa em direção axial e de 91,7Mpa em direção transversa, sendo a tensão máxima de $39,3 \%$ da resistência ao escoamento.

Preocupado com as variáveis clinicas que afetam as cargas das próteses sobre implantes, WEINBERG; KRUGER ${ }^{113}$ neste mesmo ano, realizaram uma avaliação comparativa das cargas no parafuso de ouro, parafuso do pilar, e no implante em quatro diferentes situações clínicas que incluíram: inclinação cuspídea, inclinação do implante, desvio horizontal e vertical do implante. Através de uma configuração prótese - implante com dimensões conhecidas (utilizadas como padrão), um modelo matemático foi utilizado para calcular o momento de 
torque no parafuso de ouro e do pilar e na porção coronal do implante. Concluíram que:

- Para cada $10^{\circ}$ de aumento na inclinação da cúspide, houve aproximadamente um aumento de $30 \%$ na carga do conjunto prótese / implante.

- Para cada $10^{\circ}$ de aumento na inclinação do implante houve aproximadamente um $5 \%$ de aumento na carga no conjunto prótese / implante

- Para cada mm de desvio lingual do implante houve um aumento de $15 \%$ no momento de torque.

- Para cada mm de desvio apical do implante houve um aumento de aproximadamente $4 \%$ do momento de torque.

WISKOTT; NICHOLLS; BELSER ${ }^{115}$, (1995) explicaram que máquinas para ensaios de fadiga são capazes de colocar uma amostra sob tensão repetitivamente; entretanto os parâmetros de tensão que são aplicados podem diferir consideravelmente. Esses parâmetros são: freqüência cíclica, o préestresse, amplitude da tensão, raio da tensão, e o valor do estresse (compressão, tensão). Algumas máquinas são desenvolvidas para reproduzir um ambiente úmido por controle da temperatura, sendo que as amostras possam ser testadas simulando um ambiente bucal. Segundo os autores para determinar o numero de ciclos que deva ser aplicado à estrutura dental o seguinte cálculo deve ser realizado: primeiramente assumir que três períodos de 15 minutos de mastigação são realizados por dia, em uma freqüência de 60 ciclos por minuto $(1 \mathrm{~Hz})$; a média individual seriam de 2.700 ciclos por dia, esta quantidade corresponderia a $10^{6}$ ciclos por ano. Se a média de vida de uma prótese parcial fixa dada por alguns trabalhos é de 20 anos, esta prótese suportará $2 \times 10^{7}$ ciclos, porém pode ser pensado que nem todo ciclo mastigatório é ativo (aplicando a máxima tensão à estrutura), conseqüentemente esse total de $2 \times 10^{7}$ calculado previamente deve ser reduzido por um fator médio entre 5 e 20 para se obter um valor real; pelo que para aplicações dentais, o teste de fadiga deve ser realizado com um mínimo de 
$10^{6}$ ciclos. Também é importante entender, segundo os autores, que uma carga funcional nos dentes implica numa condição de forças multidirecionais, sendo que ensaios uniaxiais a estruturas, reproduzirão só em parte as condições mecânicas do meio bucal.

BASTEN et al $^{12}$, em 1996, compararam as propriedades de fadiga de dois sistemas de implante / pilar Nobel Biocare utilizados na prática clinica quando apertados com três diferentes valores de torque. Este estudo de laboratório simulou uma situação clínica, sendo investigado: (1) o numero de ciclos de carga de fadiga requeridos para criar falhas nos pilares ceraone e esteticone; (2) se existia um efeito na carga de fadiga nos sistemas de pilares ceraone e esteticone quando o torque foi aumentado ou diminuído $20 \%$ do valor de torque recomendado pelo fabricante. Os implantes foram incluídos em resina epóxica utilizando-se um dispositivo, onde o diâmetro do implante foi centralizado na resina. O torque foi aplicado utilizando-se um torquímetro Tohnichi 9 BTG-A, calibrado com uma precisão de $0,6 \mathrm{~N}$.cm. Sobre os pilares (ceraone e esteticone) um cilindro de ouro foi colocado, encerado e fundido com uma liga metálica (Degudent H / Degussa), sendo que no pilar ceraone um orifício foi realizado no topo da fundição para permitir o aperto do parafuso, e a supra-estrutura foi reposicionada ao pilar e cimentada com cimento fosfato de zinco. No pilar estheticone a supra-estrutura fundida e finalizada foi parafusada com o torque requerido. Uma máquina de fadiga foi utilizada para aplicar uma tensão senoidal em cada amostra, sendo que a máquina parou quando existiu uma falha da amostra. A carga foi aplicada com uma angulação de $30^{\circ}$, simulando uma inclinação cuspídea. A máquina foi programada para aplicar uma carga cíclica a $16 \mathrm{~Hz}$ e $70 \mathrm{~N}$ durante todo o teste. Após 2000 ciclos a máquina foi parada e os parafusos reapertados no valor de torque especificado, depois reiniciada até a falha de um dos componentes. Os resultados mostraram no pilar ceraone que dez dos 15 implantes fraturam entre 15.000 e 676.000 ciclos; em nove amostras a fratura foi localizada abaixo do final do parafuso de ouro; na décima amostra tanto o implante quanto o parafuso do pilar fraturaram ao mesmo nível. Quatro 
parafusos do pilar falharam entre 169.000 e 1.492 .000 ciclos. No pilar esteticone só um parafuso do pilar de titânio fraturou, nenhum dos parafusos de ouro falharam. Todos os outros parafusos falharam na parte das roscas, próximo da haste, estas fraturas foram localizadas aproximadamente $2 \mathrm{~mm}$ abaixo do topo do implante. Uma significativa diferença estatística foi encontrada entre os dois tipos de pilares e entre os diferentes níveis de torque utilizados em cada sistema. Os autores concluíram que: (1) Existem diferenças estatisticamente significantes entre os dois pilares testados em relação ao numero de ciclos para a falha; (2) não houve diferença estatisticamente significante em relação aos ciclos para a falha para três grupos do esteticone e três grupos do cereone; (3) o elo fraco do sistema esteticone está no parafuso de titânio do pilar e não no parafuso de retenção de ouro; (4) em 10 das 15 amostras do sistema ceraone o elo fraco foi o implante de titânio; (5) em 4 das 15 amostras do sistema ceraone foi o parafuso de ouro do pilar.

Com o objetivo de avaliar características selecionadas de três sistemas de implantes de hexágono externo, BINON ${ }^{18}$, em 1996, avaliou a tolerância de adaptação dos sistemas Steri-Oss, Lifecore, e Calcitek. Na sua metodologia realizou medidas nos implantes e seus respectivos análogos de laboratório; e em dois diferentes tipos de pilares dos sistemas Steri-Oss e Calcitek e três para o sistema Lifecore. Utilizou um micrometro digital e um micrometro microscópico, para as medidas do diâmetro coronal e a largura da extensão hexagonal, um mínimo de dez implantes e análogos foram medidos. Também registrou a liberdade rotacional e a resistência a torsão da conexão pilar / implante dos sistemas testados. Concluiu que:

- A média da largura da extensão hexagonal dos implantes variou de 2,685 a 2,700mm, encontrando uma correlação próxima com as dimensões dos análogos correspondentes. 
- Uma reduzida liberdade rotacional foi encontrada nos três sistemas avaliados, sendo de 1,6 a 2,2 graus no sistema Lifecore, 2,4 a 2,6 graus no sistema Steri-Oss, e 3,5 a 5,2 no sistema calciteck.

- A resistência a torsão no sistema Lifecore foi de $154,5 \mathrm{~N} . \mathrm{cm}$ e $175,8 \mathrm{~N} . \mathrm{cm}$, Steri-Oss de 124,3, e Calcitek 122,7N.cm.

Estes resultados, segundo o autor, sugerem uma tendência de alguns fabricantes em melhorar a tolerância, precisão e consistência dos componentes de implantes.

Neste mesmo ano BINON ${ }^{15}$, avaliou as características físicas, mecânicas, e clinicas de implantes com conexão tipo "spline" (Calcitek). Utilizou 45 implantes, 15 pilares retos cimentáveis e 40 parafusos para realizar testes de torsão, cargas cíclicas e de compressão e tolerância rotacional; seguindo as especificações de um protocolo previamente estabelecido. Para determinar a resistência a torsão; pilares foram unidos aos implantes através do parafuso com $30 \mathrm{~N} . \mathrm{cm}$ de torque. Depois, foram fixados a um medidor de torque, e com uma chave de torque o pilar foi girado até que ocorresse a falha. Para a carga dinâmica, o mesmo protocolo estabelecido em trabalho anterior ${ }^{22}$ para realizar os testes de cargas cíclicas foi utilizado. Os testes de compressão foram realizados unindo implantes a pilares de $9 \mathrm{~mm}$ de comprimento e $4 \mathrm{~mm}$ de diâmetro, aplicando-se $30 \mathrm{~N} . \mathrm{cm}$ de torque aos parafusos. Cada conjunto foi fixado com uma inclinação de $30^{\circ} \mathrm{em}$ um bloco teste onde foram levados a uma máquina de ensaios Instron e aplicada uma carga compressiva a 0,03 polegadas por minuto até a falha. Concluiu que:

- 8 de 10 amostras permaneceram por mais de 10 milhões de ciclos, uma amostra falhou em 9,4 milhões de ciclos e um implante fraturou 10 milhões de cilclos. O torque residual após as cargas cíclicas foi de $15 \mathrm{~N} . \mathrm{cm}$.

- A média de resistência a torsão foi de $219,3 \mathrm{~N} . \mathrm{cm}$, excedendo $17,1 \%$ a $82,9 \%$ o sistema hexagonal.

- A carga de compressão máxima para a falha foi de $3,467 \mathrm{~N}$, sendo o modo de falha igual para todas as amostras, ao nível do spline do implante. A 
interface spline resultou ser 3 a 5 vezes mais forte que a interface do sistema de hexágono externo e octagono interno.

- A média de movimento rotacional observada foi 0,267ㅇ․

- A interface mostrou uma adequada fidelidade de superfície com microfendas externas de 10 a $15 \mu \mathrm{m}$.

Continuando essa mesma linha de pesquisa, no mesmo ano BINON 20 avaliou o efeito da desadaptação entre a extensão do hexágono do implante e o hexágono interno do pilar, na estabilidade do parafuso, durante cargas cíclicas simuladas. Uma máquina que permitisse a aplicação de cargas cíclicas foi desenhada e construída, de forma a ciclar dez amostras simultaneamente. Cinqüenta implantes $3,75 \times 10 \mathrm{~mm}$ de hexágono externo (Lifecore), com uma média hexagonal de $2,684 \mathrm{~mm}$, foram fixados em uma resina que simulou a resilência e elasticidade do osso. Pilares cônicos especiais tipo UCLA foram construídos de titânio, com $8 \mathrm{~mm}$ de altura e um diâmetro na parte superior de $8 \mathrm{~mm}$; o hexágono interno dos pilares variou de 0,1065 a 0,1110 polegadas. Antes da aplicação da carga, foram medidas as liberdades rotacionais entre os hexágonos externos dos implantes e interno dos pilares, de cada uma das amostras. Médias de liberdade rotacional de $1,94^{\circ}$ nas conexões com menores desadaptações e de 14,87 graus nas conexões com maiores desadaptações rotacionais. Os pilares foram conectados aos implantes utilizando um parafuso de titânio, sendo aplicado um torque de $30 \mathrm{~N} . \mathrm{cm}$ com dispositivo de torque mecânico (Implant Support Systems). As amostras foram fixadas na máquina de ensaios e aplicada uma carga vertical de 1,150 ciclos por minuto, e uma força de 133,3N, sendo que quando existiu uma abertura da interface pilar / implante a máquina parou e o numero de ciclos foi registrado. Os resultados mostraram:

- Existiu uma correlação direta entre a liberdade rotacional e a estabilidade do parafuso, encontrando-se que a maior liberdade rotacional, determina uma maior possibilidade de afrouxamento do parafuso.

- $\quad$ Falhas foram encontradas entre 134.000 e 9.3 milhões de ciclos. 
- Uma liberdade rotacional menor que dois graus resulta em uma união mais estável e uma maior resistência ao afrouxamento do parafuso, com média de 6.7 milhões de ciclos e um aumento de $26 \%$ da resistência quando comparado com as amostras que tinham uma liberdade maior (3,06 graus)

- Uniões com mais de cinco graus de liberdade rotacional, se comportaram de uma forma similar, com afrouxamento do parafuso entre 2,1 e 1,1 milhões de ciclos, um $63 \%$ de redução quando comparado com as amostras melhores adaptadas.

BINON; MACHUGH ${ }^{22}$ (1996) avaliaram a influência da liberdade rotacional em implantes de hexágono externo de dimensões diferentes, na estabilidade da união parafusada. No seu experimento, utilizaram dois grupos diferentes de pilares UCLA não segmentados, sendo um grupo com pilar hexagonal pré-fabricado em ouro com seu parafuso de fixação de titânio; e outro grupo com pilar hexagonal fundível em plástico e seu correspondente parafuso de fixação. Com estes, pilares cônicos total metálicos foram obtidos com $8 \mathrm{~mm}$ de altura por $8 \mathrm{~mm}$ de largura. Como grupo controle utilizaram pilares pré-fabricados em ouro. Nas amostras, foram aplicados $20 \mathrm{~N} . \mathrm{cm}$ de torque inicialmente e depois do primeiro milhão de ciclos foram reapertados a $30 \mathrm{~N} . \mathrm{cm}$. Em todas as amostras foram aplicadas cargas cíclicas utilizando a metodologia desenvolvida por Binon ${ }^{20}$ previamente, com 133,3N de carga, uma rotação anti-horária de 28 ciclos por minuto, 1,150 ciclos por minuto de carga vertical até ocorrer a falha do parafuso. Seus resultados mostraram uma média de liberdade rotacional de $5^{\circ}$ em ambos grupos testes, sendo todas as amostras do grupo pré-fabricado afrouxaram entre 384.215 e 409.170 ciclos, na primeira parte do experimento. No segundo grupo teste, só um implante falhou em 597.366 ciclos, as outras amostras permaneceram estáveis no primeiro milhão de ciclos, sendo que o segundo grupo teste teve uma maior resistência ao afrouxamento, na primeira e segunda parte do experimento. Encontrourse também uma correlação direta entre a liberdade rotacional entre o pilar / implante e o afrouxamento do parafuso; sendo que esta união é mais resistente ao afrouxamento quanto menor é a liberdade rotacional. 
CARR; BRUNSKI; HURLEY ${ }^{31}$ (1996) mediram e comparam a pré-carga produzida em cilindros de ouro pré-fabricados e cilindros de plástico fundidos após os procedimentos de acabamento e polimento. Utilizaram cilindros compatíveis com o pilar Nobel Biocare (SDCA 004). Cilindros de plástico (SGC 34 3i) e cilindros de ouro (DCA 072 Nobel Biocare e SGC 30 3i), foram selecionados para fundição com ligas metálicas de alta e baixa fusão, para analisar os efeitos da temperatura nas medidas de pré-carga. Um pilar com três "strain gauges" foi fixado ao implante para obter as medidas de pré-carga. Concluíram que na união do cilindro de ouro pode ser afetada pelo processo de fundição e que a seleção do tipo de cilindro, a liga metálica, revestimento, técnica de acabamento e polimento, influenciam na produção da pré-carga nesta união. Cilindros metálicos quando comparados com os cilindros de plásticos revelaram uma pré-carga significativamente maior. No grupo de cilindros de plástico a liga de baixa fusão produziu uma pré-carga significativamente mais alta que a liga de alta fusão. Um aumento significante na pré-carga foi encontrado com os procedimentos de acabamento e polimento nos cilindros de plástico, enquanto que com os cilindros metálicos não foi encontrada nenhuma melhoria.

CAVAZOS; BELL ${ }^{33}$ (1996) descreveram uma técnica para prevenir o afrouxamento do parafuso de fixação que une o pilar ao implante. Na técnica, socavados ou irregularidades são criadas acima da cabeça do parafuso na superfície interna do canal de acesso da coroa. Um material a base de polivinilsiloxano é injetado e condensado nos socavados e no hexágono ou fenda dos parafusos, acima deste uma resina composta é fotopolimerizada para assegurar o material na posição condensada. Os autores afirmaram que esta técnica é simples e proporciona excelentes resultados.

Com o objetivo de avaliar a compatibilidade dos parafusos de retenção protética, JAARDA; RAZZOOG; GRATTON ${ }^{54}$ testaram parafusos de fenda de quatro fabricantes diferentes ( $3 \mathrm{i}$, Impla-Med, Implant support System e 
Nobelpharma) e dois tipos de ligas metálicas (ouro e titânio) para determinar resistência à tensão final, sendo os parafusos de retenção de ouro de fenda (Nobelpharma) serviram utilizados como controle. Um dispositivo foi desenvolvido para a realização dos testes, este utilizou uma prótese fundida que incorporou um cilindro de ouro Nobelpharma de $4 \mathrm{~mm}$. A prótese foi unida soldando um análogo de laboratório durante o procedimento de teste com o apropriado parafuso de retenção; o análogo soldado foi fixado a parte inferior de uma máquina de ensaio universal; uma segunda infraestrutura unida à parte superior da máquina encaixou a prótese. Cada parafuso foi apertado com um torque de $10 \mathrm{~N} . \mathrm{cm}$ utilizando um torquímetro Tohnichi BTG-6. Quando a variabilidade entre sistema não foi maior que a variabilidade intra sistema, o parafuso foi considerado compatível. Testes de resistência à tração foram realizados, sendo que os parafusos receberam carga até a sua fratura. Os resultados mostraram os seguintes valores de máxima resistência a tração:

\begin{tabular}{lccc}
\hline Fabricante & Liga metálica & $\begin{array}{l}\text { Máxima resistência à } \\
\text { tração em kg }\end{array}$ & $\begin{array}{c}\text { do } \\
\text { controle }\end{array}$ \\
\hline Nobelpharma & Ouro & 84,5 & 100 \\
Implant Innovation & Ouro & 74,4 & 89,19 \\
Impla-Med & Ouro & 76,1 & 89,97 \\
Implant Innovation & Titânio & 41,3 & 48,85 \\
Implant support systems & Titânio & 108.1 & 127,84 \\
\hline
\end{tabular}

do grupo controle e quando comparados entre si. Houve também grande variabilidade nos resultados em relação ao tipo de liga utilizada, encontrando que parafusos de ouro e titânio reagiram de forma diferente, sendo que os autores concluíram que a existência de uma grande variabilidade entre os diferentes parafusos testados em relação à resistência a tração pode influenciar na integração de um sistema seguro. 
CLAYTON; DRISCOLL; HONDRUM ${ }^{36}$, em 1997, avaliaram a resistência à retenção e as discrepâncias do assentamento marginal de cinco agentes cimentantes no sistema ceraone. Dez amostras utilizadas com cada um dos cimentos (Vitremer, Fuji I, Temp Bond, Fosfato de zinco, e Panavia) foram submetidas a testes de resistência retentiva sob condições experimentais. Os resultados encontrados mostraram que o cimento fosfato de zinco teve a maior média de resistência retentiva $(46,06 \mathrm{~kg})$, enquanto que o cimento à base de óxido de zinco eugenol (Temp Bond) apresentou a menor média retentiva $(6,85 \mathrm{~kg})$. A microscopia eletrônica mostrou maiores microfendas marginais (62,167ìm) entre o pilar e o cilindro quando o cimento fosfato de zinco foi utilizado, embora estes valores sejam clinicamente aceitáveis.

DELLOW; DRIESSEN; NEL ${ }^{38}$ (1997) utilizaram microscopia eletrônica de varredura (MEV) para investigar a adaptação da interface pilar / implante de quatro sistemas diferentes de implantes, assim como para determinar a adaptação desta interface quando os componentes são intercambiados. Os sistemas Southern Implants, Branemark, Swede-Vent, e Steri-Oss foram utilizados; quatro implantes e quatro pilares de cada sistema foram avaliados. Os implantes / pilares foram agrupados em todas as possíveis combinações. Cada combinação foi montada em uma placa de alumínio para colocação dentro do MEV. Medidas foram realizadas aleatoriamente em três áreas selecionadas da interface. As circunferências das conexões foram observadas e avaliadas seguindo os seguintes critérios: (1) Valores do espaço vertical entre implante e pilar (microfenda) do mesmo sistema para controle, assim como para as combinações intercambiadas. (2) A formação de espaço horizontal (sobrecontorno) entre o implante e o pilar, do mesmo sistema, assim como para as combinações intercambiadas, relacionando-as de forma positiva ou negativa aos implantes. Os resultados relataram não existir diferenças estatisticamente significantes entre os pilares e os sistemas de implantes testados, em relação a microfenda. Diferenças estatisticamente significantes foram encontradas em relação a sobrecontorno, entre os pilares e cada um dos implantes utilizados. Os valores da microfenda 
para os grupos controles de todos os sistemas avaliados indicaram claramente que todos os sistemas têm excelentes tolerâncias de usinagem, com valores de microfenda de 0 a $7,15 \mu \mathrm{m}$. Os sistemas Swede-Vent e Southern mostraram os menores valores de microfenda, seguido do Steri-Oss. Em relação ao sobrencontorno, o sistema Branemark mostrou o maior sobrecontorno de todos os sistemas avaliados.

Em um estudo in vitro, JANSEN; CONRADS; RICHTER ${ }^{56}$ (1997) determinaram a infiltração microbiana na interface implante / pilar de diferentes sistemas de implantes. Em treze combinações de nove sistemas diferentes, foram realizados testes microbiológicos nos quais a penetração da bactéria Escherichia coli na área da interface implante / pilar foi observada. Os desenhos dos sistemas testados foram diferentes em vários aspectos, como na forma da interface as quais foram cônicas e planas; pilares de uma parte e de várias partes conectados aos implantes por parafusos separados. Dez amostras de cada sistemas foram testadas sob condições estéreis; a parte interna do implante foi inoculada com uma suspensão de Escherichia coli que é uma bactéria móvel gram negativa que mede 1,1 a $1,5 \mu \mathrm{m}$ de diâmetro e 2,6 $\mu \mathrm{m}$ de extensão. As amostras foram colocadas em tubos de ensaio contendo uma solução nutriente e armazenadas a $37^{\circ}$ C. Nos dias $1,2,5,7,10$, e 14 uma possível penetração da bactéria na solução circundante foi avaliada; esta penetração causou colonização bacteriana e resultou em uma solução turva. Na maioria dos sistemas de implantes, os componentes da conexão resultaram em apenas alguns casos de contaminação na porção externa, entretanto para os sistemas Ankilos e Astra a suspensão bacteriana invadiu a parte externa em mais da metade das amostras. Em uma segunda parte do estudo uma amostra de cada tipo foi aleatoriamente selecionada e analisada no microscópio eletrônico de varredura (MEV), a adaptação marginal entre o implante e o pilar foram medidos em 12 áreas com um aumento de $775 \mathrm{X}$. Os resultados mostraram que as fendas marginais de todas as partes préfabricadas foram menores de $10 \mu \mathrm{m}$, somente o pilar Octa mostrou fenda máxima de $12 \mu \mathrm{m}$. O valor médio esteve abaixo de $5 \mu \mathrm{m}$ para todos os sistemas. Os autores 
concluíram que os sistemas de implantes comuns não podem prevenir a infiltração microbiana e a colonização bacteriana da parte interna do implante, sendo que há necessidade de modificações para selar a área de contato impla nte / pilar. Uma solução promissora é a arruela de silicone do pilar Frialit-2, o qual claramente reduz a infiltração quando comparado aos outros pilares convencionais.

Neste mesmo ano, HEBEL; GAJJAR ${ }^{52}$ discutiram a influência da estética e da oclusão na seleção do uso de sistemas parafusados ou cimentados, como retenção para próteses sobre implantes. Para os autores um dos argumentos mais utilizados pelos defensores das próteses parafusadas é o de dar condição da prótese ser reutilizável, mas que quando é selecionado um cimento adequado a prótese cimentada também se torna reutilizável. Desvantagens importantes como a de instabilidade do parafuso são encontradas nas próteses parafusadas, Quando uma força vertical ou oblíqua atua sobre a prótese, produz-se tensão no parafuso, o que provoca instabilidade ou afrouxamento do mesmo. O desenho da oclusão na prótese também se torna prejudicado pelo orifício de acesso do parafuso; já que se é considerado que o diâmetro dos parafusos é de $\pm 3 \mathrm{~mm}$, o orifício de acesso será também de $\pm 3 \mathrm{~mm}$, o que representa no mínimo $50 \%$ da mesa oclusal de molares e mais de $50 \%$ em pré-molares; esta área pode ser crítica para se obter uma ótima oclusão, e como conseqüência disto à estética também será afetada. As vantagens das próteses cimentadas tornam-nas um mecanismo viável; estas proporcionam passividade, quando existem discrepâncias nas infraestruturas, e podem ser ajustadas com procedimentos de rotina no consultório odontológico. A ausência de orifícios aumenta a resistência nas propriedades físicas das cerâmicas ou das resinas. Melhoram o acesso ao setor posterior da boca, reduzem custos, complexidade de componentes e de procedimentos laboratoriais, alem de reduzir o tempo clínico, e tendo como resultado uma estética superior.

Em um estudo experimental, MOLLERSTEN; LOCKOWANDT; LINDEN ${ }^{84}$, ainda neste ano avaliaram a influência da profundidade da união pilar / implante 
na resistência ao dobramento e o modo de falha de sete diferentes sistemas de implantes (Astra Tech, ITI Bonefit, Frialit-e, implan-Med, Nobelpharma Esteticone, IMZ titanium abutment, e IMZ conector). Dez implantes com seu pilar e parafuso foram aleatoriamente selecionados de cada sistema. Em cada um deles coroas de ouro padronizadas foram fundidas, com um sulco em forma de $v$ a $6 \mathrm{~mm}$ da margem, onde mais tarde seria aplicada uma força compressiva. Coroa, pilar e implante foram unidos por parafuso, exceto nos sistemas onde a coroa não era provida de parafuso ("IMZ titanium abutment" e Frailt-2), nestes casos as coroas foram cimentadas com um cimento resinoso. Os parafusos foram apertados manualmente pelo mesmo operador, por meio do instrumento fornecido pelo fabricante. Cada amostra foi incluída em um tubo com resina acrílica autopolimerizável, e fixado em um dispositivo desenvolvido para o experimento, o qual, posteriormente foi montado em uma máquina de ensaios (Zwick 1454, Alemanha). Uma carga compressiva perpendicular ao eixo longitudinal da amostra foi aplicada até a falha ser evidente, após o teste cada amostra foi removida e examinada a condição de ocorrência da falha. Em outra parte do estudo, uma averiguação do torque produzido por aperto manual foi realizada, por meio de dois parafusos. Um foi o parafuso da coroa Impla-Med de 1,4mm de diâmetro, e o outro do "IMZ conector abutment" de 3,0mm de diâmetro. As coroas foram apertadas e afrouxadas manualmente dez vezes utilizando a chave fornecida pelo fabricante. Os resultados mostraram existir uma correlação estatisticamente significante entre a profundidade da união e os valores de força de falha do mesmo sistema de implante. Uniões rasas foram correlacionadas com valores de falha baixos; enquanto que uniões profundas proporcionaram valores de falha altos. A resistência à falha teve valores médios entre 138N para Nobelpharma esteticone a $693 \mathrm{~N}$ para "IMZ titanium abutment". A condição de falha mais comum foi na união pilar / coroa, devido à fratura do parafuso ou fratura do cimento (nos casos de coroas cimentadas) em combinação com dobramento ou fratura dos pilares. A falha menos freqüente ocorrida foi na união implante / pilar que depende da falha do parafuso do pilar. A média do valor de torque obtido de forma manual foi de 
$8,8 \mathrm{~N} . \mathrm{cm}$ nos parafusos de $1,4 \mathrm{~mm}$ de diâmetro e de $13,1 \mathrm{~N} . \mathrm{cm}$ nos parafusos de 3,0mm de diâmetro.

SCHULTE; COFFEY ${ }^{98}$ ainda neste ano avaliaram a capacidade de retenção de nove tipos de pilares de um fabricante. Três amostras pilar / implante de cada sistema testado foram fixadas em um cilindro de resina acrílica autopolimerizável. Os parafusos foram apertados aos implantes com um torque de $30 \mathrm{~N}$.cm utilizando um dispositivo de torque digital (DTG-12; John Charillon \& Son). O torque de remoção foi realizado dez minutos após o aperto inicial; 20 minutos depois foi reapertado novamente e 24 horas depois. Este procedimento foi repetido em todos os sistemas exceto em parafusos de retenção donde foram aplicados $10 \mathrm{~N} . \mathrm{cm}$ de torque. Todos os parafusos foram de titânio à exceção de um parafuso de retenção de ouro. Os resultados mostraram não existir diferenças estatisticamente significantes nos valores de torque de remoção com relação ao tempo ou número de reapertos. O torque de remoção foi menor que o torque de aperto em todos os sistemas testados (média de $25.45 \%$ ). Os parafusos de retenção foram menos retentivos quando comparados com os parafusos do pilar.

BINON ${ }^{17}$, em 1998, avaliou a efetividade da técnica para prevenir afrouxamento do parafuso preconizada por CAVAZOS e BELL ${ }^{33}$. Nesta técnica, são realizados entalhes na superfície interna do canal de acesso do parafuso, injetado material de moldagem e condensado com bolinhas de algodão, o torque do parafuso é aplicado de forma manual. Para a realização do experimento foi padronizada a técnica e comparada com um grupo controle onde os parafusos foram apertados com um torquímetro a $20 \mathrm{~N} . \mathrm{cm}$ como recomendado pelo fabricante e nenhum material de moldagem foi introduzido no canal de acesso. Cinco amostras de cada grupo com pilar UCLA padronizado (8mm de altura por $8 \mathrm{~mm}$ de largura) foram testadas aplicando-es cargas cíclicas com o mesmo protocolo previamente publicado por Binon ${ }^{20}$. A carga foi aplicada até a falha do parafuso ocorrer, considerando-se como falha a mobilidade do pilar. Os resultados mostraram que esta técnica parece não diminuir o micromovimento do parafuso, já 
que no grupo teste as falhas encontradas foram entre 136.645 a 2.067 .355 ciclos enquanto que no grupo controle as falhas foram em uma média de 2.447.214 ciclos. Porém, encontrando-se uma técnica viável para obturar o canal de acesso do parafuso. O autor acredita que devido às características de elasticidade dos materiais de moldagens, não é possível a diminuição da vibração ou movimento lateral do complexo pilar / implante, não permitindo a melhora da resistência ao afrouxamento do parafuso quando comparada com a técnica convencional.

BYRNE et al $^{29}$, em 1998, compararam o encaixe marginal e a adaptação de pilares pré-fabricados usinados, com pilares fundidos e polidos em laboratório. Nestes avaliaram: adaptação marginal entre o pilar e o implante; e a adaptação entre a parte inferior da cabeça do parafuso de ouro e a base do parafuso do pilar. Seis combinações de pilares e implantes foram estudados: (1) pilar ceraone / implante Nobel Biocare; (2) pilares STR 3i / implantes 3i; (3) pilares UCLA fundidos 3i / implantes 3i; (4) pilares UCLA fundido / implantes Nobel Biocare; (5) pilares UCLA pré-fabricados / implantes 3i; e (6) pilares UCLA pré-fabricados / implantes 3i. Para a padronização do enceramento das infra estruturas metálicas, um implante (Nobel Biocare) foi fixado œm resina acrílica autopolimerizável em um manequim, na área correspondente a um incisivo central, e os pilares que seriam fundidos e que receberiam cerâmica, foram preparados e submetidos a processo de fundição e ciclos de queima da cerâmica simulados. Todos os conjuntos foram apertados com um torque de 32N.cm, a exceção dos grupos 3 e 4 que foram unidos com um torque de $20 \mathrm{~N}$.cm. Os parafusos utilizados em todas as amostras foram de ouro. Após a fundição, acabamento e polimento das amostras foram examinadas em um microscópio (Mitutoyo). As amostras foram limpas e levadas ao microscópio para serem medidas em duas áreas de encaixe e adaptação interna em um aumento de 100 X. As medidas obtidas nos grupos 1, 2 , 5, e 6 (pilares pré fabricados) foram comparadas com as medidas obtidas nos grupos 3 e 4 (pilares fundidos), nas duas áreas de medidas. Os resultados encontrados mostraram: 
- Fenda externa: Os grupos 1, 3, e 4 tiveram médias de 74 a $86 \mu \mathrm{m}$, sendo estas as maiores discrepâncias, enquanto que as menores discrepâncias foram encontradas no grupo 2 com $36 \mu \mathrm{m}$.Discrepância horizontal: $\mathrm{O}$ grupo 1 mostrou a maior discrepância horizontal externa $-66 \mu \mathrm{m}$; todas as outras discrepâncias foram semelhantes e de menor magnitude, sendo que o grupo 2 teve a menor média.

- Superfície externa do implantes ao primeiro contato: A maior distância horizontal $(129 \mu \mathrm{m})$ da extremidade do implante até o primeiro contato com o pilar foi para o grupo 4; o grupo 1 obteve média de $100 \mu \mathrm{m}$, os outros mostraram discrepâncias que variaram de 40 a 80um.

- Acabamento externo do pilar: Os pilares fundidos de plástico (grupos 3 e 4) mostraram os maiores valores 68 e $66 \mu \mathrm{m}$ respectivamente, enquanto que os pilares pré fabricados mostraram médias de 15 a $35 \mu \mathrm{m}$.

- Contato: As maiores médias de contato ocorreram para os conjuntos com componentes pré-fabricados (grupos 1, 2, 5, e 6), com valores médios de 308 a $374 \mu \mathrm{m}$; enquanto que os grupos 3 e 4 tiveram médias de 205 a $202 \mu \mathrm{m}$.

Os autores concluíram que pilares pré-fabricados incluindo aqueles que são fundidos dretamente e são sujeitos a queima da cerâmica, são superiores em adaptação, àqueles que são totalmente fundidos e com acabamento no laboratório.

Neste mesmo ano, $\mathrm{KANO}^{60}$ avaliou a adaptação na interface pilar / cilindro de ouro utilizando-se componentes do mesmo sistema, e combinações de componentes de diferentes sistemas. Seis conjuntos de implantes compatíveis foram utilizados: 3i, Lifecore, Conexão, Implamed, Nobelbiocare, e NAPIO. Cada implante foi montado em um bloco de resina acrílica autopolimerizável, onde foi conectado um pilar convencional "standard" com um torque de $20 \mathrm{~N} . \mathrm{cm}$. Sobre este, foram fixados os cilindros de ouro dos diferentes sistemas com a aplicação de um torque de $10 \mathrm{~N} . \mathrm{cm}$. Cada conjunto foi levado a um microscópio comparador com cabeçotes micrométricos digitais (Mitutoyo TM - modelo 5050), onde foi avaliada a interface em oito sítios diferentes. Os resultados da análise intra sistema, mostraram que não houve diferenças estatisticamente significantes em 
relação ao desajuste, um desajuste médio de 7,85 ìm foi encontrado. O melhor ajuste foi encontrado nos sistemas Nobelbiocare e Implamed e o pior nos sistemas Lifecore e 3i. Os resultados das análises entre sistemas encontrados sugeriram que nem todas as combinações podem ser consideradas compatíveis.

MCGLUMPHY; MENDEL; HOLLOWAY ${ }^{77}$, neste mesmo ano, realizaram uma explicação clara da mecânica de funcionamento do parafuso e descrevem o porque os parafusos afrouxam. Segundo os autores os parafusos afrouxam porque as forças que tentam separar as partes unidas são maiores que as forças que mantêm as partes unidas. As forças que tentam separar as partes são chamadas de forças de separação; e as que unem as partes são chamadas de forças de aperto. Desta forma existem dois fatores envolvidos para manter os parafusos apertados: Maximizar as forças de aperto e minimizar as forças de separação. Para conseguir uma união segura, os parafusos devem ser tensionados para produzir uma força de aperto maior que a força externa que tenta separar a união. No desenho do parafuso de união rígida, o mais importante desde o ponto de vista funcional é a força de aperto inicial desenvolvida pelo aperto do parafuso. A resistência da união é mais afetada pela força de aperto que pela resistência a tensão dos parafusos. A força de aperto é proporcional a força de torque. Um torque baixo pode permitir a separação da união e resultar em fadiga ou afrouxamento do parafuso. Um torque maior pode causar falha do parafuso ou um desgaste das roscas. Quando o torque é aplicado, desenvolve uma força dentro do parafuso chamada de pré-carga, que é a carga inicial do parafuso em tensão. Esta força de tensão no parafuso desenvolve uma força compressiva de aperto entre as partes. Entretanto, a pré-carga do parafuso é igual à força de aperto em magnitude. Para os autores a pré-carga é determinada pelos seguintes fatores:

1- Torque aplicado

2- Liga do parafuso

3- Desenho da cabeça do parafuso

4- Liga do pilar 
5- Superfície do pilar

6- Lubrificante

Dois fatores limitam a quantidade de torque que pode ser aplicada; o limite de resistência mecânica do parafuso e o modo como o torque é aplicado. A máxima pré-carga é obtida antes de ocorrer falha, conseqüentemente um ótimo torque de aperto pode ser calculado utilizando $75 \%$ do máximo valor obtido até a falha; pelo que uma ótima força de aperto pode ser desenvolvida com mínimo risco de fratura do parafuso.

BOGGAN et $\mathrm{a}^{\mathrm{P} 3}$, em 1999, avaliaram a influência do diâmetro da base do implante, a altura do hexágono na resistência mecânica e a qualidade da adaptação da interface pilar / implante. Para seu estudo, utilizaram implantes de hexágono externo (Maestro implant system / BioHorizons implant systems) com 4 e $5 \mathrm{~mm}$ de diâmetro da base e 1,0mm de altura do hexágono, sobre estes, pilares de $8 \mathrm{~mm}$ com desenho específico para o experimento foram fixados com parafusos a $30 \mathrm{~N} . \mathrm{cm}$ uma hora e cinco minutos antes dos testes de carga estática e carga dinâmica realizados. No primeiro teste, uma carga compressiva foi aplicada até ocorrer fratura de um dos componentes. No segundo teste, cargas cíclicas compressivas foram aplicados a $15 \mathrm{~Hz}$, sendo que as falhas foram consideradas quando fratura de uma das partes do conjunto pilar / implante ocorreu; os valores obtidos destas falhas foram utilizados para identificar o limite de resistência ou de carga para cada diâmetro de implante. Os resultados mostraram que nos testes de carga estática uma média de falha de $966 \mathrm{~N}$ e $1955 \mathrm{~N}$, nos implantes de 4 e $5 \mathrm{~mm}$, respectivamente, sendo uma diferença estatisticamente significante quando se comparam ambos grupos. Nos testes de cargas cíclicas a média do limite de resistência dos grupos foi de $350 \mathrm{~N}$ e $625 \mathrm{~N}$, respectivamente. Nos testes de carga estática foi observado dobramento ou deformação do parafuso, enquanto que nos testes de carga cíclica, a fratura do parafuso foi o modo de falha mais comum. Na microscopia eletrônica de varredura, foi encontrado contato intimo de $100 \%$ entre a base do implante e o pilar, em todas as amostras independente do diâmetro. Pelo que os autores 
afirmaram que implantes de largo diâmetro devem ser utilizados para reduzir fraturas dos componentes.

FAULKNER; WOLFAARDT; CHAN ${ }^{42}$, (1999) determinaram se o Periotest têm potencial para detectar clinicamente o afrouxamento do parafuso do pilar nas restaurações de próteses sobre implantes, determinando-se dessa forma a efetividade do periotest em detectar mudanças na rigidez da união, no estudo também foram comparadas medidas subjetivas realizadas por três clínicos experientes. Foi desenhado um dispositivo especial, onde foram fixados rigidamente quatro implantes aos quais foram unidos pilares com um torque de 10 N.cm. Após calibração do instrumento uma serie de torque de 20 , 32, e $45 \mathrm{~N} . \mathrm{cm}$ foram aplicados, sendo posteriormente afrouxados. Os resultados mostraram que - Periotest foi encontrado ser mais sensível do que a detecção manual para avaliação do afrouxamento do parafuso do pilar; entretanto o instrumento não foi sensível ou suficiente para indicar deterioração do afrouxamento do parafuso antes da perda da pré-carga.

Com o objetivo de avaliar comparativamente o grau de micro infiltração de fluídos, na interface implante / pilar GROSS, ABRAMOVICH, WEISS ${ }^{48}$, neste mesmo ano, avaliaram cinco sistemas de implantes comercialmente disponíveis. Três conjuntos pilar / implante de cada um dos sistemas Spline, ITI, Nobelpharma (ceraone), Steri-Oss, e 3i, foram utilizados, sendo que para o experimento torques de aperto de $10 \mathrm{~N} . \mathrm{cm}, 20 \mathrm{~N} . \mathrm{cm}$, e o torque recomendado pelos fabricantes foram aplicados. Os conjuntos implante / pilar, foram imerso em uma serie de tubos de silicone, contendo corantes de baixo peso molecular, os quais foram imersos em água destilada a uma pressão de ar constante, para evitar a passagem passiva dos fluidos através da interface. Leituras foram realizadas em intervalos de 5, 20, e 80 minutos desde o tempo de ativação da pressão inicial. Antes de cada leitura, os constituintes do tubo primário foram misturados para assegurar a distribuição homogênea do corante e transferidos para um micro tubo secundário de 0,6ml, para a realização das leituras em um espectofotômetro. Os resultados mostraram 
um aumento gradual na microiinfiltração com o passar do tempo, para todas as amostras observadas. Como as três amostras iniciais do sistema Steri-Oss mostraram médias e desvios padrão consideravelmente mais altos que os outros sistemas, o número de amostras foi aumentado para sete, sendo que ainda assim foram encontrados valores médios de microinfiltração notavelmente mais altos. Quando as amostras foram comparadas quanto ao torque aplicado, foi encontrada uma interação entre o valor de torque e o grau de micro-infiltração, sendo que esta diminuiu significativamente na medida que o torque aumentou de $10 \mathrm{~N} . \mathrm{cm}$ para 20 N.cm, até o torque recomendado pelos fabricantes. Diferenças estatisticamente significantes foram encontradas entre os sistemas testados.

GROSS et $\mathbf{a l}^{47}$, (1999) avaliaram o torque de aperto gerado de forma manual por nove clínicos experientes em prótese sobre implantes utilizando cinco diferentes sistemas de implantes. Na metodologia empregada, uma condição clínica foi simulada sobre um manequim odontológico no qual foi fixado um implante na área de um primeiro molar maxilar direito. Neste, os clínicos foram orientados a aplicar cinco vezes o torque que normalmente usam sob condições clínicas (torque habitual); e cinco vezes o máximo torque que eles poderiam aplicar (torque máximo), utilizando a chave de cada sistema; sendo que entre cada torque aplicado um descanso mínimo de 30 segundos foi permitido. Para as leituras do torque gerado por cada clínico, o implante foi conectado a um torquímetro (Tohnichi / Japan), que foi fixado no manequim. Os resultados mostraram uma variabilidade no torque produzido por cada clínico e entre os diferentes clínicos; sendo que no torque habitual foram encontradas médias de 7,0 a 14,6 N.cm o que significa uma média de porcentagem de 29 a $55 \%$ do torque recomendado pelos fabricantes. Quando o torque máximo foi aplicado foram encontrados valores entre 9,4 a 19,9N.cm, uma média de porcentagem de 32 a $76 \%$ do torque recomendado pelos fabricantes, em nenhum dos testes os clínicos atingiram os níveis de torque recomendados pelos fabricantes, sendo demonstrada uma alta inconsistência na geração do torque nos diferentes sistemas testados 
KEITH et $\mathbf{a l}^{61}$, ainda neste ano, avaliaram a magnitude da discrepância marginal da interface prótese / implante, em restaurações parafusadas e cimentadas, utilizando implantes ITI (Straumann). 20 implantes 4,1 x 10mm foram divididos em dois grupos. Um ao qual foram conectados pilares de $5,5 \mathrm{~mm}$ parafusados com $35 \mathrm{~N} . \mathrm{cm}$, e outro ao qual foram conectados pilares octagonais e aplicado o mesmo torque. Coroas metâlocerâmicas, com um protocolo laboratorial padronizado, foram fabricadas em ambos grupos. As amostras do grupo cimentado foram divididas em dois, e fixadas utilizando agentes de cimentação diferentes; ionômero de vidro, e cimento fosfato de zinco. A manipulação dos cimentos foi realizada seguindo as instruções dos fabricantes, sendo as coroas assentadas com pressão digital inicialmente, seguida da aplicação de uma carga constante de $10 \mathrm{~kg}$, durante dez minutos. As amostras foram armazenadas a $37^{\circ}$ em $100 \%$ de umidade por 24 horas, e levadas a uma máquina de ensaio universal, onde foi aplicada uma força de separação até a falha do cimento, após este procedimento, as coroas foram recimentadas. No grupo parafusado as coroas foram fixadas ao pilar utilizando um parafuso oclusal de titânio de $4 \mathrm{~mm}$, com uma força de torque de $15 \mathrm{~N} . \mathrm{cm}$. Inspeção da discrepância marginal na interface coroa / implante foi realizada utilizando um aumento de $50 \mathrm{X}$, com um estereomicroscopio em quatro áreas marcadas ao redor da circunferência do implante. Seus resultados mostraram que a menor discrepância marginal foi encontrada no grupo parafusado (2,6 $\mu \mathrm{m}$ antes da fundição do cilindro de ouro, 6,0 $\mu \mathrm{m}$ após a fundição e 8,8um após acabamento da coroa). O grupo cimentado teve uma maior média de discrepância marginal sendo de $32 \mu \mathrm{m}$ antes da fundição, $54 \mu \mathrm{m}$ após a fundição; e de $57,4 \mu \mathrm{m}$ e $67,4 \mu \mathrm{m}$ após da cimentação, com ionômero de vidro e fosfato de zinco respectivamente; sendo estas diferenças, estatisticamente significantes entre os cimentos.

KORIOTH; CARDOSO; VERSLUIS ${ }^{63}$, em 1999, testaram a hipótese de que a utilização de uma arruela cônica de pressão aumentaria a necessidade do deslocamento para o afrouxamento completo do parafuso de ouro. Dois implantes 
de $8,5 \mathrm{~mm}$ de comprimento (Branemark, Nobel Biocare) foram incluídos em um bloco de resina acrílica, com uma separação que permitisse a confecção de uma prótese fixa substituindo um pré-molar. Pilares convencionais de $3 \mathrm{~mm}$ foram fixados sobre os implantes com um torque de $20 \mathrm{~N} . \mathrm{cm}$, e uma prótese parcial fixa de três elementos foi fundida em uma liga de metal básico. Parafusos de retenção de ouro foram fixados utilizando-se um controlador de torque no qual foi adaptada uma célula de carga em miniatura que permitia registrar o tempo durante o qual atuava o deslocamento axial no afrouxamento do parafuso (torque reverso). Arruelas foram colocadas em ambos implantes ou só no mesial, ou no distal, ou em nenhum deles. Os resultados mostraram um aumento significativo no deslocamento axial quando as arruelas foram utilizadas, e que implantes onde os parafusos de retenção de ouro tinham arruelas precisaram ser girados de $30 \%$ a $35 \%$ a mais antes de se afrouxar. Concluíram que a inclusão de arruela aumenta significativamente 0 movimento rotacional necessário para afrouxar completamente o parafuso de retenção de ouro.

LANG; MAY; WANG ${ }^{66}$, (1999) examinaram a necessidade de utilizar um dispositivo de contra torque para evitar a transmissão de forças na interface implante / osso, no momento de aplicação do torque do parafuso do pilar. $\mathrm{Na}$ metodologia utilizaram 30 implantes de $3,75 \mathrm{~mm}$ de diâmetro por $10 \mathrm{~mm}$ de comprimento, e dez implantes de $5,0 \mathrm{~mm}$ de diâmetro por $10 \mathrm{~mm}$ de comprimento (Nobel Biocare). Os 30 implantes de 3,75 x 10mm foram dividido em três grupos de dez implantes os quais receberam pilares ceraone com $32 \mathrm{~N} . \mathrm{cm}$ de torque (grupo 1), esteticone $20 \mathrm{~N} . \mathrm{cm}$ de torque (grupo 2), e procera $32 \mathrm{~N} . \mathrm{cm}$ de torque (grupo 3). O grupo dos implantes com base de assentamento de largo diâmetro $(5,0 \times 10 \mathrm{~mm})$ receberam pilares AurAdapt com 45N.cm de torque (grupo 4). Em cada grupo, na metade das amostras foi utilizado o contra torque. Os implantes foram parafusados rigidamente simulando a osseointegração e um dispositivo, o qual foi posicionado em um medidor de torque (Tohnichi BTG 6). Os parafusos dos pilares foram apertados utilizando-se um controlador de torque (Nobel Biocare). O medidor de torque registrou a força transmitida através do implante na 
área que simulou a interface implante / osso. Seus resultados mostraram uma média de $91 \%$ da pré-carga produzida no aperto do parafuso passa para a base do implante e para a interface implante / osso na ausência de dispositivo de contra torque; em todos os sistemas de pilares testados neste estudo menos de $10 \%$ da pré-carga recomendada foi transmitida quando o contra torque foi utilizado.

Avaliando sistemas de implantes de conexão interna, NORTON ${ }^{86}$, neste mesmo ano, comparou o torque de afrouxamento com o torque de aperto nos sistemas ITI e Astra Tech (8 e $11^{\circ}$ de cone interno respectivamente). Para a realização dos testes implantes / pilares foram montados em um dispositivo fixado rigidamente de forma a permitir as forças de torque. Um transmissor que utilizou dois "strain gauges" para medir o momento de torque foi desenhado e utilizado para transmitir os dados obtidos ao computador. Testes foram realizados em ambiente úmido e seco em uma série de baixo torque de 4 a $50 \mathrm{~N}$.cm; e uma serie de alto torque de 100 a $300 \mathrm{~N} . \mathrm{cm}$. Em cada serie 4 ITI e 5 Astra, implantes foram utilizados, sendo que em dois destes, um tempo de 10 e 60 minutos (em 200N.cm) foi esperado entre cada teste para determinar se a recuperação elástica influenciava no torque de afrouxamento. Concluíram que na série de baixo torque em ambiente seco e úmido, nenhuma das amostras excedeu a $100 \%$ do torque de aperto, sendo sempre entre $80 \%$ e 90\%. Em 100 e $300 \mathrm{~N} . \mathrm{cm}$, o torque de afrouxamento excedeu o torque de aperto, antes da falha do componente, qua ndo uma deformação plástica era esperada. Médias de 109\% e 104\% foram encontrados em amostras Astra $(4 \mathrm{~mm})$ e ITI respectivamente. Não foram encontradas diferenças estatísticas ao se comparar meio úmido e seco; assim como quando 10 e 60 minutos foram esperados para recuperação elástica. Para níveis de aperto de relevância clinica (20 a $40 \mathrm{~N} . \mathrm{cm}$ ), o torque de afrouxamento foi entre 80 e $85 \%$ em todas as amostras utilizadas.

STANDLEE; CAPUTO ${ }^{101}$, ainda neste mesmo ano, avaliaram a precisão de sete dispositivos de torque eletrônicos (Nobel Biocare modelo DEA-020) em uso clinico. No seu experimento, desenvolveram uma metodologia onde utilizaram um 
torno em miniatura como implante teste para transferir a rotação gerada pelos dispositivos a uma máquina de testes Instron. Dez repetições foram realizadas por cada dispositivo em cada nível de torque de 10, 20 e 32N.cm. Os resultados obtidos mostraram que os dispositivos foram precisos, porém inexatos, ou seja, eles tiveram um pequeno desvio padrão, mas o torque gerado foi diferente em relação ao torque para o qual foram programados, com uma ampla variação do torque gerado pelos dispositivos do mesmo modelo. No torque de $10 \mathrm{~N} . \mathrm{cm}$, foi observada uma tendência a gerar valores de torque superiores aos programados $(-22 \%$ a $+165 \%)$. Em $20 \mathrm{~N} . \mathrm{cm}$ as médias de torque foram mais próximas ao programado $(-40 \%$ a $+40 \%)$, enquanto que em $32 \mathrm{~N} . \mathrm{cm}$, foi observada uma tendência a aplicar um torque baixo $(-44 \%$ a $+14 \%)$ do torque programado. Os autores acreditam que quando um sobre torque é aplicado nos parafusos, uma maior pré-carga é gerada ou deformação plástica e fratura do parafuso podem ocorrer; entretanto quando um torque baixo é aplicado existe uma maior possibilidade de afrouxamento do parafuso.

ABOYOUSSEF, WEINER; EHRENBERG ${ }^{1}$, no ano de 2000, avaliaram uma forma de aumentar a resistência ao afrouxamento da união coroa / pilar; realizando quatro sulcos em forma de $\mathrm{v}(1 \times 1 \mathrm{~mm})$ ao redor da área periférica dos pilares (pilares modificados). No estudo três desenhos de pilares para testar a resistência a forças rotacionais, foram utilizados, sendo estes: convencionais de $3 \mathrm{~mm}$, convencionais modificados e esteticones. Cada grupo foi fixado sobre análogos de implantes (3i), e aplicado um torque de $20 \mathrm{~N} . \mathrm{cm}$ utilizando um dispositivo eletrônico de torque. Em cada amostra parafusos de ouro hexagonais foram apertados sobre os pilares com $10 \mathrm{~N}$.cm de torque. Uma força rotacional foi aplicada até a falha na união pilar / implante ou na união cilindro de ouro / pilar ocorrer. Seus resultados mostraram um afrouxamento do parafuso nos três grupos testados, não ocorrendo nenhuma fratura. Nos grupos esteticone e convencional modificado o afrouxamento ocorreu na interface pilar / implante, enquanto que no grupo convencional na interface cilindro de ouro / pilar. Uma média de falha, de $70 \mathrm{~N} . \mathrm{cm}$ e $71 \mathrm{~N} . \mathrm{cm}$ de torque, para o grupo convencional modificado e esteticone 
respectivamente; no grupo convencional a média de falha foi de $21,28 \mathrm{~N}$.cm. Os autores concluíram que a adição de característica de forma de resistência anti rotacionais aumentam o comprimento do braço de alavanca o que pode ser um fator importante na resistência da perda da pré-carga causada pela ação do torque.

Em um trabalho sobre implantes e componentes, BINON ${ }^{19},(2000)$, realizou uma classificação clara da extensa variedade de implantes disponíveis, baseada na forma de conexão da interface pilar / implante, na forma e na superfície do implante. Em relação à forma de união pilar / implante, afirmou que existem mais de 20 tipos diferentes de configurações desta interface. Desta forma, dois grandes tipos de conexões são conhecidos, externo e interno que são caracterizados pela presença ou ausência de uma configuração geométrica que se estende acima da superfície coronal do implante. A conexão coronal também pode ser caracterizada como uma união que permite movimento de deslize, onde existe um pequeno espaço entre as partes e a conexão é passiva; ou como uma união por fricção, donde não existe espaço entre os componentes e as partes são forçadas para adaptar. Outro tipo de interface encontrado é a união de topo, que consiste em duas superfícies de ângulos retos; e a união angulada, onde as superfícies são anguladas externa ou internamente. A superfície de união também pode incorporar uma geometria que inclua uma configuração de resistência rotacional ou estabilização lateral. Dessa forma, a geometria pode ser octagonal, hexagonal, cone parafuso, cone hexagonal, cilíndrica hexagonal, spline, entre outros. Segundo o autor, conexões internas na qual o parafuso recebe pouca carga e as superfícies do pilar estão em íntimo contato com as paredes do implante, para resistir micromovimentos, resultam em uma interface mais estável. Para evitar falhas que provoquem instabilidade da prótese, procedimentos clínicos assim como parâmetros mecânicos são críticos. Em relação aos componentes, uma ótima tolerância de adaptação, liberdade rotacional mínima, propriedades físicas melhoradas, e uma aplicação de torque adequado, são determinantes na estabilidade da interface. Assim mesmo na parte clinica, uma adequada 
distribuição, cargas dirigidas no longo eixo do implante, numero, diâmetro e comprimento dos implantes, adaptação passiva da prótese, controle das cargas oclusais são igualmente importantes.

Discutindo os principais aspectos de uma conexão de hexágono externo e a estabilidade do parafuso nesta união, BINON ${ }^{21}$, neste mesmo ano, descreveu os princípios de funcionamento dos componentes e cada um dos fatores que podem levar a falhas da interface pilar / implante. Segundo o autor, a função básica do parafuso é criar uma força de travamento entre as duas partes da conexão, de forma a prevenir a separação, perda da tensão e evitar afrouxamento quando exposto a vibração ou cargas cíclicas externas. O aperto cria uma tensão tanto na cabeça do parafuso que assenta no pilar, como entre as roscas internas do implante e as roscas do parafuso; essa tensão é denominada de pré-carga, sendo esta, diretamente proporcional ao torque aplicado. Vários fatores podem prejudicar a pré-carga e conseqüentemente a estabilidade da união. Rugosidade da superfície, deformação plástica, interação elástica, fricção, temperatura, fluídos corrosivos, dobramento, desalinhamento, desadaptação, rigidez, tolerância de usinagem, cargas cíclicas, fadiga, desenho do parafuso e incompatibilidade do material. Ao analisar a superfície dos componentes, afirma que a condição das superfícies das partes que entram em contato tem uma influência direta na obtenção de uma adequada força de travamento e manutenção da estabilidade. Quando é aplicada uma pré-carga no parafuso e a força de travamento une as partes, se inicia um processo de achatamento das micro-rugosidades existentes na superfície devido à compressão gerada pelo contato entre as superfícies metálicas; quando estas superfícies se achatam, a distância microscópica diminui, e a força de travamento e a pré-carga reduzem. Para minimizar este efeito, o parafuso deve ser apertado no valor de torque requerido e após cinco minutos realizar um reaperto com o mesmo torque aplicado. Para o autor quando a interface não esta corretamente alinhada devido a desadaptação dos componentes, a união é seriamente comprometida, já que a pré-carga aplicada é direcionada ao alinhamento das partes, e mais pré-carga é requerida para unir as 
partes, assim o torque aplicado se torna insuficiente para obter uma força de travamento adequada.

CASTILIO $^{32}$, (2000) avaliou a adaptação da interface pilar / componentes protéticos, utilizando cilindros de plásticos, fundidos em titânio e cobalto-cromo, em monobloco e após a realização de soldagem a laser. No seu estudo utilizou dez amostras, sendo que cada uma estava composta de três componentes protéticos unidos entre si por uma barra. Cinco amostras foram fundidas em titânio e cinco em cobalto-cromo. Mensurações foram realizadas nas interfaces pilar / componente protético com a utilização de um microscópio comparador. Os resultados mostraram que as estruturas fundidas em monobloco (peça única) apresentavam um maior desajuste da interface (desajuste médio de 26,164ìm) que as mesmas após a soldagem a laser (desajuste médio de 19,943ìm); diferenças estatisticamente significantes também foram encontradas entre as duas ligas metálicas utilizadas na fundição, onde o titânio apresentou um desajuste médio de 21,262ìm enquanto que o cobalto-cromo um desajuste médio de 24,845ìm.

GUICHET et $\mathbf{a l}^{49}$, (2000) compararam a integridade marginal e a tensão gerada durante 0 assentamento de restaurações retidas por implantes, cimentadas e parafusadas. A passividade de adaptação e as discrepâncias entre as próteses cimentadas e parafusadas foram avaliadas por um modelo fotoelástico de um arco mandibular parcialmente edêntulo posterior com três implantes do tipo roscados. Três implantes de 10mm (Nobel Biocare) foram fixados na área do primeiro e segundo pré-molar, e do primeiro molar, sobre estes, dez próteses foram fabricadas (cinco parafusadas e cinco cimentadas) em liga de ouro. Nas próteses parafusadas, foi utilizado um pilar cônico (3i) e sobre este um cilindro de ouro, no qual foi encerada e obtida a prótese. O desenho de próteses cimentadas foi obtido utilizando pilares de perfil de emergência tipo postes (3i), os quais foram colocados sobre o modelo de trabalho e preparados seguindo as instruções do fabricante. Após polimento foi realizado o enceramento e a fundição das próteses. 
As fundições parafusadas foram fixadas sobre os implantes com os valores de torque recomendados e as cimentadas assentadas utilizando cimento de oxido de zinco e eugenol (Temp Bond, Kerr), sob uma carga de 4,5kg. Leituras da adaptação marginal foram realizadas antes e depois da cimentação e antes e depois do torque nas restaurações parafusadas. A passividade e a tensão gerada durante 0 assentamento foi avaliado através de modelo fotoelástico. Concluíram que a desadaptação marginal das próteses, antes de ser parafusadas ou cimentadas, não foram estatisticamente diferentes entre os dois grupos (parafusadas 46,7 $\mu \mathrm{m}$, e cimentadas $45,0 \mu \mathrm{m}$ ). Após serem fixadas, o grupo de próteses parafusadas teve uma desadaptação marginal estatisticamente diferente que o grupo de próteses cimentadas após sua cimentação (parafusadas 16,5 $\mu \mathrm{m}$, cimentadas 49,1 $\mu \mathrm{m})$. Quando a geração da tensão foi avaliada após a fixação ou cimentação das próteses, o desenho parafusado apresentou uma maior variabilidade na intensidade e localização da tensão que o desenho de próteses cimentadas.

Neste ano, MEYER ${ }^{80}$ avaliou a precisão de adaptação e a compatibilidade entre os componentes implante e pilar, dentro de um sistema nacional, ou estrangeiro e no intercambio entre marcas comerciais, utilizando como padrão de comparação os componentes do sistema Nobelpharma. As marcas comerciais Neodent (ND), Conexão (CX), Nobelpharma (NB), e 3i (3I) foram avaliadas na interface implante / pilar através de microscopia eletrônica de varredura. As dimensões das bases dos implantes, e dos pilares foram avaliados utilizando um paquímetro digital; e a liberdade rotacional existente entre o sextavado externo do implante e o interno do pilar, foi examinada com a utilização de um dispositivo desenvolvido para esse fim. Seus resultados mostraram as menores medidas de adaptação vertical entre o implante e o pilar nas combinações dos sistemas da marca Conexão com $3 \mathrm{i}(0,67 \pm 0,92 \mathrm{ìm})$; enquanto que as maiores desadaptações foram encontradas nas combinações do sistema Nobelpharma $(7,62 \pm 2,43 i ̀ m)$. Em relação à adaptação horizontal as melhores adaptações foram observadas nos sistemas $3 \mathrm{i}$ e Conexão (3,56 \pm 6,64ìm). Houve diferenças estatisticamente 
significantes nas dimensões dos diferentes implantes e pilares dos sistemas examinados, assim como dentro dos sistemas; encontrando valores em $\mathrm{mm}$ de:

\begin{tabular}{lrrrc}
\hline & Neodent & Conexão & Nobelpharma & $3 \mathbf{i}$ \\
\hline Larg_base_implante & 4,118 & 4,058 & 4,077 & 4,13 \\
Altura_hex_implante & 0,685 & 0,694 & 0,690 & 0,630 \\
Largura_hex_implante & 2,693 & 2,691 & 2,699 & 2,702 \\
Largura_base_pilar & 4,051 & 4,063 & 3,972 & 4,038 \\
Largura_hex_pilar & 2,715 & 2,706 & 2,707 & 2,708 \\
Diam_rosca_parafuso & 1,964 & 1,965 & 1,930 & 1,938 \\
Comp_rosc_parafuso & 2,961 & 2,758 & 3,695 & 4,163
\end{tabular}
componentes do sistema Conexão $\left(1,32^{\circ}\right)$, enquanto que as maiores medidas foram encontradas utilizando-se combinações com o sistema Nobelpharma $\left(4,62^{\circ}\right)$.

Neste mesmo ano, NORTON ${ }^{87}$ realizou um estudo como o objetivo de avaliar a resistência a dobramento de dois tipos de implantes Astra Tecn e ITI, e os pilares "Astra Tecn Uni-abutment", e "ITI conical abutment", com conexão interna de 11 e $8^{\circ}$. As amostras foram formadas de um conjunto implante / pilar, unido com o torque recomendado pelo fabricante, sendo de $25 \mathrm{~N} . \mathrm{cm}$ para os pilares "Uni-abutment", e de 35N.cm para nos pilares "conical abutment". Para a realização dos testes as amostras foram colocadas em uma máquina de ensaios, onde foram realizados testes de três pontos até induzir deformação plástica ou a máxima de carga até a falha. Os resultados mostraram que o ponto de deformação plástica permanente para o sistema Astra foi de $4176 \mathrm{~N} \mathrm{~mm}$ (carga de $167 \mathrm{~N}$ ), e no sistema ITI de $2526 \mathrm{~N} \mathrm{~mm}$ (carga de $101 \mathrm{~N}$ ). A máxima carga foi de $5507 \mathrm{~N} \mathrm{~mm} \mathrm{(carga} \mathrm{de} 220 \mathrm{~N}$ ) para o sistema Astra comparado com 3269N mm (carga de $131 \mathrm{~N}$ ) para o sistema ITI. A área de deformação plástica no sistema Astra foi a parte cilíndrica da unidade sólida do pilar. No sistema ITI as falhas 
ocorreram com fratura na cabeça do parafuso, abaixo da base. Os resultados mostraram não existir diferença estatisticamente significante na deformação plástica e nas falhas de ambos sistemas.

Preocupados com a reutilização das próteses cimentadas retidas por implantes, MICHALAKIS; PISSIOTIS; HIRAYAMA ${ }^{81}$ (2000) avaliaram a resistência retentiva de quatro agentes de cimentação provisória. Os cimentos ImProv (Steri-Oss), Nogenol (GC América), Temp Bond (Kerr), e Temp Bond NE (Kerr), foram testados sobre próteses fixas de quatro unidades suportadas por dois e quatro implantes $375 \times 15 \mathrm{~mm}$ (Nobel Biocare). Pilares UCLA hexagonais (Lifecore) foram fundidos em ouro e fixados aos implantes incluídos em blocos de resina acrílica autopolimerizável. Sobre os pilares foram construídas as próteses fixas. A cimentação foi realizada seguindo as instruções do fabricante, aplicando uma quantidade de $0,01 \mathrm{ml}$ na parte interna da prótese, e assentando-a sobre o pilar mantendo uma carga axial controlada de $5 \mathrm{~kg}$, por dez minutos. Depois armazenadas em $100 \%$ de umidade a $37^{\circ} \mathrm{C}$ por 23 horas e 50 minutos. Com uma máquina de teste (Accu-force III, Ametek), foi aplicada uma força uniaxial de tração. O cimento ImProv mostrou os maiores valores de resistência retentiva nos dois tipos de próteses testadas, seguido pelo Temp Bond NE, Temp Bond, e Nogenol. Para os autores, quando a reutilização da prótese é considerada ser importante o Nogenol é o cimento mais apropriado.

Utilizando modelos de análises finito MERZ; HUNENBART; BELSER $^{79}$, (2000) estudaram o comportamento mecânico de duas conexões pilar / implante. Um modelo de elemento finito criado tomando como base um implante ITI de $12 \mathrm{~mm}$ e um pilar de $7 \mathrm{~mm}$ de altura; com uma conexão, implante / pilar de oito graus (cone morse). O outro modelo criado com o mesmo implante, com uma conexão de topo similar à de um implante de hexágono externo. Condições de cargas de $35 \mathrm{~N} . \mathrm{cm}$ de torque foram aplicadas similarmente a ambos modelos. Uma força de $380 \mathrm{~N}$ foi introduzida sobre o pilar a $0^{\circ}, 15^{\circ}$, e $30^{\circ}$ fora do longo eixo do implante. Concluíram que o aperto do pilar leva a uma distribuição simétrica da 
tensão na área do implante e o pilar, em ambos modelos. Na conexão cônica, ocorre um efeito de cunha, no qual as duas primeiras roscas do pilar estão sob tensão. $\mathrm{Na}$ conexão de topo níveis de tensão significantemente altos foram encontrados em toda a conexão, entretanto estes não parecem ser um problema do ponto de vista mecânico. Quando foram aplicadas cargas axiais $\left(0^{\circ}\right)$, o pilar foi comprimido dentro da conexão cônica encontrando-se relaxamento das roscas, e níveis de tensão simétricos foram observados em todas as partes. Na conexão de topo também ocorreu o mesmo com áreas de tensão nas roscas. Com cargas aplicadas com $15^{\circ}$, a tensão é assimétrica, sendo que no lado da carga ocorre uma tensão e no lado oposto uma compressão. Na conexão cônica, a maior parte da tensão foi transferida do pilar ao implante, através da conexão, sendo as roscas do parafuso submetidas a pequenos níveis de tensão. Já na conexão de topo altos níveis de tensão ocorreram nas roscas no lado da carga, sendo uma distribuição de tensão típica de dobramento na porção do parafuso do pilar. Com cargas de $30^{\circ}$ a tensão aumentou, sendo basicamente o mesmo mecanismo observado no caso de $15^{\circ}$.

TAYLOR; AGAR; VOGIATZI ${ }^{110}$, (2000) afirmaram que a seleção de próteses cimentadas ou parafusadas envolve uma preferência pessoal, não existindo evidencias de que um método de retenção é superior a outro. Para os autores as vantagens da restauração parafusada são limitadas à reutilização ou recuperação da restauração, enquanto que dentre as vantagens das restaurações cimentadas encontram-se: uma melhor estética, melhor oclusão, simplicidade de fabricação e redução dos custos dos componentes e da fabricação. Uma possível vantagem adicional da restauração cimentada é que tem potencial de ser colocada de forma passiva na boca, devido à ausência de um parafuso para puxar a desadaptação dos componentes com a força de aperto. Se uma pode ser feita para assentar passivamente em vários pilares, a introdução de cimento dentro do espaço entre as próteses e o pilar não introduzirá tensão no sistema. Esta potencial vantagem com as outras mencionadas, fazem que a restauração implantocimentada tenha aumentado. Defensores da restauração cimentada 
afirmam ainda que a reutilização pode ser mantida se um cimento provisório é utilizado. Infelizmente existem poucas evidências que demonstrem previsibilidade da reutilização de vários agentes cimentantes provisórios, quando são cimentados dois componentes metálicos, isto é provavelmente que um cimento que funciona como provisório para restaurações cimentadas a dentes, será um agente cimentante definitivo para metal cimentado a metal. Similarmente cimentos utilizados para cimentação permanente, podem ser inadequados quando cimentamos metal a metal.

Para determinar se os procedimentos laboratoriais de confecção das próteses suportadas sobre implantes, alteram as superfícies de contato do pilar com a cabeça do implante, VIGOLO; MAJZOUB; CORDIOL ${ }^{112},(2000)$ avaliaram as alterações da interface implante / pilar após a fundição com um metal nobre e aplicação de cerâmica em pilares tipo UCLA de ouro (3i). Utilizaram 30 pilares (SGUCGI), que foram parafusados a análogos fixados em resina. Nos pilares, foram realizados enceramentos com dimensões de um incisivo central e fundido com uma liga aurica de alta fusão. Nestes, foram realizadas aplicações de cerâmica, seguindo as instruções recomendadas pelos fabricantes. Medidas foram realizadas antes, após a fundição e depois da aplicação de cerâmica da profundidade e largura da porção interna do hexágono, diâmetro da base do pilar UCLA, e liberdade rotacional entre a extensão hexagonal do implante e a contraparte do pilar. Os resultados evidenciaram médias de 0,620 mm, 0621 mm, e 0620 $\mathrm{mm}$ na profundidade do hexágono; 2,712mm, 2,710mm, e 2,711mm para a largura do hexágono interno; 4,408mm, 4,407mm, e 4,409mm para o diâmetro da base; 60,33min, 60,37min, 60,68min de liberdade rotacional (antes, após fundição e após aplicação da cerâmica respectivamente). Concluíram que a adaptação dos pilares UCLA de ouro (3i), não demonstraram alterações significantes das medidas originais, ou da liberdade rotacional na superfície da porção interna. Sugeriram a seleção adequada de componentes com baixa tolerância de usinagem, seleção adequada da liga metálica e a utilização de procedimentos 
clínicos e laboratoriais meticulosos, para reduzir a desadaptação rotacional e aumentar a estabilidade do parafuso.

Para determinar se existe perda da quantidade do torque aplicado quando são realizados ciclos de torque de aperto e de afrouxamento em varias repetições consecutivas, WEISS; KOZAK; GROSS ${ }^{114}$, (2000) compararam o efeito apertos múltiplos em diferentes sistemas de implante / pilar. No seu trabalho, utilizaram sete conexões tipo: cone Morse (ITI e Alpha-Bio), spline (Calcitek), um sistema de conexão plana integral (Calcitek), hexágono externo (Steri-Oss e Branemark), e octágono interno (Omnilock). Cada conexão foi fixada em um medidor de torque e, aplicado um torque a $20 \mathrm{~N} . \mathrm{cm}$ por cinco segundos com um torquímetro manual. Depois de um período de dez segundo de repouso foi realizado o torque de afrouxamento e registrado o valor obtido; este procedimento foi repetido 200 vezes consecutivas e os dados obtidos submetidos à análise estatística. Seus resultados mostraram uma progressiva perda da quantidade de torque de afrouxamento em todos os sistemas testados, sendo encontradas diferenças significantes entre eles. Os sistemas que mantiveram maiores valores de torque de afrouxamento consistentemente foram o cone Morse e o spline. A percentagem de perda de torque imediato entre os sistemas foi de $3 \%$ a $20 \%$; de $3 \%$ a $31 \%$ depois de cinco ciclos; e de $4.5 \%$ a $36 \%$ em 15 ciclos. Os dois sistemas cone Morse testados (ITI e Alpha-Bio) tiveram uma média de perda de torque imediato de 0,5 e 0,6N.cm, respectivamente, o sistema spline (Calcitek) uma média de 1,2N.cm; enquanto que o sistema integral (Calcitek) teve perda de $2,6 \mathrm{~N} . \mathrm{cm}$, os dois sistemas de hexágono externo (Steri-Oss e Branemark) tiveram perda imediata de 3,4 e $6,2 \mathrm{~N} . \mathrm{cm}$ respectivamente, e o sistema de octágono interno (Omnilock) de $6,5 \mathrm{~N} . \mathrm{cm}$. Depois de 200 ciclos de torque de aperto e afrouxamento dos primeiros quatro sistemas baixaram o nível de torque para $15 \mathrm{~N} . \mathrm{cm}$ aproximadamente, os sitemas Sterei-Oss e Omniloc para $12 \mathrm{~N} . \mathrm{cm}$ aproximadamente e o sistema Branemark falhou em 32 ciclos. Os autores acreditam que para minimizar o afrouxamento dos parafusos, o numero de aperto e afrouxamento nos procedimentos clínicos e laboratoriais antes da fixação final devem ser reduzidos. 
BROSCO $^{27}$, em 2001, avaliou através de microscopia eletrônica de varredura (MEV) o desajuste horizontal e a precisão de adaptação de pilares unitários em sistemas de implantes nacionais com hexágono externo. Os sistemas Titanium Fix (A.S Tecnology), Dentoflex (Dentoflex), Neodente (Neodente), e Master Screw (Conexão), foram avaliados, e comparados com o Sistema Branemark (Nobel Biocare) utilizado como grupo controle. Pilares do tipo Ceraone ou UCLA foram selecionados de acordo com a disponibilidade do sistema. Imagens obtidas através da MEV foram analisadas utilizando-se um programa computadorizado específico para medidas lineares das diferentes faces, áreas e ângulos de implantes e pilares. Seus resultados mostraram médias de largura do hexágono externo do implante e interno do pilar, e do desajuste horizontal da conexão implante / pilar de:

\begin{tabular}{|c|c|c|c|}
\hline Sistema & $\begin{array}{c}\text { Larg_hex_implant } \\
\mathrm{mm}\end{array}$ & $\begin{array}{c}\text { Larg_hex_pilar } \\
\text { mm }\end{array}$ & $\begin{array}{c}\text { Desaj_horizont } \\
\text { ì m }\end{array}$ \\
\hline Dentoflex & 2,685 & 2,809 & 19,420 \\
\hline Titanium Fix & 2,697 & 2,899 & 22,387 \\
\hline Neodente & 2,807 & 2,843 & 19,603 \\
\hline Master Screw & 2,699 & 2,827 & 16101 \\
\hline Branemark & 2,773 & 2,848 & 11,231 \\
\hline
\end{tabular}

CIBIRKA et $\mathbf{a}^{\beta 5}$, (2001) examinaram diferenças no destorque após testes de fadiga em implantes com hexágono externo. Sendo que as dimensões entre 0 hexágono externo do implante e o hexágono interno do pilar foram alteradas, ou o hexágono externo do implante eliminado. Três desenhos experimentais de implantes foram utilizados no seu trabalho; dez de cada desenho. (1) Implante de 
plataforma regular de $3,75 \mathrm{~mm}$ com hexágono externo convencional, tendo uma superfície média de largura hexagonal de 2,700mm e uma altura de 0,633mm. (2) Implante de plataforma regular de $3,75 \mathrm{~mm}$, com hexágono externo modificado, tendo uma média de largura hexagonal de $2,664 \mathrm{~mm}$ e uma altura de 0,608mm. (3) Implante de $3,75 \mathrm{~mm}$ com hexágono removido por desgaste para criar uma forma circular com um diâmetro de 2,668mm e uma altura de 0,668mm. Trinta pilares procera CAD / CAM (Nobel Biocare) foram fabricados com uma plataforma de carga inclinada com 25 graus. Os implantes foram fixados rigidamente em um dispositivo especial, e os pilares apertados com um parafuso de ouro a $32 \mathrm{~N} . \mathrm{cm}$, utilizando-se um controlador eletrônico de torque (Nobel Biocare). O conjunto fixado no dispositivo foi levado a uma máquina de ensaios. Uma carga dinâmica foi aplicada sobre a plataforma de cada pilar por um pistão em uma única direção. A máquina foi controlada com uma carga cíclica entre 20 e $200 \mathrm{~N}$ de força, a oito ciclos por minuto, sendo contínua por 5,000,000 de ciclos. Um exame macroscópico e radiográfico da interface pilar / implante de cada amostra foi realizado. Depois da carga, as amostras foram fixadas em um dispositivo, e com um medidor de torque Tohnichi BTG-6 foram removidos os parafusos e registrados os valores do destorque. Através do exame macroscópico e radiográfico não foi observado afrouxamento ou deslocamento rotacional na interface pilar / implante. A média de destorque nos três desenhos testados foi de $14,40,14,70$, e 16,40N.cm nos desenhos 1,2, e 3 respectivamente. Os autores concluíram que o aumento da distância no entre o largo do hexágono externo do implante e o hexágono interno do pilar não produz efeito estatisticamente significante nos valores de destorque do parafuso depois de 5,000,000 de ciclos em testes de fadiga. A eliminação do hexágono externo do implante e no aumento da altura teve um efeito significante nos valores de destorque do parafuso de ouro. Amostras com e sem hexágono externo não tiveram sinais de instabilidade ou afrouxamento do parafuso.

Na sua tese de mestrado DIAS ${ }^{39}$, em 2001, avaliou o grau de liberdade rotacional entre os hexágonos e o ajuste horizontal dos pilares das empresas 3i, 
implamed e Nobelbiocare. Utilizou pilares para reconstrução de próteses unitárias todos com a presença de hexágono interno; ceraone (Nobelbiocare), UCLA usinado em ouro (3i), e UCLA usinado em titânio (Implamed). Imagens obtidas através da microscopia eletrônica de varredura, foram utilizadas para a realização das medidas dos hexágonos dos implantes e pilares, essas imagens foram processadas através de um programa de computador. Seus resultados mostraram a existência de diferenças estatisticamente significantes entre as áreas dos hexágonos dos implantes e dos pilares nos três grupos avaliados, encontrando-se o menor grau de liberdade rotacional no grupo de implantes / pilares Nobelbiocare com $0,296 \mathrm{~mm}^{2}$. A diferença de diâmetros dos hexágonos dos implantes e pilares também mostrou diferenças menores no grupo Nobelbiocare. As medidas lineares das faces opostas dos hexágonos dos implantes e dos pilares mostraram diferenças estatisticamente significantes entre os grupos da Nobelbiocare e Implamed. Entre o grupo Nobel e $3 i$ não foram encontradas diferenças estatisticamente significantes. A menor média de desajuste horizontal do pilar conectado ao implante foi encontrada entre os grupos de implantes Implamed e pilares 3l $(3,506 \mu \mathrm{m})$; entretanto no grupo de implantes Implamed e pilares Nobelbiocare foi encontrada a maior média $(35,464 \mu \mathrm{m})$. Concluiu que a diferença encontrada quanto ao grau de liberdade dos hexágonos, pode não ter efeito clínico em nenhum dos sistemas de implantes e pilares estudados, considerandoos com precisão aceitável pelo nível de ajuste entre estes componentes. Quanto a liberdade hexagonal e o desajuste horizontal, afirmou que os três sistemas de implantes e pilares estudados podem ser intercambiados entre si.

Avaliando o micromovimento da interface implante / pilar depois da aplicação de cargas cíclicas, GRATTON; AQUILINO; STANFORD ${ }^{46}$, neste mesmo ano, testaram o efeito da aplicação de diferentes quantidades de torque no parafuso do pilar, quando submetida a testes de fadiga dinâmica. Infra-estruturas foram fabricadas sobre pilares UCLA e fixadas a implantes de hexágono externo (3i) por médio de um parafuso de ouro. Três grupos de cinco amostras foram criados, sendo em cada grupo aplicado 16, 32 e $48 \mathrm{~N} . \mathrm{cm}$ de torque, 
respectivamente. Cada amostra foi fixada em um dispositivo metálico, sendo alinhado um "strain gauge" na base do implante e na infra-estrutura do pilar para registrar o micromovimento da interface. Este conjunto foi levado a uma máquina de ensaios (MTS 810 Material testing system); onde foi aplicada uma carga axial cíclica a $6 \mathrm{~mm}$ do centro do implante e $12 \mathrm{~mm}$ de altura coronal. A máquina foi calibrada com uma força de 20 a $130 \mathrm{~N}$ e uma velocidade de $6 \mathrm{~Hz}$. O micromovimento da interface foi determinado antes da aplicação da carga, e depois de 100, 500, 1.000, 5.000, 10.000, 50.000, e 100.000 ciclos. Os resultados mostraram que a interface se manteve estável depois de 100,000 ciclos para os três grupos testados. Um maior micromovimento da interface foi observado no grupo onde foi aplicado $16 \mathrm{~N} . \mathrm{cm}$ de torque, em todos os intervalos. Diferenças estatisticamente significantes foram encontradas no micromovimento entre os grupos testados: grupo $16 \mathrm{~N} . \mathrm{cm}$ (68 ìm), grupo de $32 \mathrm{~N} . \mathrm{cm}(41 \mu \mathrm{m})$, e grupo 48 N.cm $(35 \mu \mathrm{m})$.

HOYER et $\mathbf{a l}^{53}$, em 2001, avaliaram a fadiga de parafusos tipo UCLA em restaurações sobre implantes de largo diâmetro $(6 \mathrm{~mm})$ versus restaurações sobre implantes de diâmetro convencional $(3,75 \mathrm{~mm})$. Em cinco implantes de cada grupo foram fabricadas infra-estruturas metálicas nas quais foram realizados testes de carga cíclicas. Todos os hexágonos assim como os parafusos de ambos grupos tinham o mesmo diâmetro para permitir comparações. Nos implantes de 3,75mm foram utilizados parafusos de ouro nos quais foram aplicados torques de $32 \mathrm{~N} . \mathrm{cm}$; e nos parafusos dos implantes de largo diâmetro foram utilizados parafusos de titânio com um torque de 25N.cm, aplicado por um torquímetro Tohnichi 9BTG-N. Duas amostras de cada grupo foram alteradas nas bordas do hexágono interno do pilar com uma broca esférica. Para quantificar as medidas da integridade da interface implante / pilar, foram utilizados "strain gauges", os quais foram fixados com uma ponta na infra-estrutura fabricada no pilar e a outra ponta num dispositivo alinhado na base do implante. A este conjunto foi aplicada uma carga cíclica com uma máquina fabricada com este propósito; a uma freqüência de $11 \mathrm{~Hz}$, com uma carga cíclica compressiva de $120 \pm 10 \mathrm{~N}$ por 500.000 diclos. A 
carga foi aplicada a $4 \mathrm{~mm}$ do centro do implante para simular uma carga na cúspide de um molar, a uma altura de $10 \mathrm{~mm}$ da união pilar / implante e a $180^{\circ} \mathrm{da}$ posição do "strain gauge". Os resultados deste estudo mostraram que ambos grupos experimentais foram capaz de manter a integridade da união implante / pilar, não existindo diferenças estatisticamente significantes, com uma variação na abertura da união das amostras não alteradas de 0 a 20ìm depois dos 500,000 ciclos. Dentre as amostras que foram alteradas dois $3,75 \mathrm{~mm}$ falharam em manter a estabilidade da união (abertura $>50$ ìm), sendo que uma amostra de $3,75 \mathrm{~mm}$ e uma de $6,0 \mathrm{~mm}$ fraturaram o parafuso; concluindo que o ajuste interno na interface diminui a vida do parafuso do pilar.

Em um estudo "in vitro" MARTIN et $\mathbf{a l}^{74}$, (2001) realizaram testes para medir a rotação e o torque de remoção em quatro diferentes parafusos de pilares, avaliando o potencial de geração de précarga. Os parafusos de matériais e superfícies diferentes avaliados foram: "Gold Tite (Gt) 3i", "Torq Tite (Tt) SteriOss", "Gold alloy (Ga) 3i" e "Titanium alloy (Ta) 3i". Na sua metodologia, 20 parafusos de cada tipo foram utilizados sobre 80 implantes hexágono externo 3,75 $x$ 15mm 3i. Sendo estes, divididos em dois grupos de dez, para serem aplicados 20 N.cm e 32 N.cm. Cinco medidas em cada torque foram realizadas. Cada conjunto foi fixado e com um dispositivo de plástico de $360^{\circ}$, fabricado com a finalidade de medir o ângulo de rotação, de cada parafuso. Os conjuntos que representavam as maiores médias de cada grupo foram levadas ao microscópio eletrônico de varredura para verificação da relação de contato entre as roscas e a sua localização. Os resultados mostraram que os maiores ângulos de rotação foram vistos para os grupos com parafusos $\mathrm{Tt}(21,2 \pm 3,1$ e 38,1 \pm 8,7 graus em 20 e $32 \mathrm{~N} . \mathrm{cm}$ respectivamente). Os maiores valores de pré-carga em 20 e $32 \mathrm{~N} . \mathrm{cm}$ foram encontrados nos grupos Gt (596,8 $\pm 101,2 \mathrm{~N}$ e $1015.3 \pm 191,2 \mathrm{~N})$ respectivamente. A análises de varredura mostrou que os contatos das roscas localizaram-se na porção média da rosca do parafuso do pilar. O maior número de contatos nas roscas foi encontrado no grupo Gt (14 dos possíveis 20 contatos). Concluíram que os parafusos Gt e Tt reduziram os coeficientes de fricção, 
produzindo maiores ângulos rotacionais e maiores valores de pré-carga do que os parafusos convencionais $\mathrm{Ga}$ e Ta.

Com o objetivo de testar a precisão de dispositivos eletrônicos de torque Nobelpharma DEA 020 (Nobel Biocare) que estavam em uso clinico por um tempo mínimo de cinco anos, MITRANI et al ${ }^{83}$, (2001) compararam o torque gerado por estes, com o toque gerado por dispositivos novos. No seu trabalho desenvolveram uma técnica no laboratório que simulou uma situação clínica utilizando um implante osseointegrado $13 \times 3.75 \mathrm{~mm}$ do sistema Branemark sobre o qual foi colocado um pilar ceraone, fixado com um parafuso de ouro. Para medir a quantidade de torque produzida por cada dispositivos um medidor analógico de torque Tohnichi 9BTG-A com uma precisão de $\pm 3 \%$ foi utilizado. Os testes de torque foram realizados em 10, 20 e $32 \mathrm{~N} . \mathrm{cm}$ em alta e baixa velocidade, sendo realizado em cada nível de torque dez repetições para cada dispositivo. Seus resultados não mostraram existir correlação significante entre o torque gerado pelos dispositivos e o tempo em uso; ao comparar os dispositivos em uso clínico com os dispositivos novos, os autores também não encontraram diferenças estatisticamente significantes.

PESUM et al $^{92}$, (2001) avaliaram e compararam forças axiais compressivas e torques aplicados simultaneamente em parafusos de ouro por pessoas com diferentes graus de experiência. Para o estudo foi fixado em resina acrílica, um implante osseointegrado (Nobel Biocare) 3,75 x 8mm de comprimento. Um pilar convencional "standard" de $3 \mathrm{~mm}$ foi unido ao implante por meio do correspondente parafuso, com um torque de $20 \mathrm{~N} . \mathrm{cm}$. Uma coroa total metálica assentada passivamente ao implante foi unida ao pilar com um parafuso de ouro aplicando-se um torque de $10 \mathrm{~N} . \mathrm{cm}$. Estudantes sem experiência em restaurações com implantes, residentes de próteses com menos de dois anos de experiência e professores da faculdade com no mínimo de cinco anos de experiência em restaurações com implantes foram orientados a apertar e afrouxar os parafusos de ouro três vezes. A magnitude e duração da força axial compressiva e o torque 
dado foram avaliados simultaneamente utilizando uma célula de carga em miniatura, adaptada a um dispositivo eletrônico de torque. Os resultados mostraram que os professores fixaram os parafusos com uma força axial compressiva maior que os estudantes e os residentes, sendo a quantidade de torque um pouco menor que o recomendado $10 \mathrm{~N} . \mathrm{cm}$. Os professores tiveram uma menor variação nos procedimentos de aperto e afrouxamento. Concluindo que pessoas com uma maior experiência na área, tem uma maior consistência nos procedimentos de aperto e afrouxamento dos parafusos de ouro. Uma maior força axial compressiva foi aplicada durante o afrouxamento quando comparada com a força de aperto. Forças compressivas removeram parte da pré-carga resultando em quantidade diminuída de torque necessária para remover o parafuso de ouro, o que pode explicar porque os estudos de remoção de torque mostram valores menores durante a remoção do parafuso, do que na sua colocação.

TAN; NICHOLLS ${ }^{105}$, (2001) mediram e compararam a pré-carga produzida em parafusos de sete diferentes tipos de pilares hexagonais. A medida da précarga foi realizada fixando dois "strain gauge" ao pilar que foi unido a um implante $3,75 \times 15 \mathrm{~mm}$ (Branemark system, Nobel Biocare). Pilares convencionais "standard", esteticone, miruscone, pilar de titânio, ceraone, Cilindro de ouro, e tiadpat foram utilizados. Um controlador eletrônico de torque (Nobel Biocare) aplicou 20 ou 32 N.cm de torque em alta e baixa velocidade, seguindo o indicado pelo fabricante, e a pré-carga foi registrada no computador, através dos "strain gauges". Os resultados encontrados nos diferentes pilares mostraram médias de pré-carga de $181,6 \mathrm{~N}$ convencionais, 291,3N esteticone, 456,5N miruscone, 369,7 pilar titânio, 643,4N ceraone, 536,3N Cilindro de ouro, e 556,9N tiadapt. Diferenças estatisticamente significantes foram encontradas entre os diferentes sistemas e na velocidade de aplicação do torque. Pilares com parafusos de ouro tiveram maiores valores de pré-carga. Dessa forma os autores concluíram que a pré-carga na união implante / pilar depende do desenho, diâmetro, e material do parafuso, assim como do torque de aperto e da velocidade do torque. 
Analisando as forças oclusais desenvolvidas sobre diferentes materiais utilizados na superfície oclusal de próteses sobre implantes, BASSIT; LINDSTROM; RANGERT ${ }^{11}$, em 2002, investigaram se as forças transmitidas aos implantes, em vivo, são influenciadas pela resina acrílica ou a cerâmica como material de revestimento. Cinco pacientes previamente tratados com implantes osseointegrados na região posterior da boca, foram utilizados no estudo, sendo a região do pré-molar selecionada para a realização dos testes. Duas coroas foram fabricadas para cada paciente; uma com resina acrílica (Meliodent, Heraus Kulzer) sobre um "coping" plástico convencional (Branemark System), e a outra cerâmica (Vintage, Shofu) sobre uma liga de ouro cerâmico, fundido sobre um cilindro de ouro "standard" $4 \mathrm{~mm}$ (Branemark System). As coroas unitárias foram unidas a pilares "standard" de 5,5mm, aos quais estavam unidos três "strain gauges". Para assegurar que as forças oclusais foram transmitidas através das próteses, estas foram ajustadas em supra-oclusão, de forma a estabelecer sempre o primeiro contato durante a mastigação e/ou oclusão sobre a prótese. Inicialmente os pacientes foram orientados a realizar um movimento de mordida rápido, e depois vários movimentos de mordidas rápidos. As forças aplicadas foram registradas, bem como a tensão e a correspondente força axial foi calculada. Este protocolo também foi aplicado a um modelo "in vitro", no qual o implante foi colocado em um aço e o impacto da mandíbula foi gerado por um peso de 164gr desde uma altura determinada. O pico de força máximo foi registrado. As medidas em vivo mostraram uma grande variação no pico de força aplicada, não se encontrando diferenças estatisticamente significantes entre os diferentes materiais testados. $O$ coeficiente do pico de força variou entre $20 \%$ e $130 \%$, com pico mínimo de $154 \mathrm{~N}$ e máximo de $2055 \mathrm{~N}$ para a resina acrílica, e de $63 \mathrm{~N}$ e $1280 \mathrm{~N}$ para a cerâmica, respectivamente, entre os diferentes pacientes. No modelo "in vitro", os picos de forças foram maiores, sendo encontrado na cerâmica um pico maior de força que na resina. O coeficiente de variação no pico de força foi de $10 \%$ a $35 \%$ tanto na resina quanto na cerâmica. Picos de forças mínimos de $110 \mathrm{~N}$ e máximo de $530 \mathrm{~N}$ para a resina; e de $310 \mathrm{~N}$ e $3.668 \mathrm{~N}$ para a cerâmica respectivamente. Os autores concluíram que os diferentes materiais oclusais não levam a geração de forças 
diferentes sobre os implantes nos pacientes; e que o grau de resiliência entre a cerâmica e a resina, foi observado somente no estudo "in vitro", onde a força é gerada por um choque e o implante é rigidamente ancorado.

BONACHELA ${ }^{24}$, (2002) avaliou a adaptação da interface pilar / componentes protéticos, utilizando cilindros de plásticos, fundidos em titânio e cobalto-cromo, em monobloco e após a realização de soldagem a laser em função dos parafusos de fixação desses cilindros, parafusos de ouro e de fenda com aplicação de um torque de $10 \mathrm{~N}$.cm. No seu estudo utilizou dez amostras, sendo que cada uma estava composta de três componentes protéticos unidos entre si por uma barra. Cinco amostras foram fundidas em titânio, e cinco em cobaltocromo. Mensurações foram realizadas nas interfaces pilar / componente protético com cada tipo de parafuso de fixação antes e após a soldagem a laser, com a utilização de um microscópio comparador. Seus resultados mostraram não existir diferenças estatisticamente significantes em relação à liga metálica utilizada, solda, e parafusos. Na fundição de liga de cobalto-cromo, a utilização dos parafusos de fenda e de hexágono mostraram diferenças estatisticamente significantes, sendo que na fundição em monobloco, uma melhor adaptação para os parafusos de fenda foi observada (24,13ìm), quando comparada com os parafusos hexagonais $(27,93 i ̀ m)$.

ÇEHRELI; IPLIKÇIOGLU; BILR ${ }^{34}$, (2002) avaliaram a influência da localização da carga na transferência da tensão a redor dos implantes, quando são aplicadas cagas axiais ou obliquas em próteses cimentadas. "Strain gauges" foram fixados a dez implantes fixados em resina acrílica autopolimerizável, pilares retos foram reduzidos a $6 \mathrm{~mm}$ e conectados aos implantes, nos quais quatro modelos de próteses fixas foram fabricados em nickel cromo com uma configuração oclusal plana. Os procedimentos de cimentação foram realizados utilizando um cimento provisório (Temp bond) com um modificador para facilitar a remoção e reutilização das próteses. Uma carga axial de $50 \mathrm{~N}$ foi aplicada no centro de cada implante, e fora do centro do implante. Registros dos dados de 
cada desenho foram avaliados e observados os pontos de transferência das cargas. Uma tendência a um aumento da magnitude da tensão na carga fora do centro do implante foi observada. O tipo de tensão registrado foi dependente da posição do "strain gauge" no implante, onde a colocação circunferencial pode ter registrado tensão de tração. O ponto de transmissão de carga afetou quantitativamente as tensões ocorridas nas cargas axiais, assim com nas cargas não axiais; entretanto análises estatísticos não revelaram diferenças quando os implante foram posicionados em forma curva, o que reafirma a idéia de que quando implantes são posicionados em diferentes planos na região posterior da boca a tensão é diminuída. Para o autor um controle biomecânico na carga dos implantes é imperativo para se conseguir sucesso longitudinal, sendo que o desenho das próteses e a transmissão das forças têm uma influência definitiva na quantificação da tensão.

KHRAISAT et al $^{62}$, (2002) avaliaram a resistência à fadiga e a condição de falha de dois desenhos de interface implante / pilar de restaurações unitárias. Os sistemas Branemark com pilar ceraone e ITI com conexão de topo e $8^{\circ}$ de conexão interna foram avaliados. Sete amostras de cada sistema foram montadas em bloco de resina acrílica transparente, com $3 \mathrm{~mm}$ de exposição da base do implante. Nos pilares ceraone, foi aplicado um torque de $32 \mathrm{~N} . \mathrm{cm}$ e nos pilares ITI de $35 \mathrm{~N} . \mathrm{cm}$. A cada pilar foi cimentada, utilizando-se cimento fosfato de zinco uma supra-estrutura metálica de forma circular. Cada conjunto foi montado em um dispositivo metálico e levado à máquina de ensaio de fadiga, onde foram aplicadas cargas cíclicas com forças de 0 a $100 \mathrm{~N}$, sendo estas forças perpendiculares ao eixo do implante, e a $11,5 \mathrm{~mm}$ da interface implante / pilar. Os corpos de prova foram submetidos a 1.800 .000 ciclos, a uma freqüência de 75 ciclos / minuto. Seus resultados mostraram que os parafusos dos pilares ceraone fraturaram entre 1.178.023 e 1.733 .526 ciclos, enquanto que os pilares ITI permaneceram estáveis até $1,800,000$ ciclos. Sendo que a área mais critica de falha dos parafusos do sistema ceraone, à parte de união entre as roscas e a haste do parafuso; nenhuma descimentação ou afrouxamento da supra-estrutura fixada ao pilar foi 
encontrado. Concluindo-se que a dispersão da tensão na interface de união do sistema ITI, pode ter sido a razão para a alta resistência do sistema às cargas cíclicas de fadiga.

Seguindo o princípio observado por BINON ${ }^{14}$ de que as discrepâncias entre os hexágonos dos pilares e dos implantes, e que a liberdade rotacional do pilar sobre o implante deve ser menor de cinco graus para se obter uma união estável; LANG; WANG; MAY ${ }^{67}$, (2002) examinaram a orientação do hexágono do pilar no hexágono do implante depois do aperto do parafuso, em diferentes sistemas de pilares. Examinaram também, a influência do dispositivo de contra torque na configuração hexagonal do pilar / implante após o aperto do parafuso. Na sua metodologia, utilizaram implantes (Nobel Biocare) de plataforma regular $(3,75 \mathrm{x}$ $10,0 \mathrm{~mm})$ e implantes de largo diâmetro $(5,0 \times 10,0 \mathrm{~mm})$. Os pilares ceraone, esteticone, procera e auradapt, foram também estudados. Cada implante foi fixado em um dispositivo e depois aplicado o torque recomendado para cada sistema, utilizando-se um controlador eletrônico de torque (Nobel Biocare). Em cinco amostras de cada grupo no aperto foi utilizado um dispositivo de contra torque e nas outras cinco não. Depois do aperto as amostras foram removidas e incluídas em uma resina (EKACT / Kulzer). Um corte foi realizado em direção horizontal ao nível do hexágono. A orientação do hexágono interno do pilar no hexágono externo do implante foi avaliada, assim como o grau e a direção da rotação do hexágono do pilar no hexágono do implante. Os resultados mostraram uma média do grau de rotação para os quatro sistemas testados, com e sem o uso do contra torque menor de 3,53 graus. Quando o contra torque foi utilizado, todos os sistemas tiveram uma média absoluta de rotação menor que 1,50 graus, depois do aperto do parafuso do pilar. Concluíram que à orientação he xágono - hexágono medida como a liberdade rotacional, nos sistemas testados foi abaixo de cinco graus o que sugere uma ótima estabilidade da união parafusada e que o uso do contra torque tem pouca influencia na orientação do hexágono do pilar ao redor do hexágono do implante. 
Ainda neste mesmo ano LEE et al $^{69}$ investigaram o efeito da mastigação simulada sobre componentes de implantes, utilizando análise de vibração para documentar o mecanismo básico de afrouxamento do parafuso em um meio oral simulado. Um dispositivo pneumático cilíndrico para a aplicação das cargas cíclicas foi fabricado para simular o movimento mastigatório. Sendo que 13 pilares "Standards" de $4 \mathrm{~mm}$ de altura foram conectados a implantes de hexágono externo com um parafuso de titânio, no qual foi aplicado um torque de $20 \mathrm{~N}$.cm. Em cada conjunto implante pilar foi fixado uma coroa unitária com um parafuso de ouro de $3 \mathrm{~mm}$ onde foi aplicado um torque de $10 \mathrm{~N} . \mathrm{cm}$. Nos corpos de provas foram aplicadas cargas utilizando o dispositivo mencionado, com uma força de $100 \mathrm{~N}$, em um ângulo de $30^{\circ}$ do eixo do implante, a uma freqüência de $1 \mathrm{~Hz}$. Um grupo controle de 13 corpos de prova com as mesmas características do grupo experimental foi utilizado, onde foram aplicadas cargas axiais com as mesmas especificações. O efeito de um milhão de ciclos e várias forças de torques $(2,4,6$, 8, 10, e 12N.cm), no afrouxamento do parafuso foram avaliados pela análise de vibração. Os resultados mostraram que o modo de vibração foi dividido em quatro estágios, para o afrouxamento dos parafusos de ouro: (1) deslocamento inicial; (2) vibração inicial; (3) deformação elástica; e (4) estágio de recuperação. Entretanto os estágios de deslocamento e vibração inicial não foram perceptíveis no afrouxamento dos parafusos de ouro. Do grupo experimental quatro parafusos de ouro afrouxaram antes de 1.000.000 de ciclos, e não houve afrouxamento no grupo controle. O afrouxamento do parafuso não teve efeito no estágio de deformação elástica. Concluído-se que o torque de aperto tem um efeito significante no afrouxamento do parafuso, sendo que este torque deveria ser maior de $10 \mathrm{~N} . \mathrm{cm}$ como recomendado para os parafusos de ouro neste sistema de hexágono externo.

RAFEE et $\mathbf{a l}^{94}$, (2002) avaliaram o efeito de repetidos torques e a contaminação da saliva na máxima resistência a tração de parafusos de fenda retenção de ouro. Quarenta e cinco parafusos (3i) divididos em nove grupos foram testados, sendo que um grupo $\mathrm{OX}$ onde não foi aplicado torque serviu como 
controle. Em quatro grupos sob condições de contaminação foi determinada a resistência à tração em diferentes números de repetições de $10 \mathrm{~N}$.cm de torque: grupo 1X, grupo 5X, grupo 10X, grupo 20X. Estes mesmos grupos sob condições de contaminação também foram testados, conformando-se um total de oito grupos testes e um grupo controle. Os resultados mostraram valores médios de fratura de $97,6 \pm 2,2 \mathrm{~kg}$ (grupo 0X) a 102,0 $\pm 2,1 \mathrm{~kg}$ (grupo 5X); sendo que não foram encontradas diferenças estatisticamente significantes entre os grupos quando estiveram ou não sob condições de contaminação. Em todos os grupos não existiu uma diminuição significativa nos valores de carga para fratura. Os autores sugeriram que os parafusos testados podem ser apertados e removidos acima de 20 vezes sem afetar a máxima resistência tração.

RAMBHIA et $\mathbf{a P}^{95}$, (2002) determinaram a influência de defeitos na resistência a tração de parafusos de retenção de ouro, e examinaram a microestrutura e microdureza, e os principais componentes constituintes de parafusos de duas marcas comerciais (3i e Nobelpharma) e dois lotes diferentes. Dois parafusos 3i, e dois Nobelpharma foram incluídos em resina acrílica e preparados através de procedimentos metalográficos para serem examinados os defeitos, utilizando-se microscopia ótica. A microestrutura da superfície dos parafusos foi examinada por condicionamento das amostras preparadas com solução de ácido nítrico e ácido hidroclorídrico. Em outra parte do estudo 36 parafusos, foram submetidos a testes de tensão para determinar a resistência à fratura. Os sítios de fratura foram analisados através de microscopia eletrônica de varredura, para identificar defeitos que pudessem levar a falhas desses parafusos. Os resultados das análises microscópicas não revelaram defeitos significativos nos parafusos examinados. Diferenças foram encontradas na microestrutura, microdureza, composição da liga, e valores de fratura a carga, de ambos fabricantes. Características metalúrgicas diferentes e diferenças no processo de fabricação foram encontradas nos parafusos. Os valores de fratura foram de $850 \mathrm{~N}$ a $1093 \mathrm{~N}$. Uma diferença significante foi encontrada nos valores médios de fratura de diferentes lotes nos parafusos 3i. A fratura dúctil foi a condição de falha dos 
parafusos. A partir destes dados os autores concluíram que estas diferenças podem afetar os resultados clínicos quando estes parafusos são utilizados.

SEQUIER; PSOTER; TAYLOR ${ }^{100}$, (2002) examinaram o efeito da anodização e a redução da área de conexão do sistema cone morse, nos valores de torque de afrouxamento em implantes do sistema ITI. Neste sistema existem dois tipos de superfície do pilar: anodizado e convencional. A anodização é um processo de revestimento utilizado para dar cor ao titânio de forma a facilitar a seleção dos componentes; também existem dois tipos de conexões cone Morse convencional e cone Morse octogonal; o último reduz a área de superfície interna, com a incorporação de entalhes, de 24 para $16 \mathrm{~mm}^{2}$. No seu estudo quatro grupos de 20 amostras foram utilizados, sendo que em dois grupos a superfície do pilar foi anodizada nos outros dois grupos a área de superfície foi convencional. De cada grupo um foi com uma configuração cone Morse convencional e outro cone Morse octagonal. Nas amostras, os parafusos foram fixados com $35 \mathrm{~N} . \mathrm{cm}$ de torque e armazenados a temperatura ambiente por um mínimo de 30 dias. $\mathrm{O}$ torque de afrouxamento foi realizado após o tempo mencionado e os dados obtidos foram submetidos a análises estatísticas. Concluíram que o torque de afrouxamento foi $20 \%$ superior no grupo de implantes com superfície convencional quando comparado com o grupo com superfície anodizada. Nos grupos com uma conexão cone Morse octogonal e superfície convencional foram obtidos melhores resultados, de torque de afrouxamento quando comparado com o torque de aperto, média de 106.2\%, entretanto no grupo com superfície anodizada e uma conexão convencional foram obtidas médias de 78,9\%.

Com o objetivo de comparar a precisão de dispositivos mecânicos de aplicação de torque em próteses sobre implantes, STANDLEE et al ${ }^{102}$, neste mesmo ano, avaliaram três sistemas de torque. No experimento, utilizaram a mesma metodologia desenvolvida por eles em um trabalho anterior ${ }^{101}$, na qual o torque gerado pelos diferentes dispositivos é transferido a uma máquina Instron através de um torno em miniatura. Seis dispositivos Nobel Biocare (em 10 e 20 
N.cm), cinco Strauman ITI (em 15 e 35N.cm), e seis Dyna Torq ITL (em 10, 20 e 30 N.cm), foram testados, sendo realizadas um mínimo de dez repetições em cada nível de torque. Os resultados obtidos mostraram que no dispositivo eletrônico Nobel Biocare existiu uma tendência a uma maior precisão na aplicação do menor torque $(10 \mathrm{~N} . \mathrm{cm})$, porém variações significantes entre $8 \%$ e $41 \%$ foram encontradas nestes dispositivos de forma individual. No dispositivo ITI e ITL, uma menor variabilidade nos valores de torque gerados foi observada, com uma variação não maior de $10 \%$, sendo os valores de torques gerados próximos aos programados pelos fabricantes. Concluíram que o torque gerado por cada dispositivo individual tem uma variação em diferentes graus, do torque para o qual os mesmos são programados.

TAN; NICHOLLS ${ }^{106}$, neste mesmo ano, afirmaram que uma ótima pré-carga no parafuso de retenção de ouro é necessária para manter a estabilidade da união pilar / cilindro de ouro; pelo que mediram a condição de pré-carga obtida no parafuso de ouro em três sistemas de aplicação de torque. Dispositivos de torques manuais, controladores de torque eletrônico e aplicação através de chaves de torque foram comparados. Cinco implantes (Nobel Biocare) foram fixados com resina acrílica numa mandíbula edêntula. Nestes, pilares "standards" de $4 \mathrm{~mm}$ foram fixados aos implantes utilizando parafusos com um torque de $20 \mathrm{~N} . \mathrm{cm}$. Em cada pilar três "Strain Gauge" foram fixados para obter as medidas através de um computador. No pilar um cilindro de ouro foi utilizado e um parafuso de ouro com cabeça plana foi testado aplicando-se $10 \mathrm{~N}$.cm de torque; utilizando-se três dispositivos de torques manuais (Nobel Biocare), quatro controladores de torques eletrônicos (Nobel Biocare), e três operadores aplicaram um torque manual. Os resultados mostraram que os dispositivos de aplicação de torque manual tiveram uma variação significativa na pré-carga induzida sobre o parafuso de ouro, média de 291,2N; controladores de torque eletrônico produziram média de $384,3 \mathrm{~N}$; e os diferentes operadores produziram média de $140,8 \mathrm{~N}$. Os controladores de torque eletrônicos produziram uma maior pré-carga que os outros dos sistemas de torque testados, porém os autores sugerem uma recalibração destes dispositivos em 
intervalos de tempo regulares, para assegurar um ótimo resultado. A média de pré-carga produzida pelos dispositivos de torque manuais foi a mais próxima da quantidade de pré-carga teoricamente recomendada nestes parafusos $300 \mathrm{~N}$. O uso de chaves manuais para aplicação do torque produziu uma pré-carga insuficiente ao parafuso de ouro, sendo inconsistente entre os diferentes operadores. Os autores acreditam também, que quando o cilindro de ouro é submetido aos diferentes processos de confecção da prótese, fundição e polimento; a pré-carga é prejudicada.

TZENAKIS et al $^{111}$, (2002) avaliaram o efeito de repetidos torques e a contaminação da saliva no torque produzido em parafusos de fendas de retenção de ouro. 15 parafusos foram testados em um dispositivo metálico desenvolvido para o experimento. No dispositivo, um implante $3.75 \times 10 \mathrm{~mm}$ foi fixado, e sobre este um pilar "standard" conectado com um torque de $20 \mathrm{~N} . \mathrm{cm}$. Um cilindro de ouro e um parafuso do pilar para cada um dos 15 parafusos de retenção de ouro testados foi utilizado. Em cada parafuso teste foi aplicado um torque de $10 \mathrm{~N} . \mathrm{cm}$, sob condições de contaminação com saliva humana; este toque foi repetido dez vezes utilizando-se um dispositivo eletrônico de torque; após o torque um intervalo de tempo de cinco minutos foi esperado para remoção e retorque do parafuso. Registros das pré-cargas produzidas em cada torque aplicado foram realizados através de "strain gauges", em uma repetição (grupo 1X), cinco repetições (grupo 5X), e dez repetições (grupo 10X). Os resultados mostraram um aumento estatisticamente significante nas médias dos valores de pré-cargas produzidos nos grupos testados, encontrando-se médias no grupo $1 \mathrm{X}(184,3 \pm 28,9 \mathrm{~N})$, grupo $5 \mathrm{X}$ $(202,5 \pm 27,7 N)$, e grupo $10 X(220 \pm 29,0 N)$. Este aumento foi de $8,3 \%$ do grupo $1 \mathrm{X}$ para o grupo $5 \mathrm{X}$; e de $16,3 \%$ do grupo $5 \mathrm{X}$ para o grupo $10 \mathrm{X}$; os autores atribuíram este aumento nos valores de pré-carga a uma diminuição gradual das forças friccionais na união das roscas do parafuso, devido ao fenômeno de assentamento. Segundo os autores com os repetidos torques à eliminação gradual das microrugosidades existentes na união das superfícies permitiu um melhor 
contato entre as roscas, aumentando as forças de torque que se transformaram em um aumento da pré-carga.

TAVAREZ et al $^{107}$, (2002) em um estudo ainda em publicação, avaliaram a quantidade de torque necessária para remover o parafuso (destorque) quando é aplicado um torque determinado; utilizando quatro diferentes tipos de parafusos de retenção de próteses sobre implantes. Dez implantes de hexágono externo 3,75 X $13 \mathrm{~mm}$ (ST313 / 3i) foram incluídos em um bloco de resina acrílica autopolimerizável, sobre os quais foram avaliados dez parafusos dos tipos: UCLA de titânio (UNIHT / 3i), UCLA de ouro (UNIHG / 3i), de retenção de ouro (GSH30 3mm / 3i) e esteticone (CA001S / 3i), utilizando-se um torquímetro (TOHNICHI BTG60CN / JAPAN). Após ser aplicado um torque determinado mediou-se o destorque em cada parafuso. Os resultados mostraram uma diminuição do torque de $12,80 \%$ nos parafusos esteticone; de $14,07 \%$ nos parafusos de retenção de ouro; de $15,77 \%$ nos parafusos UCLA de titânio, e de $30,61 \%$ nos parafusos UCLA de ouro. Em todos os grupos testados sempre a força de torque foi maior que a de destorque, concluindo-se assim, que quando um torque é aplicado em um parafuso, utilizando estes sistemas, uma diminuição desse torque deve ser esperada quando o destorque é realizado.

TAVAREZ et al $^{108}$, (2002) em um estudo ainda em publicação, avaliaram no laboratório o torque gerado de forma manual por dez profissionais em quatro diferentes tipos de parafusos de próteses sobre implantes. Os parafusos UCLA de titânio (UNIHT / 3i); UCLA de ouro (UNIHG / 3i), de retenção de ouro (GSH30 $3 \mathrm{~mm} / \mathrm{ii}$ ) e esteticone (CA001S / 3i), forma testados sobre quatro implantes osseointegrados $3,75 \times 13 \mathrm{~mm}$ (ST313 / 3i) fixados em um manequim odontológico na área de primeiro e segundo molar inferior esquerdo e direito. $\mathrm{Na}$ realização dos testes os profissionais foram orientados a simular uma condição clínica. Após a aplicação do torque, foi medido o destorque, utilizando-se um torquímetro (TOHNICHI BTG60CN / JAPAN), Os resultados encontrados mostraram diferenças estatisticamente significantes entre os diferentes 
profissionais, porém não foram encontradas diferenças entre o sexo feminino e masculino, nos parafusos testados. As médias dos valores encontrados foram de: 9,53N.cm nos parafusos UCLA de ouro; $10,07 \mathrm{~N}$.cm nos parafusos de retenção de ouro; $12,56 \mathrm{~N} . \mathrm{cm}$ nos parafusos UCLA de titânio; e de 18,87N.cm nos parafusos esteticone. Concluindo-se assim que quando uma força de torque é aplicada de forma manual uma variabilidade, entre parafusos e entre profissionais, no torque produzido deve ser esperada, pelo que métodos mais precisos devem ser utili zados.

Em outro estudo "In vitro" ainda em publicação TAVAREZ et al ${ }^{109}$ (2002) avaliaram e compararam a quantidade de torque gerada por quatro torquímetros de diferentes marcas comerciais utilizados na aplicação do torque: Nobelpharma de 20 e 32N.cm, Torque Driver 3i de 20 e 32N.cm, Torque-Lock em 20 e 30N.cm, e Dyna de 20 e $30 \mathrm{~N} . \mathrm{cm}$. O torque produzido por cada torquímetro em dez parafusos UCLA titânio (3i), foi medido através da quantidade de torque necessária para o afrouxamento do parafuso após o torque, utilizando-se um torquímetro (TOHNICHI BTG60CN). Os resultados mostraram diferenças estatisticamente significantes quando foi aplicado um torque de $20 \mathrm{~N} . \mathrm{cm}$, nos torquímetros Nobelpharma $(19,94 \mathrm{~N} . \mathrm{cm})$ e $3 \mathrm{i} \quad(18,86 \mathrm{~N} . \mathrm{cm})$ com os torquímetros Torque Lock $(14,67 \mathrm{~N} . \mathrm{cm})$ e Dyna $(13,75 \mathrm{~N} . \mathrm{cm})$. Houve também, diferenças estatisticamente significantes entre os torquímetros quando aplicado um torque de $32 \mathrm{~N} . \mathrm{cm}$, entre os torquímetros Nobelpharma $(26,67 \mathrm{~N} . \mathrm{cm})$ e $3 \mathrm{i}(29,93 \mathrm{~N} . \mathrm{cm})$, assim como quando aplicado um torque de $30 \mathrm{~N} . \mathrm{cm}$ entre os torquímetros Torque Lock $(23,77 \mathrm{~N} . \mathrm{cm})$ e Dyna $(21,33 \mathrm{~N} . \mathrm{cm})$. Concluindo-se que o torquímetro eletrônico Nobelpharma e 3i de 20 e 32N.cm geram a quantidade de torque para a qual são programados enquanto que os torquímetros Torque Lock e Dyna torque de $20 \mathrm{e}$ $30 \mathrm{~N} . \mathrm{cm}$ não geram a quantidade de torque para 0 qual são programados. 
REVISÃO DA LITERATURA ESTUDOS DE AVALIAÇÃO CLÍNICA DAS PRÓTESES UNITÁRIAS SUPORTADAS POR IMPLANTES 
Em um estudo de acompanhamento clínico JEMT; LEKHOLM; GRONDAHL $^{58}$, em 1990, avaliaram reconstruções protéticas unitárias suportadas por implantes Branemark durante um período de três anos. Neste, um grupo de 16 pacientes (oito homens e oito mulheres), receberam 21 implantes na maxila e dois implantes na mandíbula, totalizando 23 fixações. Exame clínico foi realizado inicialmente duas semanas, e três meses após a instalação das coroas e se nenhum problema mecânico ou patológico foi encontrado, os pacientes foram citados para controle anual. Após três anos de função, os implantes / coroas foram examinados quanto à estabilidade, presença ou ausência de placa, recessão gengival, nível ósseo e estabilidade das coroas. Após 30 meses de função, dois implantes foram perdidos, sendo que 21 implantes (91\%), permaneceram estáveis depois do período de observação. As complicações protéticas incluíram a substituição de 13 restaurações uma vez, e duas restaurações tiveram que ser substituídas duas vezes, durante os três anos de seguimento; nove destas substituições foram devido a razões estéticas e cinco para melhora da união do parafuso. Outras três restaurações foram trocadas por trauma ou fraturas do material. Dez restaurações (43\%) permaneceram estáveis no primeiro ano de função e oito (35\%) durante todo o período de avaliação, sendo que afrouxamento do parafuso foi encontrado em $57 \%$ das restaurações durante o primeiro ano. Fístulas foram associadas a afrouxamento de quatro restaurações e tratadas com reaperto dos parafusos do pilar.

No ano seguinte JEMT et al ${ }^{57}$, reportaram os resultados de outro estudo de acompanhamento clínico onde foram colocados 107 implantes unitários em 92 pacientes (45 homens e 47 mulheres), em sete centros clínicos internacionais. $82 \%$ dos implantes foram colocados na maxila e $18 \%$ na mandíbula. A avaliação clínica foi realizada através de controles de uma semana, 6, 12, 24, 36, 48, 60 meses após a inserção da coroa; nesta parte do estudo o controle foi realizado até 12 meses. Os seguintes parâmetros clínicos foram registrados: gengivite, profundidade de sondagem, índice de sangramento, e mobilidade dentaria. Neste período somente três implantes $(2,8 \%)$ foram perdidos. A condição gengival se 
apresentou saudável (82\% dos pacientes) em volta das coroas, coincidindo com a situação clinica dos dentes naturais adjacentes. Fístulas foram encontradas em 11 restaurações (10\%); em seis destas foram associadas à mobilidade dos parafusos do pilar. A principal complicação associada a restaurações ou componentes protéticos foi o afrouxamento dos parafusos do pilar (26\%), em 21 restaurações (20\%) ocorreu afrouxamento uma vez, e em oito restaurações (7,5\%) ocorreu afrouxamento dos parafusos varias vezes, A freqüência de afrouxamento dos parafusos teve uma tendência a diminuir com a progressão do estudo.

Já no ano de 1992, ANDERSON et al $^{4}$ introduziram o pilar ceraone para restaurações de elementos unitários utilizando o sistema Branemark. No seu desenvolvimento, 32 pacientes foram tratados com 35 implantes unitários e sua reabilitação protética realizada utilizando este pilar, sendo avaliados até 24 meses. Este sistema apresenta características onde a parte que se une ao implante tem uma configuração antirrotacional hexagonal interna, e sua porção superior tem uma altura de 3,8mm, e o pilar é disponível em alturas de 1, 2, 3, 4, e 5mm. O pilar é conectado ao implante através de um parafuso de ouro ou titânio, ao qual é recomendado $32 \mathrm{~N} . \mathrm{cm}$ de torque, utilizando-se um dispositivo de contra-torque. Duas técnicas foram utilizadas sobre o pilar, uma capa de cerâmica de óxido de alumina sinterizada, a qual foi aplicada cerâmica, e uma capa de plástico sobre à qual foi realizado enceramento e procedimentos de fundição e aplicação da cerâmica. As cimentações das coroas foram realizadas utilizando-se cimento fosfato de zinco. Depois de 12 e 24 meses de instalação das 35 coroas os parafusos de ouro permaneceram estáveis, e só um dos pilares que foi fixado com parafuso de titânio afrouxou depois de 12 meses.

LEVIS; LLAMAS; AVERA ${ }^{73}$, (1992) reportaram através de um trabalho de publicação os vários usos do pilar UCLA, suas vantagens e desvantagens quando comparado com componentes convencionais. Apresentaram também os resultados de uma avaliação clínica de quatro anos de uso do pilar UCLA. Uma vantagem deste componente mencionada pelos autores é que a restauração 
confeccionada emerge desde os tecidos gengivais o que permite uma restauração mais estética. Os autores também comentaram que os processos de fundição são mais sensíveis tecnicamente, enquanto que os componentes pré-fabricados são mais precisos. Dessa forma, uma fundição com uma pobre adaptação, resulta em afrouxamento ou fratura do parafuso, e possibilidade de fratura ou perda do implante, portanto uma adaptação precisa é necessária neste tipo de componente. Também relataram os resultados de um estudo clínico de quatro anos utilizando este pilar sobre implantes Branemark. Explicaram que problemas envolvendo distância interoclusal limitada, estética, angulação, distância interproximal reduzida, foram resolvidos; sendo que para 46 pacientes tratados com 118 pilares UCLA a porcentagem de sucesso foi de $95,8 \%$.

Em 1994, EKFELD; CARLSSON; BORJESSON ${ }^{41}$ realizaram uma avaliação clínica de restaurações unitárias suportadas por implantes Branemark, durante um período de 14 a 55 meses. As restaurações permaneceram em função de 3 a 46 meses, media de 18 meses. Em 77 pacientes foram colocados 93 implantes para confecção de próteses unitárias. Sendo que duas fixações foram perdidas, uma antes da conexão do implante com o pilar, e outra durante o primeiro ano em função. Observaram que a complicação protética mais comum foi o afrouxamento do parafuso do pilar; o qual ocorreu em $43 \%$ das restaurações, sendo que em 28 restaurações os parafusos afrouxaram uma vez, e em 12 duas ou mais vezes; dois parafusos tiveram que ser cambiados durante os primeiros dois anos devido a afrouxamento do parafuso sob coroas permanentemente cimentadas. Concluíram que as restaurações unitárias sobre implantes oferecem uma alternativa de tratamento promissor, com excelentes resultados biológicos, estéticos, e funcionais; enquanto que o método de fixação precisa de alteração para diminuir o afrouxamento do parafuso.

Ainda no mesmo ano, LANEY et al $^{65}$ apresentaram a continuação do estudo relatado por JEMT et al $^{57}$, em 1991, realizado em sete centros clínicos internacionais durante um ano. Neste, foram avaliadas próteses unitárias 
suportadas por implantes do sistema Branemark durante três anos. Dos 92 pacientes tratados inicialmente com 117 implantes, 82 (89\%) permaneceram neste estudo de três anos com 95 (89,6\%) implantes suportando coroas unitárias. Após um ano de função sobreviveram $97,2 \%$ dos implantes, entre o primeiro e terceiro ano $100 \%$ dos implantes sobreviveram, com um índice de sucesso acumulado de $97,2 \%$. Nenhuma alteração foi encontrada nos parâmetros clínicos registrados anteriormente; gengivites, profundidade de sondagem, sangramento à sondagem, mobilidade dos implantes e os dentes. Perda óssea marginal medida através de radiografias permaneceu inferior a $0,1 \mathrm{~mm}$ durante o segundo e terceiro ano. Entre um e três anos seis pacientes tiveram ocorrência de fístulas, e em dois uma inflamação da mucosa; isto foi resolvido sem o compromisso dos implantes. Fratura da coroa ocorreu em três restaurações, e em dois foi encontrada falha estética. Um pilar "standard" foi substituído por um ceraone. A principal complicação protética continuou sendo afrouxamento do parafuso do pilar, pelo que reaperto dos mesmos foi registrado em dez pacientes, e em cinco pacientes o parafuso de titânio foi substituído por parafuso de ouro, o que diminuiu o problema.

ANDERSSON et al $^{3}$, em 1995, apresentaram os resultados de um estudo de acompanhamento clínico de restaurações unitárias utilizando o sistema de pilar ceraone. Avaliaram 57 pacientes (33 homens e 24 mulheres), nos quais foram colocados 65 implantes (três na mandíbula e 62 na maxila). Os pacientes foram divididos em dois grupos: (1) Grupo A com 57 pacientes nos quais 65 coroas foram colocadas, sendo que este grupo foi acompanhado por dois anos após a cimentação das coroas; (2) Grupo B com 34 pacientes onde foram colocadas 37 coroas; este grupo foi acompanhado por um período de três anos, todos os pacientes deste grupo estavam incluídos no grupo A. Onze dos implantes foram cônicos e os 54 implantes restantes foram cilíndricos. Em relação aos pilares utilizados neste estudo os 3 primeiros foram conectados utilizando parafusos de titânio e os outros com parafusos de ouro. Exame clínico, exame da mucosa periimplantar, posição da margem da coroa, estética, complicações e exames 
radiográficos; assim como consultas de acompanhamento foram realizadas em duas semanas, um, três e seis meses, um, dois, três, quatro e cinco anos após a cimentação da coroa. Os resultados encontrados mostraram que somente um implante foi perdido em um paciente masculino do grupo $B$, sendo que este implante foi dado como não osseointegrado duas semanas após a cimentação da coroa. Um sucesso de $98,5 \%$ em dois a três anos no grupo A, e de $97,3 \%$ em três a quatro anos para o grupo B. Quanto à sobrevivência das coroas 60 das 65 coroas permaneceram em função por dois anos no grupo A, e no grupo B, 29 das 37 coroas permaneceram estáveis por três anos de seguimento. Quatro coroas totalcerâmicas falharam, sendo que uma mostrou inflamação a redor do implante diagnosticando-se radiográficamente um espaço entre o pilar e o implante no exame de seis meses. Outra coroa mostrou perda óssea e uma fístula emanada da interface pilar implante 11 meses após a cimentação; os outros dois pacientes tiveram fraturas da coroa. Uma complicação encontrada foi em um parafuso de titânio que afrouxou após um ano de função, após aperto manual com um parafuso de ouro, nenhum outro problema ocorreu. A posição do nível gengival foi estável em relação ao nível do pilar / coroa, e os resultados estéticos foram tidos como bons para todas as coroas, tanto pelos pacientes quanto pelos profissionais; sendo que os autores acreditam que o uso deste pilar ajuda na obtenção de um resultado estético e evita complicações de afrouxamento e formação de fístula.

Em um estudo retrospectivo, BECKER; BECKER $^{13}$ apresentaram os resultados de restaurações unitárias suportadas por implantes substituindo molares mandibulares e maxilares. Vinte e dois pacientes (16 mulheres e seis homens) receberam 24 implantes que foram acompanhados por um período médio de 24 meses. Vinte e um dos implantes tinham um diâmetro de 3,75 mm, 1 de $4 \mathrm{~mm}$ e 2 de $5 \mathrm{~mm}$, sendo 18 implantes mandibulares e seis maxilares. Restaurações foram realizadas e fixadas utilizando-se parafusos de ouro, duas semanas após a inserção das coroas os parafusos foram reapertados. A oclusão de todas as restaurações foi desenvolvida minimizando contatos cêntricos e interferências laterais. O índice acumulado de sucesso foi de 95,7\% após um ano. 
Afrouxamento dos parafusos de retenção ocorreu em oito implantes (38\%), sendo que $14,2 \%$ afrouxaram uma vez, 9,5\% duas vezes e 14,3\% três vezes. Fratura do parafuso do pilar ocorreu em um paciente, e nenhuma fratura da coroa ou implante ocorreu. O índice de sucesso foi relacionado a diversos fatores: qualidade e quantidade óssea adequada, comprimento o mais longo quanto anatomicamente possível e exclusão dos pacientes com hábitos para-funcionais, já que foram descritos como fator de risco relacionado à fratura do implante e perda do parafuso de ouro, devido à incidência de forças excessivas. Os autores acreditam que a alta incidência de afrouxamento do parafuso de ouro (38\%), pode ser diminuída com a utilização do pilar ceraone.

Ainda no mesmo ano, HASS et $\mathbf{a}^{51}$ reportaram experiências de 76 restaurações unitárias suportadas por implantes Branemark, colocadas em 71 pacientes ( 35 mulheres e 36 homens). Os implantes foram restaurados com os pilares unitários originais (Nobelpharma AB), e com o pilar ceraone. Dois implantes $(2,63 \%)$ foram removidos durante todo o período, sendo relatado uma sobrevivência de $96,3 \%$ após 66 meses. A complicação protética mais comumente observada foi o afrouxamento do parafuso do pilar, o qual ocorreu em 12 restaurações, e foi observada em alguns meses após a instalação das restaurações; entretanto foi possível reduzir esta ocorrência de afrouxamento aplicando um torque definido. Parâmetros periimplantares foram investigados em 56 implantes que estavam instalados por mais de um ano, a função aceitável do implante foi demonstrada com parâmetros clínicos e radiográficos preestabelecidos, e apresentados os resultados durante seis anos. Parâmetros clínicos de índice de placa simplificado, índice gengival, profundidade de bolsa, mobilidade, também foram avaliados, permanecendo os mesmos estáveis depois de um ano. Os autores concluíram que com os resultados clínicos e estéticos obtidos que as restaurações unitárias suportadas por implantes podem ser recomendadas. 
ARBER; ZARB ${ }^{6}$, em 1996, relataram a efetividade clínica de restaurações unitárias suportadas por implantes no sistema Branemark. Trinta e oito pacientes com 42 implantes foram acompanhados, por um período de um a oito anos. As restaurações foram realizadas incluindo pilares "standards" antirrotacionais, angulados, e ceraone; com parafuso de ouro ou de titânio com cabeça hexagonal ou de fenda. Avaliações foram realizadas após a carga em uma semana, 6 e 12 meses, e anualmente até o último controle. Em cada avaliação as coroas foram removidas e cada implante foi avaliado clínica e radiográficamente; complicações protéticas também foram registradas. No último controle foi dado um questionário para avaliar o grau de satisfação do paciente com o tratamento; obtendo-se $94 \%$ de aceitação. Todos os implantes permaneceram estáveis, porém afrouxamento do parafuso da coroa ou do pilar foi a complicação protética mais comum, sendo que isto ocorreu com mais freqüência nos parafusos de titânio do pilar, quando estes foram trocados por parafusos de ouro e apertados com o controlador de torque Nobelpharma, essa ocorrência diminuiu. Fratura do parafuso de titânio do pilar ocorreu em dois pacientes, em outras cinco coroas ocorreu fratura da cerâmica.

Em um estudo comparativo de acompanhamento clínico, BALSHI et $\mathbf{a l}^{9}$, no mesmo ano, avaliaram 47 pacientes tratados com implantes Branemark para substituição da perda de um molar. Os pacientes foram divididos em dois grupos, sendo que 22 restaurações foram realizadas utilizando um implante grupo 1, e 25 com dois implantes grupo 2. Os implantes foram colocados seguindo os princípios cirúrgicos recomendados pela técnica Branemark e esperado o tempo de cicatrização de três a quatro meses na mandíbula e cinco a seis meses na maxila. Dos 72 implantes colocados 66 (92\%) foram na mandíbula, e 6 (8\%) na maxila. A seleção dos pacientes para colocar um ou dois implantes foi realizada baseada na largura interdental do espaço edêntulo. Pacientes com espaço maior a $12 \mathrm{~mm}$ dois implantes foram colocados, pacientes com espaço menor um implante foi utilizado. O material restaurativo utilizado foi porcelana fundida sobre ouro, e a função oclusal foi estabelecida utilizando contactos cêntricos firmes e pouca pressão nos 
movimentos excursivos. Esta condição foi controlada e ajustada se preciso, a cada seis meses. Em cada visita a mobilidade da prótese foi avaliada. Durante o primeiro ano de função um implante foi perdido, com uma percentagem de sucesso de 99\%; entre o segundo e terceiro ano nenhum implante foi perdido com $100 \%$ de sucesso. A mobilidade da prótese ou afrouxamento do parafuso foi a complicação mais freqüente $(48 \%)$ predominando no grupo 1 com restaurações suportadas por um implante; no grupo 2 onde as restaurações foram suportadas por dois implantes essa complicação foi substancialmente reduzida (8\%). Os problemas mecânicos das restaurações utilizando um implante foram diminuídos utilizando uma união mais forte com os pilares ceraone, sendo que todos os oito pilares deste tipo utilizados permaneceram estáveis; enquanto que todas as fraturas e afrouxamento ocorridos apareceram no pilar "standard" (Nobelpharma $A B$ ). Com os resultados deste estudo os autores sugerem que a terapia de substituir um molar utilizando implante pode ser efetiva, e confirmam que esta substituição proporciona maiores vantagens biomecânicas quando são utilizados dois implantes.

Estudando próteses fixas cimentadas suportadas por implantes osseointegrados, SINGER; SERFATY ${ }^{99}$ (1996) realizaram um estudo de avaliação clínica com 70 pacientes (41 mulheres e 29 homens), nos quais foram instaladas 92 próteses parciais fixas, incluindo próteses unitárias. Duzentos e vinte e cinco implantes foram colocados (86 na maxila e 139 na mandíbula) dos sistemas Spectra (Core Vent), Screw-Vent, Bio-Vent, Micro-Vent; e do sistema Integral e Integral-Omnilock (Calcitek). A maioria dos implantes foi de hexágono interno, nos quais pilares com sistema hexagonal foram adaptados aos implantes por um parafuso central, outros pilares foram tipo parafuso sem sistema hexagonal. Os pilares foram preparados da seguinte forma: (1) moldagem e obtenção de modelo de trabalho com os análogos, (2) preparo dos pilares com um adequado espaço interoclusal e conexidade de seis a oito graus, (3) prova do pilar intraoral e refinamento do preparo, se necessário, (4) moldagens convencionais para fabricação da restauração como se os pilares preparados fossem dentes naturais; 
e finalização da restauração, (5) cimentação que foi realizada com Temp Bond (Kerr) e IRM (Caulk / Densply). O cimento utilizado comumente foi o Temp Bond, sendo que o IRM foi utilizado nos casos de dissolução do cimento. As próteses foram avaliadas por um período de seis meses a três anos, com media de 16 meses. A complicação mais comum observada foi dissolução do cimento, a qual ocorreu em $9,8 \%$ das próteses parciais fixas, destas $6,7 \%$ ocorreram em próteses parciais fixas de três elementos, e 2,2\% em próteses unitárias. Estas complicações ocorreram no primeiro ano de instalação das próteses. Outras complicações foram, fratura da cerâmica $(2,2 \%)$, e mobilidade da restauração $(2,2 \%)$ causada por afrouxamento do parafuso central. Devido aos resultados obtidos, os autores acreditam que pela baixa percentagem de falha deste sistema, a reutilização da prótese quando ocorre dissolução do cimento, custo baixo, este sistema é uma alternativa as próteses parafusadas.

BALSHI et $\mathbf{a l}^{10}$, em 1997, em um estudo multicentro investigaram a sobrevivência de implantes osseointegrados (Nobel Biocare) quando conectados a pilares convencionais ou angulados; sendo observadas as alterações periimplantarias e protéticas, por um período de três anos. Sessenta e três próteses fixas maxilares e dez mandibulares foram colocadas em 71 pacientes, pilares angulados ou uma combinação de pilares convencionais e angulados foram utilizados para suportar as próteses. Dos 425 implantes colocados inicialmente quatro falharam antes da conexão com o pilar; dos 421 remanescentes 209 foram conectados a pilares angulados e 212 a pilares convencionais. Os pilares angulados utilizados no estudo foram de $30^{\circ} \mathrm{com}$ alturas máximas de $4 \mathrm{~mm}$ e mínima de $1,5 \mathrm{~mm}$. As 73 próteses fixas corresponderam a 44 próteses completas, 25 próteses parciais, duas próteses conectadas a implantes e dentes naturais, e duas próteses unitárias. Cinco e três por cento dos implantes com pilares angulados, e 7,5\% com pilares convencionais falharam. O sucesso das próteses foi de $96,8 \%$ na maxila e 100\% na mandíbula; sendo que as complicações encontradas no estudo incluíram fraturas do material oclusal em três pacientes, fratura da infra-estrutura em outros três pacientes, e 
após os três anos de estudo quatro parafusos do pilar precisaram ser reapertados em 3 pacientes. As avaliações das alterações periimplatarias indicaram que os pilares angulados não necessariamente promovem alterações. Os autores concluíram que o comportamento clínico dos pilares angulados pode ser comparado ao dos pilares convencionais como uma modalidade previsível na reabilitação protética.

Ainda no mesmo ano, LEVINE et $\mathbf{a l}^{70}$ avaliaram a sobrevivência de implantes ITI quando utilizados para restaurações unitárias. Compararam coroas cimentadas e parafusadas, observando as complicações protéticas associadas. Cento setenta e quatro implantes foram colocados em 129 pacientes, em 12 centros clínicos nos Estados Unidos. As restaurações estiveram em função por um mínimo de seis meses (média de 12 meses), e foram localizadas na região posterior (151 restaurações) e na região anterior (23 restaurações), sendo que 110 foram localizadas na mandíbula e 64 na maxila. Em 92 implantes foram colocadas restaurações parafusadas utilizando pilares "octabutment", e em 82 as restaurações colocadas foram cimentadas utilizando um pilar "solid conical abutment". Avaliação periodontal e complicações protéticas foram registradas. Um $97,7 \%$ de sobrevivência dos implantes foi observado em seis meses de carga. Afrouxamento do parafuso de retenção foi encontrado em oito de 92 implantes restaurados com coroas parafusadas $(8,7 \%)$; destes dois estavam colocados no setor anterior e seis no setor posterior. Em restaurações cimentadas, ocorreu afrouxamento de três pilares $(3,7 \%)$ colocados em um paciente no primeiro molar superior direito e esquerdo, e no primeiro molar mandibular esquerdo. $\mathrm{O}$ autor acredita que o desenho cônico interno com componente antirrotacional deste sistema unido a aplicação de um torque de $35 \mathrm{~N} . \mathrm{cm}$, oferece um comportamento mecanicamente favorável à interface durante as cargas funcionais; por isso a baixa incidência de afrouxamento do parafuso do pilar (3,6\%). No caso do parafuso oclusal onde um $8,7 \%$ de afrouxamento ocorreu, o autor sugere que a configuração cônica do pilar amortece o sistema da vibração e micromovimento durante a função, isto já que em nenhum caso o parafuso afrouxou em mais de 
uma vez, o que sugere que a força de aperto deve ser checada após a restauração estar em função.

NORTON ${ }^{88}$, também em 1997, realizou uma avaliação do sistema de implantes Astra Tech para restaurações de próteses unitárias, e apresentou componentes e um protocolo de tratamento que utiliza um desenho especifico em restaurações unitárias. O conceito fundamental deste sistema é baseado na utilização de uma interface implante / pilar com desenho cônico interno, e no caso de elementos unitários a esta característica é adicionada uma configuração de duplo hexágono interno que assegura anti-rotação. Trinta e nove destes implantes foram colocados em 37 pacientes, sendo 18 homens e 19 mulheres. A maioria destes colocados no setor anterior até o segundo pré-molar; 27 foram restaurados e acompanhados por período de quatro anos. Vinte e seis restaurações utilizaram o sistema cimentado, inicialmente um cimento fosfato de zinco foi utilizado, mais devido a falha do parafuso de duas coroas e dificuldade de reutilização das coroas um cimento provisório foi utili zado. Cem por cento dos implantes se mantiveram estáveis no tempo de acompanhamento, as complicações protéticas incluíram falhas do cimento de duas restaurações, e afrouxamento do parafuso do pilar em três situações, devido a isto em duas coroas tiveram que ser secionadas e refeitas já que o cimento definitivo não permitiu a reutilização das coroas. Devido a poucas complicações durante o acompanhamento, o autor acredita que este sistema de implante pode ser recomendado com eficácia para restauração de elementos unitários.

ARTZI; DREIANGEL ${ }^{7}$, em 1999, descreveram uma técnica para manter a estabilidade do parafuso de fixação da supra-estrutura protética, baseada no travamento de uma barra hexagonal, no hexágono da cabeça do parafuso. Para a realização da técnica foram utilizados os seguintes componentes: uma barra de titânio hexagonal, uma cinta de borracha, uma chave hexagonal de $1,27 \mathrm{~mm}$ e 0 parafuso de fixação. A barra adaptou-se precisa e firmemente dentro da parte fêmea do parafuso de fixação. Antes de o parafuso ser apertado, foi verificado se a supra-estrutura estava passivamente estabilizada no hexágono externo do 
implante. A prótese foi posicionada no implante e o parafuso apertado de acordo com o torque recomendado pelo fabricante. Uma radiografia periapical verificou esta posição, depois disto, a barra hexagonal foi inserida dentro do parafuso de fixação, e a cinta de borracha serviu como uma camada de isolamento; isto evitou que a resina composta penetra-se dentro da cabeça do parafuso. Após isto, aplicou-se resina composta que serviu como material de fixação da barra e também para vedar o orifício de abertura para acesso do parafuso, finalmente cortou-se a barra abaixo do nível oclusal da coroa. Os autores relataram uma avaliação de 120 restaurações unitárias parafusadas, colocadas em 100 pacientes, sendo que 75 destas restaurações foram colocadas na área de primeiro e segundo pré-molar, 40 na região do incisivo, e 15 na região posterior molar. Durante avaliações de seguimento mensais, foi encontrado que todas as restaurações estavam fixas em seu lugar, sendo que todas elas estavam funcionando com sucesso, especialmente as restaurações da região molar com planos oclusais extensos e grandes forças oclusais. Nenhum afrouxamento ou fratura do parafuso foi encontrado.

Em uma continuação do estudo retrospectivo de implantes unitários do sistema ITI iniciado em 1997, LEVINE et al $^{70}$ apresentaram os resultados de mais dois anos de seguimento clínico, comparando a sobrevivência de coroas cimentadas e parafusadas. Dos 174 implantes unitários colocados e avaliados inicialmente, 110 pacientes com 157 implantes se apresentaram para seguimento (media de 40.1 meses). Destes quatro implantes falharam devido a periimplantitis após seis ou mais meses, e outros três implantes falharam devido a fraturas, os mesmos colocados na área de primeiro molar mandibular após 40,3 meses, tendose uma sobrevivência de 95,5\%. Dos 157 implantes remanescentes 76 foram restaurados com coroas cimentadas e pilares cilíndricos, e 81 foram restaurados com coroas parafusadas com o pilar "octabutment". Os problemas restaurativos com pilares cilíndricos cônicos incluíram uma incidência de afrouxamento de 5,3\%. Apenas uma coroa unida a um pilar "octabutment" afrouxou após três anos; enquanto que 18 restaurações parafusadas $(22,2 \%)$ tiveram incidência de 
afrouxamento do parafuso de retenção; com estes dados os autores sugerem que o sistema de implantes ITI pode ser utilizado satisfatoriamente para restaurações unitárias do setor posterior da boca.

Em um estudo de dez anos de sobrevivência de implantes unitários, PRIEST $^{93}$ (1999) avaliou as complicações clínicas envolvendo as restaurações e o estado dos dentes adjacentes em 116 implantes. A sobrevivência foi avaliada desde a colocação do implante até o útimo exame. Radiografias e fotografias antes do tratamento foram utilizadas para determinar o estado dos dentes imediatamente adjacente ao espaço edêntulo. Noventa e nove pacientes receberam 112 restaurações unitária, sendo que 100 dos implantes restaurados 3i, 12 Nobel Biocare, 2 Steri-Oss, 1 Impla Med, e 1 Frialtec. O autor restaurou 107 implantes utilizando componentes $3 \mathrm{i}$, e os demais implantes foram restaurados utilizando componentes do fabricante do implante. Componentes diretos e pilares tipo UCLA, foram os mais utilizados; nos parafusos de ouro do pilar foi aplicado um torque de $32 \mathrm{~N} . \mathrm{cm}$, sendo que a restauração parafusada a mais utilizada. 109 restaurações foram metalocerâmicas e três totalcerâmicas. Oitenta e três implantes foram colocados na maxila e 33 na mandíbula, dos quais 62 implantes foram no setor anterior e 54 no setor posterior. Três implantes falharam em manter a integração tendo-se uma sobrevivência de 97,4\%. A complicação protética mais comum foi a de afrouxamento dos parafusos, que ocorreu em 7,1\% das restaurações. Dissolução do cimento em restaurações cimentadas ocorreu em $5,4 \%$. Duas restaurações foram perdidas $(1,8 \%)$, uma por perda do implante e outra por fratura do parafuso do pilar. Fratura da cerâmica foi encontrada em uma restauração $(0,9)$. Todas as complicações protéticas foram encontradas em 17 pacientes (18,8\%). Enquanto aos dentes adjacentes à restauração do implante unitário, 79,6\% permaneceram intactos ou minimamente restaurados.

SHOLANDER $^{97}$ (1999) realizou um estudo de avaliação clínica de restaurações unitárias suportadas por implantes do sistema Branemark. Duzentos e cinqüenta e nove restaurações colocadas em 183 pacientes com média de 29,8 
anos de idade, e colocadas na maxila (89\%) e na mandíbula (11\%), foram avaliadas durante um período de um a cinco anos. Em 208 restaurações (81\%), foram utilizados pilares ceraone, e em 48 (29\%) pilares unitários DCA 085-189; destas 175 foram restaurações totalcerâmicas (68\%), 79 metalocerâmicas $(30,5 \%)$, e quatro metaloplástica (1,5\%). Avaliações clínicas de estabilidade do implante, estética, oclusão, e complicações cirúrgicas e protéticas foram registradas. $98,5 \%$ das restaurações permaneceram em função depois de cinco anos de carga. A complicação mais comum foi o afrouxamento do parafuso, que ocorreu em dez restaurações (3,9\%), sendo que o afrouxamento só ocorreu em duas restaurações onde foram utilizados pilares ceraone, o autor acredita este tipo de pilar diminui o índice de afrouxamento. Outras oito coroas tiveram que ser refeitas devi do a complicações protéticas, enquanto que as condições dos tecidos a redor das restaurações mostraram-se saudável quando comparadas aos dentes adjacentes.

KRENNMAIR; SCHMIDINGER; WALDENBERGER ${ }^{64}$, em 2002, realizaram análises clínicas de 146 implantes Frialt-2 para substituição de elementos unitários. Cento e doze pacientes (67 mulheres e 45 homens) receberam um total de 84 implantes na maxila e 62 na mandíbula, localizados em todas as áreas da cavidade bucal, sendo os sítios mais freqüentes nos dentes anteriores maxilares (38), assim como pré-molares e molares mandibulares (57). Noventa e três restaurações foram cimentadas, utilizando-se um cimento provisório (Temp Bond / Kerr) e 53 parafusadas a pilares convencionais. Avaliação foi realizada por um período de 3 a 84 meses, com média de seguimento de 35,8 meses, todos os pacientes incluídos no estudo foram avaliados a cada três meses no primeiro ano, e com intervalo de seis meses após o primeiro ano. Sobrevivência dos implantes assim como incidência e complicações protéticas foram registradas. Dois implantes $(1,4 \%)$ foram perdidos, um durante os primeiros três meses de aplicação da carga, e outro após seis anos; uma sobrevivência de 97,3\%. A complicação protética mais freqüente foi a necessidade de recimentação de nove coroas $(9,9 \%)$, e a substituição de quatro coroas $(2,8 \%)$ devido à fratura da 
cerâmica. Em nenhum caso foi encontrado afrouxamento do parafuso de fixação do pilar, porém em quatro casos $(3,5 \%)$ de parafusos horizontais foi encontrado afrouxamento do pilar. Com os resultados obtidos neste estudo os autores acreditam que a baixa percentagem de afrouxamento dos parafusos é devido à conexão hexagonal interna deste sistema que se estende $5,5 \mathrm{~mm}$ dentro do implante o que aumenta a resistência da conexão quando comparada com outros sistemas.

GIBBARD; ZARB ${ }^{44}$, no mesmo ano, apresentaram a continuação do estudo de avaliação longitudinal realizado por ARBER, ZARB ${ }^{6}$, em 1996, em implantes unitários após cinco anos de função. A amostra do estudo original consistiu de 42 pacientes tratados com 49 implantes unitários do sistema Branemark. Neste estudo, 24 pacientes com 30 implantes dos originalmente tratados foram avaliados clinica e radiograficamente; a estética também foi avaliada por assistente dental, estudantes e dentistas. Todos os 30 implantes avaliados permaneceram estáveis, sendo que nenhum dos implantes foi associado à fístula ou mobilidade. Afrouxamento do parafuso de ouro foi encontrado em $13 \%$ das coroas, mas em nenhum dos parafusos dos pilares foi observado afrouxamento. Radiográficamente foi observada uma média de perda óssea anual de 0,2mm, e os pacientes avaliaram sas próteses como satisfatórias.

Em uma análise clínica de implantes ITI colocados e restaurados por periodontistas e protesistas, LEVINE et al ${ }^{71}$ (2002), avaliaram a sobrevivência de 675 restaurações unitárias no setor posterior suportadas por implantes, e compararam restaurações cimentadas e parafusadas. Quatrocentos e setenta e um pacientes (292 mulheres e 179 homens) receberam os implantes colocados na região posterior da boca, sendo 370 no molar superior, 126 pré-molar inferior, 108 pré-molar superior, e 71 molar superior, dos quais 615 implantes foram de $4,1 \mathrm{~mm}$ de diâmetro e 60 de 4,8mm. Em 600 dos implantes integrados foram realizadas restaurações cimentadas, e em 71 parafusadas. O tempo de acompanhamento após a carga dos implantes foi de 1 a 78 meses, média de 18 meses. Durante 0 
período de investigação os resultados mostraram 99,1\% de sobrevivência com $98,4 \%$ na mandíbula e $100 \%$ na maxila. As complicações com as coroas cimentadas incluíram 0,3\% de afrouxamento do parafuso (dois pacientes); 0,5\% das coroas tiveram que ser substituídas devido a fratura do pilar (três pacientes); 0,6\% re-cimentadas devido a afrouxamento por dissolução do cimento; duas coroas tiveram que ser refeita por fratura da cerâmica. As complicações associadas às coroas parafusadas incluíram 16,9\% de afrouxamento dos parafusos de retenção das coroas (12 pacientes); 1,4\% dos parafusos afrouxou varias vezes (um paciente), em um paciente que tinha uma coroa parafusada utilizando conexão direta do implante, o parafuso afrouxou (1,4\%). Em todos os pacientes onde foram instaladas coroas parafusadas ao pilar um retorque de $20 \mathrm{~N} . \mathrm{cm}$ foi aplicado, e na conexão parafusada ao implante $35 \mathrm{~N} . \mathrm{cm}$. Concluíram que os mínimos problemas restaurativos das coroas cimentadas $(98,2 \%)$ e parafusadas $(80,3 \%)$ sugerem que os implantes ITI podem ser utilizados satisfatoriamente para substituir restaurações unitárias do setor posterior da boca. 


\section{3- PROPOSIÇÃO}




\section{PROPOSIÇÃO}

Considerando que a estabilidade da interface implante / pilar influencia no sucesso longitudinal das restaurações protéticas de elementos unitários sobre implantes osseointegrados, o presente trabalho propôs:

1- Determinar se existem diferenças nas medidas das bases de assentamento e do hexágono / octágono dos implantes e pilares;

2- Examinar as dimensões dos parafusos dos sistemas de conexão externa e interna avaliados;

3- Avaliar o destorque dos parafusos de sistemas de conexão externa e interna em relação à condição inicial de torque de $30 \mathrm{~N} . \mathrm{cm}$;

4- Analisar a desadaptação vertical dos implantes conectados aos seus respectivos pilares antes e a após aplicação de uma carga de fadiga de 500.000 ciclos;

5- Determinar o destorque dos parafusos de fixação após a aplicação de uma carga de 500.000 ciclos;

6- Determinar a possível correlação entre as variáveis: dimensões dos componentes, adaptação da interface, cargas cíclicas e torque aplicado. 


\section{4- MATERIAL E MÉTODOS}




\section{MATERIAL E MÉTODOS}

\section{1: Seleção da amostra}

Para a constituição da amostra deste trabalho, estabeleceu-se o requisito de que deveriam ser selecionados sistemas com conexão externa e interna. A seleção dos sistemas de implantes e seus componentes foi realizada através da solicitação direta ao fabricante ou seu representante. Três empresas fabricantes de implantes atenderam nossa solicitação de cessão do material; os sistemas nacionais: Conexão e Emfils; e um estrangeiro Pressing Dental / Itália.

\section{2: Material}

O material utilizado neste trabalho é descrito na tabela 4.2.1. 
TABELA 4.2.1: Material utilizado:

\begin{tabular}{|c|c|c|c|}
\hline Material & Nome comercial & Composição & Fabricante \\
\hline Implantes conexão & Master screw & Titânio & Conexão Brasil \\
\hline \multirow[t]{2}{*}{ Implantes Enfils } & \multirow[t]{2}{*}{ Implantes colosso } & \multirow[t]{2}{*}{ Titânio } & Emfils / Brasil \\
\hline & & & Lote no 010209 \\
\hline Implantes TMI & Implante TMI & Titânio & $\begin{array}{c}\text { Pressing Dental / } \\
\text { Italia }\end{array}$ \\
\hline $\begin{array}{l}\text { Pilar UCLA base } \\
\text { Paládio Prata }\end{array}$ & Pilar UCLA & Paládio Prata & Conexão / Brasil \\
\hline Pilar ceraone & Pilar ceraone & Titânio & Conexão / Brasil \\
\hline Pilar reto & $\begin{array}{c}\text { Pilar adaptável de } \\
\text { titânio }\end{array}$ & Titânio & Emfils / Brasil \\
\hline Pilar de titânio & $\begin{array}{c}\text { Pilar pré-fabricado } \\
\text { de titânio }\end{array}$ & Titânio & $\begin{array}{l}\text { Pressing Dental / } \\
\text { Itália }\end{array}$ \\
\hline Liga metálica & Litecast B & Nickel Cromo & Williams / USA \\
\hline \multirow[t]{2}{*}{ Liga metálica } & \multirow[t]{2}{*}{ Pors-on 4} & Paládio -Prata & Degussa / \\
\hline & & $\begin{array}{c}(\mathrm{Pd}-57,8 \%, \mathrm{Ag}- \\
30 \%)\end{array}$ & Alemanha \\
\hline \multirow[t]{2}{*}{ Espaçador } & Adapt - Rite & & \multirow[t]{2}{*}{ Dentifax / USA } \\
\hline & Silver gold & & \\
\hline Cera para fundição & Cera P.K. opaque & & Kota / Brasil \\
\hline Revestimento & Heat Shock & & Polidental / Brasil \\
\hline $\begin{array}{c}\text { Resina acrílica } \\
\text { autopolimerizável }\end{array}$ & $\begin{array}{c}\text { Acrílico } \\
\text { autopolimerizante }\end{array}$ & & $\begin{array}{l}\text { Artigos } \\
\text { odontológicos } \\
\text { Clássico }\end{array}$ \\
\hline \multirow{3}{*}{$\begin{array}{l}\text { Cimento Fosfato de } \\
\text { zinco }\end{array}$} & Hy Bond & & Shofu / Japan \\
\hline & Zinc Phosphate & & Lote $n^{\circ} 0200$ \\
\hline & Cement & & \\
\hline
\end{tabular}




\section{3: MÉTODOS}

\subsection{1: Divisão dos corpos de prova}

Para a realização deste trabalho, os implantes e pilares (Figuras 4.3.1, 4.3.2) foram divididos em cinco grupos de dez corpos de provas, dependendo da marca comercial, do tipo de pilar e do sistema a ser testado, como mostra a tabela 4.3.1.

TABELA 4.3.1: Composição dos grupos de corpos de provas testados.

\begin{tabular}{|c|c|c|c|c|c|}
\hline Grupo & Implante & Conexão & Dimensões & Pilar / parafuso & Sistema \\
\hline \multirow[t]{2}{*}{ I } & \multirow{2}{*}{$\begin{array}{l}\text { Master screw } \\
\text { / Conexão }\end{array}$} & \multirow{2}{*}{$\begin{array}{l}\text { Hexágono } \\
\text { externo }\end{array}$} & \multirow{2}{*}{$\begin{array}{c}13 \times 3,75 \\
\mathrm{~mm}\end{array}$} & Pilar UCLA & \multirow[t]{2}{*}{ Cimentado } \\
\hline & & & & Parafuso Ti & \\
\hline II & $\begin{array}{l}\text { Colosso / } \\
\text { Emfils }\end{array}$ & $\begin{array}{l}\text { Hexágono } \\
\text { interno }\end{array}$ & $\begin{array}{c}13 \times 4,0 \\
\mathrm{~mm}\end{array}$ & $\begin{array}{l}\text { Pilar pré-fabricado } \\
\text { e parafuso } \mathrm{Ti}\end{array}$ & Cimentado \\
\hline III & $\begin{array}{l}\text { TMl / Pressing } \\
\text { Dental }\end{array}$ & $\begin{array}{l}\text { Octágono } \\
\text { interno }\end{array}$ & $\begin{array}{c}13 \times 3,7 \\
\mathrm{~mm}\end{array}$ & $\begin{array}{c}\text { Pilar pré-fabricado } \\
\text { e parafuso } \mathrm{Ti}\end{array}$ & Cimentado \\
\hline \multirow[t]{2}{*}{ IV } & \multirow{2}{*}{$\begin{array}{l}\text { Master Screw } \\
\text { / Conexão }\end{array}$} & \multirow{2}{*}{$\begin{array}{l}\text { Hexágono } \\
\text { externo }\end{array}$} & \multirow{2}{*}{$\begin{array}{c}13 \times 3,75 \\
\mathrm{~mm}\end{array}$} & Pilar UCLA & \multirow[t]{2}{*}{ Parafusadc } \\
\hline & & & & Parafuso $\mathrm{Ti}$ & \\
\hline V & $\begin{array}{l}\text { Master Screw } \\
\text { / Conexão }\end{array}$ & $\begin{array}{l}\text { Hexágono } \\
\text { externo }\end{array}$ & $\begin{array}{c}13 \times 3,75 \\
\mathrm{~mm}\end{array}$ & $\begin{array}{c}\text { Pilar ceraone } \\
\text { Parafuso } \mathrm{Ti}\end{array}$ & Cimentado \\
\hline
\end{tabular}




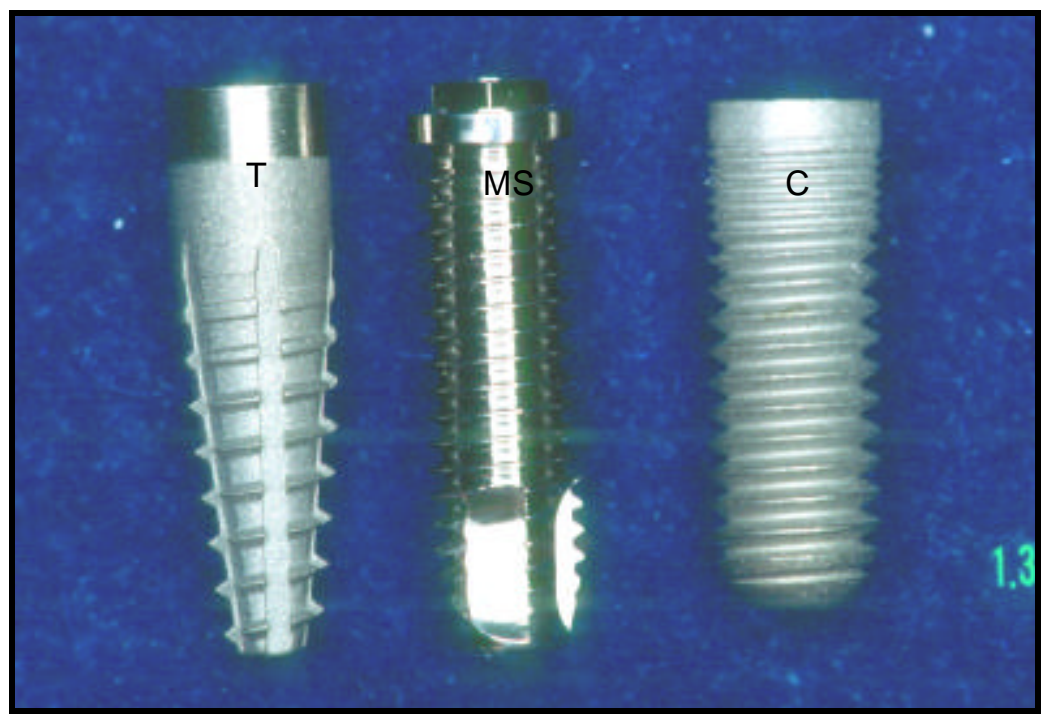

Figura 4.3.1: Implantes TMI (T), master screw (MS), colosso (C)

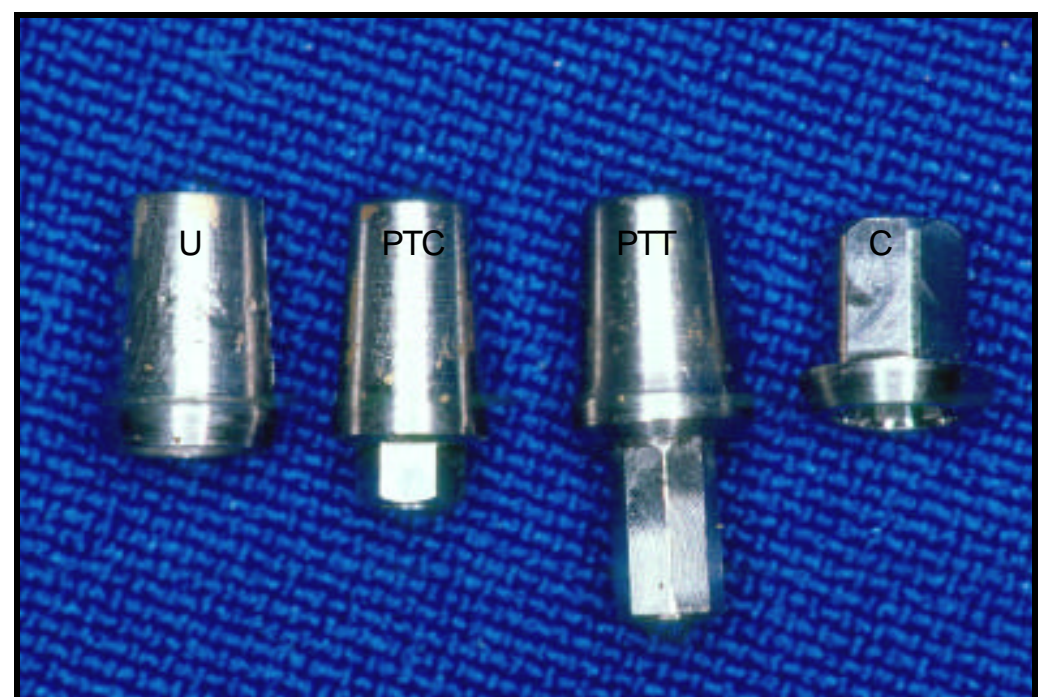

Figura 4.3.2: Pilares UCLA (U), pré-fabricado de titanio colosso (PTC), préfabricado de titânio TMI (PTT), ceraone (C) 


\subsection{2: Medida dos componentes}

Inicialmente foram realizadas medidas das dimensões das bases de assentamento do implante e do pilar, assim como das medidas dimensionais dos parafusos. Todas as medidas foram realizadas com a utilização de um paquímetro digital Mitutoyo / Japan código 500-171, modelo CD6-C, serie 0112103, com uma precisão de 0,01 mm (FIGURA 4.3.3).

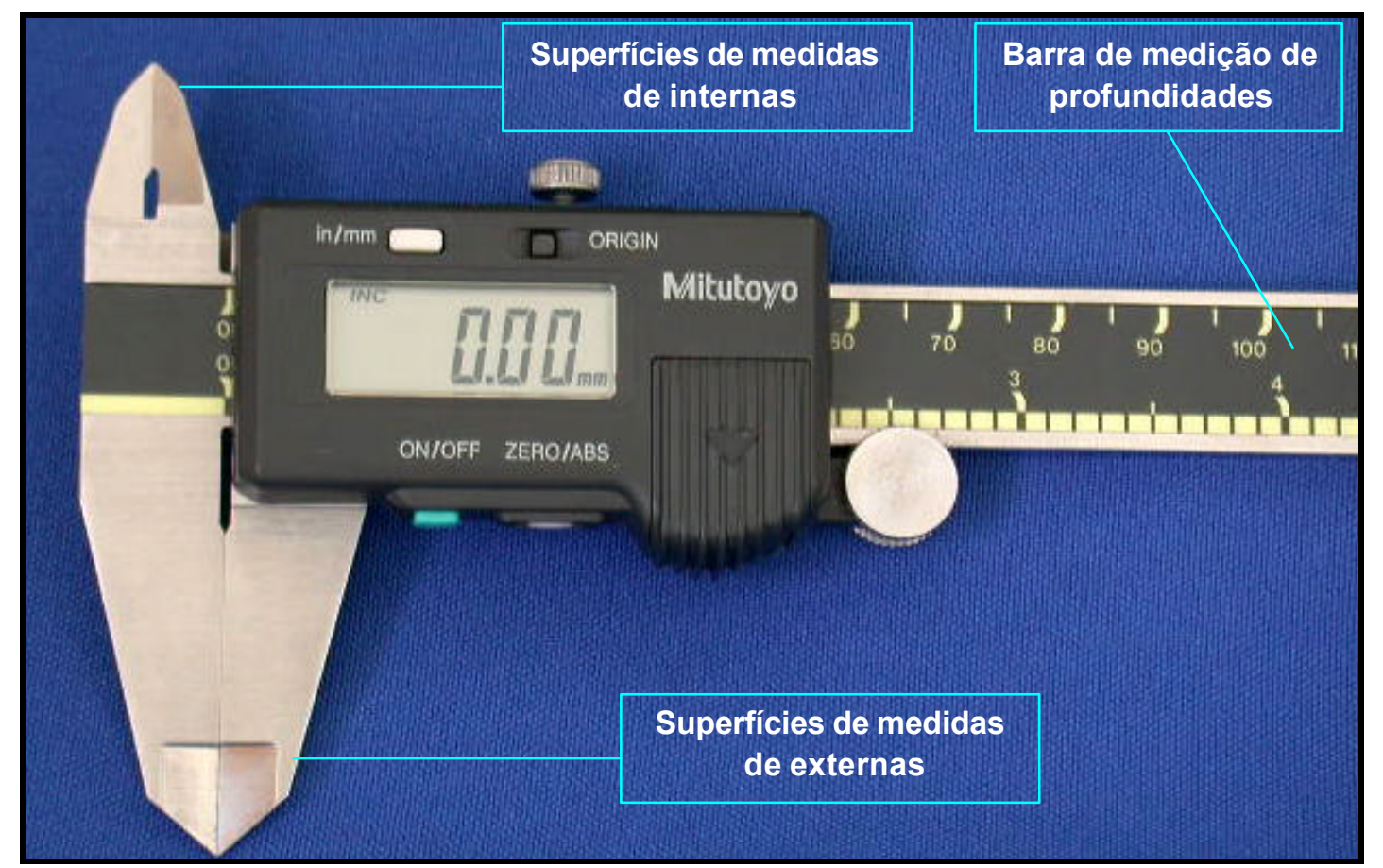

Figura 4.3.3: Paquímetro digital (Mitutoyo / Japan código 500-171, modelo CD6-C, serie 0112103)

\subsubsection{1: Diâmetro da base de assentamento dos implantes}

Para a obtenção desta medida, o paquímetro foi colocado em uma posição perpendicular ao eixo do implante, fechando-se as superfícies de medidas externas do paquímetro até as duas pontas estarem em contato na porção mais externa da base do implante, em um ponto aleatório (Figuras 4.3.4, e 4.3.5). 


\subsubsection{Diâmetro do sextavado / octágono dos implantes}

Nos casos de implantes com hexágono externo $(\mathrm{HE})$, foram realizadas as medidas nas três faces opostas do sextavado, com as superfícies de medidas externas do paquímetro, totalizando-se três medidas para cada implante. Nos implantes com hexágono interno $(\mathrm{HI})$, também foram realizadas três medidas das faces opostas do sextavado interno; e nos implantes com octágono interno (OI) foram obtidas quatro medidas das faces opostas do octágono (Figuras 4.3.4, e 4.3.5). Para os implantes com hexágono e octágono interno as medidas foram realizadas com as superfícies para medidas internas do paquímetro; em cada implante obteve-se uma média das três (implantes de HE) ou quatro (implantes de OI) medidas, sendo isto denominado média do diâmetro do sextavado / octágono do implante.

\subsubsection{3: Altura do sextavado / octágono dos implantes}

Para a obtenção desta medida, foi utilizada a barra para medição de profundidades do paquímetro, medindo-se desde a parte mais superior até a base do sextavado, esta medida foi realizada em três pontos e obtida uma média dos mesmos (Figuras 4.3.4). Nos implantes de $\mathrm{HI}$ e Ol, esta medida foi realizada no pilar, sendo esta denominada altura do sextavado / octágono do implante.

\subsubsection{4: Diâmetro da base de assentamento dos pilares}

Para a obtenção desta medida, foram utilizadas as superfícies para medidas externas do paquímetro, sendo realizada uma medida em um ponto aleatório do pilar.

\subsubsection{5: Diâmetro do hexágono / octágono interno ou externo dos pilares}

Para a obtenção desta medida, foram utilizadas as superfícies para medidas internas do paquímetro, sendo que foram realizadas três medidas nas faces opostas do hexágono (pilares com HI). Nos pilares com HE, foram realizadas três medidas nas faces opostas do hexágono e nos pilares com octágono externo (OE) foram realizadas quatro medidas como descrito 
anteriormente, utilizando-se as superfícies para medidas de externas do paquímetro.

\subsubsection{6: Altura do sextavado / octágono dos pilares}

Para obtenção desta medida foi utilizada a barra para medição de profundidades do paquímetro, sendo realizada a medição desde a parte superior até a base do sextavado, esta medição foi feita em três pontos. No caso de pilares com HI não foi realizada esta medida.

\subsubsection{7: Comprimento dos parafusos}

Foi medido desde a superfície superior da cabeça dos parafusos até a ponta oposta utilizando-se as superfícies para medidas externas do paquímetro (Figura 4.3.6).

\subsubsection{8: Extensão das roscas dos parafusos}

Foi medido desde o inicio do primeiro passo da rosca até o fim do último passo da rosca, utilizando-se as superfícies para medidas externas do paquímetro (Figura 4.3.6).

\subsubsection{9: Diâmetro das roscas dos parafusos}

Com as superfícies para medidas externas do paquímetro, foi medido o diâmetro das roscas dos parafusos, fechando-se o paquímetro nas roscas do parafuso em um ponto aleatório (Figura 4.3.6). 


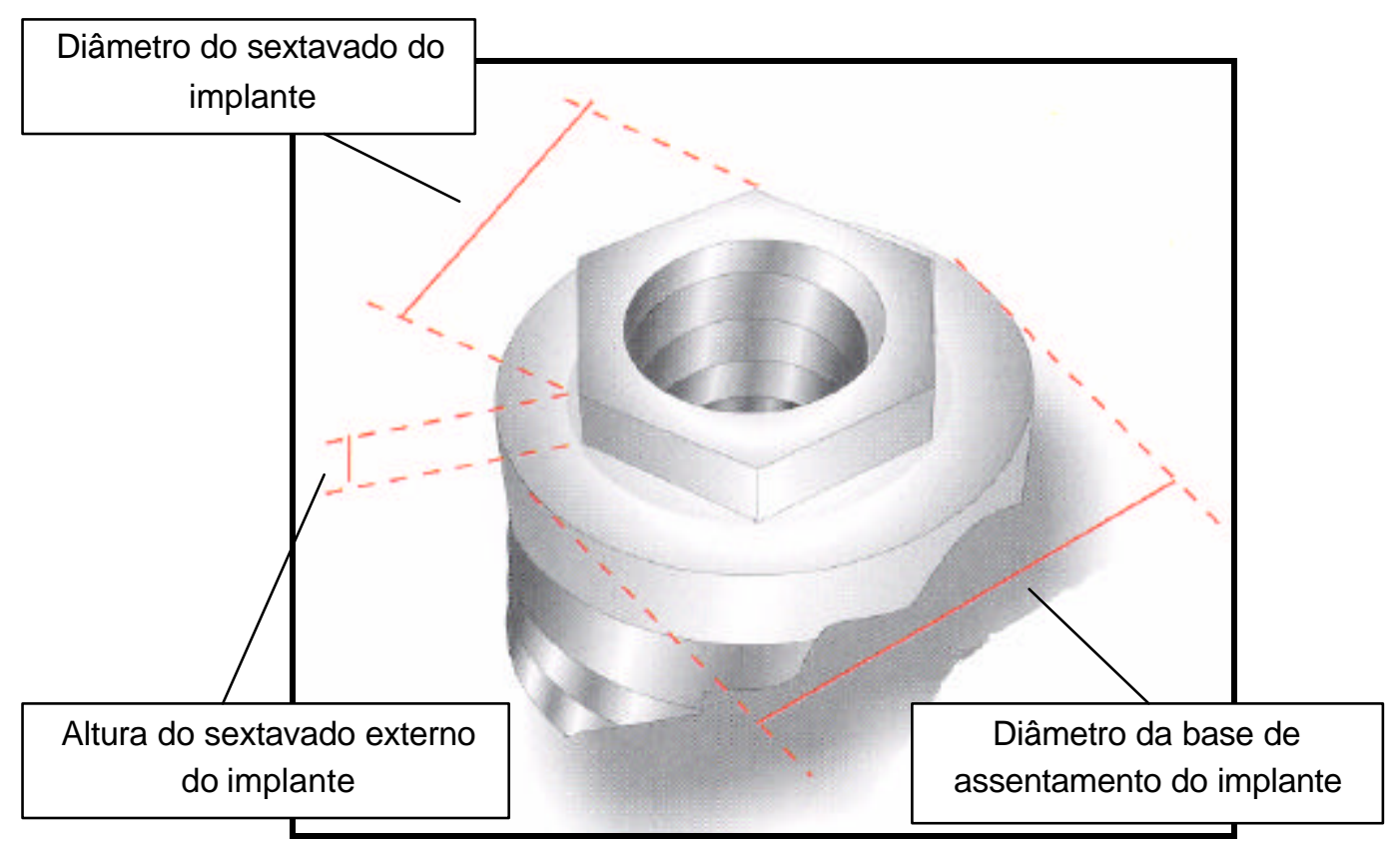

Figura 4.3.4: Desenho esquemático de implante de hexágono externo e suas medidas obtidas.

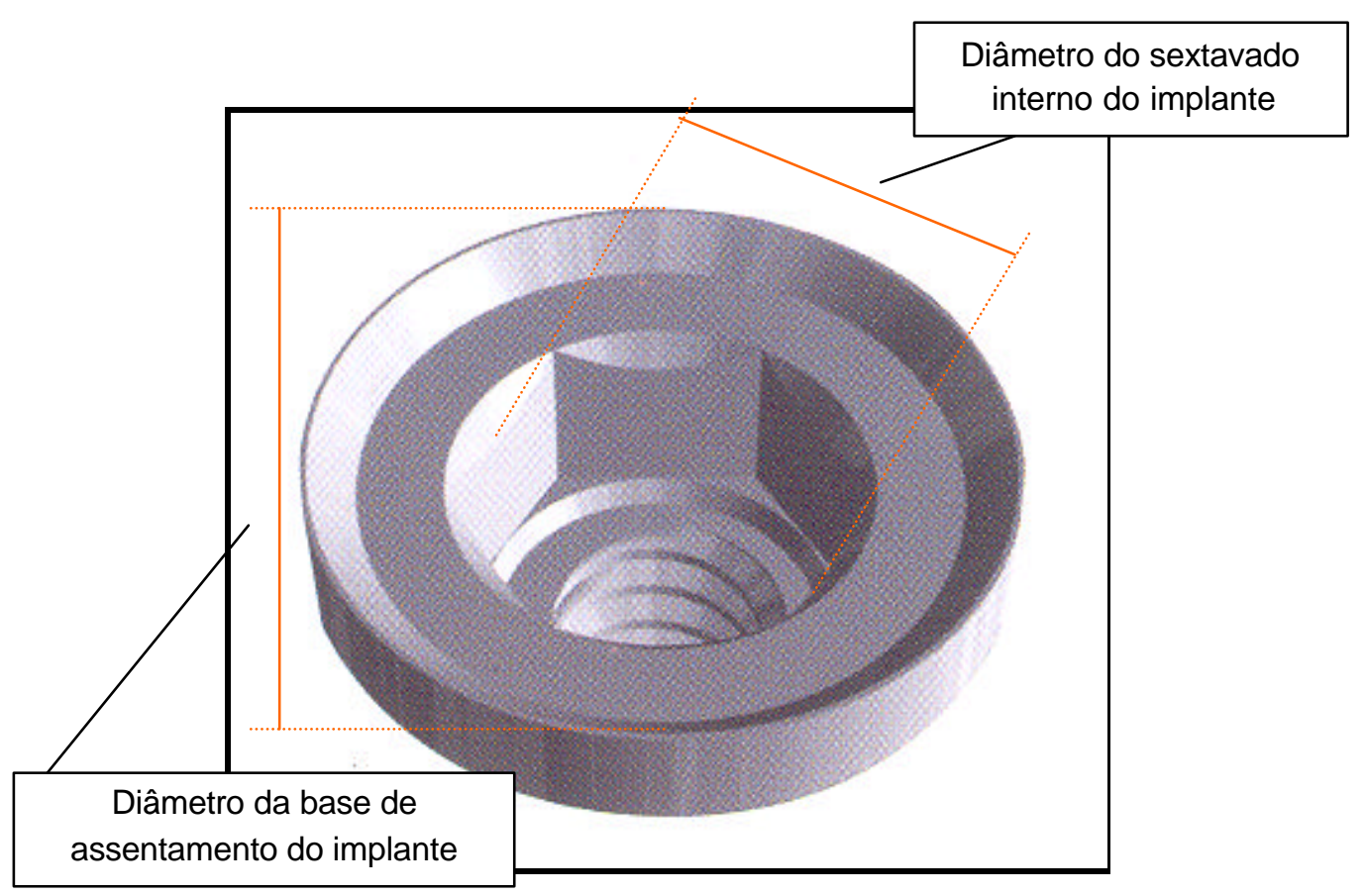

Figura 4.3.5: Desenho esquemático de implante de hexágono interno e suas medidas obtidas. 


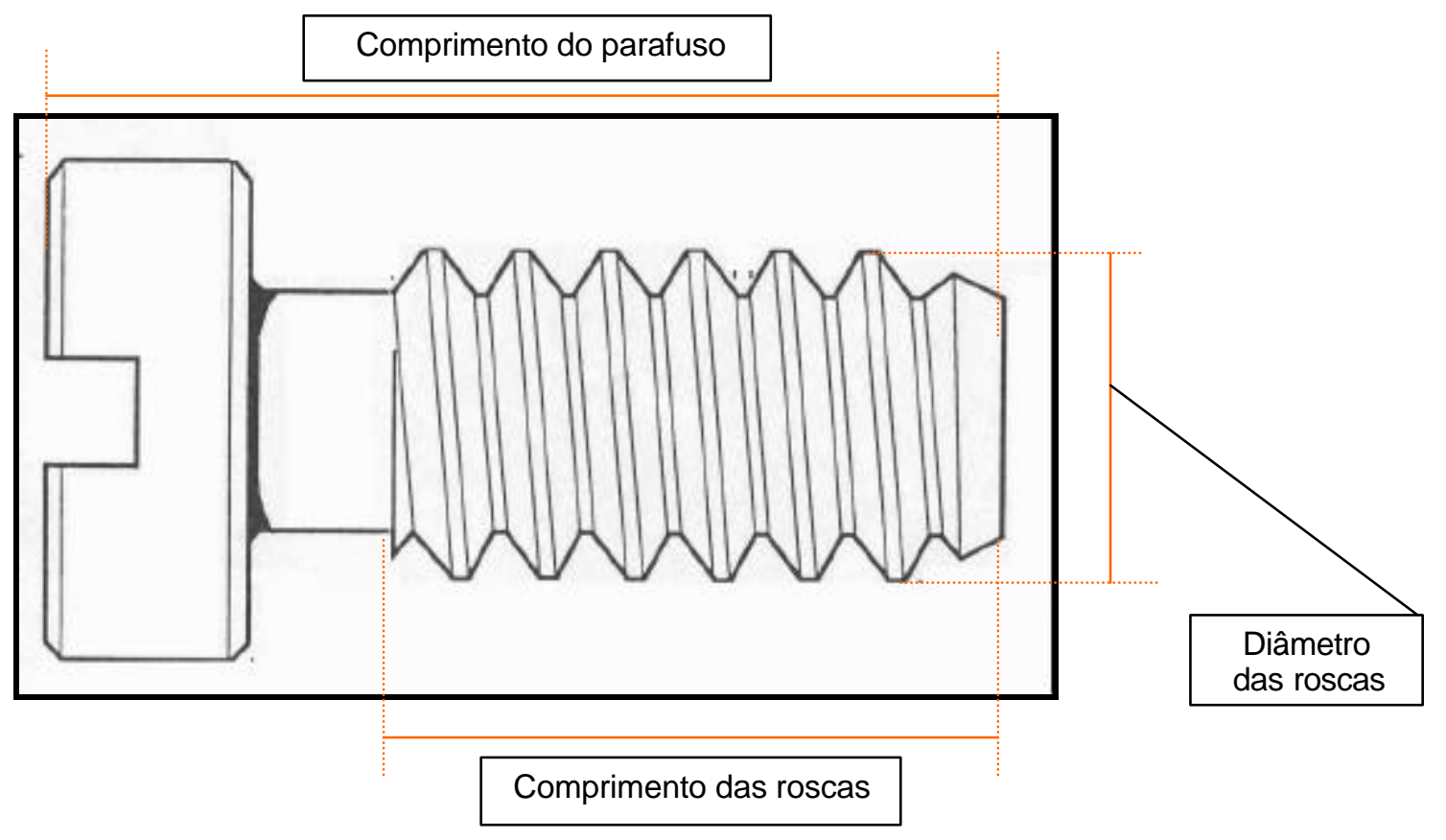

Figura 4.3.6: Desenho esquemático de um dos parafusos de fixação determinando suas áreas de medidas

\section{4: Obtenção dos corpos de prova}

\subsection{1: Fixação dos implantes}

$\mathrm{Na}$ obtenção dos corpos de prova, os implantes foram fixados em um bloco de resina acrílica autopolimerizável de $16 \mathrm{~mm}$ de altura por $21 \mathrm{~mm}$ de largura, utilizando um dispositivo metálico que permitiu a colocação do implante no centro do bloco de resina acrílica e em um eixo vertical.

\subsection{2: Descrição do dispositivo}

O dispositivo consta de três partes sendo elas encaixadas perfeitamente entre si, permitindo desta forma fixar o implante no correto espaço geométrico no formato hexagonal da base da resina acrílica (Figuras 4.4.1 A e B). 

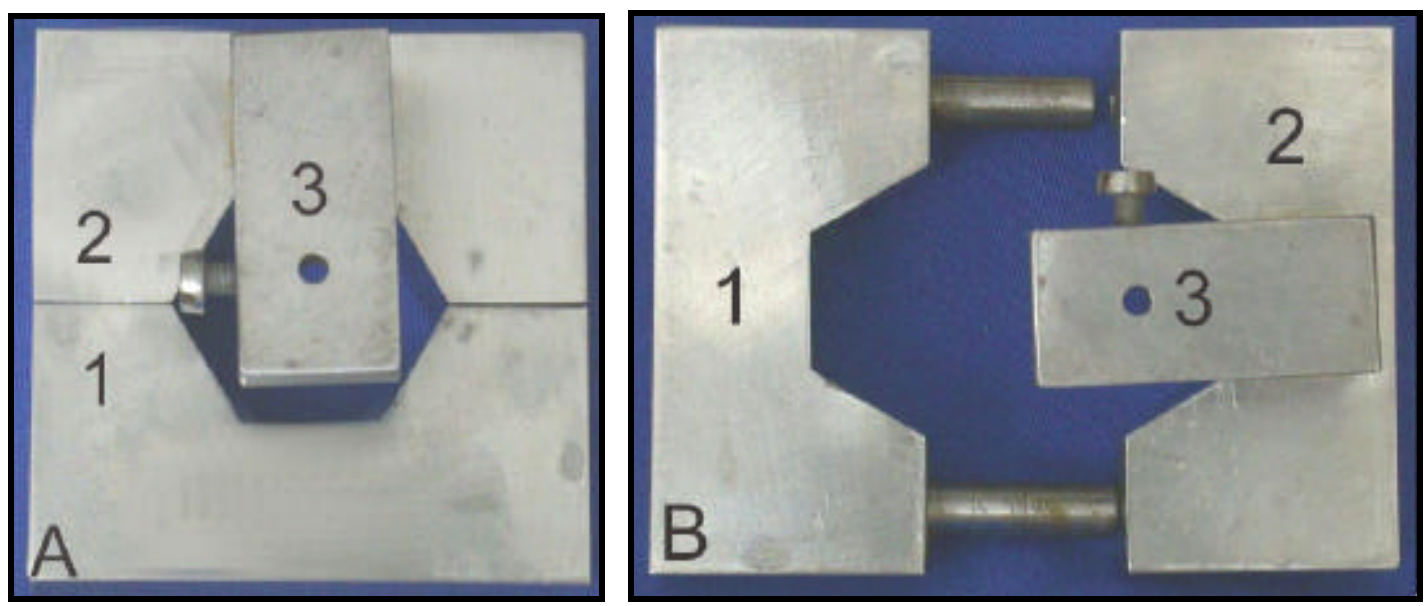

Figuras 4.4.1 A e B: Dispositivo metálico para fixação dos implantes em posição vertical e inclusão em blocos de resina acrílica autopolimerizável, partes 1, 2, e 3.

Para a fixação, o implante foi posicionado no dispositivo com o auxílio de um parafuso de componente de moldagem o qual foi parafusado no implante e no dispositivo, isto permitiu que o implante fosse colocado em uma posição totalmente vertical. Depois de fixadas, as duas partes do dispositivo foram unidas e o espaço foi preenchido com resina acrílica autopolimerizável (Figuras 4.4.2 A e B). A forma hexagonal do bloco foi realizada com o objetivo de obter seis faces que serviriam de base para as leituras de adaptação vertical. A fixação dos implantes foi realizada, deixando-se a base do implante com $2 \mathrm{~mm}$ de exposição (Figura 4.4.2 A e B, 4.4.3). 

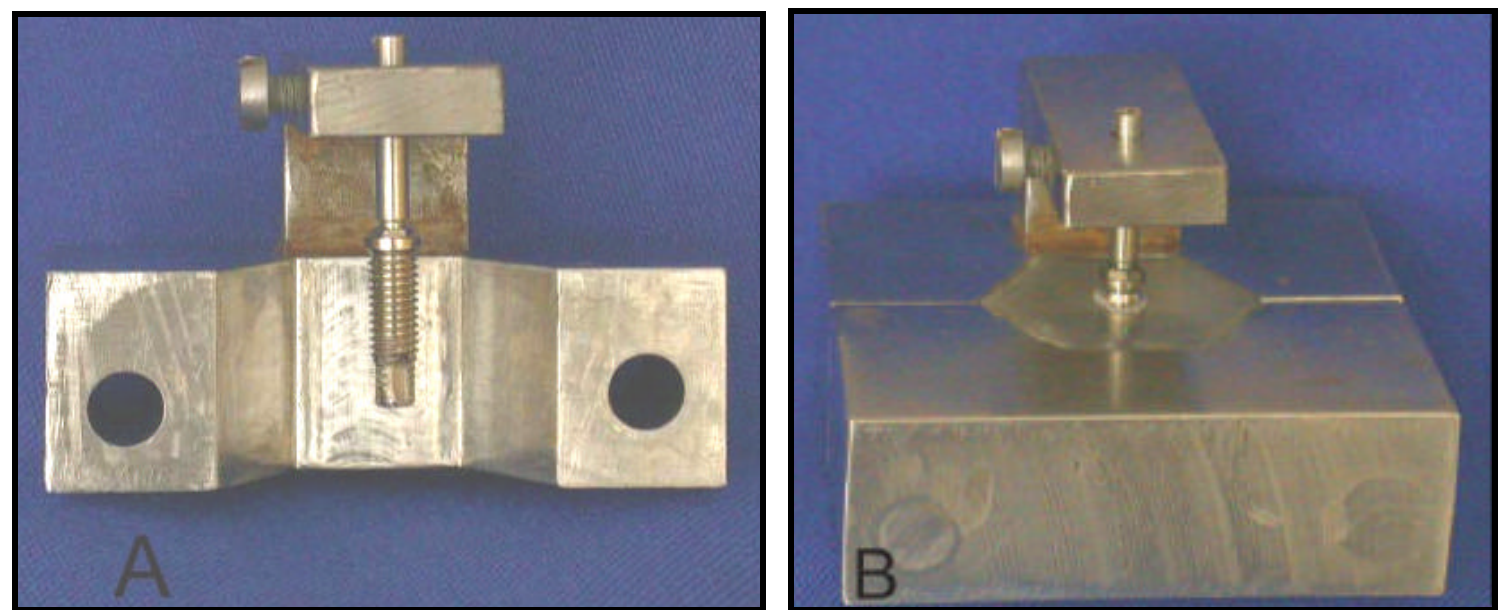

Figuras 4.4.2 A e B: Implante de hexágono externo fixado no dispositivo metálico; e as partes do dispositivo unidas e o espaço preenchido com resina acrílica autopolimerizável.

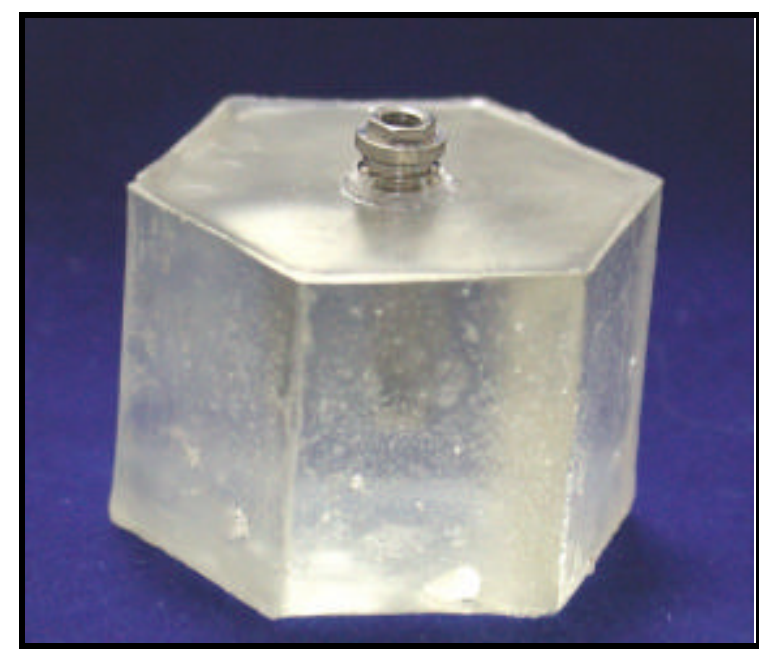

Figura 4.4.3: Implante de hexágono externo fixado em bloco de resina acrílica com forma hexagonal e com exposição de $2 \mathrm{~mm}$ da base de assentamento do implante. 


\subsection{3: Obtenção do pilar e a parte coronária}

\subsubsection{1: Grupo I (UCLA cimentado)}

Os corpos de provas deste grupo foram constituídos de implantes de $\mathrm{HE} \mathrm{e}$ pilares UCLA com liga paládio prata. Estes pilares foram cortados numa altura de $8 \mathrm{~mm}$ e fundidos com liga metálica de paládio prata (Pors-on 4 - Degusa Dental / Alemanha). Depois de fundidos os pilares foram torneados, numa altur a de $6 \mathrm{~mm}$ e com uma inclinação de quatro graus, iniciando-se a $1 \mathrm{~mm}$ da base de assentamento. $O$ torneamento foi realizado em conjunto com os pilares dos grupos II, e III, com o objetivo de padronizar altura, largura e a inclinação das paredes do pilar (Figura 4.4.4 A). Sobre o pilar foram aplicadas duas camadas de espaçador (Adapt - Rite, Silver Gold Dentifax / USA), e depois realizado um enceramento (utilizando-se cera para fundição P.K. opaque, Kota / Brasil) de uma coroa, na forma de um pré-molar sem cúspides, com uma altura desde a base do pilar até a altura oclusal de $8 \mathrm{~mm}$ e um diâmetro na superfície oclusal de $8 \mathrm{~mm}$ (Figura 4.4.4 B), seguindo a metodologia utilizada por BINON20. Para padronizar o enceramento nas dimensões antes mencionadas foi utilizado um paquímetro digital na determinação das medidas, com o qual foi possível obter corpos de provas com dimensões similares. Para a fundição do enceramento foi utilizada uma liga metálica de Nickel Cromo (Litecast B Will-Ceram / USA); e o processo de fundição realizada seguindo as especificações da liga utilizada. 

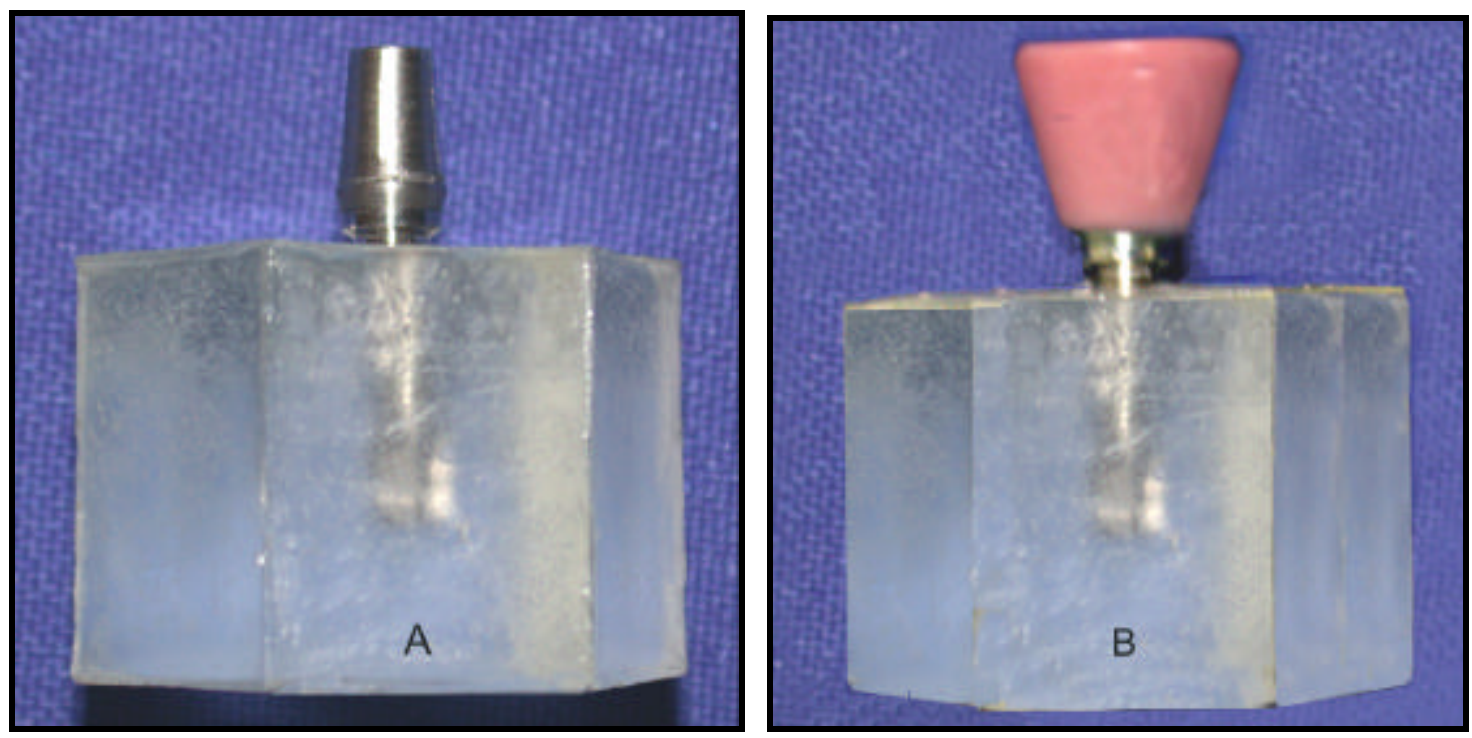

Figuras 4.4.4 A e B: Implante com pilar UCLA torneado e enceramento realizado.

\subsubsection{2: Grupo II (Emfils cimentado)}

Os corpos de prova deste grupo foram constituídos de implantes com $\mathrm{HI}$ e pilares pré-fabricados em Titânio. Os pilares foram torneados com as mesmas características do grupo anterior e o enceramento e a fundição da parte coronária realizada com as mesmas dimensões do grupo I, utilizando-se para a fundição a mesma liga metálica dos corpos de provas do grupo I.

\subsubsection{3: Grupo III (TMI cimentado)}

Os corpos de provas deste grupo foram constituídos de implantes com Ol e pilares pré-fabricados em Titânio. Os pilares e a parte coronária de cada corpo de prova foram obtidos como descritos no grupo I.

\subsubsection{4: Grupo IV (UCLA parafusado)}

Os corpos de provas deste grupo foram constituídos de implantes de HE e pilares UCLA com base de paládio prata. Os pilares UCLA foram cortados em uma altura de $8 \mathrm{~mm}$ e sobre estes, realizado um enceramento da parte coronária com as mesmas dimensões dos grupos anteriores. A fundição foi realizada na liga de paládio prata (Porson 4 - Degusa Dental / Alemanha). 


\subsubsection{5: Grupo V (Ceraone cimentado)}

Os corpos de provas deste grupo foram constituídos de implantes de HE e pilares de titânio ceraone de $1 \mathrm{~mm}$ de altura. Sobre os pilares foi posicionado um "coping" de plástico para pilar ceraone, sobre o qual foi realizado o enceramento da parte coronária, com as mesmas dimensões que os grupos anteriores, este enceramento foi fundido na mesma liga metálica que os grupos I, II, e III.

Em todos os casos os enceramentos foram realizados deixando-se um orifício de acesso na parte coronária, com o objetivo de deixar livre a passagem dos parafusos de retenção para serem realizados os testes de torque e destorque. Nas fundições na liga de Nickel Cromo (Litecast B Will-Ceram / USA), um corpo de prova de cada grupo foi incluído em cada fundição, sendo que foram realizadas dez fundições com quatro coroas dos grupos I, I, III, e V. No caso das coroas fundidas na liga metálica de paládio prata (Pors-on 4 - Degusa Dental / Alemanha), as fundições foram realizadas com uma coroa de cada vez, em conjunto com um pilar do grupo I que também foi fundido nesta liga metálica. Dessa forma, foram obtidos todos as os corpos de provas dos grupos testados (Figura 4.4.5).

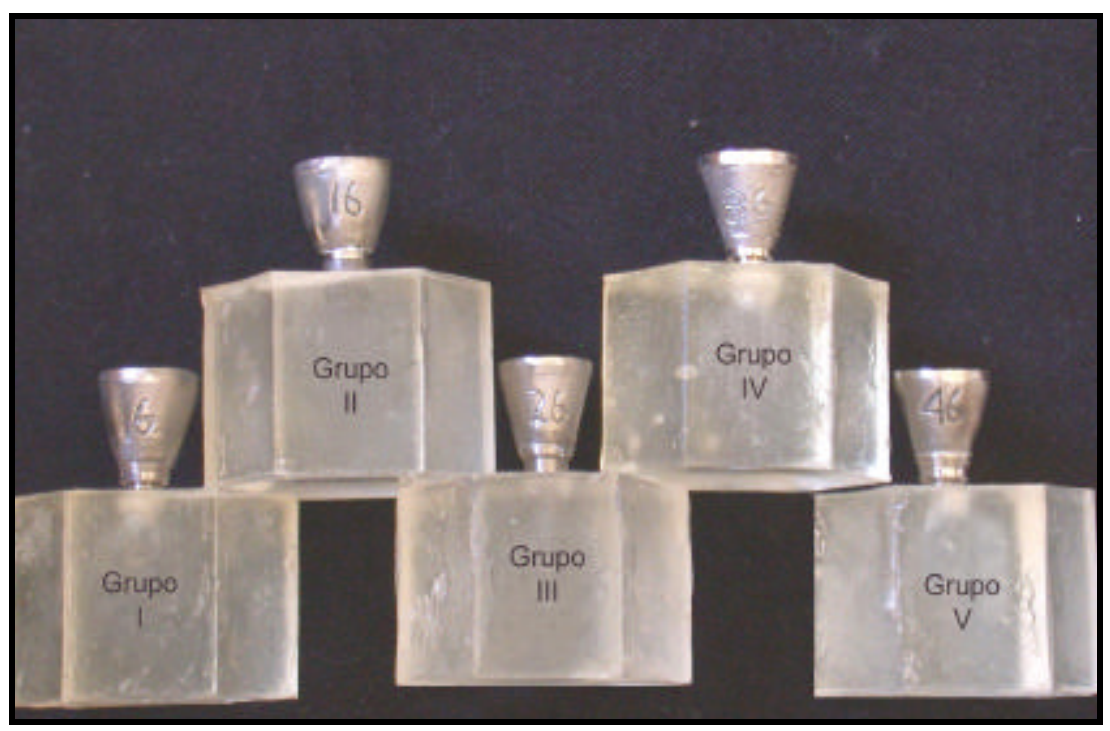

Figura 4.4.5: Corpos de provas fundidos e fixados sobre os implantes. Um corpo de prova de cada um dos cinco grupos testados. 


\section{5: Cimentação}

Antes da cimentação da parte coronária dos grupos I, II, III, e V; os pilares foram fixados com seu respectivo parafuso de retenção, com a utilização de uma chave de torque manual, sem a aplicação de nenhum torque determinado e realizado os procedimentos de cimentação.

Todas as coroas foram cimentadas utilizando-se cimento fosfato de zinco (Hy-Bond Zinc Phosfate cement / Shofu / Japan), seguindo as instruções do fabricante. Antes da cimentação os corpos de provas foram jateados internamente com óxido de alumínio 50ìm de forma a limpar e eliminar imperfeições ocorridas durante o processo de fundição. O cimento foi preparado e em seguida aplicada uma fina camada no interior da coroa. Após este procedimento a coroa foi levada a posição por uma pressão digital, e posteriormente levada a uma prensa estática com um peso constante de $5 \mathrm{kgf}$ por dez minutos, e depois deste tempo eliminados os excessos de cimento. Neste momento o corpo de prova estava pronto para a realização dos testes de torque e destorque e para avaliação da interface implante / pilar (Figura 4.5.1).

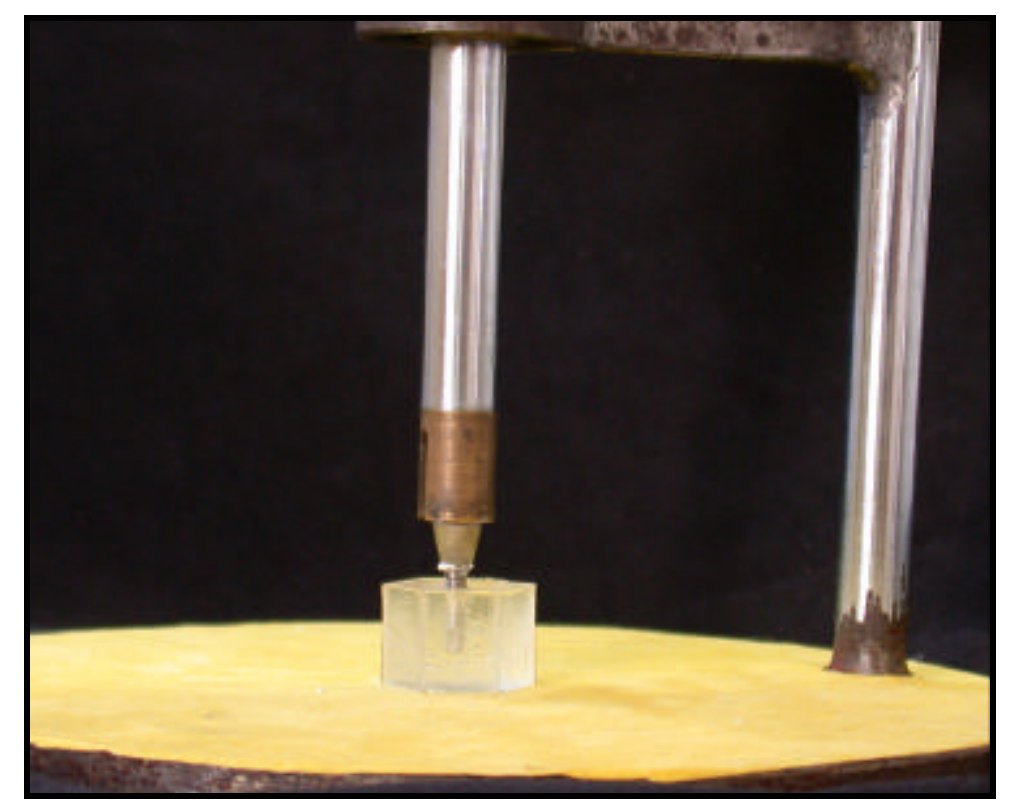

Figura 4.5.1: Corpo de prova na prensa estática durante o processo de cimentação. 


\section{6: Aplicação do torque e medida do destorque inicial, antes da aplicação} das cargas cíclicas.

Todos os parafusos dos corpos de provas dos cinco grupos foram submetidos a um torque de $30 \mathrm{~N} . \mathrm{cm}$ com a utilização de um torquímetro analógico Tohnichi BTG60CN / Japan (Figuras 4.6.1 A e B), com uma precisão de $\pm 2 \%$. Este instrumento permite medir o torque em sentido horário (torque de aperto ou também denominado de Torque), e em sentido anti-horário (torque de afrouxamento ou também denominado Destorque). Para poder realizar o torque e o destorque foi unida ao mandril do medidor uma chave fabricada com as características do hexágono de cada parafuso. Na aplicação do torque, o corpo de prova foi fixado em um dispositivo metálico de forma que no momento de realizar o torque e o destorque o corpo de prova se manteve totalmente rígido (Figura 4.6.2). Em cada implante foi aplicado um torque de $30 \mathrm{~N} . \mathrm{cm}$, e após um intervalo de tempo de dois minutos foi realizado o destorque, seguindo a metodologia de BREEDING et $\mathrm{al}^{26}$, esta leitura foi considerada como destorque inicial. Este procedimento foi repetido três vezes para se obter uma média de destorque inicial, antes da medida da adaptação vertical e da aplicação da carga. O destorque incial foi realizado com o objetivo de ter uma medida base "baseline", que servisse para efeito de comparação, com as medidas obtidas após os corpos de provas serem submetidos a cargas cíclicas.
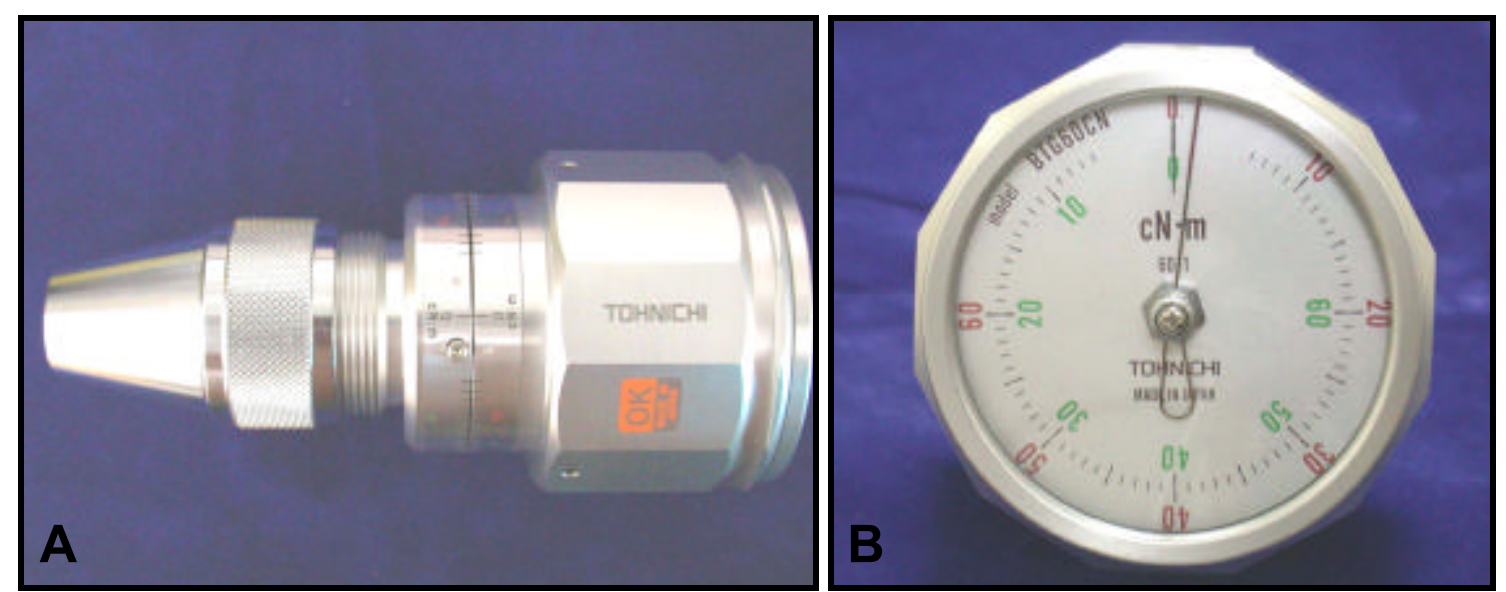

Figuras 4.6.1 A e B: Torquímetro analógico Tohnichi BTG60CN / JAPAN. 


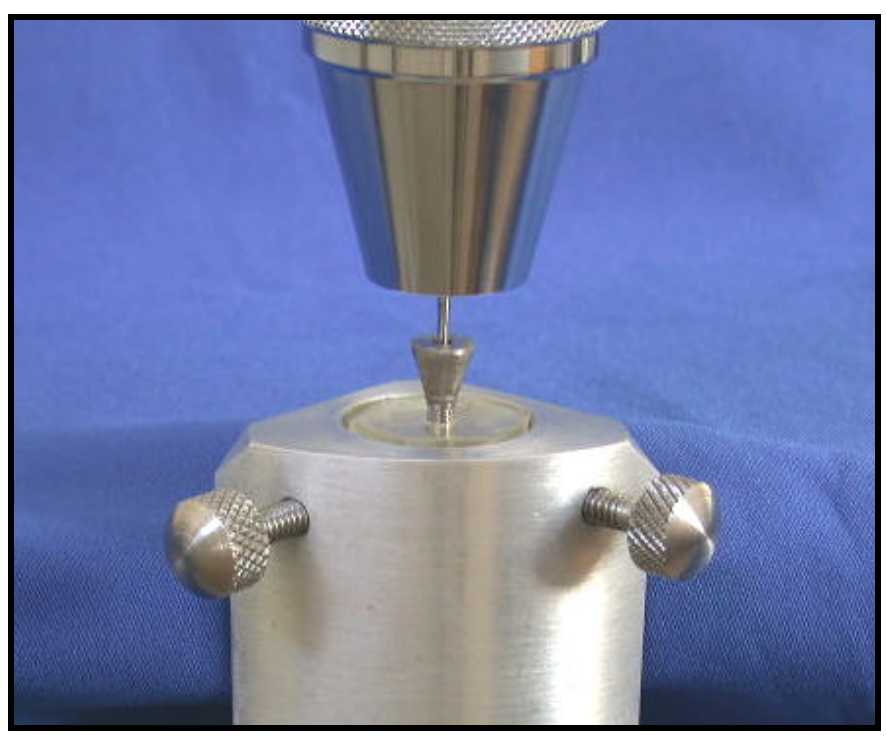

Figura 4.6.2: Corpo de prova fixado em dispositivo metálico no momento da aplicação do torque.

4.7: Medida da desadaptação vertical na interface implante / pilar antes da aplicação das cargas cíclicas.

A análise desta interface foi realizada com o auxílio do microscópio óptico Mitutoyo TM - modelo 5050 / Japan, código 176-811A (Figura 4.7.1), com aumento de 150 vezes (ocular de 15X e objetiva de 10X) e cabeçotes micrométricos, código 164-162, com mostrador digital embutido e precisão de 1 $\mu \mathrm{m}$ (Figura 4.7.2). 


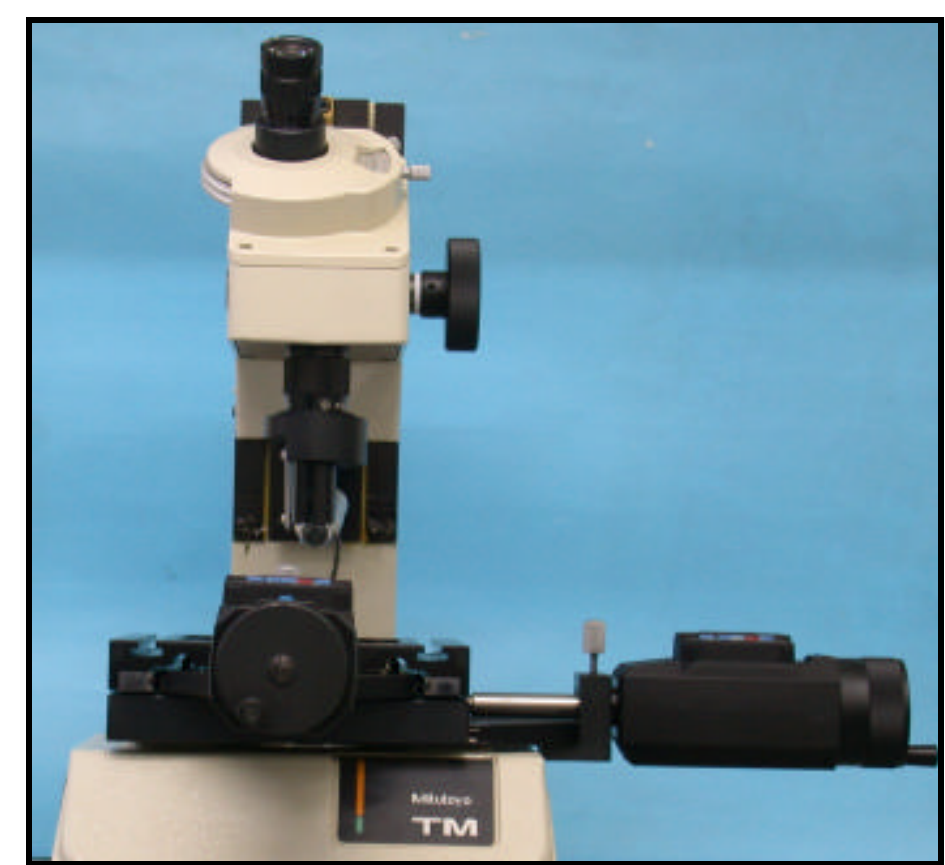

Figura 4.7.1 : Microscópio óptico Mitutoyo TM - modelo 5050 / JAPAN.

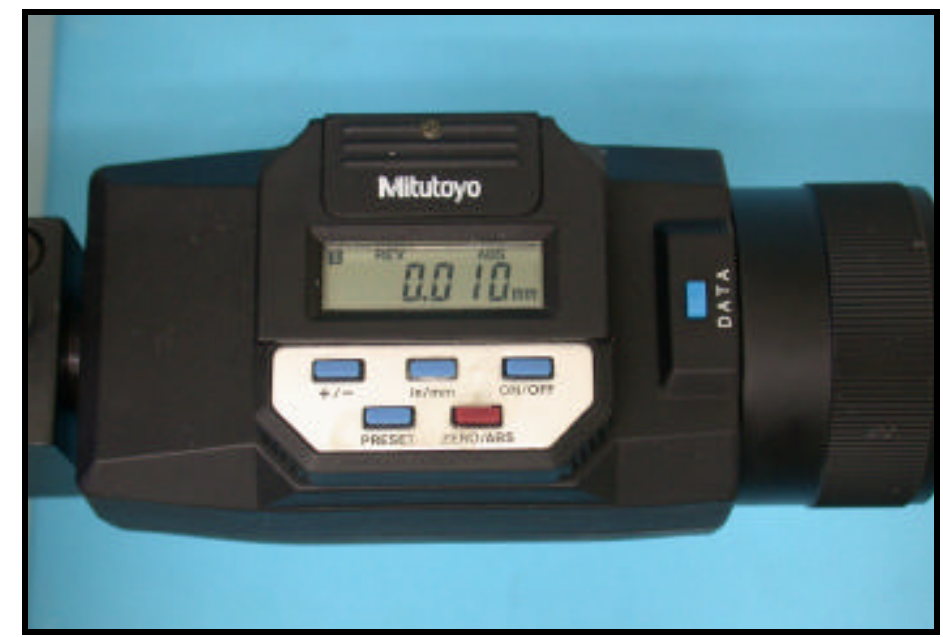

Figura 4.7.2: Detalhe do cabeçote micrométrico do microscópio óptico Mitutoyo TM. 
Cada corpo de prova foi avaliado em seis faces, determinadas pelo hexágono da base de resina acrílica do corpo de prova (Figura 4.7.3). Uma marca foi realizada no lugar da leitura de forma que pudesse reproduzida a medida no mesmo lugar após as cargas cíclicas. Depois de realizadas as medidas os corpos de prova encontravam-se pronto para serem submetidos ao ensaio de fadiga.

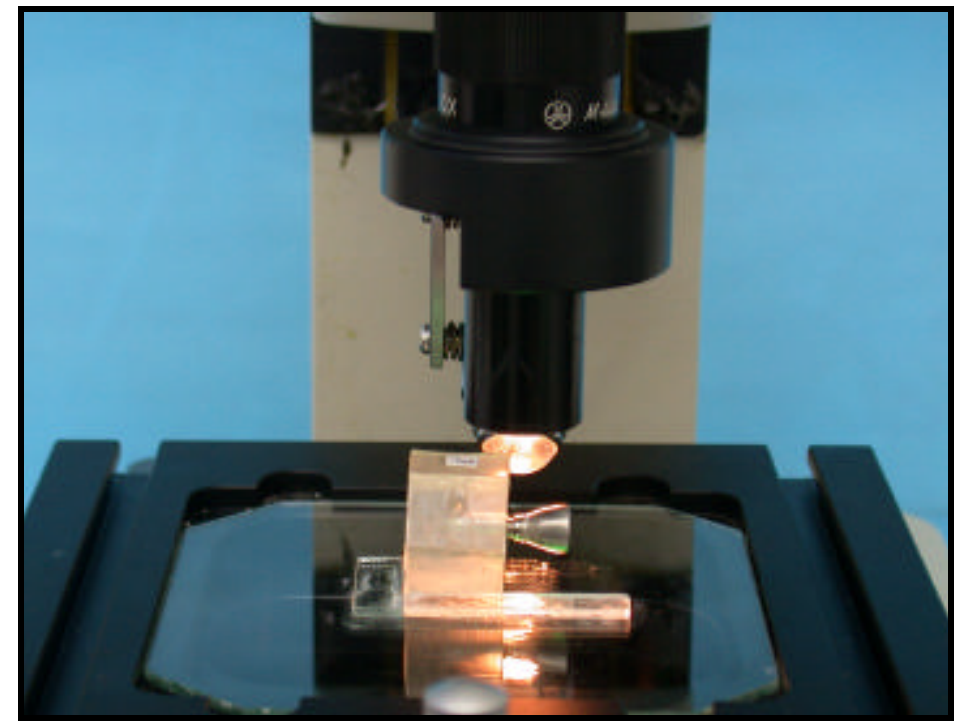

Figura 4.7.3: Corpo de prova em posição no microscópio no momento da avaliação da interface implante / pilar.

Considerourse como desadaptação a ocorrência de um espaço na interface implante / pilar visível ao microscópio através da passagem da luz. Este espaço foi analisado de perfil, e era medido quando as interfaces se apresentavam paralelas, seguindo a metodologia empregada por KANO ${ }^{60}$ (Figura 4.7.4). As medidas foram expressas em micrometros.

\section{Fotomicrografias}

Devido a impossibilidade de se fotografar as interfaces visualizadas através do microscópio óptico durante as análises, optou-se em fotografá -las em um microscópio eletrônico de varredura (JEOL Scanning Microscope - T22OA) para fins ilustrativos. 


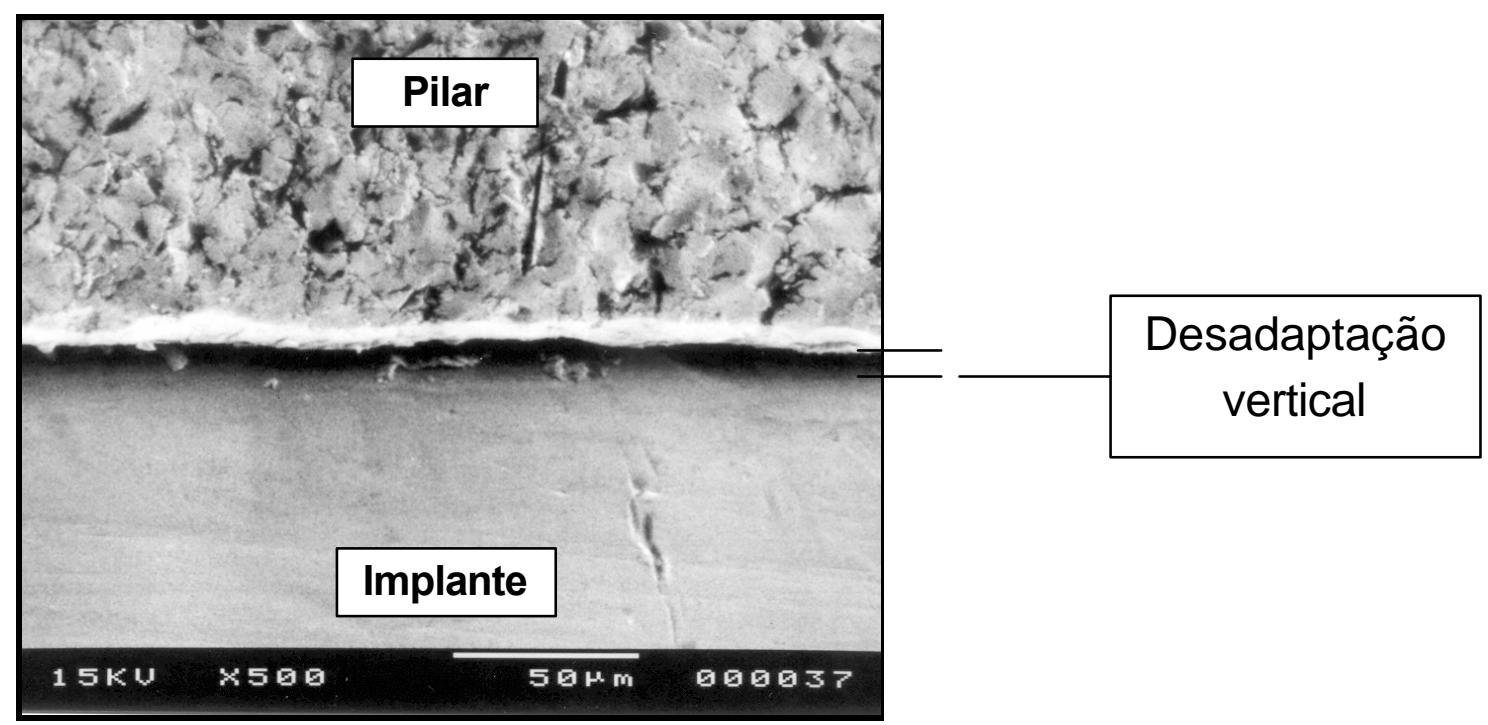

Figura 4.7.4: Desajuste vertical da interface implante / pilar, em um corpo de prova.

Considerourse como ajuste quando existia um contato íntimo na interface implante / pilar de tal forma que não havia espaço a ser medido e que recebeu valor de zero (Figura 4.7.5). A configuração externa dos componentes não foi considerada.

\section{8: Ensaio de fadiga}

Este ensaio foi realizado em uma máquina de ensaio para teste de fadiga MTS 810 (Material Testing System / MTS Systems Corporation / USA). Esta máquina é desenhada para a realização de testes de carga dinâmica de alta freqüência, de aplicações multiaxial (Figura 4.8.1). 


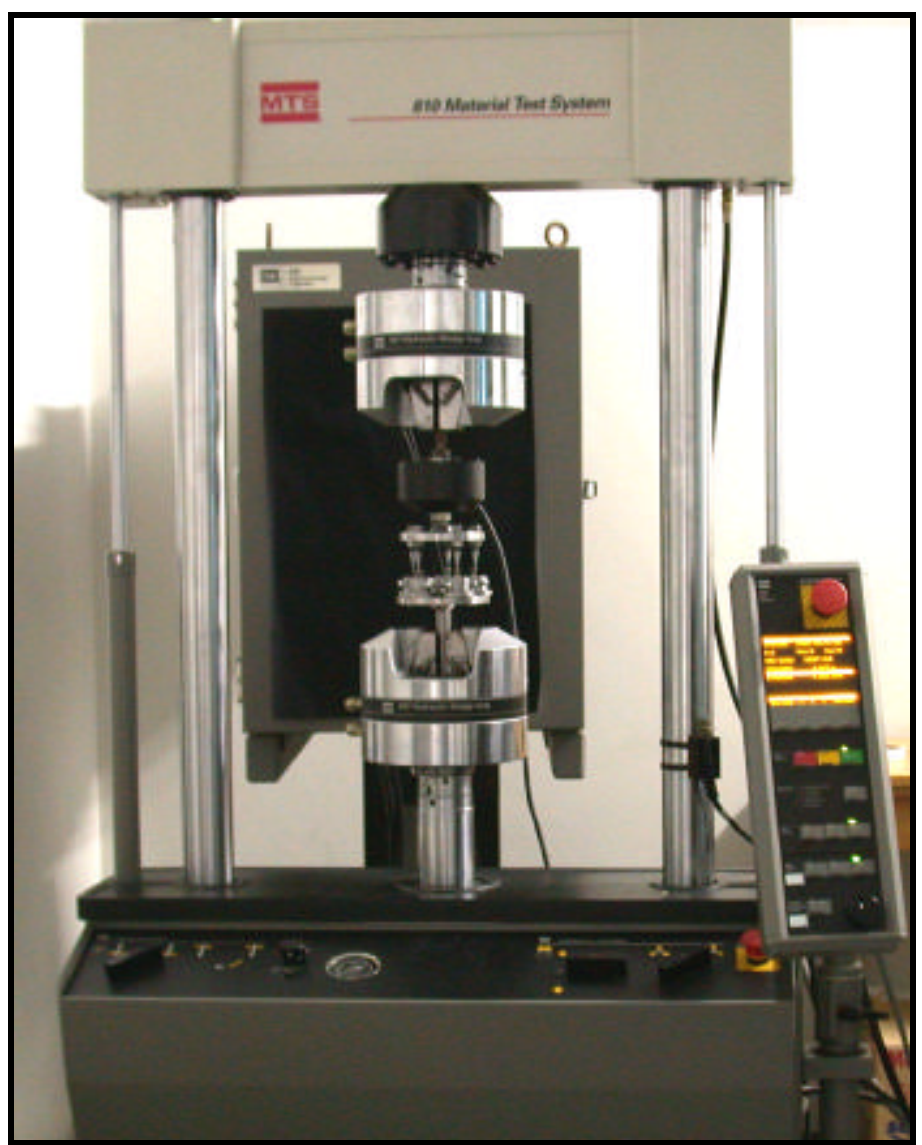

Figura 4.8.1: Máquina de ensaios MTS 810 (Material Testing System / MTS Systems Corporation / USA), utilizada no ensaio de fadiga.

\subsection{1: Descrição da máquina de ensaio}

A parte funcional da máquina é composta de duas garras de pressão hidráulica em cada um dos extremos. Na garra superior é conectada uma célula de carga, a qual é ligada a um sistema de computador que controla a força, freqüência do ensaio e outras funções. No presente experimento, utilizamos uma célula de $10 \mathrm{kN}$, onde foi conectado o dispositivo superior para a realização dos testes. A parte inferior da máquina tem uma garra que é conectada a um sistema hidráulico e sobre o qual é fixado rigidamente o dispositivo de teste inferior (Figura 4.8.2). 


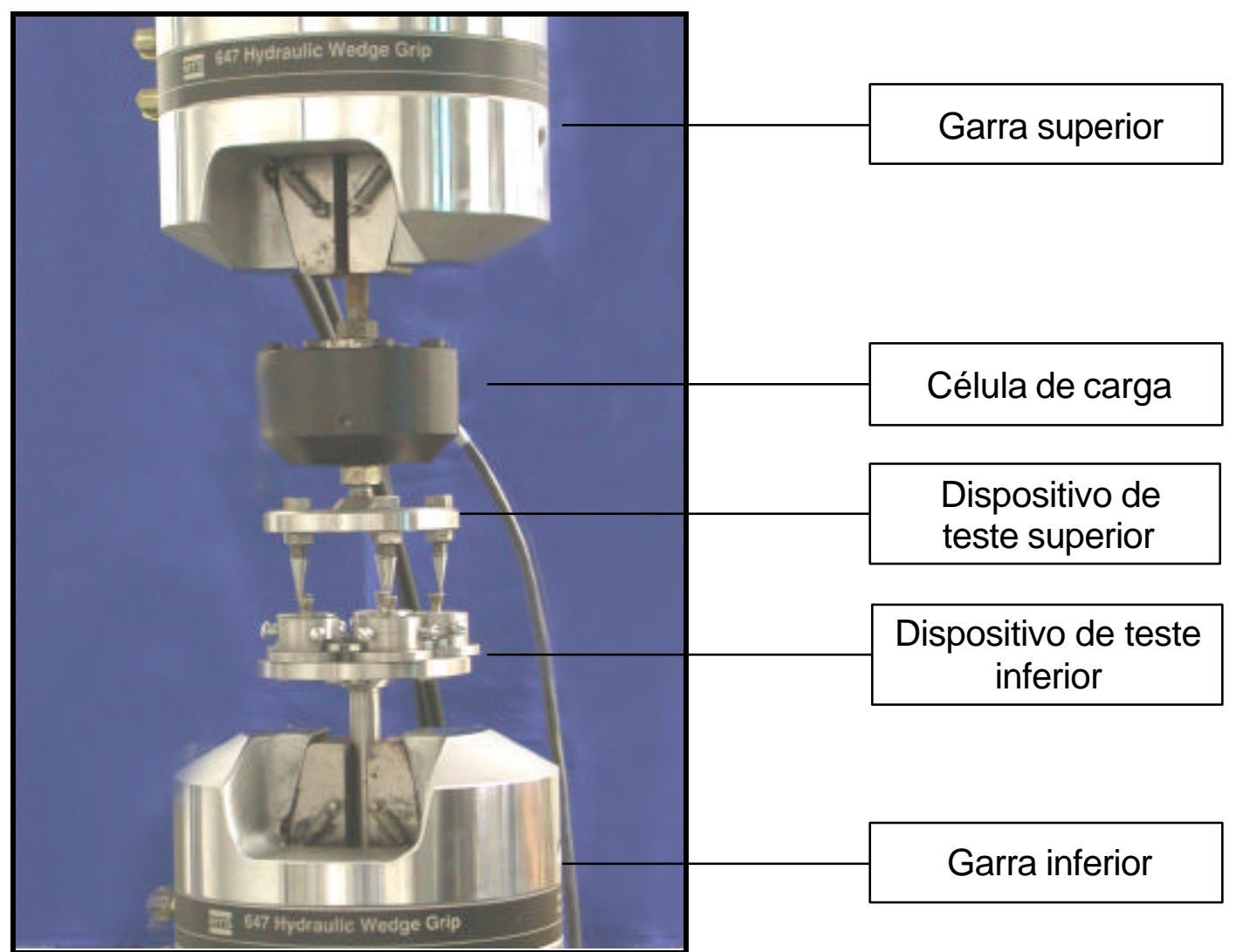

Figura 4.8.2: Parte superior e inferior da máquina de ensaios com dispositivo de teste fixado.

\subsection{2: Dispositivo para colocação dos corpos de provas e realização do ensaio.}

Previamente ao desenvolvimento do ensaio de cargas cíclicas, realizou-se um estudo piloto onde foram testados diferentes dispositivos para a fixação dos corpos de provas, até chegar ao aperfeiçoamento do dispositivo e a padronização das diferentes fases do ensaio.

O dispositivo desenvolvido foi composto de duas peças metálicas que conectadas à máquina permitiram a realização do ensaio em cinco corpos de provas simultaneamente, sendo que um corpo de prova de cada um dos cinco grupos foi testado em cada ensaio, totalizando-se dez ensaios.

A parte superior do dispositivo, a ser conectada à célula de carga foi composta de uma placa em forma circular com um diâmetro de 150mm e 12mm 
de espessura, onde foram fixadas cinco pontas de $50 \mathrm{~mm}$ de comprimento distribuídas em distâncias iguais na borda do círculo e do centro da força. A parte final de cada ponta tinha uma forma arredondada de $1,0 \mathrm{~mm}$; estas pontas foram fixadas através de roscas e de duas porcas uma superior e outra inferior (porca e contra porca), para poder serem calibradas na altura desejada e ao mesmo tempo fixadas de forma a evitarem micromovimentos durante os ensaios (Figura 4.8.3).

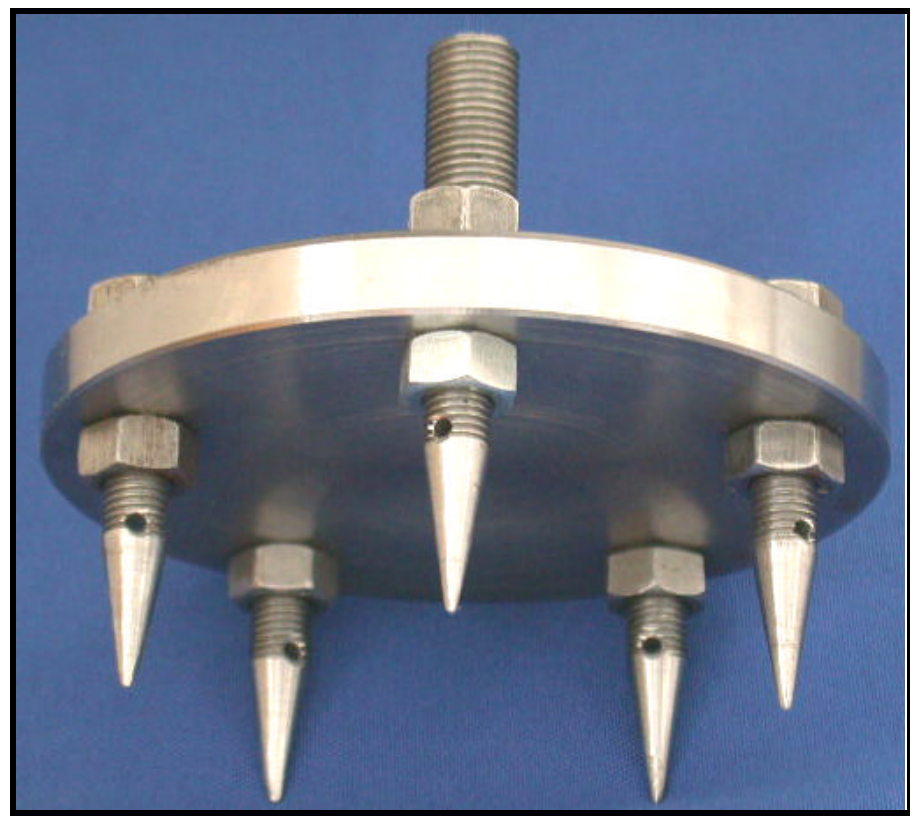

Figura 4.8.3: Parte superior do dispositivo para realização do ensaio de fadiga.

A parte inferior do dispositivo foi composta de uma placa circular com as mesmas dimensões que a placa da parte superior, onde estavam fixados cinco suportes para a colocação dos corpos de provas. Cada corpo de prova foi fixado com três parafusos de forma a tornar todo o conjunto totalmente rígido. Esse conjunto foi suportado por uma haste metálica e soldado no centro da placa circular o que permitiu a fixação na garra inferior da máquina (Figura 4.8.4). Durante o ensaio todo o conjunto (superior e inferior) estava totalmente rígido o que permitiu que a força aplicada fosse distribuída de forma igual em todos os corpos de prova. 


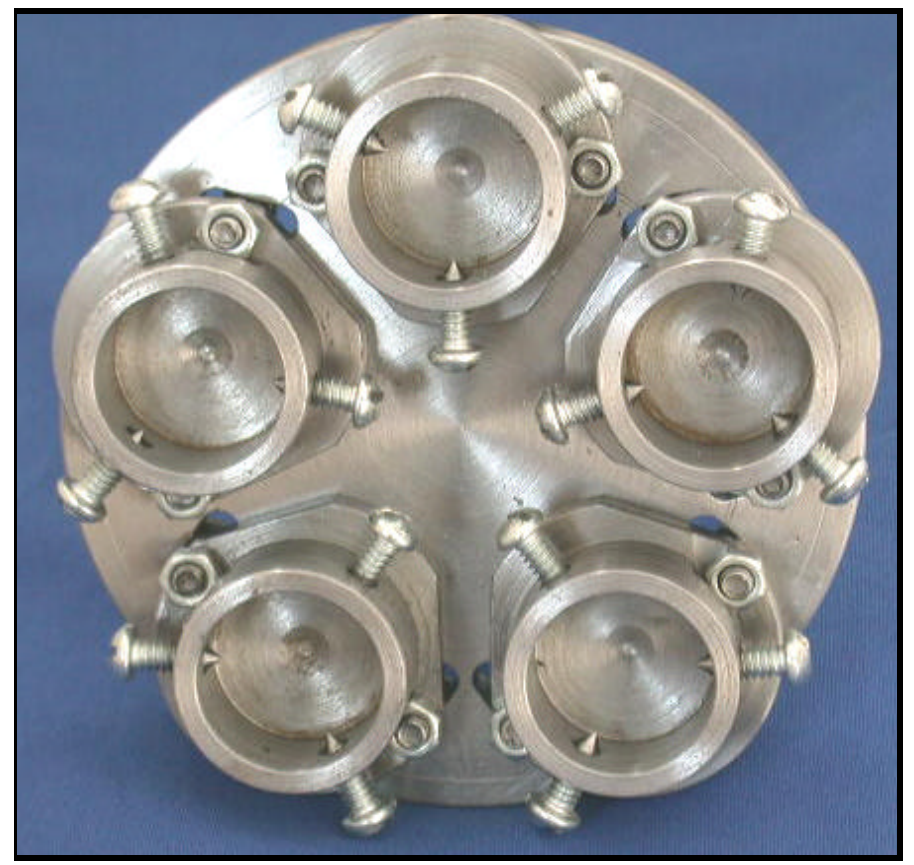

Figura 4.8.4: Parte inferior do dispositivo para realização do ensaio de fadiga.

\subsection{3: Fixação dos corpos de prova}

Os corpos de prova foram fixados nos suportes da parte inferior do dispositivo através de três parafusos, que o mantiveram sem movimento durante o ensaio. Inicialmente as duas partes do dispositivo foram fixadas na máquina e deixadas bem próximas, para que cada ponta fosse calibrada até entrar em contacto com o corpo de prova. Para assegurar que esse contacto existia realmente e determinar que todas as pontas estivessem tocando ao mesmo tempo, utilizou-se um multímetro analógico FTG modelo FT-1000A (Figura 4.8.5), que permitiu medir a relação de contato de cada um dos cinco corpos de provas. Durante o ensaio foi testada essa relação de contato em todos os corpos de provas a cada 50.000 ciclos até terminar o ensaio. A carga aplicada em cada corpo de prova pela ponta do dispositivo foi colocada a uma distância de $3 \mathrm{~mm}$ fora do centro do implante (Figura 4.8.6), o qual foi medido com o paquímetro digital (Mitutoyo código 500-171, modelo CD6-C, serie 0112103, com uma precisão de $0,001 \mathrm{~mm}$ ). Antes dos corpos de provas serem fixados no dispositivo e iniciado o ensaio, foi realizado um reaperto dos parafusos com $30 \mathrm{~N} . \mathrm{cm}$. 


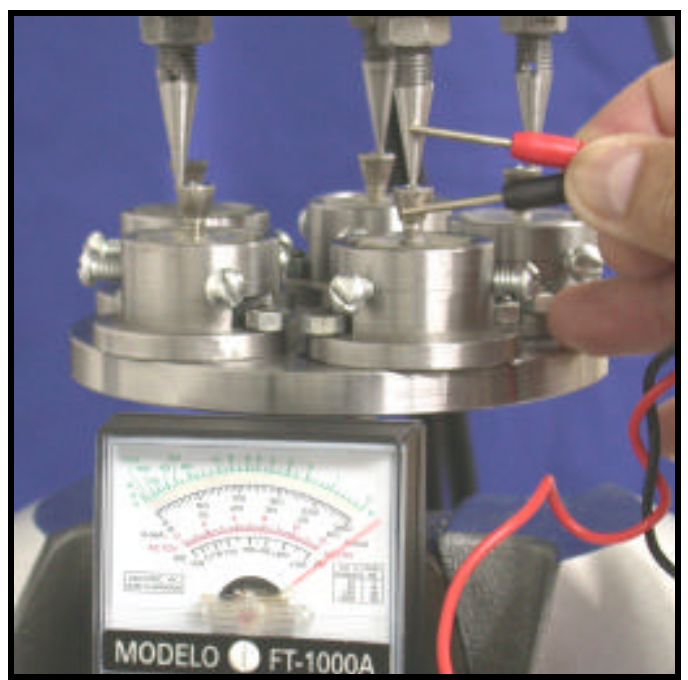

Figura 4.8.5: Multímetro analógico FTG modelo FT-1000A, usado para determinar o contato entre o dispositivo e o corpo de prova.

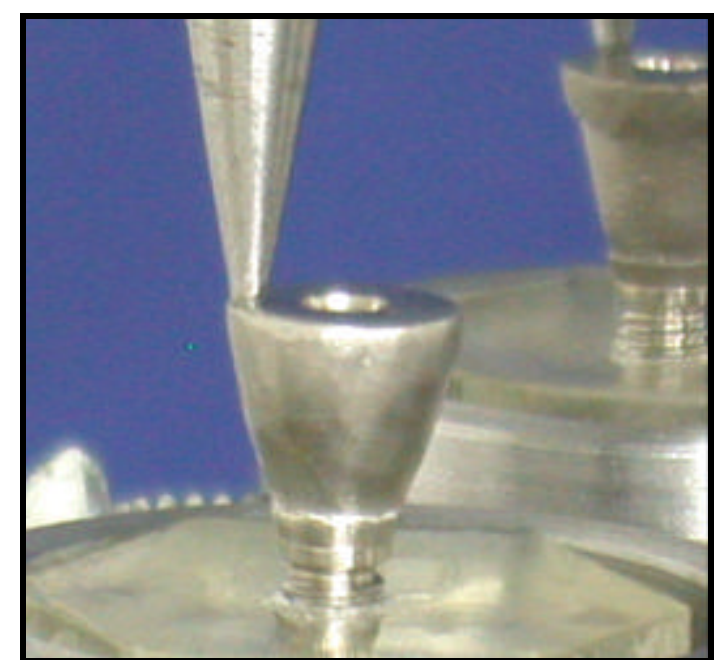

Figura 4.8.6: Aplicação da carga no corpo de prova a 3mm fora do centro do implante.

\subsection{4: Aplicação das forças}

A construção do dispositivo para fixação dos corpos de prova foi baseado no princípio de decomposição das forças onde, segundo este, uma força pode ser decomposta em duas ou outras, cuja soma tem que corresponder à força vertical aplicada inicialmente ${ }^{89}$. Desse princípio, a seguinte fórmula é dada para medir a distribuição da carga atuante em cada corpo de prova: 


$$
\frac{F_{v}}{N}=F_{i}
$$

onde: $\mathrm{F}_{\mathrm{i}}=$ Força que atua em cada corpo de prova

$F_{v}=$ Força vertical aplicada

$\mathrm{N}=$ Número de corpos de provas

Para a aplicação da força desejada a seguinte fórmula foi deduzida:

$$
665 \mathrm{~N}=133 \mathrm{~N}
$$

5

\subsection{5: Programação da máquina para o ensaio}

A programação do ensaio foi realizada seguindo o protocolo de carga axial e a freqüência utilizada por BINON ${ }^{20}$. A máquina utilizou o programa Test Works, sendo aplicado uma amplitude de força axial de $665 \mathrm{~N}$, com uma média de $332,5 \mathrm{~N}$. Esta força foi programada partindo-se do princípio descrito anteriormente, de forma que em cada corpo de prova foi aplicado uma carga de $133 \mathrm{~N}$. A freqüência utilizada foi de $19.1 \mathrm{~Hz}$ que correspondeu a 1.150 ciclos por minutos. $\mathrm{O}$ número total de ciclos em cada ensaio foi de 500.000 (Figura 4.8.7). 


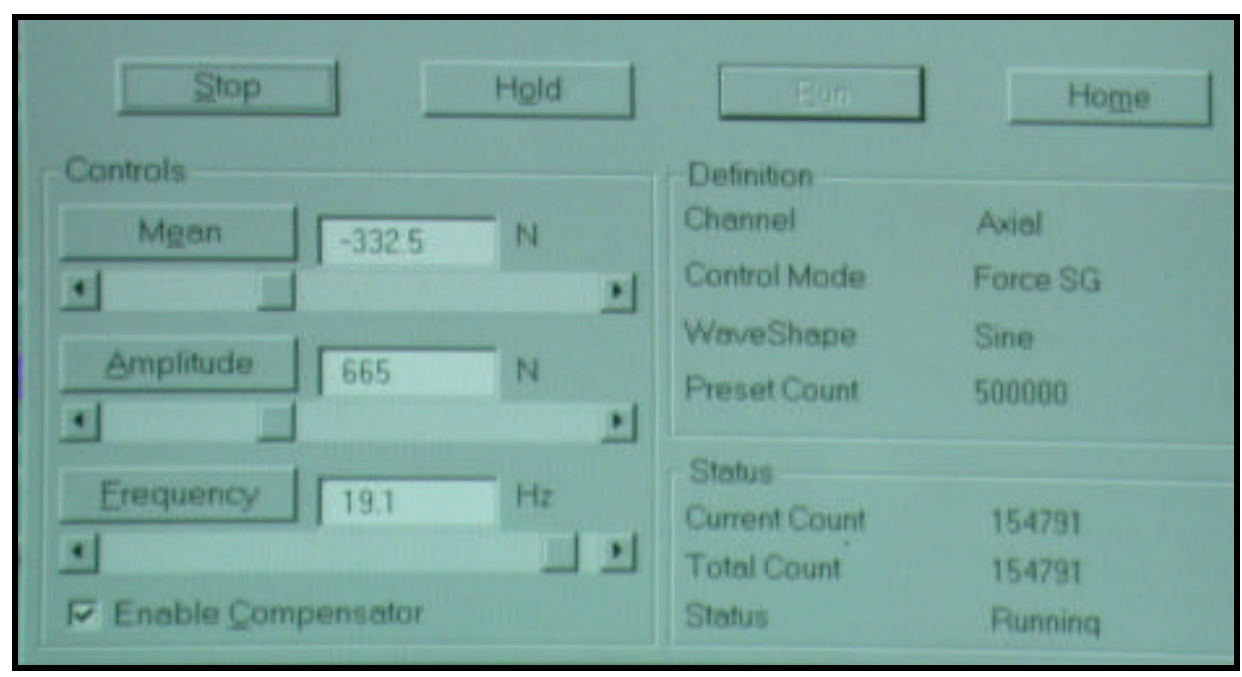

Figura 4.8.7: Tela do computador com programação do ensaio através do programa Test Works.

\section{9: Medida da desadaptação vertical na interface implante / pilar depois da} aplicação das cargas.

Após o ensaio, os corpos de prova foram novamente levados ao microscópio e realizadas novas leituras desta interface no mesmo lugar onde as leituras anteriores tinham sido realizadas antes do teste de fadiga e com o mesmo critério descrito anteriormente no item 4.7 .

\subsection{0: Medida do destorque final depois das cargas.}

Depois do ensaio, os corpos de prova foram colocados novamente no dispositivo para a fixação e com a utilização do medidor analógico de torque, foi realizado o destorque como descrito anteriormente no item 4.6. Esta medida foi denominada destorque final.

\subsection{1: Análise estatística}

Os dados obtidos nas diferentes fases de análises foram submetidos à análise estatística descritiva e análise de variância (ANOVA) com nível de significância de $5 \%$, quando detectada diferença estatística, os valores foram submetidos ao Teste Tukey para comparações múltiplas. 
5- RESULTADOS 


\section{RESULTADOS}

Em cada um dos corpos de provas foram obtidas medidas individuais (Anexos 1 ao 11), a partir das quais foram realizadas médias para cada grupo, as quais foram submetidas à análise estatística, que são apresentadas neste capítulo. Para o melhor entendimento dos resultados obtidos, realizou-se uma ordenação dos resultados em três grupos, seguindo a seguinte distribuição:

5.1: Resultados obtidos através das medidas dimensionais dos implantes, pilares e parafusos.

5.2: Resultados obtidos através das medidas da desadaptação vertical da interface implante / pilar, antes e após o ensaio de fadiga.

5.3: Resultados obtidos a partir das medidas de destorque antes e após o esaio de fadiga.

\section{1: Resultados obtidos através das medidas dimensionais dos implantes, pilares, e parafusos.}

Os resultados das medidas do diâmetro da base de assentamento, altura do hexágono / octágono e diâmetro do sextavado / octágono dos implantes; além do diâmetro do hexágono / octágono e da base de assentamento dos pilares, junto com as dimensões dos parafusos dos cinco sistemas de implantes avaliados, são apresentados nas tabelas: $5.1 .1 ; 5.1 .2 ; 5.1 .3,5.1 .4,5.1 .5$ e gráficos: 5.1.1; 5.1.2; 5.1.3. 
TABELA 5.1.1: Médias e desvio padrão em $\mathrm{mm}$, do diâmetro da base de assentamento, altura do hexágono / octágono e diâmetro do sextavado / octágono dos implantes dos sistemas avaliados.

\begin{tabular}{lcccc}
\hline \multicolumn{1}{c}{ Grupo } & $\begin{array}{c}\text { Larg_bas. } \pm \\
\text { dp }\end{array}$ & $\begin{array}{c}\text { Alt_Hex. } \pm \\
\text { dp }\end{array}$ & $\begin{array}{c}\text { Larg_Hex. } \pm \\
\text { dp }\end{array}$ & $\begin{array}{c}\text { No. corpos } \\
\text { provas }\end{array}$ \\
\hline I Master screw - HE & $4,01 \pm 0,00$ & $0,66 \pm 0,02$ & $2,69 \pm 0,01$ & 10 \\
II Colosso - HI & $4,00 \pm 0,01$ & $1,50 \pm 0,02$ & $2,36 \pm 0,00$ & 10 \\
III TMI - OI & $3,76 \pm 0,01$ & $4,23 \pm 0,05$ & $2,50 \pm 0,01$ & 10 \\
IV Master screw - HE & $4,02 \pm 0,02$ & $0,63 \pm 0,02$ & $2,68 \pm 0,01$ & 10 \\
V Master screw - HE & $4,07 \pm 0,03$ & $0,63 \pm 0,01$ & $2,68 \pm 0,01$ & 10 \\
\hline Todos grupos * & $3,97 \pm 0,11$ & $1,53 \pm 1,41$ & $2,58 \pm 3,97$ & 50 \\
\hline
\end{tabular}

As medidas dos diâmetros da base de assentamento dos implantes nos sistemas avaliados mostraram poucas diferenças entre os grupos de um mesmo fabricante (I, IV, e V). Uma maior diferença foi encontrada com os implantes do grupo III. Igual comportamento encontrourse na altura do hexágono. O diâmetro do sextavado do implante teve médias com poucas diferenças entre os grupos I, IV, e V; enquanto que nos grupos II e III as diferenças foram maiores, sendo que os implantes do grupo II tiveram a menor média. O desvio padrão mostrou-se regular, com uma maior variação nas médias da altura do hexágono.

* Valor nominal:

$\begin{array}{lccc} & \text { Larg_bas. } & \text { Alt_Hex. } & \text { Larg_Hex. } \\ \text { Master screw } & 4,0 & 0,6 & 2,7 \\ \text { Colosso } & 4,0 & 1,5 & 2,35 \\ \text { TMI } & 3,7 & 4,5 & 2,5\end{array}$


GRÁFICO 5.1.1: Representação gráfica das medidas em $\mathrm{mm}$ do diâmetro dos implantes, altura e diâmetro do hexágono / octágono dos implantes nos sistemas avaliados.

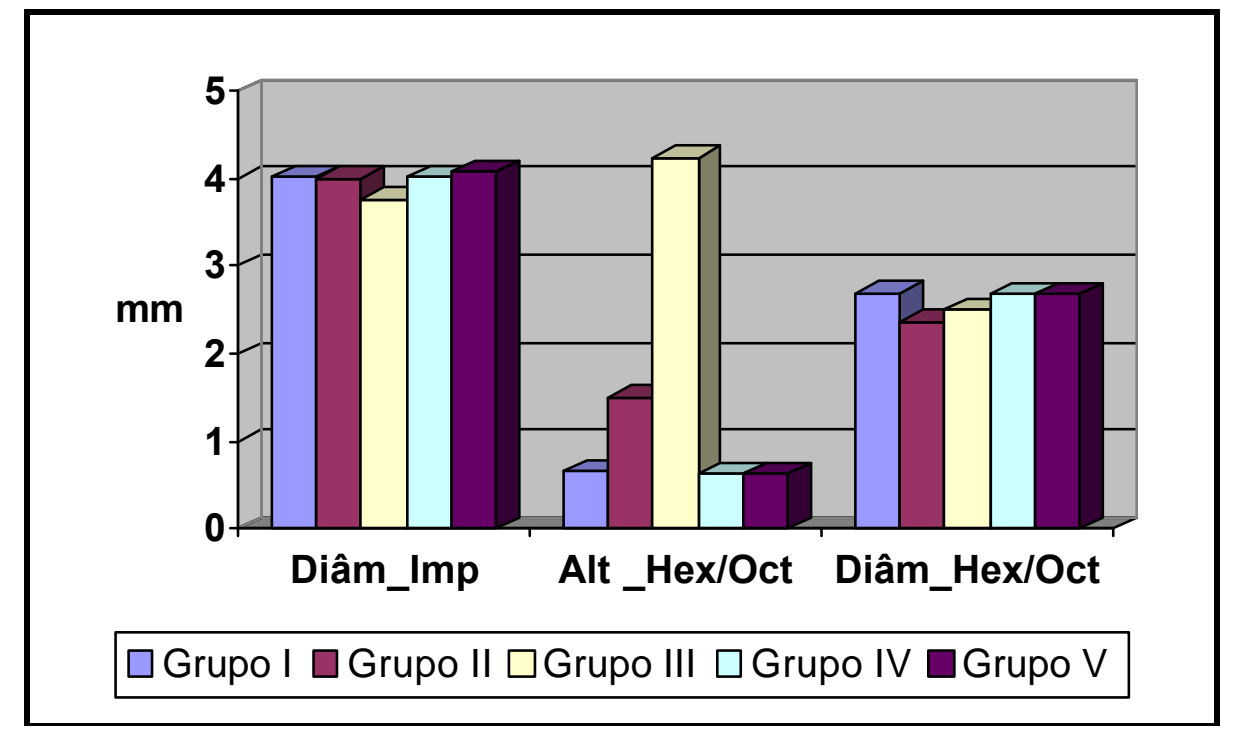

TABELA 5.1.2: Médias e desvio padrão em $\mathrm{mm}$ do diâmetro do hexágono / octágono e do diâmetro da base de assentamento dos pilares nos sistemas avaliados.

\begin{tabular}{lccc}
\hline \multicolumn{1}{c}{ Grupo } & Larg_Hex. \pm dp & Larg_Base \pm dp & $\begin{array}{c}\text { No. corpos } \\
\text { provas }\end{array}$ \\
\hline I UCLA & $2,70 \pm 0,01$ & $4,16 \pm 0,05$ & 10 \\
II Pré-fabricado Ti & $2,36 \pm 0,00$ & $3,97 \pm 0,02$ & 10 \\
III Pré-fabricado Ti & $2,47 \pm 0,01$ & $4,51 \pm 0,05$ & 10 \\
IV UCLA & $2,70 \pm 0,01$ & $4,18 \pm 0,04$ & 10 \\
V Ceraone & $2,73 \pm 0,02$ & $4,17 \pm 0,03$ & 10 \\
\hline Todos grupos * & $2,59 \pm 0,15$ & $4,20 \pm 0,18$ & 50 \\
\hline
\end{tabular}


As médias entre os diâmetros do hexágono do pilar dos sistemas avaliados mostraram pequenas diferenças entre os grupos I, IV, e V; enquanto que nos grupos II, e III, maiores diferenças foram encontradas. O diâmetro da base de assentamento dos pilares teve um comportamento similar sendo encontradas poucas diferenças. Nos grupos II e III as diferenças foram maiores. O desvio padrão manteve-se regular, sendo encontradas variações próximas em todos os grupos, em ambos aspectos.

* Valor nominal:

Larg_bas. Larg_Hex.

$\begin{array}{lll}\text { Master screw } & 4,0 & 2,7 \\ \text { Colosso } & 4,0 & 2,35 \\ \text { TMI } & 3,7 & 2,5\end{array}$

GRÁFICO 5.1.2: Representação gráfica das médias em $\mathrm{mm}$ do diâmetro do hexágono / octágono, e do diâmetro da base de assentamento dos pilares, nos sistemas avaliados.

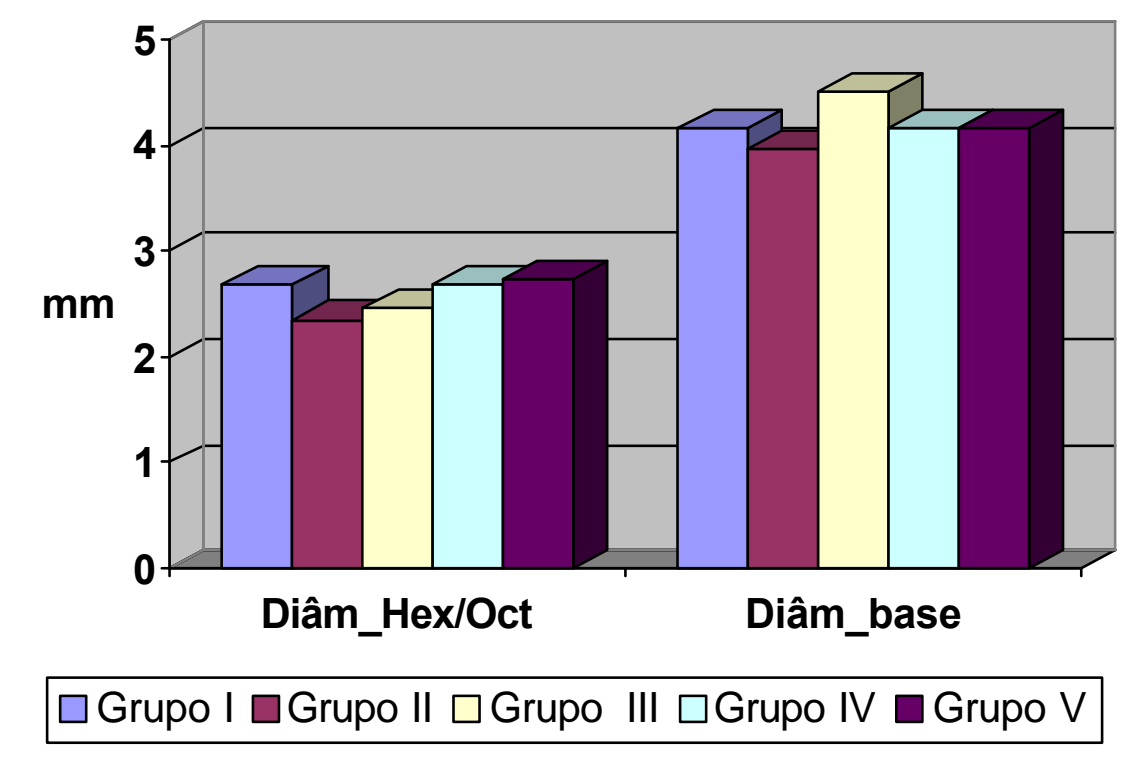


TABELA 5.1.3: Médias e desvio padrão em $\mathrm{mm}$, do diâmetro da base de assentamento dos implantes e o diâmetro da base de assentamento dos pilares e as diferenças entre as médias, nos sistemas de implantes avaliados.

\begin{tabular}{lccc} 
Grupo & $\begin{array}{c}\text { Larg_Base } \\
\text { Pilar } \pm d p\end{array}$ & $\begin{array}{c}\text { Larg_Base Imp. } \pm \\
\mathbf{d p}\end{array}$ & Diferenças \\
I UCLA_ciment. & $4,16 \pm 0,05$ & $4,01 \pm 0,00$ & 0,15 \\
II Emfils_ciment. & $3,97 \pm 0,02$ & $4,00 \pm 0,01$ & $-0,03$ \\
III TMI_ciment. & $4,51 \pm 0,05$ & $3,76 \pm 0,01$ & 0,75 \\
IV UCLA_paraf. & $4,18 \pm 0,04$ & $4,02 \pm 0,02$ & 0,16 \\
V Ceraon_ciment. & $4,17 \pm 0,03$ & $4,07 \pm 0,03$ & 0,10 \\
\hline Todos grupos & $4,20 \pm 0,18$ & $3,97 \pm 0,11$ & 0,23 \\
\hline
\end{tabular}

Houve uma diferença positiva do diâmetro da base do pilar em relação à base do implante, nos grupos I, III, IV, e V; e negativa no grupo II. 
TABELA 5.1.4: Médias e desvio padrão em mm, do diâmetro do hexágono / octágono dos pilares e o diâmetro do hexágono / octágon dos implantes e as diferenças entre os valores médios, nos sistemas avaliados.

\begin{tabular}{lccc} 
Grupo & $\begin{array}{c}\text { Larg_Hex. Pilar } \\
\mathbf{\pm d p}\end{array}$ & $\begin{array}{c}\text { Larg_Hex. } \\
\text { Implante } \pm \mathbf{d p}\end{array}$ & Diferenças \\
\hline I UCLA_ciment. & $2,70 \pm 0,01$ & $2,69 \pm 0,01$ & 0,01 \\
II Emfils_ciment. & $2,36 \pm 0,00$ & $2,36 \pm 0,00$ & 0,00 \\
III TMI_ciment. & $2,47 \pm 0,01$ & $2,50 \pm 0,01$ & $-0,03$ \\
IV UCLA_paraf. & $2,70 \pm 0,01$ & $2,68 \pm 0,01$ & 0,02 \\
V Ceraon_ciment. & $2,73 \pm 0,02$ & $2,68 \pm 0,01$ & 0,05 \\
\hline Todos grupos & $2,59 \pm 0,15$ & $2,58 \pm 3,97$ & 0,01 \\
\hline
\end{tabular}

A maior diferença entre o diâmetro do hexágono / octágono do pilar e do implante, foi observada no grupo $\mathrm{V}$, enquanto que a menor diferença foi observada no grupo II. 
TABELA 5.1.5: Médias e desvio padrão em $\mathrm{mm}$, dos comprimentos dos parafusos, das roscas dos parafusos e dos diâmetros das roscas dos parafusos, nos sistemas de implantes avaliados.

\begin{tabular}{lcccc}
\hline Grupo & $\begin{array}{c}\text { Comp_paraf. } \\
\pm \mathrm{dp}\end{array}$ & $\begin{array}{c}\text { Comp_rosc. } \\
\pm \mathrm{dp}\end{array}$ & $\begin{array}{c}\text { Diâm_rosc. } \\
\pm \mathrm{dp}\end{array}$ & $\begin{array}{c}\text { No. corpos } \\
\text { provas }\end{array}$ \\
\hline I UCLA_ciment. & $6,05 \pm 0,04$ & $4,56 \pm 0,06$ & $1,96 \pm 0,03$ & 10 \\
II Emfils_ciment. & $6,74 \pm 0,66$ & $5,55 \pm 0,05$ & $1,93 \pm 0,01$ & 10 \\
III TMI_ciment. & $8,83 \pm 0,61$ & $5,72 \pm 0,07$ & $1,79 \pm 0,01$ & 10 \\
IV UCLA_paraf. & $6,07 \pm 0,10$ & $4,55 \pm 0,03$ & $1,97 \pm 0,02$ & 10 \\
V Ceraon_ciment. & $5,95 \pm 0,15$ & $4,52 \pm 0,10$ & $1,97 \pm 0,02$ & 10 \\
\hline Todos grupos & $6,73 \pm 1,10$ & $4,98 \pm 0,55$ & $1,92 \pm 0,07$ & 50 \\
\hline
\end{tabular}

As médias dos comprimentos dos parafusos dos sistemas utilizados mostraram pequenas diferenças entre os grupos do mesmo fabricante (I, IV, e V). Diferenças maiores foram encontradas nos parafusos dos grupos II e III, sendo que os parafusos do grupo III, tiveram a maior média de comprimento. $O$ comprimento das roscas dos parafusos teve um comportamento similar. As médias dos diâmetros das roscas dos parafusos tiveram menores variações entre todos os grupos, sendo que o grupo III teve a menor média de diâmetro. O desvio padrão se manteve regular, observando-se a maior variação no comprimento do parafuso. 
GRÁFICO 5.1.3: Representação gráfica das médias em $\mathrm{mm}$ do comprimento dos parafusos, comprimento e diâmetro das roscas, nos sistemas avaliados.

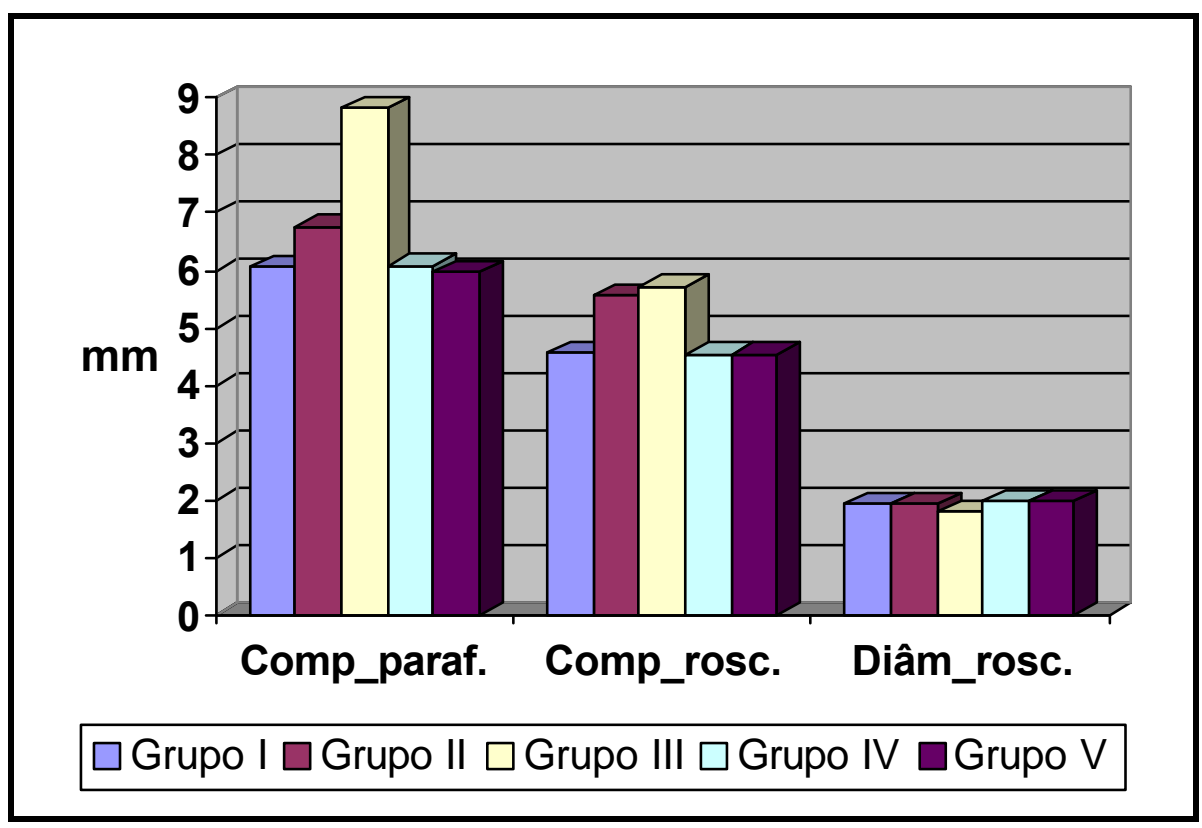

5.2: Resultados obtidos através das medidas da desadaptação vertical da interface implante / pilar, antes e após o ensaio de fadiga.

As médias das medidas obtidas da desadaptação vertical da interface implante / pilar antes e após o ensaio de fadiga foram submetidas à análise estatística, através da análise de variância com nível de significância de $5 \%$, e o Teste Tukey para determinação dos grupos homogêneos, sendo os mesmos representados nas tabelas: $5.2 .1 ; 5.2 .2 ; 5.2 .3 ; 5.2 .4 ; 5.2 .5$; e 5.2 .6 e no gráfico: 5.2.1. 
TABELA 5.2.1: Médias e desvio padrão em $\mu \mathrm{m}$ da desadaptação vertical na interface implante / pilar antes do ensaio de fadiga.

\begin{tabular}{lcc}
\hline \multicolumn{1}{c}{ Grupo } & Antes_carga \pm dp & No. corpos provas \\
\hline I UCLA_ciment. & $12,88 \pm 6,43$ & 10 \\
II Emfils_ciment. & $4,33 \pm 3,13$ & 10 \\
III TMI_ciment. & $4,79 \pm 3,43$ & 10 \\
IV UCLA_paraf. & $9,67 \pm 3,08$ & 10 \\
V Ceraon_ciment. & $3,86 \pm 4,60$ & 10 \\
\hline Todos grupos & $7,14 \pm 5,54$ & 50 \\
\hline
\end{tabular}

As médias de desadaptação vertical antes do ensaio de fadiga mostraramse diferentes, sendo encontrada a menor média no grupo $V$, enquanto que as maiores médias foram encontradas nos grupos I e IV. Os desvios padrões apresentaram valores próximos, encontrando-se o maior desvio padrão no grupo I, e o menor no grupo IV. 
TABELA 5.2.2: Médias e desvio padrão em $\mu \mathrm{m}$ da desadaptação vertical na interface implante / pilar após o ensaio de fadiga.

\begin{tabular}{lcc}
\hline \multicolumn{1}{c}{ Grupo } & Depois_carga \pm dp & No. corpos provas \\
\hline I $\quad$ UCLA_ciment. & $17,28 \pm 8,77$ & 10 \\
II Emfils_ciment. & $4,83 \pm 4,50$ & 10 \\
III TMI_ciment. & $8,07 \pm 4,31$ & 10 \\
IV UCLA_paraf. & $17,78 \pm 10,99$ & 9 \\
V Ceraon_ciment. & $3,81 \pm 4,84$ & 10 \\
\hline & & 49 \\
\hline
\end{tabular}

As médias da desadaptação vertical após a aplicação do ensaio de fadiga mostraram-se diferentes, observando-se que os maiores valores das médias, foram encontrados nos grupos I e IV; enquanto que os menores valores das médias foram encontradas nos grupos $\mathrm{V}$ e II. O desvio padrão foi encontrado ser maior nos grupos I e IV. Nesta fase da avaliação da desadaptação somente foram examinadas 49 amostras já que uma amostra do grupo IV o parafuso soltou, e não pode ser avaliada. 
GRÁFICO 5.2.1: Representação gráfica das médias em $\mu \mathrm{m}$ da desadaptação vertical na interface implante / pilar dos grupos avaliados, antes e após o ensaio de fadiga.

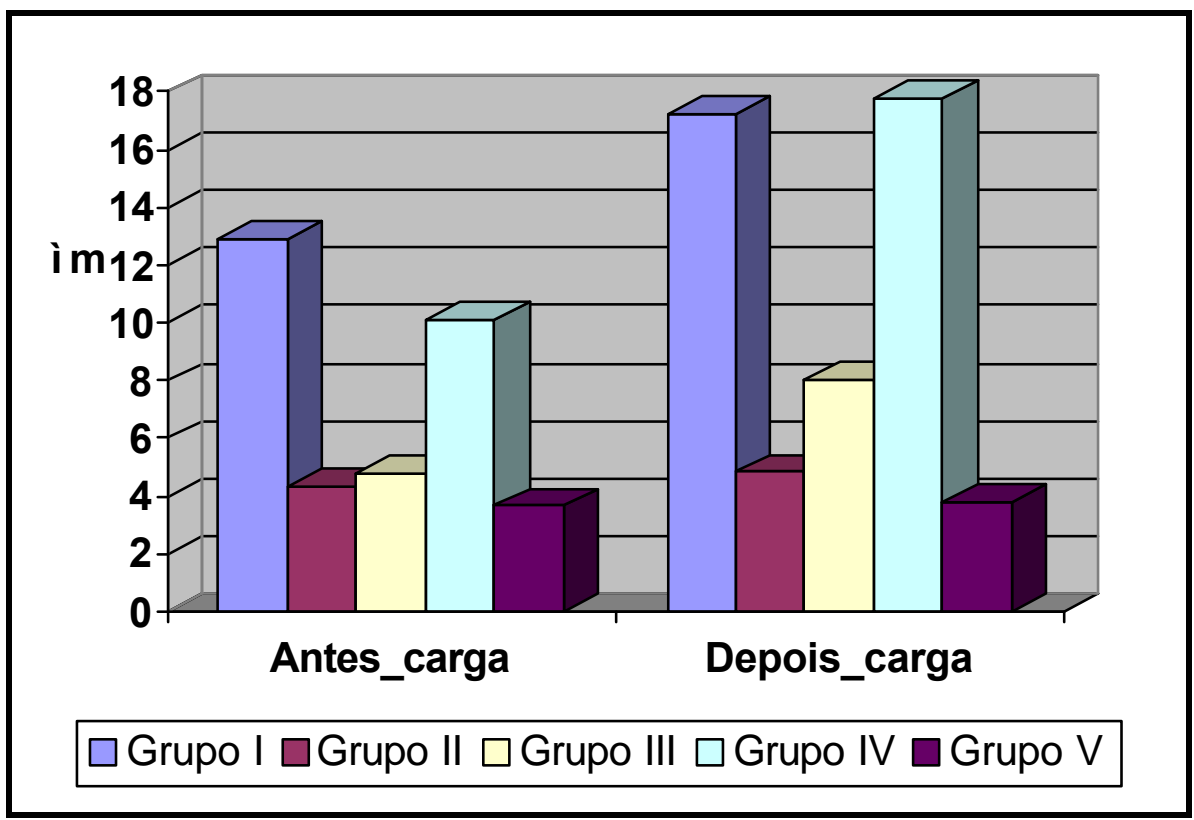

TABELA 5.2.3: Análise de variância (ANOVA) a dois critérios (Grupo, Desadaptação) para comparação das diferenças entre as médias das medidas de desadaptação vertical na interface implante / pilar, dos grupos avaliados.

\begin{tabular}{lcccccc}
\hline \multicolumn{1}{|l}{ Variação } & $\begin{array}{c}\text { GL } \\
\text { efeito }\end{array}$ & $\begin{array}{c}\text { Quadrado } \\
\text { médio }\end{array}$ & $\begin{array}{c}\text { GL } \\
\text { erro }\end{array}$ & $\begin{array}{c}\text { Quadrado } \\
\text { médio erro }\end{array}$ & $\mathbf{F}$ & $\mathbf{P}$ \\
\hline Grupo & 4 & 556,7720 & 44 & 51,57025 & 10,79638 & $0,000003^{*}$ \\
Desadaptação & 1 & 243,4237 & 44 & 17,59458 & 13,83515 & $0,000562^{*}$ \\
Interação & 4 & 46,2313 & 44 & 17,59458 & 2,62759 & $0,047088^{*}$ \\
\hline
\end{tabular}


Através da análise de variância (ANOVA) encontrourse que existe diferença no comportamento entre grupos, desadaptação e interação. Por causa da interação os grupos foram analisados separadamente antes e depois do ensaio de fadiga utilizando-se Teste Tukey, onde foram realizadas as comparações múltiplas de todos os grupos.

TABELA 5.2.4: Teste Tukey para comparações de grupos homogêneos, da desadaptação da interface implante / pilar antes do ensaio de fadiga.

\begin{tabular}{lll|l}
\hline \multicolumn{2}{c}{ Grupo } & \multicolumn{2}{c}{ Média (ìm) } \\
\hline V Ceraon_ciment. & 3,86 \\
II Emfils_ciment. & 4,33 & \\
III TMI_ciment. & 4,79 & $\mid$ \\
IV UCLA_paraf. & 9,67 & $\mid$ \\
I UCLA_ciment. & 12,88 & $\mid$ \\
\hline
\end{tabular}

Os grupos unidos por barra vertical não possuem diferença estatisticamente significante entre si $(p<0,05)$. 
TABELA 5.2.5: Teste Tukey para comparações de grupos homogêneos, da desadaptação da interface implante / pilar depois do ensaio de fadiga.

\begin{tabular}{|c|c|c|c|}
\hline \multicolumn{2}{|r|}{ Grupo } & \multicolumn{2}{|r|}{ Média ( ìm) } \\
\hline $\mathbf{v}$ & Ceraon_ciment. & 3,81 & \\
\hline II & Emfils_ciment. & 4,83 & \\
\hline III & TMI_ciment. & 8,07 & \\
\hline I & UCLA_ciment. & 17,28 & \\
\hline IV & UCLA paraf. & 17,78 & \\
\hline
\end{tabular}

Os grupos unidos por barra vertical não possuem diferença estatisticamente significante entre si $(p<0,05)$. 
TABELA 5.2.6: Teste Tukey para comparação de cada grupo examinado, na desadaptação da interface implante / pilar, antes e depois da do ensaio de fadiga.

\begin{tabular}{lcc|c}
\multicolumn{1}{c}{ Grupo } & Carga & Média (ìm) \\
\hline Grupo I & Antes_carga & 12,88 & \\
UCLA_ciment. & Depois_carga & 17,28 & \\
\hline Grupo II & Antes_carga & 4,33 & \\
Emfils_ciment. & Depois_carga & 4,83 & \\
\hline Grupo III & Antes_carga & 4,79 & \\
TMI_ciment. & Depois_carga & 8,07 & \\
\hline Grupo IV & Antes_carga & 9,67 & \\
UCLA_paraf. & Depois_carga & 17,78 & \\
\hline Grupo V & Antes_carga & 3,86 & \\
Ceraon_ciment. & Depois_carga & 3,81 & \\
\hline
\end{tabular}

Os grupos unidos por barra vertical não possuem diferença estatisticamente significante entre si $(p<0,05)$. 
5.3: Resultados obtidos a partir das médias das medidas de destorque antes e após o ensaio de fadiga.

As médias do destorque do parafuso de fixação do pilar antes e após o ensaio de fadiga foram submetidas à análise estatísticas, através da análise de variância com nível de significância de 5\%, e o Teste de Tukey para determinação dos grupos homogêneos, sendo os mesmos representados nas tabelas: 5.3.1; 5.3.2; 5.3.3; 5.3.4; 5.3.5; 5.3.6; 5.3.7; 5.3.8; 5.3.9; 5.3.10; 5.3.11; 5.3.12; 5.3.13; e 5.3.14; 5.3.15; e 5.3.16; e nos gráficos: 5.3.1, e 5.3.2.

TABELA 5.3.1: Médias e desvio padrão em N.cm do torque e do destorque inicial realizado nos parafusos de fixação, antes do ensaio de fadiga.

\begin{tabular}{lccc}
\hline Grupo & Torque & $\begin{array}{c}\text { Destorque inicial } \\
\pm \mathrm{dp}\end{array}$ & Diferenças \\
\hline I UCLA_ciment. & 30 & $24,50 \pm 0,85$ & 5,50 \\
II Emfils_ciment. & 30 & $28,50 \pm 0,53$ & 1,50 \\
III TMI_ciment. & 30 & $25,60 \pm 1,43$ & 4,40 \\
IV UCLA_paraf. & 30 & $24,10 \pm 0,99$ & 5,90 \\
V Ceraon_ciment. & 30 & $26,80 \pm 0,92$ & 3,20 \\
\hline Todos grupos & 30 & $25,90 \pm 1,88$ & 4,10 \\
\hline
\end{tabular}

As maiores diferenças entre o torque aplicado e o destorque inicial realizado foram encontradas nos grupos I e IV, enquanto que a menor diferença foi encontrada no grupo II. 
TABELA 5.3.2: Médias e desvio padrão em N.cm do torque, do destorque final e suas diferenças, realizados nos parafusos de fixação, após o ensaio de fadiga.

\begin{tabular}{lccc}
\hline Grupo & Torque & $\begin{array}{c}\text { Destorque final } \\
\pm \mathrm{dp}\end{array}$ & Diferenças \\
\hline I UCLA_ciment. & 30 & $11,00 \pm 7,99$ & 19 \\
II Emfils_ciment. & 30 & $24,70 \pm 4,55$ & 5,3 \\
III TMI_ciment. & 30 & $18,30 \pm 3,74$ & 11,7 \\
IV UCLA_paraf. & 30 & $9,50 \pm 7,79$ & 20,5 \\
V Ceraon_ciment. & 30 & $22,50 \pm 3,10$ & 7,5 \\
\hline Todos grupos & 30 & $17,20 \pm 8,26$ & 12,8 \\
\hline
\end{tabular}

As maiores diferenças entre o torque e o destorque final após o ensaio de fadiga foram encontradas nos grupos I e IV, enquanto que a menor diferença foi encontrada no grupo II. 
TABELA 5.3.3: Médias e desvio padrão em N.cm do destorque inicial, e do destorque final realizado nos parafusos de fixação, após o ensaio de fadiga.

\begin{tabular}{lccc}
\hline Grupo & $\begin{array}{c}\text { Destorque } \\
\text { inicial } \pm \mathbf{d p}\end{array}$ & $\begin{array}{c}\text { Destorque final } \\
\mathbf{1} \mathbf{d p}\end{array}$ & Diferenças \\
\hline I UCLA_ciment. & $24,50 \pm 0,85$ & $11,00 \pm 7,99$ & 13,50 \\
II Emfils_ciment. & $28,50 \pm 0,53$ & $24,70 \pm 4,55$ & 3,80 \\
III TMI_ciment. & $25,60 \pm 1,43$ & $18,30 \pm 3,74$ & 7,30 \\
IV UCLA_paraf. & $24,10 \pm 0,99$ & $9,50 \pm 7,79$ & 14,60 \\
V Ceraon_ciment. & $26,80 \pm 0,92$ & $22,50 \pm 3,10$ & 4,30 \\
\hline Todos grupos & $25,90 \pm 1,88$ & $17,20 \pm 8,26$ & 8,70 \\
\hline
\end{tabular}

As maiores diferenças entre o destorque inicial e o destorque final após o ensaio de fadiga encontraram-se nos grupos I e IV, enquanto que as menores diferenças foram encontradas nos grupos II e V. 
Gráfico 5.3.1: Representação gráfica das médias em N.cm do destorque inicial e final dos parafusos de fixação dos grupos avaliados.

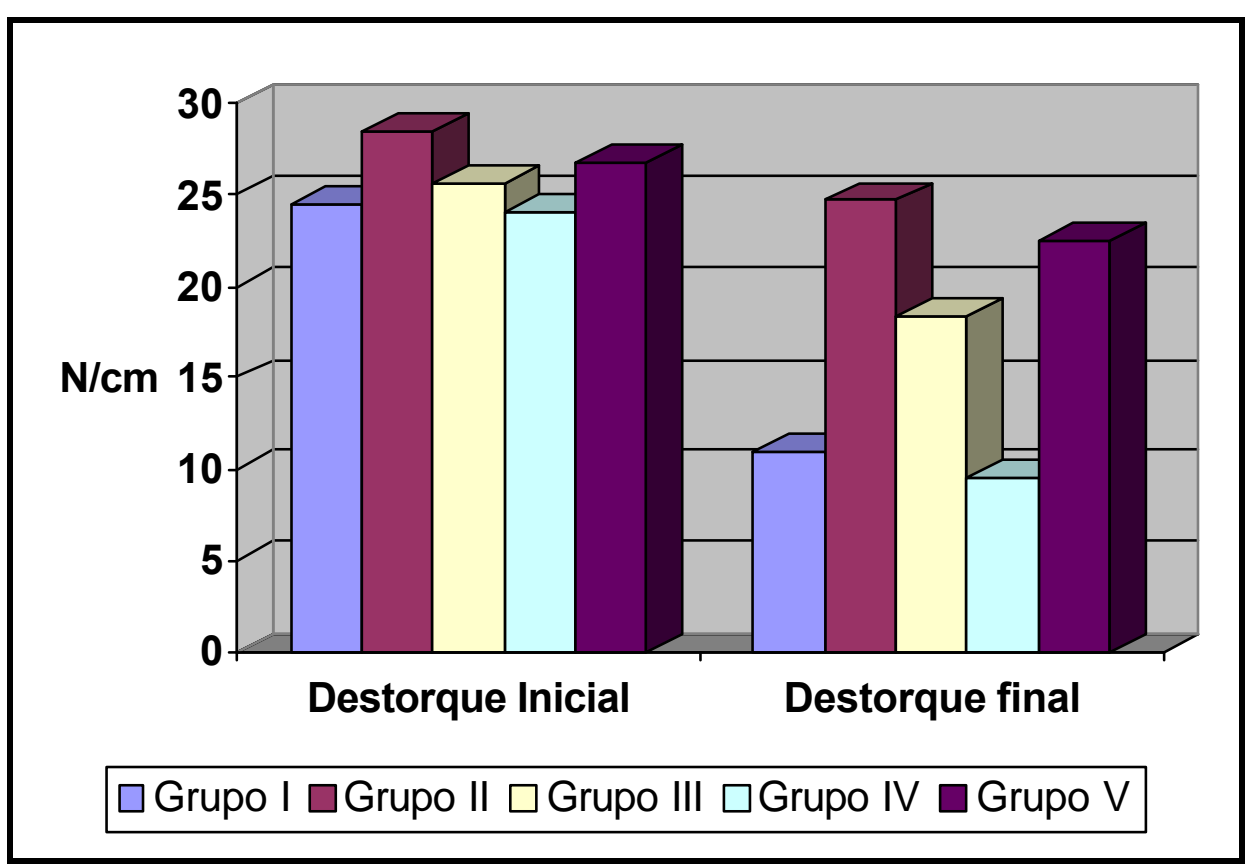

TABELA 5.3.4: Análise de variância (ANOVA) a dois critérios (Grupo, Destorque) para comparação das diferenças entre as médias do destorque dos parafusos de fixação do pilar, dos grupos avaliados.

\begin{tabular}{ccccccc}
\hline Variação & $\begin{array}{c}\text { GL } \\
\text { efeito }\end{array}$ & $\begin{array}{c}\text { Quadrado } \\
\text { médio }\end{array}$ & $\begin{array}{c}\text { GL } \\
\text { erro }\end{array}$ & $\begin{array}{c}\text { Quadrado } \\
\text { médio erro }\end{array}$ & $\mathbf{F}$ & P \\
\hline Grupo & 4 & 361,375 & 45 & 19,08333 & 18,9367 & $0,00000^{*}$ \\
Destorque & 1 & 1892,250 & 45 & 15,060778 & 121,2376 & $0,00000^{*}$ \\
Interação & 4 & 128,975 & 45 & 15,60778 & 8,2635 & $0,00044^{*}$ \\
"diferença estatisticamente significante $(\mathrm{p}<0,05)$ & & & & &
\end{tabular}

Através da análise de variância (ANOVA) encontrourse que existe diferença entre grupos, destorque, e interação. Por causa da interação os grupos foram analisados separadamente nas condições antes e depois do ensaio de fadiga, 
para isto utilizou-se o Teste de Tukey, onde foram realizadas as comparações múltiplas de todos os grupos.

TABELA 5.3.5: Teste Tukey para comparações de grupos homogêneos, das médias destorque em N.cm do parafuso de fixação do pilar, antes do ensaio de fadiga.

\begin{tabular}{lll|l}
\hline \multicolumn{1}{c}{ Grupo } & \multicolumn{2}{c}{ Média } \\
\hline IV UCLA_paraf. & 24,10 & & \\
I UCLA_ciment. & 24,50 & & \\
III TMI_ciment. & 25,60 & $\mid$ & \\
V Ceraon_ciment. & 26,80 & $\mid$ \\
II & Emfils_ciment. & 28,50 & $\mid$ \\
\hline
\end{tabular}

Os grupos unidos por barra vertical não possuem diferença estatisticamente significante entre si $(p<0,05)$. 
TABELA 5.3.6: Teste Tukey para comparações de grupos homogêneos, das médias destorque em N.cm do parafuso de fixação do pilar, após o ensaio de fadiga.

\begin{tabular}{lll|l}
\hline \multicolumn{1}{c}{ Grupo } & \multicolumn{2}{c}{ Média } \\
\hline IV UCLA_paraf. & 9,50 & \\
I UCLA_ciment. & 11,00 & \\
III TMI_ciment. & 18,30 & \\
V Ceraon_ciment. & 22,50 & \\
II Emfils_ciment. & 24,70 & $\mid$ \\
\hline
\end{tabular}

Os grupos unidos por barra vertical não possuem diferença estatisticamente significante entre si $(p<0,05)$. 
TABELA 5.3.7: Teste Tukey para comparação das médias em N.cm de cada um dos grupos avaliados, antes e após o ensaio de fadiga.

\begin{tabular}{|c|c|c|}
\hline Grupo & Carga & Média \\
\hline & Antes_carga & 24,50 \\
\hline \multicolumn{3}{|l|}{ Grupo I } \\
\hline \multirow[t]{2}{*}{ UCLA_ciment. } & Depois_carga & 11,00 \\
\hline & Antes_carga & 28,50 \\
\hline \multicolumn{3}{|l|}{ Grupo II } \\
\hline \multirow[t]{2}{*}{ Emfils_ciment. } & Depois_carga & 24,70 \\
\hline & Antes_carga & 25,60 \\
\hline Grupo III & Depois caraa & 1830 \\
\hline TMI_ciment. & Antes_carga & 24,10 \\
\hline \multicolumn{3}{|l|}{ Grupo IV } \\
\hline \multirow{2}{*}{ UCLA_paraf. } & & \\
\hline & Antes_carga & 26,80 \\
\hline $\begin{array}{l}\text { Grupo V } \\
\text { Ceraon_ciment. }\end{array}$ & Depois_carga & 22,50 \\
\hline
\end{tabular}

Os grupos unidos por barra vertical não possuem diferença estatisticamente significante entre si $(p<0,05)$. 
TABELA 5.3.8: Médias e desvio padrão expressos em percentagens da redução de torque antes do ensaio de fadiga. Diferença obtida entre o torque inicial de 30 N.cm e o destorque inicial antes do ensaio de fadiga.

\begin{tabular}{lcc} 
Grupo & $\begin{array}{c}\text { Redução inicial de } \\
\text { torque } \pm \mathbf{d p}\end{array}$ & No. corpos provas \\
\hline I UCLA_ciment. & $18,33 \pm 2,83$ & 10 \\
II Emfils_ciment. & $5,00 \pm 1,76$ & 10 \\
III TMI_ciment. & $14,67 \pm 4,76$ & 10 \\
IV UCLA_paraf. & $19,67 \pm 3,31$ & 10 \\
V Ceraon_ciment. & $10,67 \pm 3,06$ & 10 \\
\hline Todos grupos & $13,67 \pm 6,25$ & 50 \\
\hline
\end{tabular}

As percentagens de redução de torque antes da aplicação das cargas foram menores no grupo II e maiores no grupo IV. O desvio padrão teve pequenas diferenças nos grupos I, IV, e V.

TABELA 5.3.9: Análise de variância (ANOVA) a um critério (Grupo) para comparação da redução de torque dos grupos avaliados, antes do ensaio de fadiga.

\begin{tabular}{cccccc}
\hline GL efeito & $\begin{array}{c}\text { Quadrado } \\
\text { médio }\end{array}$ & $\begin{array}{c}\text { GL } \\
\text { erro }\end{array}$ & $\begin{array}{c}\text { Quadrado } \\
\text { médio erro }\end{array}$ & $\mathbf{F}$ & $\mathbf{P}$ \\
\hline 4 & 357,2222 & 45 & 10,83951 & 32,95558 & $0,000000^{*}$ \\
\hline "diferença estatisticamente significante $(\mathrm{p}<0,05)$ & &
\end{tabular}


Através da análise de variância (ANOVA) encontrourse que existe diferença na redução de torque nos grupos estudados, antes do ensaio de fadiga; sendo que para comparar e interpretar as diferenças foi aplicado o Teste Tukey, onde foram realizadas comparações múltiplas de todos os grupos.

TABELA 5.3.10: Teste Tukey para comparação dos grupos examinados em relação à redução de torque, antes do ensaio de fadiga.

\begin{tabular}{lll|l}
\hline \multicolumn{1}{c}{ Grupo } & \multicolumn{3}{c}{ Média (\%) } \\
\hline IV UCLA_paraf. & 19,67 & & \\
I UCLA_ciment. & 18,33 & & \\
III TMI_ciment. & 14,67 & $\mid$ & \\
V Ceraon_ciment. & 10,67 & & \\
II Emfils_ciment. & 5,00 & $\mid$ \\
\hline
\end{tabular}

Os grupos unidos por barra vertical não possuem diferença estatisticamente significante entre si $(p<0,05)$. 
TABELA 5.3.11: Médias e desvio padrão expressas em percentagens da redução de torque após a aplicação da carga. Diferença do torque inicial de 30 N.cm e o destorque final após o ensaio de fadiga.

\begin{tabular}{llc}
\hline \multicolumn{1}{c}{ Grupo } & $\begin{array}{c}\text { Redução final de } \\
\text { torque } \pm \mathbf{d p}\end{array}$ & No. corpos provas \\
\hline I $\quad$ UCLA_ciment. & $63,33 \pm 26,62$ & 10 \\
II Emfils_ciment. & $17,67 \pm 15,16$ & 10 \\
III TMI_ciment. & $39,00 \pm 12,48$ & 10 \\
IV UCLA_paraf. & $68,33 \pm 25,93$ & 10 \\
V Ceraon_ciment. & $25,00 \pm 10,33$ & 10 \\
\hline Todos grupos & $42,67 \pm 27,56$ & 50 \\
\hline
\end{tabular}

As percentagens de redução do torque após o ensaio de fadiga tiveram grandes diferenças em todos os grupos examinados; da mesma forma houve um alto desvio padrão em todos os grupos.

TABELA 5.3.12: Análise de variância (ANOVA) a um critério (Grupo) para comparação da redução de torque dos grupos avaliados, depois do ensaio de fadiga.

\begin{tabular}{cccccc}
\hline GL efeito & $\begin{array}{c}\text { Quadrado } \\
\text { médio }\end{array}$ & $\begin{array}{c}\text { GL } \\
\text { erro }\end{array}$ & $\begin{array}{c}\text { Quadrado } \\
\text { médio erro }\end{array}$ & F & P \\
\hline 4 & 5091,111 & 45 & 374,6173 & 13,59017 & $0,000000^{*}$ \\
\hline *diferença estatisticamente significante $(\mathrm{p}<0,05)$ &
\end{tabular}


Através da análise de variância (ANOVA) encontrou-se que existe diferença na redução do torque dos grupos estudados, depois do ensaio de fadiga; sendo que para comparar e interpretar as diferenças foi aplicado o Teste Tukey, onde foram realizadas as comparações múltiplas de todos os grupos.

TABELA 5.3.13: Teste Tukey para comparação dos grupos avaliados em relação à redução de torque, após o ensaio de fadiga.

\begin{tabular}{lll|l}
\hline \multicolumn{1}{c}{ Grupo } & \multicolumn{2}{c}{ Média (\%) } \\
\hline IV UCLA_paraf. & 68,33 & \\
I UCLA_ciment. & 63,33 & $\mid$ \\
III TMI_ciment. & 39,00 & $\mid$ \\
V Ceraon_ciment. & 25,00 & $\mid$ \\
II Emfils_ciment. & 17,67 & \\
\hline
\end{tabular}

Os grupos unidos por barra vertical não possuem diferença estatisticamente significante entre si $(p<0,05)$. 
TABELA 5.3.14: Médias e desvio padrão expressas em percentagens da redução real do torque. Diferença do destorque inicial e o destorque final depois do ensaio de fadiga.

\begin{tabular}{|c|c|c|c|}
\hline & Grupo & $\begin{array}{l}\text { Redução real de } \\
\text { torque } \pm \text { dp }\end{array}$ & No. corpos provas \\
\hline I & UCLA_ciment. & $55,63 \pm 31,84$ & 10 \\
\hline II & Emfils_ciment. & $13,30 \pm 16,25$ & 10 \\
\hline III & TMI_ciment. & $28,24 \pm 16,09$ & 10 \\
\hline IV & UCLA_paraf. & $61,20 \pm 31,65$ & 10 \\
\hline \multirow[t]{2}{*}{$\mathbf{v}$} & Ceraon_ciment. & $16,12 \pm 10,79$ & 10 \\
\hline & Todos grupos & $34,90 \pm 29,88$ & 50 \\
\hline
\end{tabular}

As médias de reduções reais de torque dos grupos testados, após o ensaio de fadiga, mostraram grandes diferenças em todos os grupos. Nos grupos I e IV encontraram-se as maiores médias de redução real de torque. O grupo II teve a menor média de redução de torque. Da mesma forma, o desvio padrão apresentourse alto em todos os grupos testados. 
TABELA 5.3.15: Análise de variância (ANOVA) a um critério (Grupo) para comparação da redução real do torque dos grupos avaliados.

\begin{tabular}{cccccc}
\hline GL efeito & $\begin{array}{c}\text { Quadrado } \\
\text { médio }\end{array}$ & $\begin{array}{c}\text { GL } \\
\text { erro }\end{array}$ & $\begin{array}{c}\text { Quadrado } \\
\text { médio erro }\end{array}$ & F & P \\
\hline 4 & 4961,575 & 45 & 530,9035 & 9,345531 & $0,000014^{*}$ \\
\hline "diferença estatisticamente significante $(\mathrm{p}<0,05)$ & &
\end{tabular}

Através da Análise de Variância (ANOVA) encontrou-se que existe diferença na redução real do torque nos grupos estudados, sendo que para comparar e interpretar as diferenças foi aplicado o Teste Tukey, com o qual foram realizadas as comparações múltiplas de todos os grupos.

TABELA 5.3.16: Teste Tukey para comparação dos grupos avaliados em relação à redução real do torque.

\begin{tabular}{lcc|}
\hline \multicolumn{1}{c}{ Grupo } & \multicolumn{2}{c}{ Média (\%) } \\
\hline IV UCLA_paraf. & 61,20 \\
I UCLA_ciment. & 55,63 & $\mid$ \\
III TMI_ciment. & 28,24 & $\mid$ \\
V Ceraon_ciment. & 16,12 & $\mid$ \\
II Emfils_ciment. & 13,30 & $\mid$ \\
\hline
\end{tabular}

Os grupos unidos por barra vertical não possuem diferença estatisticamente significante entre si $(p<0,05)$. 
GRÁFICO 5.3.2: Representação gráfica das médias em percentagens da redução inicial, final, e real de torque dos parafusos de fixação dos grupos avaliados.

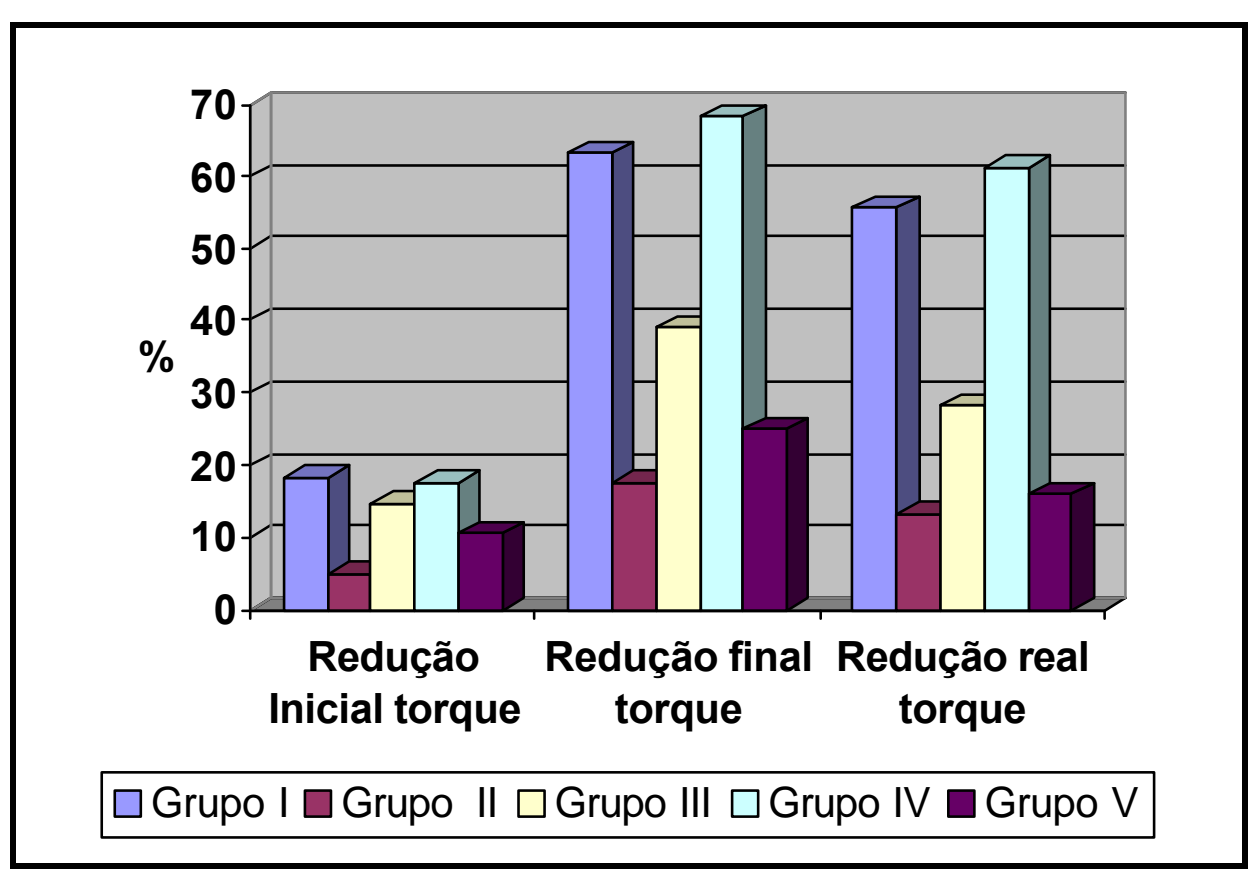




\section{6- DISCUSSÃO}




\section{DISCUSÃO}

O indiscutível sucesso dos implantes osseointegrados como suporte de restaurações unitárias tem sido demonstrado amplamente, pelos estudos longitudinais de acompanhamento clínico dos diferentes sistemas disponíveis ${ }^{3,4,6 \text {, }}$ $7,9,10,13,41,44,51,57,58,64,65,70,71,72,88,93,97,99$. Novos implantes e componentes são desenvolvidos com freqüência pelos fabricantes, no intuito de obter resultados que garantam melhoras na estética e na função das restaurações unitárias, que são o grande desafio do cirurgião-dentista reabilitador.

Falhas protéticas são comuns neste tipo de restauração, principalmente no referente à estabilidade do parafuso de fixação que une o pilar ao implante, ou do parafuso que une a prótese ao pilar. Altas percentagens de falhas são reportadas

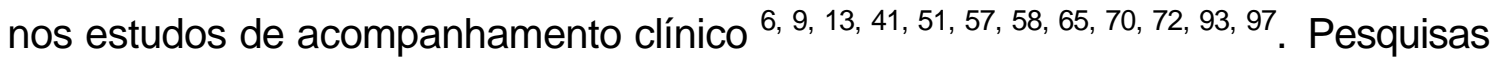
clínicas e laboratoriais são realizadas com o objetivo de estabelecer as principais causas deste tipo de falhas, de forma que possam proporcionar dados que permitam o desenvolvimento de componentes que levem à diminuição ou à eliminação deste problema.

A restauração unitária se torna biomecanicamente complicada quando se trata da substituição de elementos dentários nas áreas de pré-molares e molares; nestas áreas as forças oclusais são maiores, e podem levar a tensões elevadas nos componentes e osso, tornando a união mais susceptível a falha ${ }^{9}$. A restauração também pode ser influenciada pelo contato oclusal e a inclinação da cúspide, determinando a relação entre as forças axiais e as forças laterais. A cúspide com pouca inclinação leva componentes de forças laterais pequenos, e a uma maior relação de contato cêntrico, o que terá como conseqüência uma maior concentração de forças axiais, o que se torna favorável para a distribuição das cargas nos componentes ${ }^{90,113}$.

O comportamento biomecânico das restaurações unitárias no setor posterior e os altos índices de falhas na estabilidade da união implante / pilar, 
principalmente na área de molar, levou pesquisadores a sugerir a utilização de dois implantes para a restauração de um molar ${ }^{9}$, a utilização de implantes de largo diâmetro ${ }^{35,37}$, ou o uso de sistemas de implantes com conexões que permitam estabelecer restaurações mais estáveis ${ }^{15,}$ 64, 103, 104, e conseqüentemente determinar um maior índice de sucesso.

A conexão hexagonal externa que inicialmente foi desenvolvida para permitir a instalação do implante no leito cirúrgico ${ }^{63}$ tornourse fundamental para a restauração unitária já que permitiu desenvolver um mecanismo de estabilização anti-rotacional entre o implante e a restauração. Este aspecto também é importante na precisão da transferência da posição para o modelo de trabalho e a confecção de uma adequada relação de contato com os dentes adjacentes; além de que o hexágono torna a interface implante / pilar mais resistente ${ }^{35}$.

Da mesma forma conexões hexagonais internas foram desenvolvidas com o objetivo de melhorar a adaptação entre os hexágonos e estabelecer uma interface mais estável, aumentando assim a resistência e reduzindo conseqüentemente complicações, como afrouxamento ou fratura do parafuso de fixação ${ }^{85}$. Neste tipo de conexão, o centro de fixação do parafuso é protegido pela altura do hexágono do pilar dentro do implante, deste modo as forças laterais são transmitidas diretamente às paredes do implante, criando uma menor tensão no parafuso e proporcionando uma melhor resistência as tensões cisalhantes na união. Contrariamente, na conexão externa os componentes de forças laterais são transmitidos ao parafuso de retenção no ponto onde o implante e pilar entram em contato, assim como na base de assentamento do implante, o que eventualmente pode causar afrouxamento ou fratura do parafuso ${ }^{85}$.

A adaptação e precisão dos componentes também têm sido relatadas como um aspecto importante na estabilidade da união implante / pilar ${ }^{14,16,18,20,22, ~ 29, ~ 31, ~ 38, ~}$ $42,48,56,61,75,112$, variações na consistência da fabricação dos componentes podem levar à implicações clínicas de diferentes magnitudes. O diâmetro da base do 
implante requer um tamanho consistente com mínimas variações, com sua contraparte do pilar, já que diferenças podem resultar na formação de um espaço ou fenda, o que possivelmente provocará uma invasão bacteriana, acúmulo de placa e uma resposta tissular adversa ${ }^{48,56}$.

Na análise do diâmetro da base de assentamento dos implantes utilizados no nosso estudo, mostrado na tabela 5.1.1, é evidenciado que os sistemas de implantes estudados têm uma alta consistência dentro de cada um dos grupos, sendo que poucas diferenças são encontradas em implantes do mesmo fabricante. A mesma condição foi encontrada no diâmetro da base do pilar mostrada na tabela 5.1.2. Porém quando comparado o diâmetro da base do pilar e do implante, uma diferença positiva foi encontrada nos grupos I, II, IV, e V, e negativa no sistema do grupo II como mostrada na tabela 5.1.3; o que significa que existem pequenas alterações no contorno da interface implante / pilar, sendo estas de sobrecontorno ou subcontorno (Figuras 6.1, 6.2, 6.3, 6.4, 6.5, exemplos das interfaces dos sistemas avaliados). Provavelmente estas alterações não tenham muita importância na estabilidade da interface, mas este fator é importante, já que acúmulo de placa e aumento da atividade bacteriana nestas áreas podem ocorrer e provocar alterações gengivais.
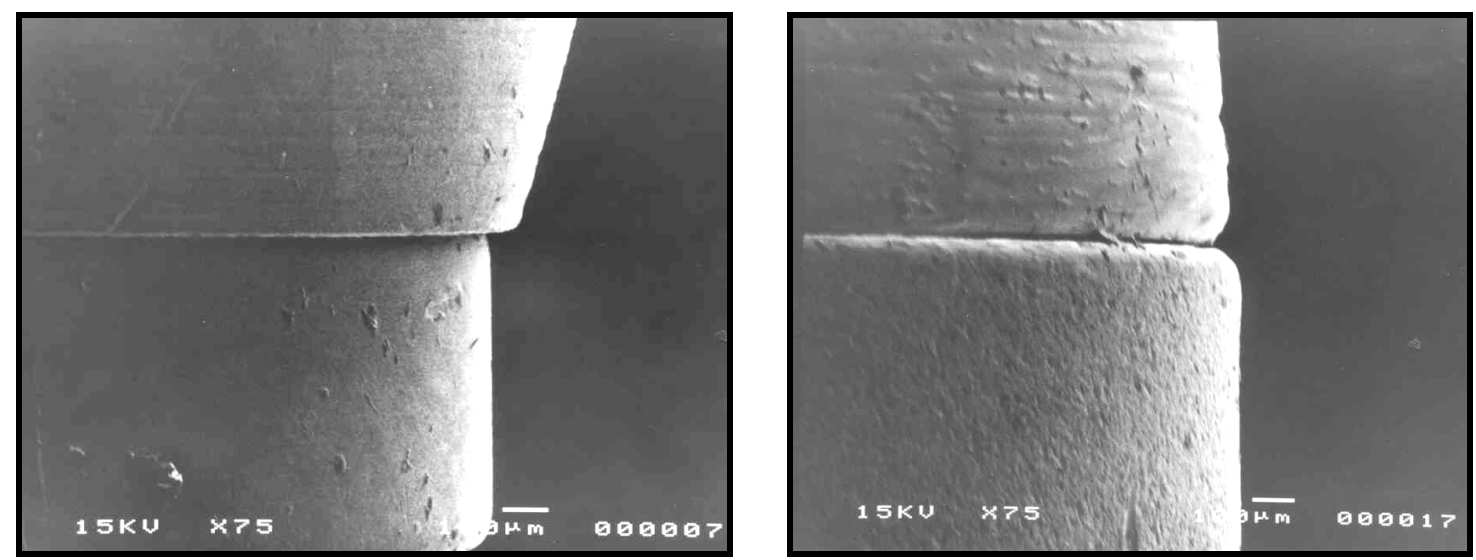

Figuras 6.1, e 6.2: Fotomicrografias da interface implante / pilar dos grupos I e II, mostrando alterações em sentido horizontal. 

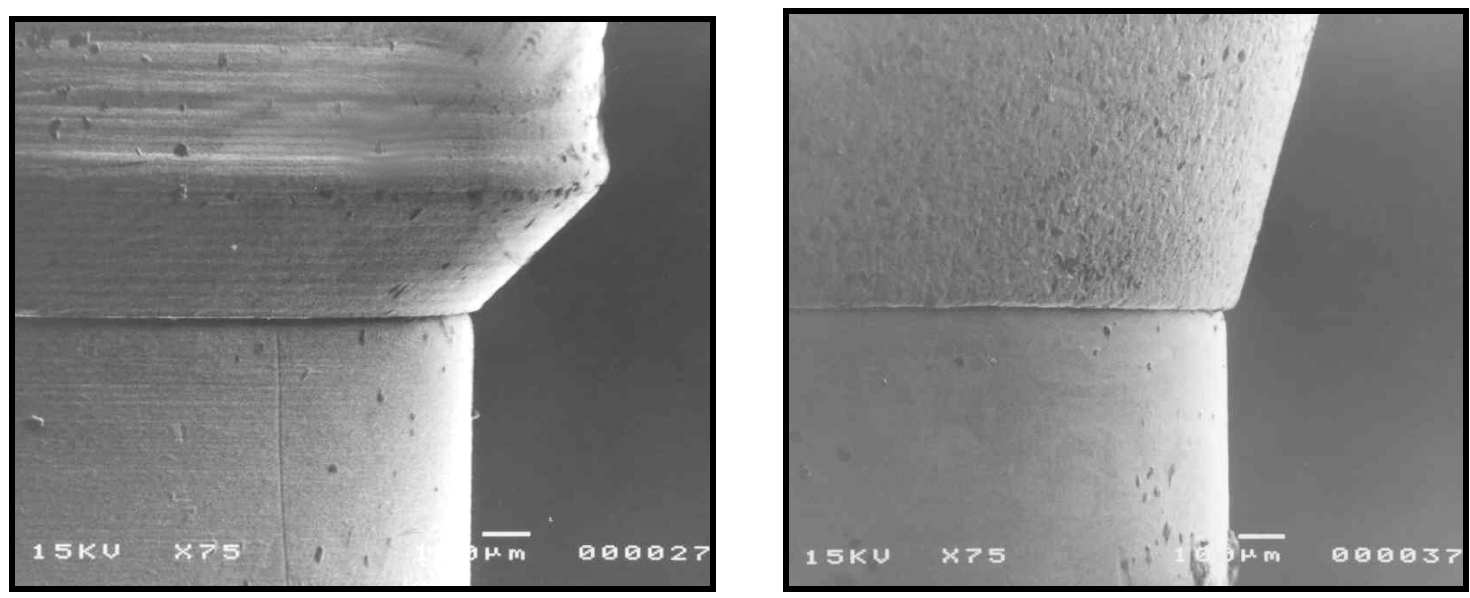

Figuras 6.3, e 6.4: Fotomicrografias da interface implante / pilar dos grupos III e IV.

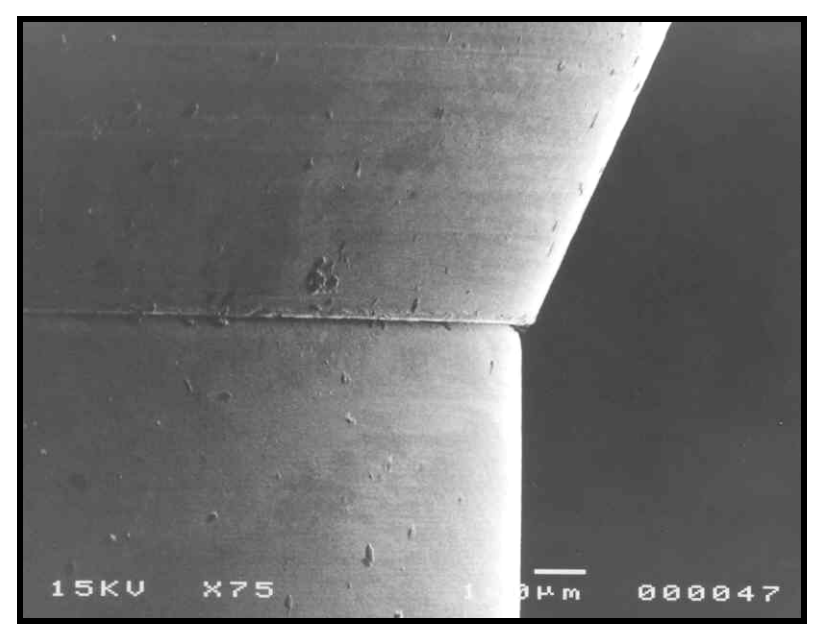

Figuras 6.5: Fotomicrografia da interface implante / pilar do grupo V.

Estes achados são também relatados na literatura, assim podemos observar que pequenas alterações foram encontradas também por BINON ${ }^{14,18}$, em diferentes combinações de sistemas de implantes. Igualmente DELLOW; DRIESSEN $^{38}$ encontraram alterações estatisticamente significantes na relação horizontal da interface implante / pilar dos sistemas Branemark, Southern, SteriOss e Swede - Vent. Da mesma forma, BYRNE et al ${ }^{29}$, MEYER ${ }^{80}$ encontraram 
esta mesma condição. Também BROSCO ${ }^{27}$ encontrou alterações horizontais entre 16,101ìm e 22,387ìm em sistemas de implantes nacionais.

Ao se analisar o diâmetro do hexágono / octágono dos implantes e pilares utilizados em nosso estudo, mostrados nas tabelas 5.1.1, e 5.1.2, observou-se uma consistência entre os grupos do mesmo fabricante (grupos I, IV, e V; e grupos II, e III); o que denota uma boa qualidade de usinagem destes componentes. Os nossos resultados em relação aos implantes de hexágono externo, estão em concordância com os encontrados na literatura, assim vemos o trabalho de BINON, onde implantes de sistemas de hexágono externo Hexlock, Restore, e Threadloc tiveram médias de largura hexagonal de 2,68 \pm 0,00mm; $2,70 \pm 0,00 ; \mathrm{mm}$ e 2,69 $\pm 0,00 \mathrm{~mm}$, respectivamente.

Da mesma forma, MEYER ${ }^{30}$ encontrou médias de 2,69; 2,69, 2,69, e 2,70mm, para os sistemas de hexágono externo, Neodente, Conexão, Nobelpharma, e 3i, respectivamente. BROSCO ${ }^{27}$ encontrou médias de 2,685, 2,697, 2,807, 2,699mm nos sistemas Dentoflex, Titanium Fix, Neodente, e Conexão (Master Screw) respectivamente. Em nossos resultados, foram obtidas médias de 2,68 $\pm 0,01 \mathrm{~mm}$, para o sistema de hexágono externo estudado. Da mesma maneira foram observadas médias de 2,36 $\pm 0,00 \mathrm{~mm}$; e 2,50 $\pm 0,01 \mathrm{~mm}$ nos sistemas Emfils de hexágono interno, e TMI de octágono interno respectivamente. A largura hexagonal da contraparte dos pilares teve médias de $2,70 \pm 0,01 \mathrm{~mm}$, nos pilares tipo UCLA, e 2,73 $\pm 0,02 \mathrm{~mm}$ nos pilares tipo ceraone; e 2,36 $\pm 0,00 \mathrm{~mm}$, e 2,47 $\pm 0,01 \mathrm{~mm}$ nos pilares do sistema Emfils, e do sistema TMI respectivamente (Figuras 6.6 a 6.11, exemplos dos sistemas avaliados). 

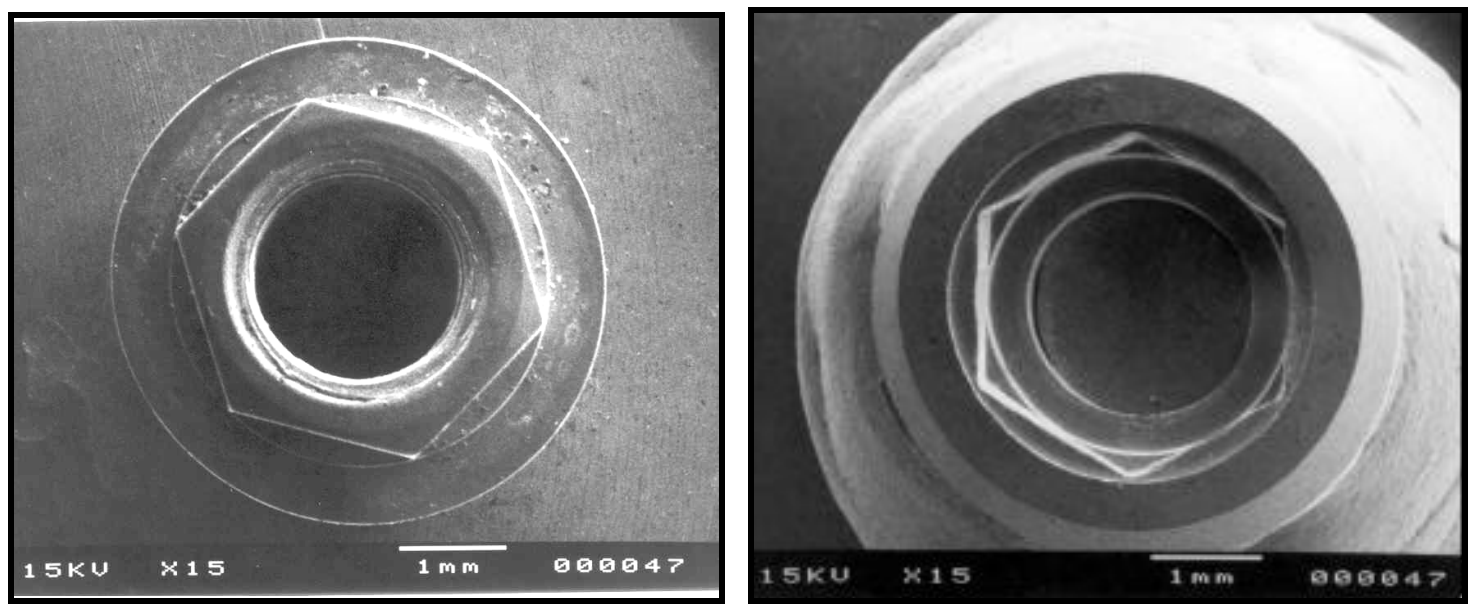

Figuras 6.6, 6.7: Fotomicrografias de implante e pilar de hexágono externo (sistema Conexão).
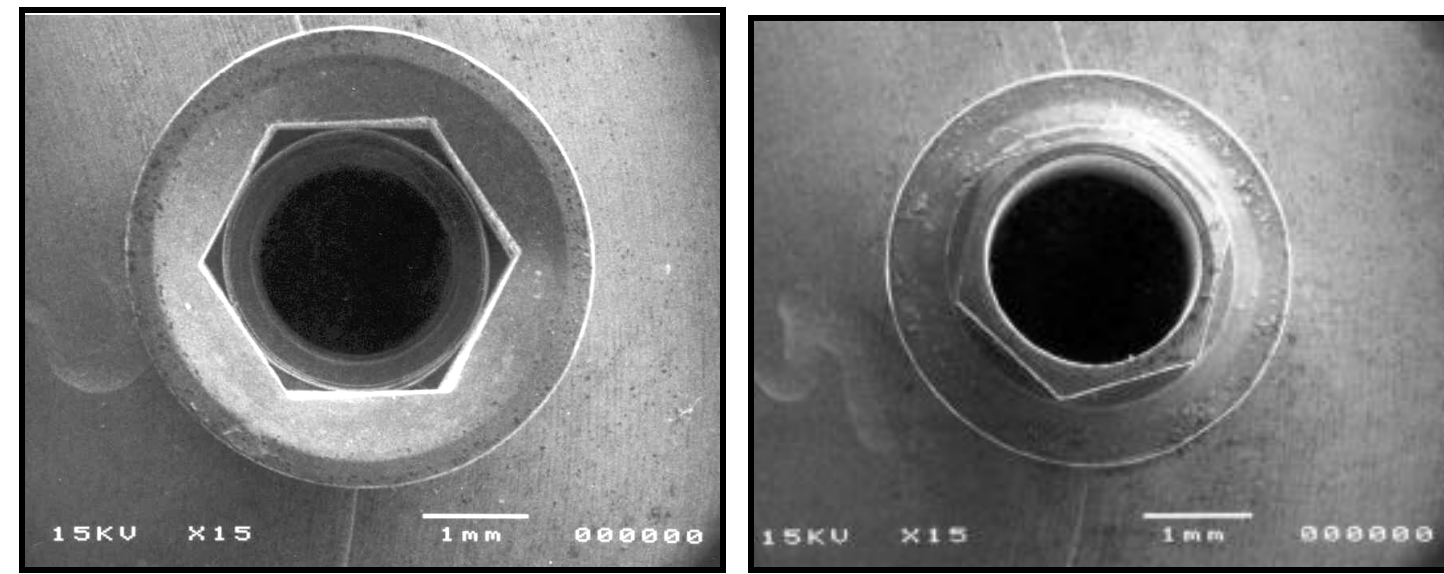

Figuras 6.8, 6.9: Fotomicrografias de implante e pilar de hexágono interno (sistema Emfils). 

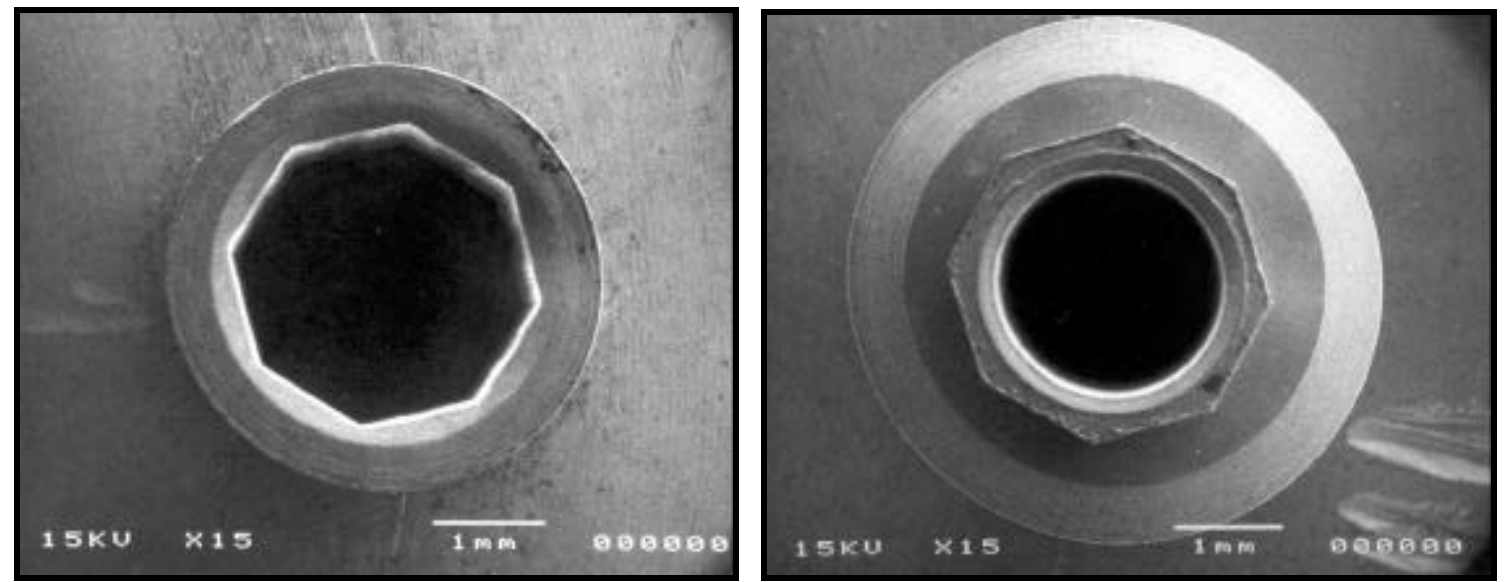

Figuras 6.10, 6.11: Fotomicrografias de implante e pilar de octágono interno

(sistema TMI).

O diâmetro hexagonal ou octagonal do implante e o pilar é relatado ser de importância na estabilidade da interface implante / pilar, já que o encaixe preciso destas áreas influencia diretamente na liberdade rotacional, e consequentemente

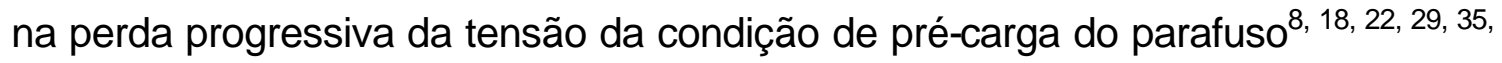
80

Dessa forma, quando se compararam as médias dos diâmetros dos hexágonos dos implantes com as médias do diâmetro dos hexágonos dos pilares (Tabela 5.1.4) foram observadas pequenas diferenças nos grupos I $(0,01 \mathrm{~mm})$, III $(0,03 \mathrm{~mm})$, IV $(0,02 \mathrm{~mm})$, e $\mathrm{V}(0,05 \mathrm{~mm})$, e nenhuma diferença no grupo II o que significa um ajuste altamente preciso entre os componentes deste grupo. Nesse sentido $\mathrm{BROSCO}^{27}$ encontrou diferenças em implantes de fabricação nacional de: 0,124mm (sistema Dentoflex), 0,201 mm (sistema Titanium Fix), 0,035mm (sistema Neodente), 0,127mm (implante Master Screw).

As variações nas dimensões dos hexágonos / octágonos, assim como as diferenças entre as medidas do implante e o pilar podem significar um maior ou menor ajuste, ou uma maior ou menor liberdade rotacional; o que pode ter influenciado o resultado de estabilidade da interface implante / pilar, após as cargas cíclicas. Isto sem observarmos que a maior resistência obtida ao afrouxamento dos parafusos nos grupos testados foi encontrada no sistema Emfils 
de conexão interna que foi também o sistema que teve a menor diferença entre os hexágonos. É claro que não só este fator é determinante na estabilidade; outros fatores como adaptação, tipo de conexão, parafuso, entre outros podem ter influenciado para que este sistema tivesse este comportamento.

Esta situação está bem estabelecida na literatura, onde é relatado que a justeza entre o implante e o pilar, é necessária para que exista uma precisão na adaptação dos hexágonos fazendo com que ocorra uma diminuição da concentração de tensão no conjunto, evitando assim afrouxamento $^{38}$. Componentes que não tenham uma adaptação precisa podem influenciar, no sucesso longitudinal, no prognóstico dos implantes e em implicações clínicas que resultam desde o freqüente afrouxamento dos parafusos de fixação dos pilares, fraturas dos parafusos, instabilidade da prótese, fístulas, respostas adversas dos tecidos moles e até a perda da osseointegração ${ }^{48,56}$.

BINON $^{18,20}$ com base nos ensaios de fadiga e desadaptação rotacional propõe que um diâmetro hexagonal com média menor que $0,015 \mathrm{~mm}$ no conjunto proporcionará um resultado de uma união estável. Além disto afirma que a ocorrência de desadaptação entre os hexágonos pode levar a discrepâncias verticais, e conseqüentemente à deformação do parafuso de fixação durante o aperto, afetando a rigidez da união, a resistência à fadiga e à pré-carga, o que contribui para o afrouxamento do parafuso.

A altura da extensão do hexágono / octágono, também tem sido relacionada como um fator significante na estabilidade da união antirrotacional ${ }^{14,68}$. Estudos de testes de resistência a torsão de BALFOUR; O'BRIEN ${ }^{\beta}$, utilizando implantes de hexágono externo de $0,7 \mathrm{~mm}$ de altura, octagono interno de $0,6 \mathrm{~mm}$, e hexágono interno de $1,7 \mathrm{~mm}$, demonstraram que o desenho da conexão pode afetar a resistência e durabilidade dos componentes; sendo que o hexágono interno de $1,7 \mathrm{~mm}$ foi encontrado ser o desenho mais efetivo, e o octágono interno de $0,6 \mathrm{~mm}$ de altura o desenho menos resistente. Nos desenhos de hexágono e octágono 
interno, o modo de falha foi limitado ao pilar, enquanto que no desenho de hexágono externo o modo de falha foi específico da conexão protética do implante, tornando o implante irrestaurável.

Da mesma forma, MOLLERSTEN; LOCKOWANDT; LINDEN ${ }^{84}$ testaram a força de dobramento até à falha, de conexões internas e externas com profundidades entre 0,6 e 6,0mm, encontrando uma forte correlação entre a profundidade da união e força necessária para falha, sendo que uniões de conexões pouco profundas precisam de valores de forças baixas para a falha, concluindo os autores que conexões profundas favorecem à resistência do sistema. Da mesma forma, BOOGAM et al ${ }^{23}$ afirmaram que quando a altura do hexágono aumenta, diminui a carga no parafuso de fixação do pilar.

No nosso estudo a altura do hexágono variou de 0,63 a 4,23mm (Tabela 5.1.1). Onde os sistemas de hexágono externo (grupos I, IV, e V), tiveram médias de 0,63 a 0,66mm; implantes de hexágono interno (grupo II) de $1,50 \mathrm{~mm}$, e implantes de octágono interno (grupo III) de 4,23mm. Não foi observada uma relação de proporcionalidade entre a altura do hexágono com a estabilidade da união às cargas cíclicas, já que o grupo que mostrou maior estabilidade foi o de hexágono interno (grupo II) de 1,50mm, seguido pelo grupo de hexágono externo e pilar ceraone (grupo V) de $0,63 \mathrm{~mm}$ de altura de conexão. O grupo que tinha a maior altura de conexão (grupo III) com 4,23mm teve um comportamento inferior aos grupos II e V, o que mostra que não somente a altura do hexágono garante a estabilidade da união. Liberdade rotacional, precisão dos componentes, diâmetro do parafuso, roscas do parafuso, composição da liga do parafuso, acabamento do parafuso podem ter influenciado para que a conexão que teve a maior profundidade (grupo III) não tivesse os melhores resultados.

A forma, tamanho, material de revestimento do parafuso e a condição de manutenção da pré-carga também têm sido bastante estudadas e reportadas na literatura $^{16,21,28,45,47,50,54,55,74,82,76,86,91,92,95,96,98, ~ 100, ~ 105, ~ 107, ~ 111, ~} 114$. 
PATERSSON; JOHNS ${ }^{91}$ afirmaram que a ausência de adaptação passiva faz com que as superfícies dos componentes não entrem em contato quando é aplicada a pré-carga, fazendo com que o parafuso receba toda a carga e diminua sua resistência à fadiga; observaram também duas áreas onde existe uma maior concentração de tensão nos parafusos de fixação, e onde provavelmente se inicia a fadiga; a primeira está entre a haste e cabeça do parafuso que é uma conseqüência do raio e o diâmetro da curvatura, e a primeira rosca que é conseqüência da geometria e onde se concentra uma grande quantidade de tensão.

Nesse sentido, BURGUETE et a ${ }^{28}$ afirmaram que a pré-carga depende do coeficiente de fricção, a geometria das roscas e das propriedades do material; sendo o primeiro fator de maior relevância, já que depende da dureza do material, do polimento da superfície, da quantidade e propriedade do lubrificante e da velocidade do aperto. Assim, o coeficiente de friç̧ão aumenta com a dureza do material e a rugosidade da superfície; e diminui com o emprego de lubrificante. Também JORNÉUS et a ${ }^{59}$ mostraram que o desenho da cabeça do parafuso, material do parafuso e o aperto são parâmetros significantes na estabilidade.

Outros estudos ${ }^{50,} 74,76,105$ mostraram que a condição de produção de précarga dos parafusos de ouro é superior quando comparada com os parafusos de titânio. Esta condição é sugerida por HAACK et al ${ }^{50}$, como conseqüência de que a resistência ao escoamento da liga de ouro que permite uma maior elongação, que a liga de titânio que possui maior resistência ao escoamento. Assim quando o parafuso de ouro é submetido a um torque recomendado pelo fabricante de $32 \mathrm{~N} . \mathrm{cm}$ produz uma pré-carga de $468,2 \mathrm{~N}$, enquanto no parafuso de titânio com um torque recomendado pelo fabricante de $20 \mathrm{~N}$.cm produz uma pré-carga de $381,5 \mathrm{~N}$.

Contrariamente a isto JAARDA; RAZZOOG; GRATTON ${ }^{55}$ submeteram cinco diferentes tipos de parafusos de ouro e de titânio a testes de tração, e 
encontraram diferenças estatisticamente significantes na resistência à tração e ao cisalhamento em todos os parafusos testados quando comparados com os parafusos de ouro Nobelpharma, porém determinaram que a máxima resistência à tração foi encontrada em um parafuso de titânio. Os autores afirmaram que a grande variabilidade nos resultados em relação ao tipo de liga utilizada, pode ter influenciado no comportamento diferente dos parafusos de ouro e de titânio. Também RAFEE et al ${ }^{94}$ submeteram parafusos de retenção de ouro a testes de resistência à tração sob condições de repetidos torques e de contaminação, encontrando que estes parafusos podem ser apertados e removidos acima de 20 vezes sem afetar a resistência à tração e que a contaminação com saliva humana não afeta a resistência dos mesmos.

Já BINON $^{16}$ acredita que diferentes condições podem levar a um inadequado aperto do parafuso:

Baixa pré-carga na união do parafuso e uma inadequada força de travamento;

- $\quad$ Falhas no reaperto do parafuso após a inserção e assentamento inicial;

Variáveis induzidas pelo operador na aplicação do torque;

Dificuldades de acesso na região posterior da boca;

Variação do torque produzido pelos diferentes dispositivos mecânicos.

Em nosso trabalho os parafusos utilizados nos cinco sistemas estudados foram de liga de titânio, encontrando-se diferentes dimensões nas medidas realizadas, em cada um deles, como é mostrado na tabela 5.1.5. Isto é importante porque como discutido anteriormente, aspectos relacionados com as dimensões geométricas podem ter influenciado os resultados de estabilidade dos mesmos.

Assim foi encontrado que o comprimento do parafuso dos sistemas estudados teve pouca diferença nos grupos I, e IV, porém maiores diferenças 
foram observadas entre os demais grupos, sendo que o grupo III teve o parafuso de comprimento maior com $8,83 \mathrm{~mm}$, seguido pelo parafuso do grupo II de $6,74 \mathrm{~mm}$. $\mathrm{O}$ menor comprimento do parafuso foi observado grupo $\mathrm{V}$ com $5,95 \mathrm{~mm}$. Igual comportamento foi observado no comprimento das roscas onde o grupo III teve a maior média de $5,72 \mathrm{~mm}$, seguido pelos parafusos do grupo II com $5,55 \mathrm{~mm}$. O menor comprimento das roscas foi observado nos parafusos do grupo V. Já no caso do diâmetro das roscas, as diferenças foram menores, encontrando-se, diâmetros similares nos parafusos dos grupos do mesmo fabricante (grupos I, IV, e V), entre 1,96 e $1,97 \mathrm{~mm}$; enquanto que no grupo III foi encontrado um menor diâmetro de $1,79 \mathrm{~mm}$, e no grupo III de $1,93 \mathrm{~mm}$.

Outro aspecto que é bastante discutido na literatura e que foi analisado nos

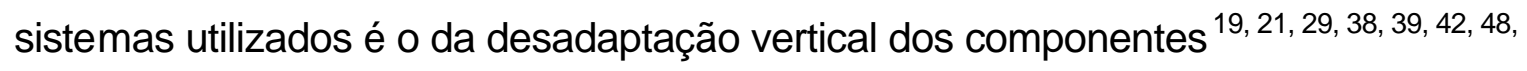
$60,61,56,49,75,80,110$. Isto, devido a que adaptação é considerada importante por ter uma relação direta com a estabilidade da união implante / pilar. Uma pobre adaptação ou desadaptação dos componentes tem como conseqüência uma menor área de superfície de contato entre o pilar e o implante na circunferência da conexão. Assim, a desadaptação leva a uma menor estabilidade, favorecendo micromovimentos entre as partes, e provocando maiores tensões sobre a união, e conseqüentemente levando ao afrouxamento do parafuso.

Desta forma, quando a interface não está corretamente alinhada, devido a desadaptação, a rigidez do conjunto é seriamente comprometida BINON ${ }^{21}$. Nesta situação o torque aplicado no parafuso para o aperto é primeiramente direcionado para o assentamento das partes, afetando assim a produção da pré-carga. É importante ficar claro que a função do parafuso é apenas manter as partes unidas já em contato por uma força de travamento e não aproxima-las sob tensão.

BINON $^{16}$ afirmou que uma prótese adequada deve estar precisamente adaptada, com uma passividade do pilar sobre o implante. Os parafusos devem manter os componentes juntos por compressão e as partes do conjunto devem 
adaptar-se intimamente com mínimas tolerâncias para evitar pequenos movimentos que levem os parafusos a instabilidade. Afirmou também que superfícies usinadas não adaptadas passivamente com o parafuso fixado firmemente provocaram um contato irregular nas roscas, causando danos nas roscas internas, aumento do assentamento, afrouxamento do parafuso, possível fratura e potencial perda do implante.

A desadaptação também tem sido relacionada à complicações biológicas. LEWIS ${ }^{73}$ relatou ter encontrado hiperplasia gengival crônica a redor dos pilares em restaurações realizadas com pilares UCLA pobremente adaptadas. GROSS; ABRAMOVICH; WEISS ${ }^{48}$ observaram um aumento da infiltração bacteriana na interface de cinco sistemas de implantes quando foram aplicados torques de 10 N.cm e uma diminuição, quando os torques foram aumentados para $20 \mathrm{~N} . \mathrm{cm}$, e para os valores de torque recomendados pelos fabricantes; concluindo que quando o valor de torque recomendado é aplicado, uma redução dos efeitos adversos da microiinfiltração pode ser esperada.

Nos sistemas avaliados foram encontradas médias de desadaptação da interface implante / pilar entre 3,85 e 12,88 ìm como mostrado no gráfico 6.12. 


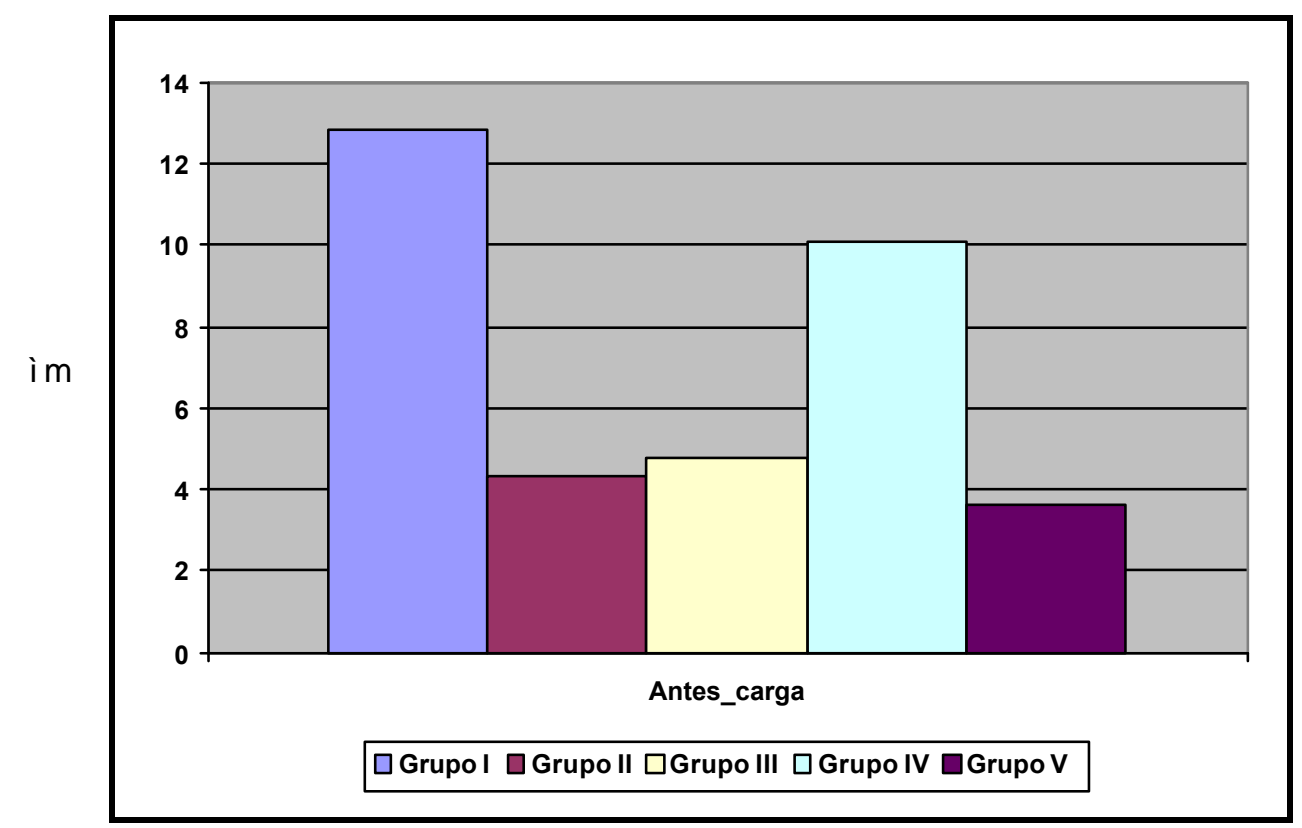

GRÁFICO 6.12: Representação gráfica das médias expressas em ìm da desadaptação dos sistemas estudados antes da aplicação do ensaio de fadiga.

$\mathrm{Na}$ análise microscópica da interface implante / pilar dos sistemas estudados, foi observado que a maioria deles apresentava bordas arredondadas ou biseladas na parte mais externa (Figuras 6.13 a 6.14, exemplos da interface dos sistemas avaliados). Isto coincide com os relatos encontrados na literatura $29,38,60$, 80. Apesar desta condição poder ter alguma repercussão biológica e de dificultar a inspeção, a presença desta condição não significa a ausência de adaptação, sendo que a leitura foi realizada sem considerar o bisel gerado pelos componentes, o que daria uma falsa desadaptação; assim os valores obtidos representam o espaço vertical real da interface. 

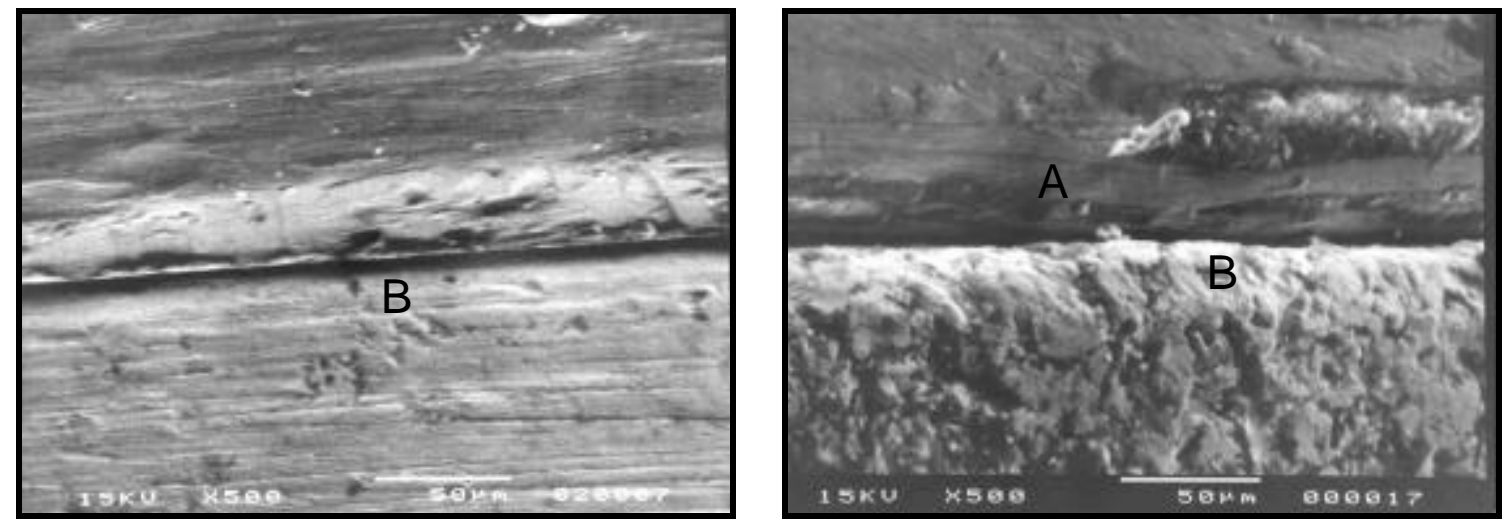

Figuras 6.13, e 614: Fotomicrografias da interface implante / pilar dos grupos I e II respectivamente, mostrando bo rdas arredondadas $(A)$ e / ou biseladas $(B)$.
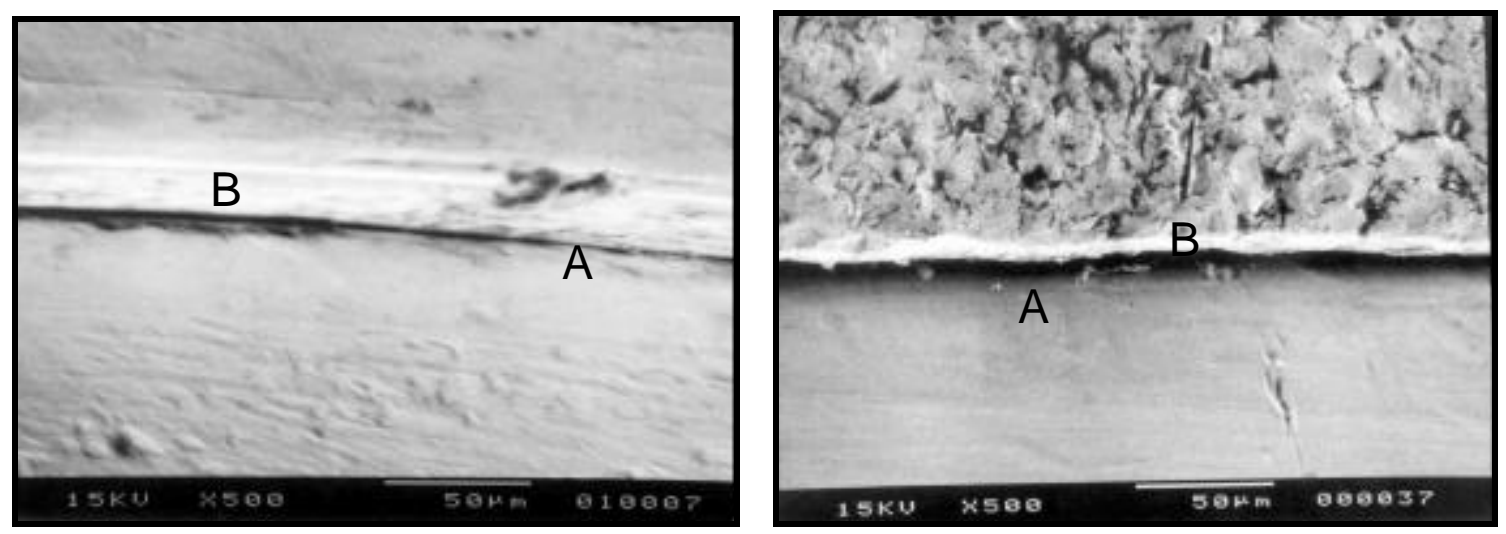

Figuras 6.15, e 616: Fotomicrografias da interface implante / pilar dos grupos III e IV, mostrando bordas arredondadas (A) e / ou biseladas (B). 


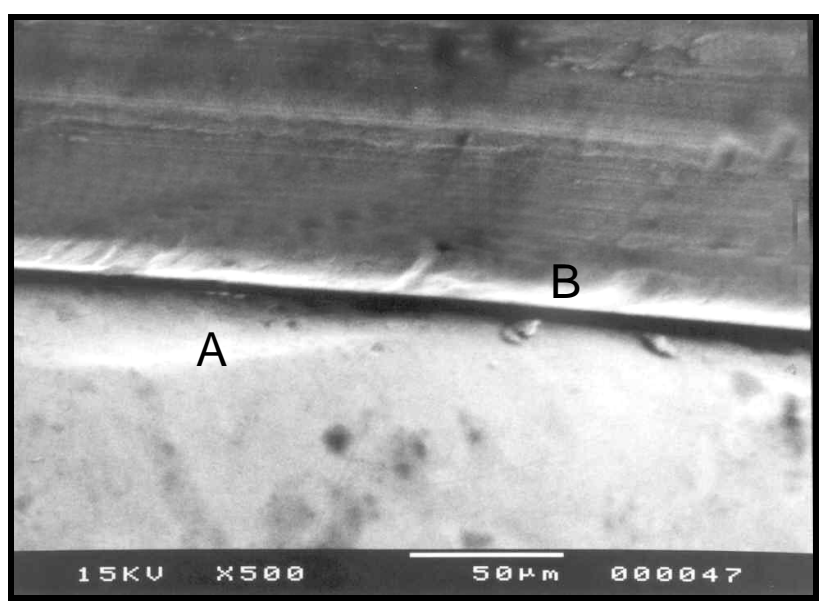

Figuras 6.17: Fotomicrografia da interface implante / pilar do grupo V, mostrando bordas arredondadas $(A)$ e / ou biseladas $(B)$.

Ao se comparar os valores de desadaptação vertical nos grupos estudados, com os resultados reportados na literatura, é possível observar diferenças que podem estar relacionadas às alterações próprias dos componentes e as metodologias empregadas

Assim, no trabalho de $\mathrm{KANO}^{60}$, que serviu como base na metodologia empregada em nossas avaliações, teve médias de desadaptação vertical de 6,0 e 9,50ìm, nos sistemas Implamed, 3I, Lifecore, Conexão, e Nobelbiocare. Em nossas avaliações obtivemos médias de 3,86 a 12,88ìm em cinco sistemas de três fabricantes diferentes. Temos que deixar claro também que neste caso os sistemas foram avaliados na interface pilar / cilindro de ouro; enquanto que em nosso trabalho foi avaliada a interface implante / pilar, o que torna difícil realizar a comparação.

O trabalho de MEYER ${ }^{80}$ que avaliou a interface implante / pilar nos sistemas Neodent, Conexão, Nobelbiocare, e 3I, encontrou médias de desadaptação entre 0,73 a 7,92ìm. Nesse trabalho o sistema Conexão utilizado teve médias de desadaptação de 1,57ìm, enquanto que neste trabalho teve médias de 3,86ì m utilizando o pilar ceraone. Porém a metodologia empregada no trabalho de 
MEYER utilizou microscopia eletrônica, enquanto que neste trabalho utilizou-se microscopia ótica.

Ao se comparar a desadaptação vertical dos grupos estudados, foram encontradas diferenças estatisticamente significantes entre os grupos II, III, e V (4,33, 4,79, 3,86ìm respectivamente); com os grupos I, e IV (12,88, e 10,13 ìm respectivamente) como mostrado nas tabelas 5.2.1, 5.2.3, e 5.2.4). Isto pode ser devido a que os grupos I, e IV que utilizaram pilar UCLA, foram aqueles que apesar de terem hexágonos pré-fabricados usinados, passaram por um processo laboratorial de fundição e de acabamento; enquanto que os grupos II, III, e V, que utilizaram pilares pré-fabricados usinados, e não passaram por nenhum processo de adaptação, o que certamente influenciou negativamente na adaptação vertical dos componentes, como é relatado na literatura ${ }^{29}$.

Um aumento na desadaptação foi observado após os grupos I, II, III, IV serem submetidos a ensaios de fadiga (Tabela 5.2.2), observando-se diferenças estatisticamente significantes entre os grupos II, III, e V; com os grupos I, e IV (Tabela 5.2.5). Quando os grupos foram comparados antes e depois da aplicação das cargas, diferenças estatisticamente significantes foram encontradas nos grupos I, III, e IV (Gráfico 6.13). Um aspecto importante observado neste estudo foi a tendência de que os grupos que tiveram uma maior desadaptação na interface implante / pilar (Grupos I, e IV), foram os que também tiveram uma maior redução da condição de torque dos parafusos, confirmando-se dessa forma a importância de uma precisa adaptação para manter a estabilidade do parafuso. Outro aspecto observado foi o de que no grupo $\mathrm{V}$ teve uma pequena melhora na adaptação da interface após a aplicação das cargas (Tabela 5.2.6). Neste grupo que foi o que teve a menor desadaptação, um melhor assentamento dos componentes pode ter ocorrido com a aplicação das cargas. 


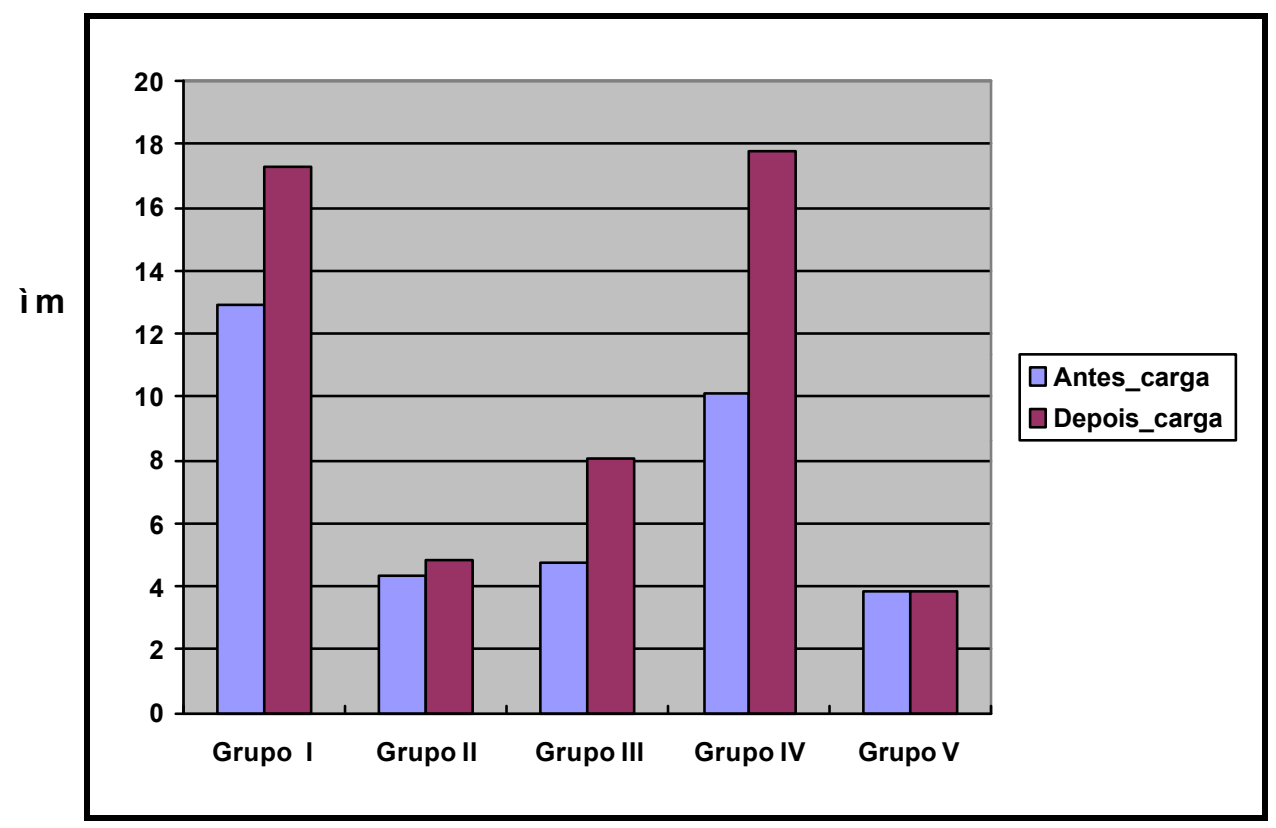

GRÁFICO 6.13: Representação gráfica das médias expressas em ìm da desadaptação dos sistemas estudados antes e depois ensaio de fadiga.

O comportamento do parafuso na estabilidade da união, também tem sido

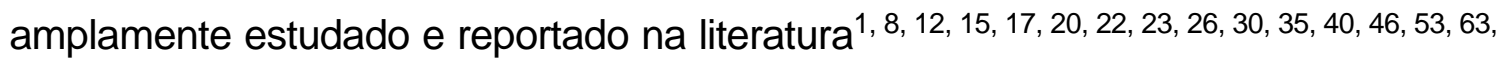
66, 67, 79, 86, 104, 106, 108

Dessa forma, a capacidade de manutenção da précarga no parafuso depois de um torque aplicado tem sido uma preocupação, no sentido da mesma influenciar na estabilidade da união.

BREEDING et al ${ }^{26}$, não encontraram uma diminuição estatisticamente significante no torque necessário para afrouxar os parafusos dos pilares de três sistemas de implantes (Minimatic, Calciteck, e Bio-vent). Contrariamente a isto, HAACK et al $^{50}$ utilizando um dispositivo de torque digital para realização do torque e do destorque, encontraram uma diminuição na tensão de torque de 20 a 30\% em parafusos de ouro e de titânio. 
Também, SEQUIER; PSOTER; TAYLOR ${ }^{100}$ encontraram uma diminuição entre 13 e $22 \%$ quando compararam a tensão de brque e de destorque, em implantes do sistema ITI tipo cone Morse e um sistema octogonal, com superfície anodizada e convencional. Destes grupos, o de conexão octogonal com superfície convencional teve um aumento da tensão de torque de $6 \%$. Acreditando os autores que esse aumento fosse devido a uma maior área de superfície de contato entre o implante / pilar do sistema octogonal.

SCHULTE e COFFEY ${ }^{98}$ avaliaram a capacidade de nove sistemas de retenção de parafusos de titânio em diferentes períodos de tempo (10 e 20 minutos e 24 horas), e não encontraram influência do tempo na relação torque e do destorque, porém encontraram uma diminuição média de $3 \mathrm{~N} . \mathrm{cm}(20 \%)$ quando compararam o torque com o destorque.

Igualmente no trabalho de TAVAREZ et $\mathrm{al}^{107}$ foi encontrada uma diminuição estatisticamente significante na relação do torque e o destorque de quatro tipos de parafusos da marca 3i. Sendo que essa diminuição foi em média de $15,77 \%$ nos parafusos UCLA de titânio, de 30,61\% nos parafusos UCLA de ouro, de 12,8\% nos parafusos esteticone e de $14,07 \%$ nos parafusos de retenção de ouro.

WEISS; KOZAK; GROSS ${ }^{114}$ observaram a relação de torque e destorque de sete sistemas de implantes diferentes, encontrando variação de 1 a $20 \%$, de perda da tensão quando foi realizado o destorque imediato e uma diminuição progressiva da tensão após 200 registros de torque e destorque em todos os sistemas (4,5 a 36\%); assim mesmo NORTON ${ }^{86}$ encontrou valores destorque entre 80 e $85 \%$ quando foram aplicados torque de 20 a $40 \mathrm{~N}$.cm em sistemas com conexão cônica interna.

Um comportamento similar aos trabalhos mencionados foi observado na relação do torque de $30 \mathrm{~N} . \mathrm{cm}$ aplicado nos cinco grupos estudados neste estudo e o destorque inicial realizado, como mostram os resultados apresentados nas 
tabelas 5.3.1; 5.3.8; 5.3.9; 5.3.10. Médias de diminuição de torque entre 5\% (1,5N.cm) e 19,67\% (5,9N.cm) foram encontradas. Sendo que no grupo I e IV que utilizaram implantes de hexágono externo e pilar UCLA, uma redução de torque de $18,33 \%$ e 19,67\% (5,5,5,9N.cm), respectivamente, foi encontrada; o grupo II que utilizou implantes de hexágono interno e um pilar pré-fabricado uma redução de $5 \%(1,5 \mathrm{~N} . \mathrm{cm})$; no grupo III com um implante de octágono interno e um pilar préfabricado uma redução de 14,67\% (4,4N.cm); e o grupo $V$ que utilizou implantes de hexágono externo e pilar ceraone uma redução de 10,67\% (3,2N.cm) (Gráfico 6.3).

Um outro aspecto que poderia influenciar a produção do torque aplicado nos parafusos de retenção dos diferentes sistemas de implantes é a forma e os dispositivos utilizados para aplicação de um torque determinado. Assim, diferenças são encontradas quando o torque é aplicado de forma manual ${ }^{45,47,92,}$ 106, 108, ou quando é aplicado por dispositivos mecânicos ${ }^{45,83,101,102,107}$. Neste trabalho, utilizourse um dispositivo de medição de torque aferido com uma precisão de $\pm 2 \%$.

O efeito de repetidos torques também foi sugerido como causa da diminuição do torque. Perda da pré-carga entre $4.5 \%$ a 36\% nos primeiros 15 ciclos de aperto e afrouxamento foi encontrada por WEISS; KOZAK; GROSS ${ }^{114}$. Contrário a isto TZNAKIS; et $\mathrm{al}^{111}$ encontraram um aumento de $16,3 \%$ na précarga produzida em parafusos de retenção de ouro depois de 20 ciclos de aperto e afrouxamento; isto segundo os autores devido a uma diminuição gradual das forças friccionais na união das roscas do parafuso, o que provoca o fenômeno de assentamento.

Ensaios de fadiga são relatados na literatura para simular a função de uso clínico dos diferentes tipos de conexões nos sistemas de implantes, e determinar a estabilidade da interface. Embora seja difícil a comparação dos resultados devido a que a grande maioria de estudos utiliza metodologias diferentes na aplicação 
dessas cargas. Variações nas forças aplicadas, número de ciclos, freqüência, lugar de aplicação das cargas, forma de aplicação, entre outras são encontradas ${ }^{8}$, $12,15,17,20,22,23,26,35,40,46,53,62,69,104$.

A partir dos resultados obtidos com o ensaio de fadiga pode-se afirmar que existe uma forte correlação entre a diminuição do torque e as cargas aplicadas, já que em todos os grupos avaliados as cargas diminuíram significativamente o torque de afrouxamento. Ao se analisar esta diminuição, observou-se que no caso dos pilares UCLA houve a maior diminuição de torque. Sendo que rão houve diferenças estatisticamente significantes entre o grupo cimentado e o grupo parafusado (63,33 e 68,33\%) (Gráfico 6.14). Neles, encontrou-se também que quatro corpos de provas, (dois em cada grupo) ao final do ensaio (500.000 ciclos) o parafuso tinha afrouxamento total (Anexo 11). É importante observar que o comportamento do grupo parafusado teve um comportamento similar ao grupo cimentado. Acreditamos que esta situação seja conseqüência de que quando cimentada a coroa, esta forma um corpo único com o pilar UCLA, como acontece quando é fundida a coroa diretamente sobre o pilar. O mesmo não aconteceu quando se teve um sistema segmentado, como no caso dos pilares ceraone. 


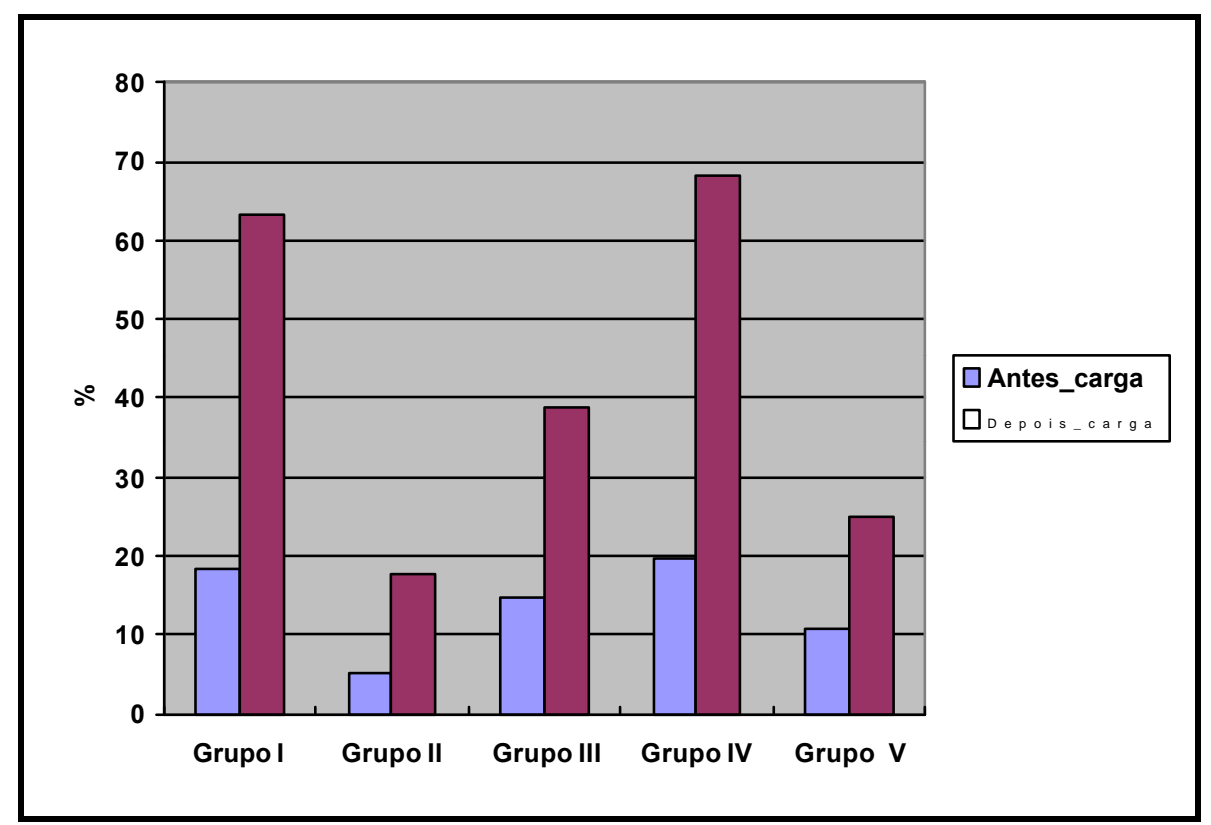

GRÁFICO 6.14: Representação gráfica das médias expressas em percentagens de redução de torque dos sistemas estudados antes e depois o ensaio de fadiga.

Neste sentido, utilizando os mesmo tipo de pilares e as mesmas especificações da carga, BINON; MCHUGH ${ }^{22}$ encontraram que quando as amostras foram apertadas a $20 \mathrm{~N} . \mathrm{cm}$, um corpo de prova falhou em 183.770 ciclos, e outros cinco pilares falharam entre 384.215 e 409.170 ciclos, com uma média para o afrouxamento de 357.162 ciclos. Quando os parafusos foram reapertados a 30 N.cm, uma média de cinco milhões de ciclos, foi necessário para o afrouxamento dos mesmos. Em um outro estudo $\mathrm{BINON}^{22}$ encontrou médias de falhas do parafuso entre 134.895 a 9.337 .080 ciclos, nos mesmo tipo de pilares, quando aplicado um torque de $30 \mathrm{~N} . \mathrm{cm}$; sendo que houve uma correlação entre a desadaptação hexagonal e o afrouxamento do parafuso.

GRATTON; AQUILINO; STANFORD ${ }^{46}$ determinaram em pilares tipo UCLA onde foram aplicados torque de aperto de 16,32 , e $48 \mathrm{~N} . \mathrm{cm}$, e submetidos a cargas de 100.000 ciclos, micromovimentos médios da união implante / pilar de 
68 ìm para o torque de $16 \mathrm{~N} . \mathrm{cm}$; de 41 ìm para o torque de $32 \mathrm{~N} . \mathrm{cm}$; e de $35 \mathrm{ìm}$ para o torque de $48 \mathrm{~N} . \mathrm{cm}$. Nesse mesmo sentido, HOYER et al ${ }^{53}$ observaram micromovimentos de 0 a $20 \mathrm{imm}$ na interface implante / pilar, após a aplicação 500,000 ciclos de carga, sobre pilares UCLA suportados por implantes de 3,75 e $6 \mathrm{~mm}$ de diâmetro.

Nos pilares ceraone, uma melhor resistência do parafuso foi observada, no nosso estudo, quando houve diminuição de $7,5 \mathrm{~N} . \mathrm{cm}(25 \%)$ do torque de aperto, e nenhuma falha do parafuso foi verificada após a aplicação das cargas (500.000 ciclos). Utilizando este mesmo tipo de pilares BASTEN; et $\mathrm{al}^{12}$ encontraram falhas dos parafusos entre 169.000 e 1.492 .000 ciclos, além de que 10 das 15 amostras utilizadas fraturaram no início das roscas do implante. Porém, contrário ao nosso estudo, onde foi utilizada uma força axial, no estudo de BASTEN a força aplicada foi em um ângulo de $30^{\circ}$.

Também KHRAISAT; et $a^{\beta^{2}}$ testaram pilares ceraone sobre implantes Branemark comparando-os com pilares pré-fabricados do sistema ITI. Quando aplicaram uma força de 0 a $100 \mathrm{~N}$, perpendicular ao longo eixo, encontraram que todos os parafusos do sistema ceraone fraturaram entre 1.178 .023 e 1.733 .526 ciclos, enquanto que o sistema ITI não houve fraturoa até 1.800 .000 ciclos; o fato de a força ser aplicada em sentido perpendicular pode sugerir o maior índice de fraturas dos parafusos.

Ao se realizar uma comparação intra - grupos, antes e depois da aplicação das cargas, foi possível observar uma diferença estatisticamente significante em todos os grupos (Tabelas $5.5 .3 ; 5.3 .4 ; 5.3 .7$ ), porém ao se realizar comparação entre - grupos depois da aplicação das cargas, não foram observadas diferenças estatisticamente significantes entre os grupos que utilizaram pilares UCLA (Grupos I e IV); entre os grupos I e III, que utilizaram pilar UCLA e um pilar pré-fabricado, respectivamente; e entre os grupos II, III, e V, que utilizaram pilares préfabricados com implantes de $\mathrm{HI}$ e $\mathrm{Ol}$, e pilar ceraone com implante de $\mathrm{HE}$ 
respectivamente. O grupo que utilizou implantes de $\mathrm{HI}$, e pilares pré-fabricados, mostrou-se com um comportamento superior aos demais grupos (Tabela 5.3.2, 5.3.6, 5.3.11).

BREEDING et $a^{26}$ compararam a resistência à fadiga de conexões de implantes de hexágono externo, octágono interno, e hexágono interno; encontrando uma diminuição no torque de aperto de $1,41 \mathrm{~N} . \mathrm{cm}$ no sistema de HE; $1,27 \mathrm{~N} . \mathrm{cm}$ no sistema de Ol e 0,34 N.cm no sistema de HI; depois de 100.002 ciclos. DIXON et al $^{35}$ também compararam a resistência à fadiga de destes três tipos de conexões, encontrando resultados diferentes sendo que uma diminuição no torque de aperto de 2,97N.cm no sistema de HE; $1,62 \mathrm{~N} . \mathrm{cm}$ no sistema de Ol; e 5.58N.cm no sistema HI; depois de 16.667 ciclos.

Apesar das dificuldades de comparar estes resultados com os obtidos em nosso estudo, devido principalmente, às diferentes metodologias utilizadas é possível obsevar grandes diferenças com estes estudos, assim vemos como nos grupos de implantes com hexágono externo houve diminuição no torque de 19 e 20,5N.cm quando foram utilizados pilares UCLA; e de 7,5N.cm nos pilares ceraone. No grupo de implantes de hexágono interno a diminuição de torque foi de $5,3 \mathrm{~N} . \mathrm{cm}$, enquanto que no grupo de implantes com octágono interno a diminuição foi de 11,7 N.cm (Tabela 5.3.2). Os implantes de hexágono interno tiveram a melhor resistência à fadiga dos três desenhos testados, comportamento que foi similar ao encontrado por BALFOUR e O'BRIEN ${ }^{8}$.

Outros estudos de fadiga relatam a resistência de diferentes conexões e diferentes sistemas de pilares, ${ }^{23,35,104}$. SUTTER; et al ${ }^{104}$ que não encontraram diminuição no torque de aperto depois de dois milhões de ciclos em uma conexão cônica do sistema ITI. BINON ${ }^{15}$ observou um aumento na resistência ao afrouxamento dos parafusos do sistema "spline". 
Pelo exposto, é possível observar que os parâmetros utilizados neste trabalho estão de acordo com os estudos atuais que também determinaram a grande complexidade mecânica experimentada destes tipos de conexões. Alem disto, existem limitações nos experimentos laboratoriais que devem ser consideradas ao se transferir estes achados nas realidades clínicas. No entanto, torna-se de fundamental importância realizar trabalhos testando sistemas e componentes, de forma que se possa contribuir de maneira efetiva na melhora e no avanço da tecnologia e da ciência odontológica. 


\section{7-CONCLUSÕES}




\section{CONCLUSÕES}

Com base na análise dos resultados obtidos, é possível concluir que:

1- Houve diferenças no diâmetro da base de assentamento dos implantes e pilares de conexão hexagonal externa entre 0,10 e 0,16mm nos; e de 0,03mm nos implantes de conexão hexagonal interna. A maior diferença foi encontrada no grupo de conexão octagonal interna com valor de $0,75 \mathrm{~mm}$.

2- Houve diferenças entre os diâmetros dos hexágonos / octágonos dos implantes e pilares entre 0,01 e 0,05mm nos grupos do sistema de conexão externa e no de conexão octagonal interna. No sistema de hexágono interno não houve diferenças.

3- O Comprimento dos parafusos variou entre 5,95 e 8,83mm; o comprimento das roscas variou entre 4,52 e 5,72mm, enquanto que o diâmetro entre 1,79 e $1,97 \mathrm{~mm}$.

4- Houve diferenças estatisticamente significantes $(p<0,05)$ no destorque inicial entre o grupo de $\mathrm{HI}$ com os demais grupos testados. A maior redução de torque foi observada no grupo de HE que utilizou pilares tipo UCLA parafusados (19,67\%), enquanto que a menor redução foi observada no grupo de $\mathrm{HI}$ com (5\%).

5- Não houve diferenças estatisticamente significantes $(p<0,05)$ na desadaptação vertical da interface implante / pilar entre o grupo de HE que utilizou pilares ceraone $(3,86 \mu \mathrm{m})$ com os grupos de $\mathrm{HI}(4,33 \mu \mathrm{m})$ e de OI $(4,79 \mu \mathrm{m})$. Assim como entre os grupos de HE que utilizaram pilares UCLA $(9,67$ e $12,88 \mu \mathrm{m})$ antes do ensaio de fadiga. 
6- Houve um aumento estatisticamente significante $(p<0,05)$ após o ensaio de fadiga na desadaptação entre o implante e o pilar dos grupos de HE que utilizaram pilares UCLA (grupos I $(17,28 \mu \mathrm{m})$ e IV $(17,78 \mu \mathrm{m})$ ). Assim como entre no grupo de Ol $(8,07 \mu \mathrm{m})$. No grupo de HE que utilizou pilar ceraone (3,81ìm) e no de $\mathrm{HI}(4,83 \mu \mathrm{m})$ não houve aumento estatisticamente significante na desadaptação desta interface.

7- Houve um aumento estatisticamente significante $(p<0,05)$ na redução do torque de todos os grupos após o ensaio de fadiga. A menor redução foi encontrada no grupo de HI (17,67\%); e a maior redução no grupo de HE que utilizou pilares UCLA parafusados com $(68,33 \%)$.

8- Houve uma forte correlação entre a condição de cargas cíclicas aplicadas e as diminuições dos valores de torque; enquanto que nas demais variáveis não existiu esse tipo de correlação, dentro das condições testadas. 


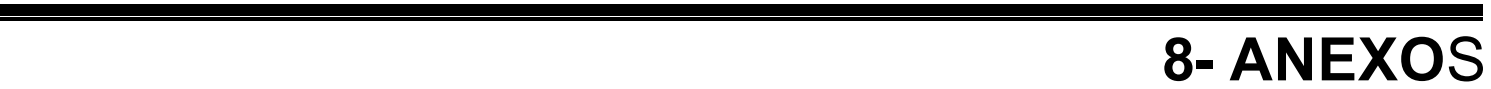




\section{ANEXOS}

Anexo 1:

Medidas da Adaptação Vertical

Grupo I / UCLA cimentado

Medidas Antes da carga expressadas em ìm

\begin{tabular}{|c|c|c|c|c|c|c|c|}
\hline $\begin{array}{c}\text { Corpo de } \\
\text { prova \# }\end{array}$ & Medida 1 & Medida 2 & Medida 3 & Medida 4 & Medida 5 & Medida 6 & Media \\
\hline $\mathbf{1}$ & 25 & 20 & 24 & 29 & 18 & 17 & 22,17 \\
\hline $\mathbf{2}$ & 25 & 23 & 10 & 19 & 13 & 10 & 16,67 \\
\hline $\mathbf{3}$ & 21 & 21 & 18 & 20 & 16 & 10 & 17,67 \\
\hline $\mathbf{4}$ & 14 & 22 & 26 & 22 & 04 & 08 & 16 \\
\hline $\mathbf{5}$ & 13 & 00 & 11 & 16 & 11 & 10 & 10,17 \\
\hline $\mathbf{6}$ & 17 & 14 & 20 & 20 & 16 & 18 & 17,5 \\
\hline $\mathbf{7}$ & 12 & 12 & 10 & 12 & 12 & 13 & 11,83 \\
\hline $\mathbf{8}$ & 00 & 00 & 00 & 00 & 00 & 00 & 0 \\
\hline $\mathbf{9}$ & 10 & 09 & 08 & 11 & 00 & 08 & 7,67 \\
\hline $\mathbf{1 0}$ & 11 & 10 & 09 & 08 & 07 & 09 & 9 \\
\hline & 14,8 & 13,1 & 13,6 & 15,7 & 9,7 & 10,3 & 12,88 \\
\hline
\end{tabular}

Medidas Depois da carga expressadas em ìm

\begin{tabular}{|c|c|c|c|c|c|c|c|}
\hline $\begin{array}{c}\text { Corpo de } \\
\text { prova \# }\end{array}$ & Medida 1 & Medida 2 & Medida 3 & Medida 4 & Medida 5 & Medida 6 & Media \\
\hline $\mathbf{1}$ & 39 & 29 & 25 & 22 & 22 & 18 & 25,83 \\
\hline $\mathbf{2}$ & 32 & 12 & 43 & 59 & 15 & 21 & 30,33 \\
\hline $\mathbf{3}$ & 19 & 24 & 27 & 10 & 26 & 20 & 21 \\
\hline $\mathbf{4}$ & 19 & 26 & 34 & 31 & 10 & 12 & 22 \\
\hline $\mathbf{5}$ & 23 & 00 & 08 & 28 & 19 & 16 & 15,67 \\
\hline $\mathbf{6}$ & 15 & 12 & 13 & 17 & 14 & 18 & 14,83 \\
\hline $\mathbf{7}$ & 12 & 12 & 03 & 10 & 15 & 15 & 11,17 \\
\hline $\mathbf{8}$ & 00 & 00 & 00 & 00 & 00 & 00 & 0 \\
\hline $\mathbf{9}$ & 12 & 16 & 08 & 15 & 00 & 10 & 10,17 \\
\hline $\mathbf{1 0}$ & 15 & 11 & 38 & 11 & 30 & 26 & 21,83 \\
\hline & 18,6 & 14,2 & 19,9 & 20,3 & 15,1 & 15,6 & 17,28 \\
\hline
\end{tabular}


Anexo 2:

\section{Medidas da Adaptação Vertical}

Grupo II/ EMFILS cimentado

Medidas Antes da carga expressadas em ìm

\begin{tabular}{|c|c|c|c|c|c|c|c|}
$\begin{array}{c}\text { Corpo de } \\
\text { prova \# }\end{array}$ & Medida 1 & Medida 2 & Medida 3 & Medida 4 & Medida 5 & Medida 6 & Media \\
$\mathbf{1 1}$ & 10 & 08 & 09 & 00 & 02 & 00 & 4,83 \\
\hline $\mathbf{1 2}$ & 07 & 00 & 00 & 03 & 00 & 17 & 4,5 \\
$\mathbf{1 3}$ & 00 & 00 & 09 & 19 & 16 & 00 & 7,33 \\
\hline $\mathbf{1 4}$ & 00 & 00 & 00 & 07 & 00 & 00 & 1,17 \\
$\mathbf{1 5}$ & 06 & 00 & 00 & 09 & 07 & 08 & 5 \\
\hline $\mathbf{1 6}$ & 06 & 10 & 10 & 11 & 00 & 09 & 7,67 \\
$\mathbf{1 7}$ & 09 & 06 & 11 & 07 & 10 & 10 & 8,83 \\
\hline $\mathbf{1 8}$ & 00 & 00 & 00 & 00 & 00 & 00 & 0 \\
$\mathbf{1 9}$ & 07 & 08 & 00 & 09 & 00 & 00 & 4 \\
\hline $\mathbf{2 0}$ & 00 & 00 & 00 & 00 & 00 & 00 & 0 \\
& 4,5 & 3,2 & 3,9 & 6,5 & 3,5 & 4,4 & 4,33 \\
\hline
\end{tabular}

Medidas Depois da carga expressadas em ìm

\begin{tabular}{|c|c|c|c|c|c|c|c|}
\hline $\begin{array}{c}\text { Corpo de } \\
\text { prova \# }\end{array}$ & Medida 1 & Medida 2 & Medida 3 & Medida 4 & Medida 5 & Medida 6 & Media \\
\hline $\mathbf{1 1}$ & 00 & 00 & 00 & 00 & 02 & 00 & 0,33 \\
\hline $\mathbf{1 2}$ & 00 & 00 & 00 & 15 & 00 & 12 & 4,5 \\
\hline $\mathbf{1 3}$ & 00 & 00 & 00 & 00 & 07 & 00 & 1,17 \\
\hline $\mathbf{1 4}$ & 00 & 00 & 00 & 11 & 06 & 00 & 2,83 \\
\hline $\mathbf{1 5}$ & 00 & 00 & 13 & 10 & 12 & 16 & 8,5 \\
\hline $\mathbf{1 6}$ & 13 & 11 & 16 & 19 & 09 & 12 & 13,33 \\
\hline $\mathbf{1 7}$ & 03 & 00 & 00 & 00 & 12 & 09 & 4 \\
\hline $\mathbf{1 8}$ & 00 & 00 & 00 & 00 & 00 & 00 & 0 \\
\hline $\mathbf{1 9}$ & 08 & 11 & 00 & 00 & 00 & 00 & 3,17 \\
\hline $\mathbf{2 0}$ & 00 & 13 & 00 & 00 & 25 & 25 & 10,5 \\
\hline & 2,4 & 3,5 & 2,9 & 5,5 & 7,3 & 7,4 & 4,83 \\
\hline
\end{tabular}


Anexo 3:

\section{Medidas da Adaptação Vertical}

Grupo III / TMl cimentado

Medidas Antes da carga expressadas em ìm

\begin{tabular}{|c|c|c|c|c|c|c|c|}
$\begin{array}{c}\text { Corpo de } \\
\text { prova \# }\end{array}$ & Medida 1 & Medida 2 & Medida 3 & Medida 4 & Medida 5 & Medida 6 & Media \\
$\mathbf{2 1}$ & 05 & 06 & 05 & 05 & 05 & 06 & 5,33 \\
\hline $\mathbf{2 2}$ & 00 & 00 & 00 & 00 & 00 & 00 & 0 \\
$\mathbf{2 3}$ & 00 & 00 & 00 & 00 & 00 & 00 & 0 \\
\hline $\mathbf{2 4}$ & 00 & 07 & 05 & 08 & 05 & 12 & 6,17 \\
$\mathbf{2 5}$ & 08 & 00 & 00 & 00 & 00 & 00 & 1,33 \\
\hline $\mathbf{2 6}$ & 10 & 12 & 10 & 10 & 10 & 08 & 10 \\
$\mathbf{2 7}$ & 13 & 08 & 08 & 11 & 07 & 07 & 9 \\
\hline $\mathbf{2 8}$ & 04 & 08 & 07 & 00 & 06 & 08 & 5,5 \\
$\mathbf{2 9}$ & 00 & 06 & 06 & 10 & 00 & 10 & 5,33 \\
\hline $\mathbf{3 0}$ & 00 & 06 & 06 & 10 & 00 & 10 & 5,33 \\
& 4 & 5,3 & 4,7 & 5,4 & 3,3 & 6,1 & 4,79 \\
\hline
\end{tabular}

Medidas Depois da carga expressadas em ìm

\begin{tabular}{|c|c|c|c|c|c|c|c|}
\hline $\begin{array}{c}\text { Corpo de } \\
\text { prova \# }\end{array}$ & Medida 1 & Medida 2 & Medida 3 & Medida 4 & Medida 5 & Medida 6 & Media \\
\hline $\mathbf{2 1}$ & 01 & 13 & 13 & 06 & 00 & 14 & 7,83 \\
\hline $\mathbf{2 2}$ & 00 & 00 & 17 & 00 & 00 & 00 & 2,83 \\
\hline $\mathbf{2 3}$ & 06 & 00 & 00 & 00 & 00 & 00 & 1 \\
\hline $\mathbf{2 4}$ & 00 & 15 & 14 & 17 & 09 & 14 & 11,5 \\
\hline $\mathbf{2 5}$ & 15 & 21 & 11 & 09 & 11 & 11 & 13 \\
\hline $\mathbf{2 6}$ & 15 & 12 & 11 & 10 & 10 & 14 & 12 \\
\hline $\mathbf{2 7}$ & 14 & 15 & 12 & 12 & 13 & 09 & 12,5 \\
\hline $\mathbf{2 8}$ & 06 & 00 & 10 & 10 & 00 & 00 & 4,33 \\
\hline $\mathbf{2 9}$ & 23 & 11 & 10 & 00 & 00 & 12 & 9,33 \\
\hline $\mathbf{3 0}$ & 00 & 13 & 14 & 12 & 00 & 00 & 6,5 \\
\hline & 8 & 10 & 11,2 & 7,6 & 4,3 & 7,4 & 8,07 \\
\hline
\end{tabular}


Anexo 4:

\section{Medidas da Adaptação Vertical}

Grupo IV / UCLA parafusado

Medidas Antes da carga expressadas em ìm

\begin{tabular}{|c|c|c|c|c|c|c|c|}
$\begin{array}{c}\text { Corpo de } \\
\text { prova \# }\end{array}$ & Medida 1 & Medida 2 & Medida 3 & Medida 4 & Medida 5 & Medida 6 & Media \\
$\mathbf{3 1}$ & 09 & 05 & 00 & 11 & 08 & 00 & 5,5 \\
\hline $\mathbf{3 2}$ & 12 & 16 & 16 & 12 & 13 & 14 & 13,83 \\
$\mathbf{3 3}$ & 14 & 15 & 18 & 12 & 14 & 00 & 12,17 \\
\hline $\mathbf{3 4}$ & 12 & 11 & 11 & 13 & 11 & 08 & 11 \\
$\mathbf{3 5}$ & 07 & 11 & 05 & 10 & 10 & 15 & 9,67 \\
\hline $\mathbf{3 6}$ & 11 & 09 & 11 & 09 & 09 & 07 & 9,33 \\
$\mathbf{3 7}$ & 09 & 07 & 09 & 10 & 09 & 09 & 8,83 \\
\hline $\mathbf{3 8}$ & 10 & 22 & 17 & 00 & 11 & 12 & 12 \\
$\mathbf{3 9}$ & 12 & 10 & 06 & 13 & 11 & 12 & 10,67 \\
\hline $\mathbf{4 0}$ & 06 & 05 & 00 & 11 & 00 & 00 & 3,67 \\
& 10,2 & 11,1 & 9,3 & 10,1 & 9,6 & 7,7 & 9,67 \\
\hline
\end{tabular}

Medidas Depois da carga expressadas em ìm

\begin{tabular}{|c|c|c|c|c|c|c|c|}
\hline $\begin{array}{c}\text { Corpo de } \\
\text { prova \# }\end{array}$ & Medida 1 & Medida 2 & Medida 3 & Medida 4 & Medida 5 & Medida 6 & Media \\
\hline 31 & \multicolumn{7}{|c|}{ Este corpo de prova não foi avaliado por que o parafuso soltou } \\
\hline 32 & 21 & 55 & 51 & 26 & 38 & 31 & 37 \\
\hline 33 & 30 & 40 & 36 & 18 & 35 & 12 & 28,5 \\
\hline 34 & 18 & 26 & 34 & 33 & 23 & 23 & 26,17 \\
\hline 35 & 17 & 19 & 17 & 31 & 16 & 20 & 20 \\
\hline 36 & 00 & 13 & 14 & 10 & 11 & 00 & 8 \\
\hline 37 & 12 & 00 & 10 & 13 & 13 & 00 & 8 \\
\hline 38 & 10 & 22 & 23 & 00 & 15 & 22 & 15,33 \\
\hline 39 & 19 & 12 & 00 & 17 & 14 & 15 & 12,83 \\
\hline 40 & 06 & 00 & 00 & 00 & 10 & 09 & 4,17 \\
\hline & 14,78 & 20,78 & 20,56 & 16,44 & 19,44 & 14,67 & 17,78 \\
\hline
\end{tabular}


Anexo 5:

\section{Medidas da Adaptação Vertical}

Grupo V / CeraOne cimentado

Medidas Antes da carga epressadas em ìm

\begin{tabular}{|c|c|c|c|c|c|c|c|}
$\begin{array}{c}\text { Corpo de } \\
\text { prova \# }\end{array}$ & Medida 1 & Medida 2 & Medida 3 & Medida 4 & Medida 5 & Medida 6 & Media \\
$\mathbf{4 1}$ & 00 & 00 & 00 & 00 & 00 & 02 & 0,33 \\
\hline $\mathbf{4 2}$ & 00 & 00 & 00 & 00 & 00 & 00 & 0 \\
$\mathbf{4 3}$ & 00 & 00 & 00 & 00 & 09 & 00 & 1,5 \\
\hline $\mathbf{4 4}$ & 00 & 00 & 08 & 00 & 07 & 00 & 2,5 \\
$\mathbf{4 5}$ & 00 & 00 & 00 & 00 & 00 & 00 & 0 \\
\hline $\mathbf{4 6}$ & 07 & 09 & 00 & 00 & 00 & 00 & 2,67 \\
$\mathbf{4 7}$ & 11 & 00 & 00 & 00 & 00 & 10 & 3,5 \\
\hline $\mathbf{4 8}$ & 09 & 00 & 00 & 13 & 00 & 00 & 3,67 \\
$\mathbf{4 9}$ & 11 & 12 & 11 & 10 & 13 & 16 & 12,17 \\
\hline $\mathbf{5 0}$ & 11 & 12 & 11 & 10 & 13 & 16 & 12,17 \\
& 4,9 & 3,3 & 3 & 3,3 & 4,2 & 4,4 & 3,86 \\
\hline
\end{tabular}

Medidas Depois da carga expressadas em ìm

\begin{tabular}{|c|c|c|c|c|c|c|c|}
\hline $\begin{array}{c}\text { Corpo de } \\
\text { prova \# }\end{array}$ & Medida 1 & Medida 2 & Medida 3 & Medida 4 & Medida 5 & Medida 6 & Media \\
\hline $\mathbf{4 1}$ & 00 & 00 & 00 & 00 & 00 & 02 & 0,33 \\
\hline $\mathbf{4 2}$ & 00 & 00 & 00 & 00 & 16 & 00 & 2,67 \\
\hline $\mathbf{4 3}$ & 00 & 00 & 00 & 00 & 11 & 00 & 1,83 \\
\hline $\mathbf{4 4}$ & 00 & 00 & 11 & 00 & 09 & 08 & 4,67 \\
\hline $\mathbf{4 5}$ & 0 & 00 & 00 & 00 & 00 & 00 & 0 \\
\hline $\mathbf{4 6}$ & 07 & 13 & 04 & 00 & 00 & 00 & 4 \\
\hline $\mathbf{4 7}$ & 00 & 00 & 00 & 00 & 00 & 00 & 0 \\
\hline $\mathbf{4 8}$ & 20 & 12 & 10 & 17 & 24 & 12 & 15,83 \\
\hline $\mathbf{4 9}$ & 0 & 00 & 08 & 00 & 00 & 00 & 1,33 \\
\hline $\mathbf{5 0}$ & 17 & 19 & 09 & 00 & 00 & 00 & 7,5 \\
\hline & 4,4 & 4,4 & 4,2 & 1,7 & 6 & 2,2 & 3,81 \\
\hline
\end{tabular}


Anexo 6:

\begin{tabular}{|c|c|c|c|c|c|}
\hline \multicolumn{6}{|c|}{$\begin{array}{c}\text { Medidas do Implante } \\
\text { Grupo I (UCLA cimentado) } \\
\text { Medidas expressadas em mm }\end{array}$} \\
\hline Corpo de prova & Altura do HE & & argur & do H & Largura da base \\
\hline 1 & 0.67 & 2.72 & 2.69 & 2.75 & 4.01 \\
\hline 2 & 0.67 & 2.70 & 2.70 & 2.70 & 4.01 \\
\hline 3 & 0.67 & 2.67 & 2.67 & 2.69 & 4.01 \\
\hline 4 & 0.70 & 2.68 & 2.68 & 2.68 & 4.01 \\
\hline 5 & 0.66 & 2.67 & 2.67 & \begin{tabular}{|l|}
2.67 \\
\end{tabular} & 4.01 \\
\hline 6 & 0.66 & 2.68 & 2.68 & 2.68 & 4.01 \\
\hline 7 & 0.65 & 2.69 & 2.69 & 2.69 & 4.00 \\
\hline 8 & 0.69 & 2.68 & 2.68 & 2.68 & 4.00 \\
\hline 9 & 0.62 & 2.69 & 2.7 & 2.70 & 4.00 \\
\hline 10 & 0.63 & 2.68 & 2.69 & 2.69 & 4.01 \\
\hline & & & & & \\
\hline
\end{tabular}

Medidas do Pilar

Grupo I (UCLA cimentado)

Medidas expressadas em $\mathrm{mm}$

\begin{tabular}{|c|c|c|c|c|}
\hline Corpo de prova & \multicolumn{3}{|c|}{ Largura do $\mathrm{HI}$} & Largura da base \\
\hline 1 & 2.70 & 2.70 & 2.70 & 4.10 \\
\hline 2 & 2.70 & 2.70 & 2.70 & 4.10 \\
\hline 3 & 2.70 & 2.70 & 2.70 & 4.10 \\
\hline 4 & 2.70 & 2.70 & 2.70 & 4.17 \\
\hline 5 & 2.70 & 2.70 & 2.70 & 4.10 \\
\hline 6 & 2.70 & 2.70 & 2.70 & 4.20 \\
\hline 7 & 2.71 & 2.71 & 2.71 & 4.22 \\
\hline 8 & 2.72 & 2.72 & 2.72 & 4.18 \\
\hline 9 & 2.70 & 2.70 & 2.70 & 4.23 \\
\hline 10 & 2.70 & 2.70 & 2.70 & 4.16 \\
\hline
\end{tabular}

Medidas do Parafuso

Grupo I (UCLA cimentado)

Medidas expressadas em $\mathrm{mm}$

\begin{tabular}{|c|c|c|c|}
\hline Corpo de prova \# & $\begin{array}{c}\text { Comprimento das } \\
\text { roscas }\end{array}$ & $\begin{array}{c}\text { Comprimento do } \\
\text { parafuso }\end{array}$ & $\begin{array}{c}\text { Diâmetro das } \\
\text { roscas do parafuso }\end{array}$ \\
\hline 1 & 4.50 & 6.0 & 1.94 \\
\hline 2 & 4.51 & 6.0 & 1.91 \\
\hline 3 & 4.50 & 6.05 & 1.98 \\
\hline 4 & 4.60 & 6.03 & 1.99 \\
\hline 5 & 4.58 & 6.05 & 1.95 \\
\hline 6 & 4.45 & 6.08 & 1.92 \\
\hline 7 & 4.60 & 6.08 & 1.96 \\
\hline 8 & 4.62 & 6.03 & 1.97 \\
\hline 9 & 4.58 & 6.13 & 1.99 \\
\hline 10 & 4.62 & 6.06 & 1.95 \\
\hline & \multicolumn{3}{|l}{} \\
\hline
\end{tabular}


Anexo 7:

\begin{tabular}{|c|c|c|c|c|}
\multicolumn{5}{c|}{$\begin{array}{c}\text { Medidas do Implante } \\
\text { Grupo II sistema EMFILS } \\
\text { Medidas expressadas em mm }\end{array}$} \\
\hline Corpo de prova & \multicolumn{3}{c|}{ Largura do HI } & Largura da base \\
\hline 11 & 2.36 & 2.36 & 2.36 & 3.99 \\
\hline 12 & 2.36 & 2.36 & 2.36 & 3.99 \\
\hline 13 & 2.36 & 2.36 & 2.36 & 3.99 \\
\hline 14 & 2.36 & 2.36 & 2.36 & 4.00 \\
\hline 15 & 2.36 & 2.36 & 2.36 & 3.98 \\
\hline 16 & 2.36 & 2.36 & 2.37 & 4.00 \\
\hline 17 & 2.36 & 2.36 & 2.36 & 4.01 \\
\hline 18 & 2.36 & 2.36 & 2.36 & 4.00 \\
\hline 19 & 2.36 & 2.36 & 2.36 & 4.0 \\
\hline 20 & 2.35 & 2.35 & 2.35 & 4.0 \\
\hline & & & & \\
\hline
\end{tabular}

Medidas do Pilar

Grupo II Sistema EMFILS

Medidas expressadas em $\mathrm{mm}$

\begin{tabular}{|c|c|c|c|c|c|}
\hline Corpo de prova & \multicolumn{3}{|c|}{ Largura do $\mathrm{HE}$} & Altura do $\mathrm{HE}$ & Largura da base \\
\hline 11 & 2.36 & 2.36 & 2.36 & 1.51 & 3.96 \\
\hline 12 & 2.36 & 2.36 & 2.36 & 1.51 & 3.96 \\
\hline 13 & 2.36 & 2.36 & 2.36 & 1.51 & 3.98 \\
\hline 14 & 2.36 & 2.36 & 2.36 & 1.52 & 3.94 \\
\hline 15 & 2.36 & 2.36 & 2.36 & 1.52 & 3.96 \\
\hline 16 & 2.36 & 2.36 & 2.37 & 1.48 & 3.98 \\
\hline 17 & 2.36 & 2.36 & 2.36 & 1.49 & 3.99 \\
\hline 18 & 2.36 & 2.36 & 2.36 & 1.49 & 4.00 \\
\hline 19 & 2.36 & 2.36 & 2.36 & 1.46 & 3.99 \\
\hline 20 & 2.35 & 2.35 & 2.35 & 1.52 & 3.96 \\
\hline
\end{tabular}

Medidas do Parafuso

Grupo II sistema EMFILS

Medidas expressadas em $\mathrm{mm}$

\begin{tabular}{|c|c|c|c|}
\hline Corpo de prova & $\begin{array}{c}\text { Comprimento das } \\
\text { roscas }\end{array}$ & $\begin{array}{c}\text { Comprimento do } \\
\text { parafuso }\end{array}$ & $\begin{array}{c}\text { Diâmetro das } \\
\text { roscas do parafuso }\end{array}$ \\
\hline 11 & 5.50 & 6.78 & 1.95 \\
\hline 12 & 5.48 & 6.80 & 1.95 \\
\hline 13 & 5.50 & 6.78 & 1.93 \\
\hline 14 & 5.58 & 6.83 & 1.93 \\
\hline 15 & 5.60 & 6.71 & 1.92 \\
\hline 16 & 5.49 & 6.66 & 1.93 \\
\hline 17 & 5.59 & 6.76 & 1.93 \\
\hline 18 & 5.59 & 6.64 & 1.93 \\
\hline 19 & 5.54 & 6.78 & 1.94 \\
\hline 20 & 5.60 & 6.67 & 1.92 \\
\hline & \multicolumn{3}{|l}{} \\
\hline
\end{tabular}


Anexo 8:

\begin{tabular}{|c|c|c|c|c|c|}
\hline \multicolumn{6}{|c|}{$\begin{array}{c}\text { Medidas do Implante } \\
\text { Grupo III sistema TMI } \\
\text { Medidas expressadas em mm }\end{array}$} \\
\hline Corpo de prova & & Largu & do H & & Largura da base \\
\hline 21 & 2.50 & 2.50 & 2.50 & 2.50 & 3.75 \\
\hline 22 & 2.51 & 2.51 & 2.51 & 2.51 & 3.75 \\
\hline 23 & 2.50 & 2.50 & 2.50 & 2.50 & 3.75 \\
\hline 24 & 2.52 & 2.52 & 2.52 & 2.52 & 3.77 \\
\hline 25 & 2.50 & 2.50 & 2.50 & 2.50 & 3.77 \\
\hline 26 & 2.50 & 2.50 & 2.50 & 2.50 & 3.75 \\
\hline 27 & 2.50 & 2.50 & 2.50 & 2.50 & 3.76 \\
\hline 28 & 2.50 & 2.50 & 2.50 & 2.50 & 3.76 \\
\hline 29 & 2.50 & 2.50 & 2.50 & 2.50 & 3.77 \\
\hline 30 & 2.50 & 2.50 & 2.50 & 2.50 & 3.76 \\
\hline
\end{tabular}

Medidas do Pilar

Grupo III sistema TMI

Medidas expressadas em $\mathrm{mm}$

\begin{tabular}{|c|c|c|c|c|c|c|}
\hline Corpo de prova & \multicolumn{4}{|c|}{ Largura do $\mathrm{HE}$} & Altura do HE & Largura da base \\
\hline 21 & 2.46 & 2.46 & 2.46 & 2.46 & 4.15 & 4.45 \\
\hline 22 & 2.46 & 2.46 & 2.46 & 2.46 & 4.15 & 4.45 \\
\hline 23 & 2.48 & 2.48 & 2.47 & 2.48 & 4.20 & 4.46 \\
\hline 24 & 2.47 & 2.47 & 2.47 & 2.47 & 4.27 & 4.59 \\
\hline 25 & 2.47 & 2.48 & 2.48 & 2.48 & 4.26 & 4.50 \\
\hline 26 & 2.47 & 2.47 & 2.48 & 2.47 & 4.26 & 4.55 \\
\hline 27 & 2.47 & 2.47 & 2.47 & 2.47 & 4.29 & 4.51 \\
\hline 28 & 2.47 & 2.47 & 2.47 & 2.47 & 4.27 & 4.53 \\
\hline 29 & 2.47 & 2.47 & 2.47 & \begin{tabular}{|l|}
2.47 \\
\end{tabular} & 4.27 & 4.53 \\
\hline 30 & 2.48 & 2.48 & 2.48 & 2.48 & 4.27 & 4.56 \\
\hline
\end{tabular}

Medidas do Parafuso

Grupo III sistema TMI

Medidas expressadas em $\mathrm{mm}$

\begin{tabular}{|c|c|c|c|}
\hline Corpo de prova & $\begin{array}{c}\text { Comprimento das } \\
\text { roscas }\end{array}$ & $\begin{array}{c}\text { Comprimento do } \\
\text { parafuso }\end{array}$ & $\begin{array}{c}\text { Diâmetro das } \\
\text { roscas do parafuso }\end{array}$ \\
\hline 21 & 5.75 & 8.80 & 1.80 \\
\hline 22 & 5.75 & 8.80 & 1.80 \\
\hline 23 & 5.78 & 8.82 & 1.78 \\
\hline 24 & 5.79 & 8.76 & 1.80 \\
\hline 25 & 5.58 & 8.80 & 1.78 \\
\hline 26 & 5.74 & 8.85 & 1.77 \\
\hline 27 & 5.63 & 8.80 & 1.79 \\
\hline 28 & 5.74 & 8.95 & 1.79 \\
\hline 29 & 5.74 & 8.90 & 1.78 \\
\hline 30 & 5.70 & 8.91 & 1.78 \\
\hline & \multicolumn{3}{|l}{} \\
\hline
\end{tabular}


Anexo 9:

Medidas do Implante

Grupo IV (UCLA Parafusado)

Medidas expressadas em $\mathrm{mm}$

\begin{tabular}{|c|c|c|c|c|c|}
\hline Corpo de prova \# & Altura do HE & \multicolumn{3}{|c|}{ Largura do HE } & Largura da base \\
\hline 31 & 0.61 & 2.68 & 2.68 & 2.68 & 4.01 \\
\hline 32 & 0.61 & 2.68 & 2.68 & 2.68 & 4.01 \\
\hline 33 & 0.62 & 2.68 & 2.68 & 2.68 & 4.00 \\
\hline 34 & 0.66 & 2.69 & 2.69 & 2.69 & 4.01 \\
\hline 35 & 0.61 & 2.68 & 2.68 & 2.68 & 4.06 \\
\hline 36 & 0.66 & $2 . .68$ & 2.68 & 2.68 & 4.05 \\
\hline 37 & 0.63 & 2.70 & 2.70 & 2.70 & 4.01 \\
\hline 38 & 0.62 & 2.68 & 2.68 & 2.68 & 4.01 \\
\hline 39 & 0.62 & 2.68 & 2.68 & 2.68 & 4.02 \\
\hline 40 & 0.61 & 2.68 & 2.68 & 2.68 & 4.00 \\
\hline & & & & & \\
\hline
\end{tabular}

Medidas do Pilar

Grupo IV (UCLA Parafusado)

Medidas expressadas em $\mathrm{mm}$

\begin{tabular}{|c|c|c|c|c|}
\hline Corpo de prova & \multicolumn{3}{|c|}{ Largura do HI } & Largura da base \\
\hline 31 & 2.69 & 2.69 & 2.69 & 4.18 \\
\hline 32 & 2.71 & 2.71 & 2.71 & 4.18 \\
\hline 33 & 2.70 & 2.70 & 2.70 & 4.13 \\
\hline 34 & 2.70 & 2.70 & 2.70 & 4.19 \\
\hline 35 & 2.70 & 2.70 & 2.70 & 4.19 \\
\hline 36 & 2.71 & 2.71 & 2.71 & 4.20 \\
\hline 37 & 2.71 & 2.71 & 2.71 & 4.18 \\
\hline 38 & 2.71 & 2.71 & 2.71 & 4.18 \\
\hline 39 & 2.70 & 2.70 & 2.70 & 4.13 \\
\hline 40 & 2.71 & 2.71 & 2.71 & 4.27 \\
\hline
\end{tabular}

Medidas do Parafuso

Grupo IV (UCLA Parafusado)

Medidas expressadas em $\mathrm{mm}$

\begin{tabular}{|c|c|c|c|}
\hline Corpo de prova \# & $\begin{array}{c}\text { Comprimento das } \\
\text { roscas }\end{array}$ & $\begin{array}{c}\text { Comprimento do } \\
\text { parafuso }\end{array}$ & $\begin{array}{c}\text { Diâmetro das } \\
\text { roscas do parafuso }\end{array}$ \\
\hline 31 & 4.52 & 5.99 & 1.96 \\
\hline 32 & 4.52 & 5.99 & 1.99 \\
\hline 33 & 4.52 & 6.20 & 1.96 \\
\hline 34 & 4.60 & 6.04 & 1.98 \\
\hline 35 & 4.50 & 6.06 & 1.99 \\
\hline 36 & 4.57 & 6.01 & 2.00 \\
\hline 37 & 4.56 & 6.18 & 1.97 \\
\hline 38 & 4.58 & 5.97 & 1.98 \\
\hline 39 & 4.57 & 6.25 & 1.94 \\
\hline 40 & 4.57 & 6.01 & 1.96 \\
\hline & \multicolumn{3}{|l}{} \\
\hline
\end{tabular}


Anexo 10:

Medidas do Implante

Grupo V (CeraOne cimentado)

Medidas expressadas em $\mathrm{mm}$

\begin{tabular}{|c|c|c|c|c|c|}
\hline Corpo de prova \# & Altura do $\mathrm{HE}$ & \multicolumn{3}{|c|}{ Largura do $\mathrm{HE}$} & Largura da base \\
\hline 41 & 0.63 & 2.67 & 2.66 & 2.66 & 4.10 \\
\hline 42 & 0.63 & 2.67 & 2.66 & 2.66 & 4.10 \\
\hline 43 & 0.64 & 2.70 & 2.70 & 2.70 & 4.08 \\
\hline 44 & 0.63 & 2.68 & 2.67 & 2.68 & 4.08 \\
\hline 45 & 0.63 & 2.68 & 2.68 & 2.68 & 4.07 \\
\hline 46 & 0.62 & $2.6 \varepsilon$ & 2.68 & 2.68 & 4.08 \\
\hline 47 & 0.63 & 2.68 & 2.68 & 2.68 & 4.08 \\
\hline 48 & 0.62 & $2.6 \varepsilon$ & 2.68 & 2.68 & 4.00 \\
\hline 49 & 0.62 & 2.68 & 2.68 & 2.68 & 4.08 \\
\hline 50 & 0.63 & 2.70 & 2.70 & 2.70 & 4.08 \\
\hline
\end{tabular}

Medidas do Pilar

Sistema Conexão

Grupo V (CeraOne cimentado)

\begin{tabular}{|c|c|c|c|c|}
\hline Corpo de prova & \multicolumn{3}{|c|}{ Largura do HI } & Largura da base \\
\hline 41 & 2.72 & 2.72 & 2.72 & 4.15 \\
\hline 42 & 2.72 & 2.72 & 2.72 & 4.15 \\
\hline 43 & 2.69 & 2.71 & 2.71 & 4.15 \\
\hline 44 & 2.74 & 2.76 & 2.75 & 4.13 \\
\hline 45 & 2.77 & 2.77 & 2.75 & 4.18 \\
\hline 46 & 2.72 & 2.74 & 2.74 & 4.17 \\
\hline 47 & 2.72 & 2.72 & 2.72 & 4.17 \\
\hline 48 & 2.72 & 2.72 & 2.74 & 4.21 \\
\hline 49 & 2.73 & 2.73 & 2.73 & 4.19 \\
\hline 50 & 2.71 & 2.71 & 2.71 & 4.2 \\
\hline
\end{tabular}

Medidas do Parafuso

Grupo V (CeraOne cimentado)

Medidas expressadas em $\mathrm{mm}$

\begin{tabular}{|c|c|c|c|}
\hline Corpo de prova \# & $\begin{array}{c}\text { Comprimento das } \\
\text { roscas }\end{array}$ & $\begin{array}{c}\text { Comprimento do } \\
\text { parafuso }\end{array}$ & $\begin{array}{c}\text { Diâmetro das } \\
\text { roscas dos } \\
\text { parafusos }\end{array}$ \\
\hline 41 & 4.62 & 6.0 & 1.95 \\
\hline 42 & 4.62 & 6.0 & 1.98 \\
\hline 43 & 4.66 & 6.01 & 2.00 \\
\hline 44 & 4.38 & 5.56 & 1.96 \\
\hline 45 & 4.53 & 5.94 & 1.98 \\
\hline 46 & 4.50 & 5.98 & 1.97 \\
\hline 47 & 4.50 & 5.98 & 1.95 \\
\hline 48 & 4.38 & 5.93 & 1.97 \\
\hline 49 & 4.57 & 6.10 & 1.98 \\
\hline 50 & 4.46 & 6.06 & 1.96 \\
\hline & \multicolumn{3}{|l}{} \\
\hline
\end{tabular}




\section{Anexo 11}

1- Torque inicial

Medidas de Torque e Destorque

2- Destorque inicial

3- Destorque depois das cargas

\begin{tabular}{|c|c|c|c|c|c|c|c|c|c|cc|}
\hline $\begin{array}{c}\text { Corpo } \\
\#\end{array}$ & \multicolumn{3}{|c|}{$\begin{array}{c}\text { Grupo \# I } \\
\text { UCLA cimentado }\end{array}$} & $\begin{array}{c}\text { Corpo } \\
\#\end{array}$ & \multicolumn{3}{|c|}{$\begin{array}{c}\text { Grupo \# II } \\
\text { EMFILS } \\
\text { cMmentado }\end{array}$} & $\begin{array}{c}\text { Corpo } \\
\#\end{array}$ & \multicolumn{3}{|c|}{$\begin{array}{c}\text { Grupo \# III } \\
\text { TMI } \\
\text { cimentado }\end{array}$} \\
\hline & $\mathbf{1}$ & $\mathbf{2}$ & $\mathbf{3}$ & & $\mathbf{1}$ & $\mathbf{2}$ & $\mathbf{3}$ & & $\mathbf{1}$ & $\mathbf{2}$ & $\mathbf{3}$ \\
\hline $\mathbf{1}$ & 30 & 23 & 0 & $\mathbf{1 1}$ & 30 & 29 & 23 & $\mathbf{2 1}$ & 30 & 28 & 19 \\
\hline $\mathbf{2}$ & 30 & 23 & 5 & $\mathbf{1 2}$ & 30 & 28 & 14 & $\mathbf{2 2}$ & 30 & 25 & 12 \\
\hline $\mathbf{3}$ & 30 & 25 & 5 & $\mathbf{1 3}$ & 30 & 29 & 26 & $\mathbf{2 3}$ & 30 & 26 & 16 \\
\hline $\mathbf{4}$ & 30 & 25 & 22 & $\mathbf{1 4}$ & 30 & 29 & 27 & $\mathbf{2 4}$ & 30 & 23 & 17 \\
\hline $\mathbf{5}$ & 30 & 24 & 12 & $\mathbf{1 5}$ & 30 & 28 & 28 & $\mathbf{2 5}$ & 30 & 27 & 20 \\
\hline $\mathbf{6}$ & 30 & 25 & 15 & $\mathbf{1 6}$ & 30 & 28 & 28 & $\mathbf{2 6}$ & 30 & 26 & 18 \\
\hline $\mathbf{7}$ & 30 & 25 & 15 & $\mathbf{1 7}$ & 30 & 28 & 28 & $\mathbf{2 7}$ & 30 & 26 & 20 \\
\hline $\mathbf{8}$ & 30 & 25 & 16 & $\mathbf{1 8}$ & 30 & 28 & 26 & $\mathbf{2 8}$ & 30 & 24 & 26 \\
\hline $\mathbf{9}$ & 30 & 25 & 20 & $\mathbf{1 9}$ & 30 & 29 & 27 & $\mathbf{2 9}$ & 30 & 25 & 20 \\
\hline $\mathbf{1 0}$ & 30 & 25 & 0 & $\mathbf{2 0}$ & 30 & 29 & 20 & $\mathbf{3 0}$ & 30 & 26 & 15 \\
\hline Media & $\mathbf{3 0}$ & $\mathbf{2 4 . 5}$ & $\mathbf{1 1}$ & & $\mathbf{3 0}$ & $\mathbf{2 8 . 5}$ & $\mathbf{2 4 . 7}$ & & $\mathbf{3 0}$ & $\mathbf{2 5 . 6}$ & $\mathbf{1 8 . 3}$ \\
\hline
\end{tabular}

\begin{tabular}{|c|c|c|c|c|c|c|c|}
\hline $\begin{array}{c}\text { Corpo } \\
\text { prova }\end{array}$ & \multicolumn{3}{|c|}{$\begin{array}{c}\text { Grupo \# IV } \\
\text { UCLA } \\
\text { parafusado }\end{array}$} & $\begin{array}{c}\text { Corpo } \\
\text { \# }\end{array}$ & \multicolumn{3}{c|}{$\begin{array}{c}\text { Grupo \# V } \\
\text { CeraOne } \\
\text { cimentado }\end{array}$} \\
\hline & $\mathbf{1}$ & $\mathbf{2}$ & $\mathbf{3}$ & & $\mathbf{1}$ & $\mathbf{2}$ & $\mathbf{3}$ \\
\hline $\mathbf{3 1}$ & 30 & 22 & 0 & $\mathbf{4 1}$ & 30 & 26 & 18 \\
\hline $\mathbf{3 2}$ & 30 & 24 & 5 & $\mathbf{4 2}$ & 30 & 26 & 16 \\
\hline $\mathbf{3 3}$ & 30 & 25 & 4 & $\mathbf{4 3}$ & 30 & 26 & 23 \\
\hline $\mathbf{3 4}$ & 30 & 24 & 12 & $\mathbf{4 4}$ & 30 & 28 & 24 \\
\hline $\mathbf{3 5}$ & 30 & 25 & 10 & $\mathbf{4 5}$ & 30 & 28 & 23 \\
\hline $\mathbf{3 6}$ & 30 & 24 & 19 & $\mathbf{4 6}$ & 30 & 27 & 25 \\
\hline $\mathbf{3 7}$ & 30 & 25 & 9 & $\mathbf{4 7}$ & 30 & 27 & 25 \\
\hline $\mathbf{3 8}$ & 30 & 25 & 24 & $\mathbf{4 8}$ & 30 & 26 & 22 \\
\hline $\mathbf{3 9}$ & 30 & 24 & 12 & $\mathbf{4 9}$ & 30 & 26 & 25 \\
\hline $\mathbf{4 0}$ & 30 & 23 & 0 & $\mathbf{5 0}$ & 30 & 28 & 24 \\
\hline & $\mathbf{3 0}$ & $\mathbf{2 4 . 1}$ & $\mathbf{9 . 5}$ & & $\mathbf{3 0}$ & $\mathbf{2 6 . 8}$ & $\mathbf{2 2 . 5}$ \\
\hline
\end{tabular}




\section{9-REFERÊNCIAS BIBLIOGRÁFICAS}




\section{REFERENCIAS BIBLIOGRAFICAS ${ }^{1}$}

1. ABOYOUSSEF, H.; WEINER, S.; EHRENBER, G. Effect of an antirotation resistance form on screw loosenig for single implant-supported crowns. J. Prosthet. Dent., v.83, n.4, p.450-455, 2000.

2. ADELL, R.; ROCKLER, L.; BRANEMARK, I. A 15 year study of osseointegrated implants in the treatment of the edentulous jaw. Int. J. Oral Surg., v.10, p.387-416, 1981.

3. ANDERSON, B. et al. Single - tooth restorations supported by osseointegrated implants: Results and experiences from a prospective study after 2 to 3 yeas. Int. J. Oral Maxillofac. Implants, v.10, p.702-711, 1995.

4. ANDERSSON, B. et al. A new Branemark single tooth abument: Handling and early clinical experiences. Int. J. Oral Maxillofac. Implants, v.7, p.105-111, 1992.

5. ANDERSSON, B. et al. Mechanical testing of superstructures on the CeraOne abutment in the Branemark system. Int. J. Oral Maxillofac. Implants, v.9, n.6, p.665-672, 1994.

6. ARBER, L.; ZARB, G. Clinical effectiveness of implant supported single tooth replacement: The Toronto study. Int. J. Oral Maxillofac. Implants, v.11, p.311-321, 1996.

\footnotetext{
${ }^{1}$ Normas recomendadas para uso no âmbito da Universidade de São Paulo, com base no documento "Referencias Bibliográficas: exemplo", emanada do conselho supervisor do Sistema Integrado de Bibliotecas da USP, em reunião de 20 de setembro de 1990.
} 
7. ARTZI, Z.; DREIANGEL, A. A screw lock for single tooth implant superstructure. J. Am. Dent. Assoc., v.130, p.677-682, 1999.

8. BALFOUR, A.; O'BRIEN, G. Comparative study of antirotational single tooth abutments. J. Prosthet. Dent. v.73, n.1, p.36-43, 1995.

9. BALSHI, T, et al. A comparative study of one implant versus two replacing a single molar. Int. J. Oral Maxillofac. Implants, v.11, p.372-378, 1996.

10. BALSHI, T, et al. Three-year evaluation of Branemark implants connected to angulated abutments. Int. J. Oral Maxillofac. Implants, v.12, p.52-58, 1997.

11. BASSIT, R.; LINDSTROM, H.; RANGERT, B. In vivo registration of force development with ceramic and acrylic resin occlusal materials on implantsupported prostheses. Int. J. Oral Maxillofac. Implants, v.17, n.1, p.1723, 2002.

12. BASTEN, C. et al. Load fatigue performance of two implant-abutment combinations. Int. J. Oral Maxillofac. Implants, v.11, n.4, p.522-528, 1996.

13. BECKER, W.; BECKER, B. Replacement of maxillary and mandibular molars with single endosseous implant restorations: A retrospective study. J Prostetic Dent., v.74, p.51-55. 1995

14. BINON, P. Evaluation of machining accuracy and consistency of selected implants, standard abutments, and laboratory analogs. Int. J. Prostodont., v.8, n.2, p.162-178, 1995. 
15. BINON, P. The spline implant: Design, engineering, and evaluation. Int. J. Prostodont., v.9, n.5, p.419-433, 1996.

16. BINON, P. et al. The role of screws in implant systems. Int. J. Oral Maxillofac. Implants, v.9, p.48-63, 1994 (Supplement).

17. BINON, P. Evaluation of the effectiveness of a technique to prevent screw loosening. J. Prosthet. Dent.,. v.79, p.430-432, 1998.

18. BINON, P. Evaluation of three slip fit hexagonal implants. Implant Dent., v.5, p.235-248, 1996.

19. BINON, P. Implants and components: Entering the new millennium. Int. J. Oral Maxillofac. Implants, v.15, n.1, p.76-94, 2000.

20. BINON, P. The effect of implant/abutment hexagonal misfit on screw joint stability. Int. J. Prosthodont., v.9, n.2, p.149-160, 1996.

21. BINON, P. The external hexagonal interterface and screw-joint stability: A primer on threaded fasteners in implant dentistry. Quint. Dent. Tecnolog., p.91-105, 2000.

22. BINON, P.; McHUGH, M. The effect of eliminating implant/abutment rotational misfit on screw joint stability. Int. J. Prosthodont., v.9, n.6, p.511-519. 1996.

23. BOGGAN, S. et al. Influence of hex geometry and prosthetic table width on static and fatigue strength of dental implants. J. Prosthet. Dent.,. v.82, n.4, p.436-440, 1999. 
24. BONACHELA, W. Avaliação da adaptação da interface intermediários I cilindros de plástico fundidos em titânio e cobalto - cromo, antes e após soldagem a laser variando os parafusos de fixação (fenda e hexágono). Bauru, 2002. 128p. Tese (Livre docencia) - Faculdade de Odontologia de Bauru, Universidade de São Paulo.

25. BRANEMARK, P.; ZARB, G.; ALBREKTSSON, T. Tissue-integrated prostheses: osse ointegration in clinical dentistry. Chicago, Quintessence, 1985.

26. BREEDIN, G. et al. Torque required to loosen single-tooth implant abutment screws before and after simulated funtion. Int. J. Prostodont., v.6, n.5, p.435-439, 1993.

27. BROSCO, H. Precisão de adaptação de intermediários transmucosos unitários em sistemas nacionais de implantes compatíveis em hexágono externo. Bauru, 2001. 100p. Tese (Livre docencia) Faculdade de Odontologia de Bauru, Universidade de São Paulo.

28. BURGUETE, $R$. et al. Tightening characteristics for screwed joints in osseointegrated dental implants. J. Prosthet. Dent., v.71, n.6, p.592-9, 1994.

29. BYRNE, D, et al. The fit of cast and premachined implant abutments. J. Prosthet. Dent. v.80, n.2, p.184-192, 1998.

30. CARR, A, et al. Reverse torque failure of screw-shaped implants in baboons: Baseline data for abutment torque application. Int. J. Oral Maxillofac. Implants, v.10, n.2, p.167-174, 1995. 
31. CARR, A.; BRUNSKI, J.; HURLEY, E. Effects of fabrication, finishing, and polishing procedures on preload in prostheses using convencional "gold" and plastic cylinders. Int. J. Oral Maxillofac. Implants, v.11, n.5, p.589598, 1996.

32. CASTILIO, D. Avaliação da adaptação da interface intermediários / cilindros de plástico fundidos em titânio e cobalto - cromo, antes e após soldagem a laser. Bauru, 2000. 93p. Dissertação (mestrado) Faculdade de Odontologia de Bauru, Universidade de São Paulo.

33. CAVAZOS, E.; BELL, F. Preventing loosenig of implant abutment screws. J. Prosthet. Dent. v.75, n.5, p.566-569, 1996.

34. ÇEHRELI, M.; IPLIKÇIOGLU, H.; BILIR, O. The influence of the location of load transfer on strains around implants supporting four unit cementretained fixed prostheses: in vitro evaluation of axial versus off-set loading. J. Oral Reabilitation, v.29, n. p.394-400, 2002.

35. CIBIRKA, R. et al. Examination of the implant-abutment interface after fatigue testing. J. Prosthet. Dent.,. v.85, n.3, p.268-275, 2001.

36. CLAYTON, G.; DRISCOLL, C.; HONDRUM, S. The effect of luting agents on the retention and marginal adaptation of the ceraone implant system. Int. J. Oral Maxillofac. Implants, v.12, n.5, p.660-665, 1997.

37. DAVAPANAH, M. et al. Wide diameter implants: New concepts. Int. J. Periodont. Rest. Dent., v.21, n.2, p.149-159, 2001. 
38. DELLOW, A.; DRIESSEN, C.; NEL, H. Scanning electron microscopy evaluation of the interfacial fit of interchanged components of four dental implant systems. Int. J. Prosthodont., v.10, n.3, p.216-221, 1997.

39. DIAS, R. Precisão de adaptação e ajuste horizontal de abutments unitários em sistemas de implantes de hexágono externo. Bauru, 2001. 204p. Dissertação (mestrado) - Faculdade de Odontologia de Bauru, Universidade de São Paulo.

40. DIXON, D. et al. Comparison of screw loosening, rotation, and deflection among three implant designs. J. Prosthet. Dent., v.74, n.3, p.270-8, 1995.

41. EKFELDT, A.; CARLSSON, G.; BORJESSON, G. Clinical evaluation of single-tooth restorations supported by osseointegrated implants: $A$ retrospective study. Int. J. Oral Maxillofac. Implants, v.9, p.179-183, 1994.

42. FAULKNER, G.; WOLFAARDT, J.; CHAN, A. Measuring abutment / implant joint integrity with the periotest instrument. . Int. J. Oral Maxillofac. Implants, v.14, n.5, p.681-688, 1999.

43. FRANCISCHONE, C.; VASCONCELOS, L. Evolução e vantagens das próteses unitárias sobre implantes. In: Osseointegração e as próteses unitárias: como otimizar a estética. São Paulo, Artes medicas, 1998. p.29-47, serie EAP / APCD

44. GIBBARD, L.; ZARB, G. A 5 year prospective study of implant-supported single-tooth replacements. J. Can. Dent. Assoc., v.68, n2, p.110-116, 2002. 
45. GOHEEN, K. et al. Torque generated by handheld screwdrivers and mechanical torquing devices for osseointegrated implants. Int. J. Oral Maxillofac. Implants, v.9, p.149-155, 1994.

46. GRATTON, D.; AQUILINO, S.; STANFORD, C. Micromotion and dynamic fadigue properties of the dental implant-abutment interface. J. Prosthet. Dent., v.85, n.1, p.47-52, 2001.

47. GROSS, M. et al. Manual closing torque in five implant abutment systems: An in vitro comparative study. J. Prosthet. Dent., v.81, n.5, p.574-578, 1999.

48. GROSS, M.; ABRAMOVICH, I.; WEISS, E. Microleakage at the abutment implant interface of osseointegrated implants: A comparative study. Int. J. Prosthodont., v.14, n.1, p.94-100, 1999.

49. GUICHET, D. et al. Passivity of fit and marginal opening in screw or cement retained implant fixed partial denture designs. Int. J. Oral Maxillofac. Implants, v.15, n.2, p.239-246, 2000.

50. HAACK, J. et al. Elongation and preload stress in dental implant abutment screws. Int. J. Oral Maxillofac. Implants, v.10, n.5, p.529-536, 1995.

51. HASS, R. et al. Branemark single tooth implants: A preliminary report of 76 implants. J Prostetic Dent; v73, p274-279, 1995.

52. HEBEL, K.; GAJJAR, R. Cement-retained versus screw-retained implant restorations: Achieving optimal occlusion and esthetics in implant dentistry. J Prostetic Dent., v.77, n.1, p.28-35, 1997. 
53. HOYER, S. et al. Dynamic fatigue properties of the dental implant-abutment interface: Joint opening in wide-diameter versus standard-diameter hextype implants. J. Prosthetic. Dent., v,85, n.6, p,599-607, 2001.

54. JAARDA, M; RAZZOOG, M.; GRATTON, D. Ultimate tensile strength of five interchangeable prosthetic retaining screws. Implant Dent., v,5, p,16-19, 1996.

55. JAARDA, M.; RAZZOOG, M.; GRATTON, D. Geometric comparison of five interchangeable implant prosthetic retaining screws. J. Prosthetic. Dent, v.74, n.4, p.373-379, 1995.

56. JANSEN, V.; CONRADS, G.; RICHTER, E. Microbial leakage and marginal fit of the implant-abutment interface. Int J Oral Maxillofac Implants; v.12, n.4, p.527-540, 1997.

57. JEMT, T. et al. Osseointegrated implants for single tooth replacement: A 1year report from a multicenter prospective study. Int. J. Oral Maxillofac. Implants, v.6, p.29-36, 1991.

58. JEMT, T.; LEKHOLM, U.; GRONDAHL, K. A 3 year followup study of early single implant restorations ad modum Branemark. Int. J. Period. Rest. Dent., v.10, p.340-349, 1990.

59. JORNEUS, L. et al. Loads and designs of screw joints for single crowns supported vy osseointegrated implants. Int. J. Oral Maxillofac. Implants, v.7, p.353-359, 1992. 
60. KANO, S. Avaliação da interface intermediário / cilindro de ouro e da compatibilidade de diferentes sistemas de implantes odontológicos: Análise intra e entre - sistemas. Bauru, 1998. 91p. Dissertação (mestrado) - Faculdade de Odontologia de Bauru, Universidade de São Paulo.

61. KEITH, S. et al. Marginal discrepancy of screw-retained and cemented metal ceramic crowns on implant abutments. Int. J. Oral Maxillofac. Implants, v.14, n.3, p.369-378, 1999.

62. KHRAISAT, A. et al. Fatigue resistance of two implant / abutment joint designs. J. Prosthet. Dent.. v.88, n.6, p.604-610, 2002.

63. KORIOTH, T. et al. Effect of washers on reverse torque displacement of dental implant gold retaining screws. J. Prosthet. Dent.. v.82, n.3, p.312316, 1999.

64. KRENNMAIR, G.; SCHMIDINGER, S.; WALDENBERGER, O. Single tooth replacement with the Frialit-2 system: A retrospective clinical analysis of 146 implants. Int. J. Oral Maxillofac. Implants, v.17, p.78-85, 2002.

65. LANEY, W. et al. Osseointegrated implants for single-tooth replacement: Progress report from a multicenter prospective study after 3 year. Int. J. Oral Maxillofac. Implants, v.9, p.49-54, 1994.

66. LANG, L., et al. The effect of the use of a counter-torque device on the abutment-implant complex. J. Prosthet. Dent., v.81, n.4, p.411-417, 1999. 
67. LANG, L.; WANG, R.; MAY, K. The influence of abutment screw tightening on screw joint configuration. J. Prosthetic. Dent., v.87, n.1, p.74-79, 2002.

68. LAZZARA, R. Restorative adavantages of the coronally hexed implant. Compendium, v.XII, n.12, p.924-930, 1991.

69. LEE, J. et al. Wave análisis of implant screw loosening using an air cylindrical cyclic loading divice. . Prosthetic. Dent. v.88, n.4, p.402-408, 2002.

70. LEVINE, R. et al. A multicenter retrospective analysis of the ITI implant system used for single tooth replacements: Preliminary results at 6 or more months of loading. Int. J. Oral Maxillofac. Implants, v.12, p.237242, 1997.

71. LEVINE, R. et al. Multicenter retrospective análisis of the solid-screw ITI implant for posterior single-tooth replacements. Int. J. Oral Maxillofac. Implants, v.17, p.550-556, 2002.

72. LEVINE, R. et al. Multicenter retrospective analysis of the ITI implant system used for single tooth replacements: Results of loading for 2 or more years. Int. J. Oral Maxillofac. Implants, v.14, p.516-520, 1999.

73. LEWIS, S.; LLAMAS, D.; AVERA, S. The UCLA abutment: A four-year review. J. Prosthet. Dent., v.67, p.509-515, 1992.

74. MARTIN, W. et al. Implant abutment screw rotations and preloads for four different screw materials and surfaces. J. Prosthetic. Dent., v.86, n.1, p.24-32, 2001. 
75. MAY, K.; EDGE, M.; RUSSELL, M, RAZZOOG M, LANG B. The precision of fit at the implant prosthodontic interface. J. Prosthetic. Dent, v.77, n.5, p.497-502, 1997.

76. MCGLUMPHY, E.; KERBY, E.; ELFERS, C. A comparison of screw preload for the single tooth implant. J. Dent. Res., v.73, p.202, 1994. /Abstract n. 809.

77. McGLUMPHY, E.; MENDEL, D.; HOLLOWAY, J. Implant screw mechanics. Dent. Clinics North. Am., v.42, n.1, p.71-89, 1998.

78. McGLUMPHY, E.; ROBINSON, D.; MENDEL, D. Implant superstructures: A comparison of Ultmate failure force. Int. J. Oral Maxillofac. Implants, v.7, n.1, p.35-39, 1992.

79. MERZ, B.; HUNENBART, S. Mechanics of the implant abutment connection: An 8 degree taper compared to a butt joint connection. Int. J. Oral Maxillofac. Implants, v.15, n.4, p.519-526, 2000.

80. MEYER, K. Analise comparativa da precisão e compatibilidade entre componentes de sistemas de implantes nacionais e estrangeiros. Porto Alegre, 200o. 135p. Dissertação (mestrado) - Faculdade de Odontologia, Pontifícia Universidade Católica do Rio Grande do Sul.

81. MICHALAKIS, K.; PISSIOTIS, A.; HIRAYAMA, H. Cement failure loads of 4 provisional agents used for the cementation of implant fixed partial dentures. Int. J. Oral Maxillofac. Implants, v.15, n.4, p.545-549, 2000. 
82. MILLER, R.; MCGLUMPHY, E.; KERBY, R. Comparison of abutment screw preload in different implant designs. J. Dent. Res., v.73, p.202, 1994. /Abstract n. 807.

83. MITRANI, R. et al. Accuracy of electronic implant torque controllers following time in clinical service. Int. J. Oral Maxillofac. Implants, v.16, n.3, p.394-399, 2001.

84. MOLLERSTEN, L.; LOCKOWANDT, P.; LINDEN, L. Comparison of strength and failure mode of seven implant systems: An in vitro test. J. Prosthetic. Dent., v.78, n.6, p.582-581, 1997.

85. NIZNICK, G. The implant abutment connection: The key to prosthetic success. Compendium, v.XII, n.12, p.932-938, 1991.

86. NORTON, M. Assessment of cold welding properties of the internal conical interface of two commercially available implant systems. J. Prosthetic. Dent. v.81, n.2, p.159-166, 1999.

87. NORTON, M. In vitro evaluation of the strength of the conincal implant-to abutment joint in two commercially available implant system. J. Prosthet. Dent., v.83, n.5, p.567-571, 2000.

88. NORTON, M. The astra tech single tooth implant system: A repot on 27 consecutively placed and restored implants. Int. J. Periodont. Rest. Dent., v.17, p. 575-583, 1997.

89. OLIVEIRA, E. A distribuição da força mastigatória em implantes. In: Bioengenharia em implantes osseointegrados. Rio de Janeiro, Ed. Pedro Primeiro, 1997, cap. IV, p.53-76. 
90. PALACCI, P. et al. Practical guidelines based on biomechanical principles. In: Optimal implant positioning \& soft tissue management for the Branemark system. Chicago, Quintessence Publishing, 1995, p.21-33.

91. PATTERSON, E.; JHONS, M. Theoretical analysis of the fatigue life of fixture screws in osseintegrated dental implants. Int. J. Oral Maxillofac. Implants, v.7, p.26-34, 1992.

92. PESUN, I. et al. Operator-induced axial forces during implant gold screw fastening. J. Prosthet. Dent., v.86, n.1, p.45-19, 2001.

93. PRIEST, G. Single tooth implants and their role in preserving remaining teeth: A 10 year survival study. Int. J. Oral Maxillofac. Implants; v14, p181-188, 1999.

94. RAFEE, M. et al. The effect of repead torque on the ultimate tensile strength of slotted gold prosthetic screws. J. Prosthet. Dent., v.88, n.2, p.176-182, 2002.

95. RAMBHIA, S. et al. Defects in hexed prosthetic screws: A metallographic and tensile analysis. J. Prosthetic. Dent v.87, n.1, p.30-39, 2002.

96. SAKAGUCHI, R.; BORGERSEN, S. Nonlinear contact analysis of preload in dental implant screws. Int. J. Oral Maxillofac Implants, v.10, n.3, p.295302, 1995.

97. SCHOLANDER, S. A retrospective evaluation of 259 single tooth replacements by the use of Branemark implants. Int. J. Prosthodont., v.12, p.483-491, 1999. 
98. SCHULTE, J.; COFFEY, J. Comparison of screw retention of nine abutment systems: A pilot study. Implant Dent., v.6, p.28-31, 1997.

99. SINGER, A; SERFATY, V. Cement-retained implant supported fixed partial dentures: A 6 month to 3 year follow-up. . Int. J. Oral Maxillofac. Implants, v.11, p.645-649, 1996.

100. SQUIER, R.; PSOTER, W.; TAYLOR, T. Removal torques of conical, tapered implant abutments: The effects of anodization and reduction of surface area. Int. J. Oral Maxillofac. Implants, v.17, n.1, p.24-27, 2002.

101. STANDLEE, J.; CAPUTO, A. Accuracy of an electric torque limiting device for implants. Int. J. Oral Maxillofac. Implants, v.14, n.2, p.278-281, 1999.

102. STANDLEE, J. et al., A. Accuracy of mechanical torque limiting devices for implants. Int. J. Oral Maxillofac. Implants, v.17, n.2, p.220-224, 2002.

103. SUTTER, F. et al. The role of screws in implant systems. Int. J. Oral Maxillofac. Implants, v.9, p.48-63, 1994 (Supplement).

104. SUTTER, F.; WEBER, H.; SORENSEN, J. The new restorative concept of the ITI dental implant system: Design and engineering. Int. J. Periodont. Rest. Dent., v.13, n.5, p.409-431, 1993.

105. TAN, K.; NICHOLLS, J. Implant-abutment screw joint preload of 7 hex-top abutment systems. Int. J. Oral Maxillofac. Implants, v.16, n.3, p.367-377, 2001. 
106. TAN, K.; NICHOLLS, J. The effect of 3 torque delivery sustems on gold screw preload at the gold cylinder abutment screw joint. Int. J. Oral Maxillofac. Implants, v.17, n.2, p.175-183. 2002

107. TAVAREZ, R. et al. Torque e destorque em 4 diferentes tipos de parafusos utilizados em proteses sobre implantes. Enviado a publicação a revista Pesquisa Odontológica Brasileira, (novembro 2002).

108. TAVAREZ, R. et al. Torque induzido de forma manual em 4 diferentes tipos de parafusos utilizados em próteses sobre implantes. Enviado a publicação a revista Pesquisa Odontológica Brasileira, (novembro 2002).

109. TAVAREZ, R. et al. Torque produzido por 4 torquímetros diferentes utilizados em próteses sobre implantes. Estudo comparativo. Enviado a publicação a revista da faculdade de odontologia de Bauru, (novembro 2002).

110. TAYLOR, T.; AGAR, J.; VOGIATZI, T. Implant prosthodontics: Current perspective and future directions. Int. J. Oral Maxillofac. Implants, v.15, n.1, p.66-73, 2000.

111. TZENAKIS, G. et al. The effect of repeated torque and salivary contamination on the preload of slotted gold implant prosthetic screws. J. Prosthet. Dent., v.88, n.2, p.183-191, 2002.

112. VIGOLO, P.; MAJZOUB, Z.; V.; CORDIOLI, G. Measurement of the dimensions and abutment rotational freedom of gold machined 3i UCLAtype abutments in the as-received condition, after casting with a noble metal alloy and porcelain firing. J. Prosthet. Dent., v.84, n.5, p.548-553, 2000 
113. WEINBERG, L.; KRUGER, B. A comparison of implant / prosthesis loading with four clinical variables. Int. J. Prosthodont., v.8, n.5, p.421-433, 1995.

114. WEISS, E.; KOZAK, D.; GROSS, M. Effect of repeated closures on opening torque values in seven abutment implants systems. J. Prosthet. Dent., v.84, n.2, p.194-199, 2000.

115. WISKOTT, A.; NICHOLLS, J.; BELSER, C. Stress fatigue:Basic principles and prosthodontic implications. Int. J. Prosthodont., v.8, n.2, p.105-116. 1995. 


\section{0- ABSTRACT}




\section{ABSTRACT}

The long term success of an implant supported restoration and the health of the surrounding tissues is closely related to prosthetic components accuracy and its fit to the fixture and abutment implants interface stability as well as its strength when subjected to masticatory loads. Under a biomechanical standpoint implant single restoration in premolar and molar areas is the most complex issue; since occlusal forces are higher in these areas, leading to high level of stress over these components. Thus, this study investigates the alterations under cyclic fatigue in implant / abutment interface, in intern and extern connection systems through measurements of components fit, in abutment screw torque and in detorque.

Fifty samples constituted of implants / abutments / crowns were divided into five groups of ten as follows: Group / was comprised of External Hexagon Implants / abutments and crown cast directly on UCLA abutment; Group I/ was comprised of Internal Hexagon implants and prefabricated abutments with cemented restoration; Group III was comprised of Intern Octagonal Implants and prefabricated abutments with cemented restoration; Group IV was comprised of External Hexagonal implants and UCLA abutments with a crown cast subsequent attached to the implant; and Group $V$ was comprised of External Hexagonal Implants and prepared ceraone abutments, with cemented restorations. Dimensions of implants, abutments bases and abutment screws were obtained. Analysis of implant/abutment interface was performed. The torque was set according manufactures instructions. All samples were subjected to 500.000 fatigue cycles in a MTS 810 Universal Machine. Detorque tests in abutment screws were performed after cyclic fatigue as well as analysis of implant/abutment interface.

Statistical analysis showed that: (1) There were differences in the width of implant and abutment bases ranged between $0,03 \mathrm{~mm}$ to $0,75 \mathrm{~mm}$; in the hexagonal width of implant and abutments ranged between 0,01 and 0,05mm, but in Group II, constituted of intern hexagon; (2) The abutment screw length ranged between 5,95 $\mathrm{mm}$ and $8,83 \mathrm{~mm}$, as long as their diameter ranged between 1,79 and $1,97 \mathrm{~mm}$; (3) After cyclic fatigue, there were a significant increase in the misfit between implant and abutment of extern hexagon with UCLA abutment and in inter hexagon group; 
the smallest misfit was observed in the extern hexagon with ceraone abutment group (3,81 ìm); (4) There were a statistically significant reduction in torque load in all groups after cyclic fatigue. The least reduction was found in the intern hexagon with cemented restoration group 5,3N/cm (17,67\%), and the most reduction was found in the screwed UCLA abutment group 20,5N/cm (68,33\%); (5) There were a strong correlation between cyclic loading input and the decrease of torque, and no other correlation was found regarding the other variables. 